Ursula Hemetek

Marko Kölbl

Hande Sağlam (eds.)

\title{
Ethnomusicology Matters
}

\section{Influencing Social and Political Realities}

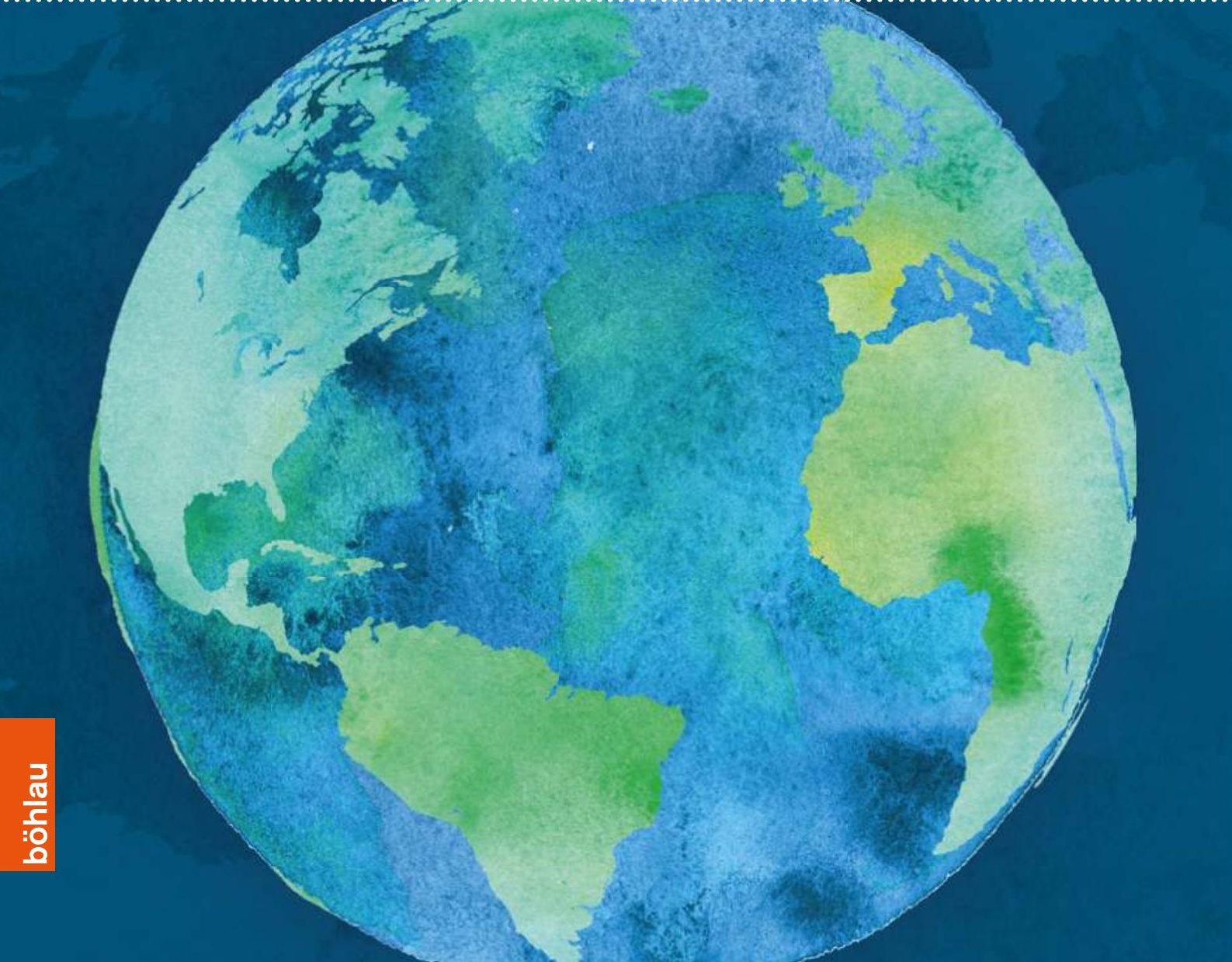


Music Traditions Vol. 1

(formerly Schriften zur Volksmusik 1-25)

Series of the Department of Folk Music Research and Ethnomusicology at the University of Music and Performing Arts Vienna

Series` editor: Ursula Hemetek

Musik Traditionen Bd. 1

(ehemals Schriften zur Volksmusik 1-25)

Reihe des Instituts für Volksmusikforschung und Ethnomusikologie an der Universität für Musik und darstellende Kunst Wien

Reihenherausgeberin: Ursula Hemetek 
Ursula Hemetek | Marko Kölbl | Hande Sağlam (eds.)

\title{
Ethnomusicology Matters
}

Influencing Social and Political Realities

\author{
BÖHLAU VERLAG WIEN KÖLN WEIMAR
}


Open Access: Except when otherwise noted, this work is licensed under a Creative Commons Attribution 4.0 Unported License. To view a copy of this license, visit HYPERLINK https://creativecommons.org/ licenses/by/4.0/

Published with the support of the University of Music and Performing Arts Vienna This publication has been double blind peer reviewed.

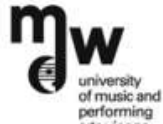

Bibliografische Information der Deutschen Bibliothek:

Die Deutsche Nationalbibliothek verzeichnet diese Publikation in der Deutschen Nationalbibliografie; detaillierte bibliografische Daten sind im Internet über https://dnb.de abrufbar.

(C) 2019 by Böhlau Verlag GmbH \& Co. KG, Kölblgasse 8-10, A-1030 Wien Alle Rechte vorbehalten. Das Werk und seine Teile sind urheberrechtlich geschützt. Jede Verwertung in anderen als den gesetzlich zugelassenen Fällen bedarf der vorherigen schriftlichen Einwilligung des Verlages.

Cover illustration: (c) Galyna_P/Shutterstock.com

Satz: SchwabScantechnik, Göttingen

Druck und Bindung: Hubert \& Co. BuchPartner, Göttingen

Printed in the EU

Vandenhoeck \& Ruprecht Verlage I www.vandenhoeck-ruprecht-verlage.com

ISBN 978-3-205-23287-2 


\section{Table of Contents}

Ursula Hemetek, Marko Kölbl, Hande Să̆Lam

Introduction

Anthony SeEger

How Does Ethnomusicology Matter?

The Socio-Political Relevance of Ethnomusicology in the $21^{\text {st }}$ Century . . . . . I5

Adelaida Reyes

The Beneficence and the Tyranny of Paradigms:

Kuhn, Ethnomusicology and Migration $\ldots \ldots \ldots \ldots$

Britta Sweers

The Position of University-Based Ethnomusicology

from an Interdisciplinary Perspective $\ldots \ldots \ldots \ldots$

Samuel Araujo

Music, Research and Public Interest

A Dialogical Praxis for Social Justice $\ldots \ldots \ldots \ldots 77$

Tan Sooi Beng

Bridging the Racial Divide in Malaysia:

Crossing Borders through Research and Process Theatre . . . . . . . . 93

Beverley Diamond

Affect, Ontology, and Indigenous Protocol:

Encounters in Canada $\ldots \ldots \ldots \ldots \ldots \ldots \ldots$ II $7 \ldots \ldots$

Rasika AJotikar

Reflections on the Epistemic Foundations of Music in Modern India

through the Lens of Caste:

A Case from Maharashtra, India $\ldots \ldots \ldots \ldots \ldots$. . . . . . . . . 35

Cornelia Gruber

Politics of Women Dancing in Madagascar:

Relating Critical Perspectives on Gender . . . . . . . . . . . . . . . . 663 $_{3}$ 
Table of Contents

Selena Rakočević

Practicing Ethnomusicology/Ethnochoreology

Within Post-Socialist Realities:

The Case of Serbia with Some Comparative

Experiences from Former Yugoslav Countries . . . . . . . . . . . . . I9I

DAN LuNDBERG

Music Archives, Identity and Democracy.

The Role of Archives from New Perspectives _. . . . . . . . . . 2 I 5

Naila Ceribašić

On Engaging Up and Expertise in Ethnomusicology:

The Example of Expert Services in the Programme for Safeguarding

Intangible Cultural Heritage $\ldots \ldots \ldots \ldots \ldots$

Philip V. Bohlman

"And from the Ruins of Time They Blossom":

On the Moral Imperative in Ethnomusicology … . . . . . . . . . 257

Notes on Contributors $\ldots \ldots \ldots \ldots \ldots \ldots$ 28 I . . . . . . 


\section{Introduction}

Usually, scholars who work in a certain discipline do think that what they do is relevant. So it comes as no surprise that the editors of this volume think that ethnomusicology matters. On the other hand, there have long been complaints by ethnomusicologists worldwide about the fact that ethnomusicology is considered a marginalized field. The relevance of the discipline varies of course according to the respective backgrounds: the national traditions of the discipline and its presence in academic institutions. Accordingly, the names of the discipline also vary: folk music research, cultural anthropology of music, musical ethnology, just to name a few. ${ }^{1}$ The structural positioning of ethnomusicology within institutions and universities is of course crucial when considering its influence. Very often we find it as a sub-discipline of musicology, especially in Europe, which makes sense of course considering that it came into existence as comparative musicology (see Titon 2015). On the other hand, folk music research as a part of ethnomusicology looks back on different historical founding narratives. The history of the discipline is not the topic of this volume, but to a certain extent it does influence the structural positioning of the discipline nowadays, which again is important in connection with power relations.

The authors of this volume primarily try to underline ethnomusicology's relevance not by its strategical positioning, but by its research topics and results that can influence social and political realities. However, the whole picture probably has to be taken into consideration when reading this book. The genesis of this publication is very much connected to both: the results of research are influential as well as structural positioning.

The symposium which laid the ground for this volume was called Musics Matter! Ethnomusicology and its Socio-political Relevance Today (28-30 September 2017) and it was held to mark the inauguration of the ICTM Secretariat in Vienna. The Secretariat of the International Council for Traditional Music is a rather influential institution in the world of ethnomusicology, and was located previously in New York, Los Angeles, Canberra and Ljubljana. It is the operational centre of the ICTM. The Council was founded in 1947 and is the key international organisation serving the field of ethnomusicology worldwide. Its mission is to deal in a scholarly manner with the entire

1 We are well aware that there are diverse research histories as well as political backgrounds involved. In spite of this we decided to choose "ethnomusicology" as the umbrella term. 
range of diverse musics that exist in our world. The positioning of the Secretariat at the University of Music and Performing Arts Vienna (mdw) signified an increase in the prestige of ethnomusicology within the university.

The ICTM Secretariat is located at the mdw's Department of Folk Music Research and Ethnomusicology, which has for decades been an important networking platform for the world's many different "musics" as well as for the various music- and dancerelated expressive forms that are situated outside the mainstream. Having brought the Secretariat to the department, Ursula Hemetek's research agenda-music and minorities-received more attention: this field of research has a great deal to do with sociopolitical relevance, and this agenda is actually a point of departure for the contents of this book.

International ethnomusicological personalities were invited to the aforementioned symposium to discuss the field's socio-political relevance in light of current lines of ethnomusicological discourse, which are of considerable political significance. Most of the contributions which make up this book were submitted as articles specifically for this publication, and after a double-blind peer reviewing process they have now been published. It is amazing to see how manifold the ethnomusicological approaches can be that contribute towards influencing political and social realities: analysing philosophical paradigms or the potential power of music itself, the positioning of the discipline as university politics, the application of gender discourses, discussing the role of heritage and archives as well as indigenous ontologies, and of course applied ethnomusicology itself as a political intervention in the interests of social justice.

Within the discipline of ethnomusicology, the links between scholarly research and socio-political realities are largely pre-specified by interpersonal relations in fieldwork. Fieldwork often implies the forming of personal bonds with individuals and/or groups-accordingly, ethnomusicologists are commonly involved with communities and the socio-political conditions surrounding them. It is the very nature of human relationships that creates the aspiration to socio-political change in a large amount of ethnomusicological research, as the articles of this volume clearly show.

Hence, ethnomusicology matters precisely because of its involvement with individuals and communities. For ethnomusicological research to gain socio-political relevance, however, a certain political intention-a vision for the way in which political realities can be influenced-is crucial. This intention manifests itself in a wide range of forms - from political statements to applied and engaged approaches to cultural and political activism; however, always involving music and/or dance. All of these forms can be read as interventions of varying extents. Research that attracts attention and critically reflects upon hegemonic structures from a theoretical perspective may have different effects than research that is explicitly 'applied', or 'engaged' practically and whose very purpose is to "benefit the community" in a "people-centered" way (Titon 
2015: 4). Still, all music- and dance-centred approaches within this spectrum have the capacity to influence political realities.

A basic element of the interactive dynamics between ethnomusicological research and political realities-and which is a key element of this volume's articles-is the identification and critical reflection of hegemonic structures of power. For all of the contributions in this book, these structures form basic preconditions-be they individual or structural discrimination, the unequal distribution of political rights, or the political and/or social oppression of individuals or groups. For the authors of this publication, these starting points stimulate a closer inquiry into the living conditions of the respective communities and the way music and/or dance play into these conditions.

The social categories along which the unequal distribution of power takes place vary from article to article. In this volume, ethnically marked Otherness makes up the prevalent form of difference that is discussed in relation to socio-political realities. Indigenous groups and ethnic minorities as well as migrant and refugee communities are read as Others in relation to an unmarked majority population that not only enjoys a significantly greater set of rights but is also assumed to hold a social and cultural predominance. Music, dance or theatre-sounds and body movements-accompany indigenous, ethnic or migrant minorities' political struggles, for which this volume provides telling examples.

Religion forms a further important parameter in regard to this book's topic. Religious beliefs may be crucial to individuals or groups and simultaneously can place them in a position of reduced social and cultural participation, less political power as well as increased discrimination. The high significance of music and dance in religious practice constitutes a specific precondition for ethnomusicological inquiry envisioning social change, as shown by contributions in this volume.

Another category of social structure which features in the articles of this volume is gender. The involvement of the human body in the production of sound and dance movements calls for a precise examination of gendered and sexualized understandings of music and dance, which helps to disclose heteronormative and binary understandings of gender and sexuality. This also makes it possible to tackle injustices such as gender inequality and sexual oppression while simultaneously paying attention to the respective cultural preconditions and the value of systems of gender and sexuality in the respective communities, as exemplified in this volume.

Difference ascribed to social standing-class-makes up another relevant parameter in grasping the socio-political relevance of ethnomusicology. As the contributions of this volume show, class positions and their tremendous effect on social participation and political power are neatly tied to specific ways of engaging with music and dance and the cultural and aesthetic agency arising from them. 
When contemplating the contributions assembled in this publication, it becomes apparent that the above-mentioned categories of social difference only become tangible in their interdependent interconnectedness-an interconnectedness that is not clear but rather "messy, chaotic and heterodox," because these categories do not define identities, but illustrate relations (Ferguson 2004: 66). This volume thus ultimately features intersectional understandings of difference and of the possibilities for action deriving from a socio-politically engaged and courageous ethnomusicology.

In his introductory article How Does Ethnomusicology Matter? The SoCio-Political Relevance of Ethnomusicology in the 21st Century, Anthony Seeger questions the roles, impacts, and socio-political relevance of ethnomusicological studies in the $21^{\text {st }}$ century. He starts with W. Rhodes' definition of ethnomusicology and addresses its current directions and trends in order to illustrate possible future developments. By describing the methodological approaches of ethnomusicology, he also makes the potential influence of ethnomusicology on society more noticeable. He considers the interdisciplinary design of ethnomusicology to be one of the most important features of our discipline for broadening perspectives in many senses. In his article, Seeger also emphasizes the important role of networking, and he underlines the immensely important role of the ICTM as the largest network in ethnomusicology for the conceptualization of our discipline.

The second article of this book The Beneficence and the Tyranny of Paradigms: Kuhn, Ethnomusicology and MigRation, written by Adelaida Reyes, gives us an overview of Kuhn's concept of science. She examines its probability for ethnomusicology, and for migration phenomena that ethnomusicology "is not yet fully confronted with." She uses the description of Kuhn concerning circumstances under which crises created by anomaly finally lead to innovation and change "[...] The significance of crisis is the indication they provide that an occasion for retooling has arrived" (Kuhn 1970: 76) in order to pose a very important question about today's musicological discourses: "Will ethnomusicology take the forced migration crises and the inevitable (re)creation or (re)construction of musical life no longer as an extravagance that we can do without, but as an occasion for much-needed retooling?" (see Reyes in this volume).

Britta Sweers focuses in her article The Position of UnIVERSITY-BASED ETHNOMUSICOLOGY FROM AN INTERDISCIPLINARY PERSPECTIVE not only on ethnomusicology and its unusual position within an interdisciplinary context, but also discusses its relevance within the context of the transformation occurring at many universities. The important function of applied ethnomusicology in socio-political matters is presented in her article in detail on the basis of concrete examples.

In their essays, Samuel Araujo, Tan Sooi Beng and Beverley Diamond describe three different approaches deployed in the applied aspects of ethnomusicology, especially towards community-based applied research. 
In his article Music, Research, and Public Interest. A Dialogical Praxis for Social JustiCE, the Brazilian ethnomusicologist Samuel Araujo reflects critically on the musical and social project Musicultura. He emphasizes the potential of and obstacles faced by participatory initiatives like Musicultura and considers this phenomenon as a chance to redefine the goals and strategies in the political struggles around the public-private continuum and to redesign the contexts of knowledge production beyond the academic/extra-academic dichotomy.

"Culture is an effective crucible for social transformation, one that is less polarizing and creates deeper connections than other social change arenas," (Goldbard 2006: 52). This quotation from the article by Tan Sooi Beng summarizes her intentions as an ethnomusicologist very clearly. In her contribution BRIDGING THE RACIAL DIVIDE in Malaysia: Crossing Borders through Research and Process Theatre she points out the meaning of being an "engaged activist researcher who not only conducts detailed ethnographic research or writes about how ordinary people use music and the arts to contest power structures and national ideologies, but one that dynamically advocates for change in the education and political systems" (see Tan in this volume). She describes how the people-centered collaborative research approach strives for more horizontal and equal relations between researchers and the subjects of research, and emphasizes the voices of the communities themselves.

The third article on community-based applied research is written by Beverley Diamond: AfFect, Ontology, and Indigenous Protocol: Encounters in CANAdA. This article considers how Indigenous protocol plays a role in promoting respectful relations. But it also reflects on situations where a failure to consider the affect of protocol-related performances may be disrespectful and counter-productive. The central question in her article implicates sound and voice in relation to the right of refusal as a starting point for a productive Indigenous-settler discussion in the context of unsettlement. "What might be the future protocols for dispute resolution, for restoring balance when violence (actual or symbolic) is encountered? The differences in new post-human worldings, and particularly the responsibilities entailed, are vast. How might a more intense sonic attentiveness help forge a discussion about such matters?" (see Diamond in this volume) are two questions which she answers in her article.

In her article Reflections on the Epistemic Foundations of Music in ModERN INDIA THROUGH THE LENS OF CASTE: A CASE FROM MAHARASHTRA, INDIA, Rasika Ajotikar attempts to decolonise ethnomusicology by making some critical reflections on the epistemic foundations of music in 20th century India by using her field research on the oppressed caste known as the Dalit community in the western Indian state of Maharashtra. Through her examination of cast structures, she tries to not only ensure the decolonizing of epistemologies of music, but also of very hierarchically-constructed knowledge traditions. She highlights literary interventions in music as counter-epis- 
temologies to dominant caste discursive and performative representations that help formulate new theoretical ideas for the study of music in contemporary India.

With her article Politics of Women Dancing in Madagascar: Relating Critical Perspectives on Gender, Cornelia Gruber provides us with an insight into her experiences of the activities of women's associations in the central Onilahy Valley in the Southwest of Madagascar. Based on her ethnographic research, she argues the necessity of acknowledging the category of "woman" as interdependent with age, generation and ancestral relations. She concludes that ethnomusicology must relate perspectives of gender scholarship to particular people and their national and transnational contexts.

Selena Rakočević considers a different research area of ethnomusicology compared to the previous articles by analysing the contemporary society of post-socialist Serbia with the tools of ethnomusicology. Her article Practicing ETHNOMUSicOlogY/ Ethnochoreology Within Post-Socialist Realities: The CaSe of Serbia With SOME Comparative EXPERIENCES From Former Yugoslav Countries is based on interviews and questionnaires and provides an overview of many individual researchers with the aim of understanding the position of ethnomusicology and ethnochoreology in the contemporary society of post-socialist Serbia, and thus the socio-political relevance of these disciplines from the perspective of the scholars themselves.

With his article Music Archives, Identity and Democracy. The Role of ARChives from New Perspectives, Dan Lundberg takes us into the archives and discusses political and financial matters and their effects on music archives using concrete examples from Sweden. On the other hand, he analyses and questions the status of ethnomusicologists as active (co-)creators of music cultures and consequently stresses their responsibilities. He argues in his article that ethnomusicologists have a special responsibility to explain the origins of archives and to provide some perspective on their background and their role in history.

The second contribution on cultural heritage is written by Naila Ceribašić. The article On ENgaging Up and EXPERTISE IN ETHNOMUSiCOlOgY: The EXAMPLE OF Expert Services in the Programme for Safeguarding Intangible Cultural HERITAGE builds on her experiences in the programme for safeguarding intangible cultural heritage on national and international levels. She makes a survey of the status of engagement in ethnomusicology compared to the concept of studying up in anthropology, and provides a snapshot on the role of experts in the ICH programme. The inevitable role of "expertise" and the significant position of ethnomusicology as a collaborative-academic discipline in the early $21^{\text {st }}$ century forms the focus of her article.

Philip V. Bohlman analyses the central role of performances in ethnomusicology. The essay "AND from the Ruins of Time They Blossom": On the Moral ImPERATIVE IN ETHNOMUSICOLOGY gives the reader a very profound description of eth- 
ics, and points out the moral responsibility of ethnomusicologists concerning performances. This begins by dealing with performance and ethnomusicology's moral imperative historically, locating it already in the foundations of the field. The article then moves towards the field's recent history and the author draws from his personal experience in the performance activities of the University of Chicago-based cabaret, the New Budapest Orpheum Society.

The authors as well as the editors of this volume seem to be in agreement with regard to their desire to join forces in order to help shape the world's future, with respect to the existence of effective strategies for doing so, and regarding the fact that ethnomusicology actually can be relevant: "Maybe it's the moment of ethnomusicology," commented Philip Bohlman at the symposium's conclusion, and it indeed sounded like a challenge issued to all of us.

We want to thank all the authors of this volume, the peer-reviewers, the language editor Mike Delaney and the mdw for contributing to these challenging processes.

References

Ferguson, Roderick A. 2004. Aberrations in Black. Toward a Queer of Color Critique. Minneapolis/London: University of Minnesota Press.

Goldbard, Arlene. 2006. New Creative Community: The Art of Cultural Development. Oakland: New Village Press.

Kuhn, Thomas S. 1970 [1962]. The Structure of Scientific Revolutions. Chicago: Chicago University Press.

Titon, Jeff Todd. 2015. "Applied Ethnomusicology: A Descriptive and Historical Account." In The Oxford Handbook of Applied Ethnomusicology. S. Pettan and J. T. Titon, eds. Oxford/ New York: Oxford University Press: 4-29. 


\section{How Does Ethnomusicology Matter?}

\section{The Socio-Political Relevance of Ethnomusicology in the 21 $1^{\text {st }}$ Century}

\section{Introduction}

Edwin Starr's performance of the 1970 Vietnam war protest song "War" opens with the repeated line: "War! Huh! Yeah! What is it good for?" to which Starr replies "Absolutely Nothing!" That refrain, along with the change in the title of the Vienna symposium, ${ }^{1}$ sparked the idea for this paper. ${ }^{2}$ Music! What is it good for? The study of music! Is it good for anything? Or is it like war-good for absolutely nothing? Definitive answers to the second question will not be found here, but this paper suggests that ethnomusicology has achieved some things, struggles to achieve others, and has not gotten very good at a few. Readers and future scholars will ultimately have to decide for themselves if ethnomusicology is good for anything, and-if it is—how it can be improved.

The original title of the ICTM Symposium in Vienna was "Ethnomusicology and its socio-political relevance in contemporary societies (working title)" (Hemetek email 30 November 2016). On June $16^{\text {th }}, 2017$, Dr. Hemetek wrote to the participants to inform us of a modification of the symposium's name. "The team agreed to find a more 'catchy'

1 This paper was originally given as the opening address at the symposium Musics Matter! Ethnomusicology and its Socio-Political Relevance in the 21st Century, both to the assembled symposium members and as a live stream. Billed as a "Keynote" on the evening before the first full day of the symposium, it was sandwiched between the formal opening and the inaugural reception with food and drink. I endeavored to address the subject matter of the symposium in a general and approachable way, using the opening refrain of Edmond Starr's "War! What is It good For?" to have the audience chant with me "Musics! What are they good for?" and "Ethnomusicology! What is it Good for?" Due to its original preparation for oral delivery, this paper does not include as many references to other literature as is standard in a written document. I have decided to maintain the oral presentation style, and regret the inevitable omissions. I thank the symposium organizers and participants for their enthusiastic chanting, stimulating comments and suggestions, as well as their wonderful papers on the following days. I also thank the anonymous reviewers for their suggestions.

2 The song is easily found on YouTube. It may be helpful to play a version that gives the song lyrics, such as https://www.youtube.com/watch?v=-dKAX7Jp8wo 
title, therefore don't be surprised that the symposium is now called Musics Matter! Ethnomusicology and its Socio-Political Relevance" (Hemetek email 16 June 2017).

The two new words in the symposium title, "Musics Matter!," matter a lot in themselves and gave me the idea for this paper. The two words matter because they allow us to contrast musics and ethnomusicology. Most of the readers of this volume probably already think that music matters; but does the study of it matter too? If so, how does it matter and for whom? The use of the word "musics" also matters. Some, but not all readers, will agree that the word "musics" is a useful term because it emphasizes that there are many musical systems rather than a single one called "music." We may be able to speak of the diversity of music as a unity if we consider only the structuring and features of time, tone, and timbre, but such a limitation ignores the diversity of musical ontologies, aesthetics, musicological thought, and social practices around the world that can be recognized as distinctive and thus plural. They may be "catchy," but the words "musics matter" also mattered for the symposium. This paper begins with a reflection on how musics matter, then moves to a consideration of whether, and how, ethnomusicology matters. This allows me to contribute to a consideration of the second half of the symposium's title, "Ethnomusicology and its socio-political relevance in contemporary societies."

\section{Musics Matter!}

Meaningful engagement with performances that purposefully structure time, tones, and timbres (my simple definition of musics) ${ }^{3}$ seems to be a pan-human attribute. So is music-associated movement, or "dance." These performances are not called music, or dance, or performances everywhere, but some such events are almost everywhere considered somehow meaningful. Even where music and dance are restricted or condemned as immoral (a position shared by several religions past and present), they are still important because they are said to be powerfully subversive and dangerous.

The ways musics matter extend far beyond the simple enjoyment of sounds and movements or concern about the moral effects of such enjoyment. David Hesmondhalgh's thoughtful, wide-ranging, and passionate book, Why Music Matters, argues that music matters because "it has the potential to enrich people's lives and enrich societies" (Hesmondhalgh 2013: 1). He explores the social value of music (which can

3 The shorthand definition of music in the text is used as a stand-in for something more complicated. Many years ago, I spent some time discussing definitions of music (Seeger 1992: 89-90). Any general definition, I believe, needs to include both sounds and human beings, though non-human beings and many kinds of soundscapes can be important as well. 
be negative as well as positive) through the relationships between music, history, society, and the self in a discussion that focuses almost exclusively on popular music and dance and on interviews with respondents in the United Kingdom. Ethnomusicologists (especially Charles Keil and Thomas Turino) are mostly discussed in the context of criticizing their focus on community and synchronicity. Music can be said to matter for Hesmondhalgh (using his chapter titles) for feeling and flourishing, love and sex, sociability and place, and commonality and cosmopolitanism. Without detracting from the significance of his book and its argument directed toward readers and policy-makers in the United Kingdom, one could argue that his discussion of how "music" matters is limited by its lack of consideration of the wealth of other musical forms and experiences that he could have found in the United Kingdom if he had looked at the use of music by more diverse communities. The significance of music and religion appears on page 105 only as an embarrassment: "With the marked decline of church attendance, religious singing has become less a part of people's lives, and many people will have experienced the agonizing discomfort of trying to sing along to unfamiliar hymns at weddings, christenings, and funerals" (Hesmondhalgh 2013: 105). This dismissal ignores the growth of Hindu temples, the cantors of Judaism, the music of the Rastafari, the prayer bands at some evangelical church services, and the uses of music in other religious communities thriving in the United Kingdom (and around the world). A corollary of largely ignoring religious music, Hesmondhalgh ignores the importance of music in establishing relationships between humans and non-humans and between humans and objects, important among numerous Indigenous groups in the Americas and the Pacific region. One of the advantages of the plural noun "musics" is to keep us from assuming that any single "music" style is all that matters in discussions of music's role and significance.

While ethnomusicological discussions of the question "why musics matter" have their limitations also, our answers are usually more broadly conceived than those based on a single region or genre. If we tend to examine smaller and more diverse musical communities, it is partly to challenge a tendency to oversimplification through a focus on European music history. Our ideas are often drawn from extensive discussions, research, and sometimes from participation in the musical lives of the communities we study. Our answers are also based on years of reading what has been reported about music in communities around the world in journals and book-length publications.

What are musics used for? Music and rhythmic movement are sometimes used to accompany labor and to help coordinate individual or joint activities. Songs that coordinate hard physical labor are fewer today as machines have replaced muscle power, but music continues to be used to accompany work and work-outs. Streaming through personal headsets are soundtracks for office work, exercise, and war 
(Daughtry 2015). People sometimes use musics in healing and health care, for reviving memories, and in developing alternative forms of communication when language fails. But people also sometimes use musics to inflict sickness, death, and harm. Musics and movements have long been part of making war as well as of opposing war. They are also used for governing and for rebelling against governments and to oppress and to resist oppression. Groups of people may use music to separate themselves from others. Individuals may use music to separate themselves from groups to which they otherwise belong. In many places, music and dance are thought to be forms of expression that transcend the human realm to connect to natural or supernatural ones. The performance of music and dance enable social and interspecies interactions of many kinds, accomplished through objects, ecosystems, hearing/sight/ smell/touch, and sounds and movements.

In sum, if I were to respond to the chant "Music! Huh! Yeah! What is it good for?" I could honestly respond "for lots of things!" But is the study of music good for anything? Apart from their minor contribution to the music industry and capitalist markets, do musicology, ethnomusicology, and other disciplines that study musics, matter?

\section{Does Ethnomusicology Matter?}

What is the study of musics good for? More specifically what is Ethnomusicology in the $21^{\text {st }}$ century good for? Teaching and writing about music are not human universals, nor is interest in musics other than that of one's own communities. Ethnomusicology does not necessarily heal, transcend, inspire, or even usually arouse passions enough to be banned. The limited readership of most of our books and journals has not been reported to include non-humans and deities. While musics clearly matter, does ethnomusicology? Our research questions, methods, and results have been shaped over the decades by Aristotelian categories, various European philosophers, colonialism and other power structures, and capitalism. Do our analyses simply reproduce the power structures from which we undertake them, or do they challenge them? Do our activities enable individuals or communities to empower themselves, or do they disempower and discourage? Does anyone read what we write or listen to the music we produce for recordings and other media and present in concerts, or are they the material artifacts of irrelevant activity? As a researcher, author, archivist, recording company director, and former President and Secretary General of the ICTM it may come as no surprise that I think our efforts are not irrelevant. But we should constantly ask ourselves how they are relevant, examine our weaknesses as well as our successes, and consider the ethical implications of what we do. 
Ethnomusicology may have been shaped by multiple influences, but many of the aspects of music and dance I listed in the previous section as proof of music's broad significance have been revealed through the research and writing of ethnomusicologists or scholars influenced by ethnomusicology. There would be very little information about how people in many different parts of the world use music and dance to shape their lives and those of others without fields that have the multidisciplinary approach to sound and movement of what are now called ethnomusicology and ethnochoreology.

Today, most musics and dance are also parts of a huge, nearly global communications and entertainment industry. Ethnomusicologists are part of it, too. We train future scholars, musicians and dancers, composers, choreographers, and consumers. Our research projects, publications, and public performances are all parts of a large interlocking set of enterprises enabled by capitalism and a variety of local, national, and international regulations and ideas about the importance of musics and dance in the world. The book in your hands or on the screen is also part of the global system. There are many local variations on how capitalism and the global music industry have had an impact on local performing arts and their study. But the important point is that we are part of the commodification of music and dance.

The word "ethnomusicology" has a roughly 70-year history. The founding of the Society for Ethnomusicology in the United States in 1955 began a period of intense introspection about the meaning of the word "ethnomusicology" that continues to this day (see Merriam 1960; 1969; Rice 2014: 1-10; 2017; Bohlman 2002, 2013b; Post 2018b). I shall not discuss the definitions of ethnomusicology from 1947 to the present-I leave readers to pursue that elsewhere. Instead, I will focus on a single article written by Willard Rhodes and published in Volume 1 number 7 of the newsletter Ethno-Musicology in April 1956 that I consider a foundational document in the field. ${ }^{4}$ The paper is especially significant because it was delivered on the same day (November $18^{\text {th }} 1955$ ) that twenty-four "interested people" ${ }^{5}$ met at the $54^{\text {th }}$ annual meeting of the American Anthropological Association and voted to form a "Society for Ethno-Musicology" (Ethno-Musicology Newsletter No. 6: 5). The slate of officers elected was Willard Rhodes President; Mieczslaw Kolinsky Vice President; David McAllester Secretary-Treasurer; and Alan P. Merriam Editor.

Earlier that day the future officers had given a panel of papers on ethnomusicology,

4 I am not alone in singling out this article. Philip Bohlman also discusses it in his introduction to the Cambridge History of World Music (Bohlman 2013b: 10).

5 Most of those present at the meeting were scholars and/or composers, but Moses Asch, the head of Folkways Records, also attended. Folkways offered a 33\% discount on all Folkways records to members of the SEM (Ethno-Musicology Newsletter 6: 28). 
chaired by Bruno Nettl. Willard Rhodes delivered the first paper, "Toward a Definition of Ethno-Musicology." The title of the 1956 published version was "On the Subject of Ethno-Musicology" (Rhodes 1956). In it, Rhodes seeks to do for ethno-musicology what Guido Adler did for Musicology in his 1885 article "The Scope, Method, and Aim of Musicology" (Mugglestone and Adler 1981 [1885]). In nine pages, Rhodes discusses what he calls-paraphrasing Adler-the "scope, objectives, and methods" of "our old discipline newly christened Ethno-Musicology" (Rhodes 1956: 1). He describes Ethno-Musicology not as something entirely new, but as a continuation of previous work. Rhodes cites as important influences the invention of the phonograph in 1877, the 1885 work of Alexander Ellis (Ellis 1885), and Guido Adler's 1885 article. He traces the heritage of Ethno-Musicology through the works of Carl Stumpf, Otto Abraham, Erich M. von Hornbostel and Curt Sachs and publications on the music of "the Near East, the Far East, Indonesia, Africa, North American Indians and European Folk Music." He writes, "this is our heritage" (Rhodes 1956: 3).

Rhodes' article also proposes some new features and subject matter for study. Ethno-Musicology is not the study of ethnic music, or world music. It is an interdisciplinary field that combines certain features of the human sciences with the study of sound-that was clear in the founding. In an important departure from the earlier publications he cites, Rhodes adds two subjects as rightful objects of research in Ethno-Musicology. These are dance and popular music. Regarding popular music, he writes "to the musician, much of this music is commonplace, dull, and lacking in aesthetic and artistic values. To the ethno-musicologist it is interesting and significant because it has value to the men who produce and consume it" (Rhodes 1956: 4, italics mine). This position has become a key feature of ethnomusicology - a focus on what music means to the people who produce and consume it, rather than its relationship to an often-hegemonic value system of those in positions of power and artistic authority. Many value systems mean many musics. Rhodes emphasizes the importance of dance by including a bibliographic article by Gertrude Kurath immediately following his address (Kurath 1956: 10-13).

Another feature of Rhodes' article is that he suggests changing fundamental aspects of the field while arguing for its continuity. He describes the self-criticism "arising within our fraternity of workers in the discipline," and suggests that the criticisms require changes in objectives and methods. Self-criticism and the proposal of new directions continue to characterize ethnomusicology in the $21^{\text {st }}$ century. Very few, if any, ethnomusicologists are doing what Rhodes describes in his 60-year-old article. Ethnomusicology has continued to change in profound ways ever since.

Ethnomusicology is not a static discipline or a single approach, nor has it ever been one. Rather, by studying music and dance in the contexts of the lives and thoughts of the people who produce and consume them, ethnomusicologists are positioned to 
contribute to understanding the variety of perspectives expressed through the musics and movements in the world. Like musics, the word "ethnomusicology" can appropriately be used in the plural: "ethnomusicologies." Different countries and musical traditions have different histories of scholarship and social and political engagement. Their approaches to music and dance may be different enough to acknowledge by using the word "ethnomusicologies." Svanibor Pettan has written "The fact that there is no single, ultimate definition of ethnomusicology suggests that we may consider the coexistence of ethnomusicologies, not only in different parts of the world but also within a single, no matter how small, location" (Pettan 2015: 37).

\section{Ethnomusicologies in the 21 $1^{\text {st }}$ Century}

Ethnomusicologists today live in a transnational and interdisciplinary world. We thrive on discussion and debate with each other, our students, and our other interlocutors, and are aware of the broader contexts of which we, our field, and our values are a part. Our work is not simply descriptive, but interpretative and engaged in productive conversations with other disciplines and authors alive and dead. A good indicator of some of the changes that have occurred since 1956 can be found in the $50^{\text {th }}$ anniversary issue of the journal Ethnomusicology (v. 50[2] 2006). Articles in it reveal powerful critical perspectives on ethnomusicology by (among others) Deborah Wong on ethnomusicology and difference (Wong 2006), Samuel Araujo and colleagues on conflict and violence as theoretical tools (Araujo 2006), Beverly Diamond on challenges to ethnomusicology's coherence (Diamond 2006), Travis Jackson's on ethnomusicology and privilege (Jackson 2006), and Steven Loza's challenges to the "Euroamericentric ethnomusicological canon" (Loza 2006). I have an article in the issue about the neglected ancestors of applied ethnomusicology (Seeger 2006). Practically none of the 2006 subjects were prefigured in the Ethno-Musicology Newsletter 50 years earlier. Additional critical perspectives were articulated in an ICTM/SEM Symposium in 2016 in Limerick, Ireland and at the Vienna symposium in 2017, in a world even more torn by war, tragically filled with uprooted peoples facing inhospitable situations, and afflicted by climate change and its disastrous effects on people, and places. ${ }^{6}$

6 Ethnomusicology continues to evolve in its focus. In the popular collection, Ethnomusicology, A Contemporary Reader edited by Jennifer Post and published in 2006, the chapters were organized into sections on commodification, globalization, media, nationalism, racial and ethnic identities, and social and political action (Post 2006). In 2016 the editor decided she could not use the same articles and headings, and solicited nineteen wholly new contributions for a separate volume (Post 2018), organized into six sections: (1) Property and Rights; (2) Applied Practice; (3) Knowledge and Agency; (4) Community and Social Space; (5) Embodiment and Cognition and (6) Curating Sound. A lot had happened in the intervening 10 years. 
Ethnomusicology in the $21^{\text {st }}$ century has been profoundly influenced by the growth of a sub-field called "applied ethnomusicology." Taking shape in conferences, publications, and paper sessions in the United States and Europe, applied ethnomusicology is an important element of $21^{\text {st }}$ century ethnomusicology. It is defined on the ICTM website as "the approach guided by principles of social responsibility, which extends the usual academic goal of broadening and deepening knowledge and understanding toward solving concrete problems and toward working both inside and beyond typical academic contexts" (ICTM Applied Ethnomusicology Study Group 2018; see also the discussion of the statement in Harrison and Pettan 2010: 14-17). The first formal meeting of the ICTM Study Group on Applied Ethnomusicology was held in Ljubljana, Slovenia, in 2008. Among the influential articles that addressed the role of ethnomusicology in the $21^{\text {st }}$ century were Samuel Araujo's "From Neutrality to Praxis: The Shifting Politics of Ethnomusicology in the Contemporary World" (Araujo 2008) and Svanibor Pettan's "Applied Ethnomusicology and Empowerment Strategies: Views from across the Atlantic" (Pettan 2008; see also Pettan and Titon 2015 for essays on the history of applied ethnomusicology and many examples of applied work). Partly a result of critiques of ethnomusicology, the wars and population displacements in the $21^{\text {st }}$ century, and the growth of something called applied ethnomusicology, many ethnomusicologists are even more engaged in the contemporary world than ten years ago.

Changes in ethnomusicology do not all derive from our engagement with current events. Many of them have come through our engagement with written texts. Just as popular music performers often listen to many more kinds of music than their ardent and opinionated fans, so most scholars read far more widely than the relatively small and focused bibliography they may cite in presenting specific arguments. Our readings include such non-musicologists as Foucault, Said, Gramsci, Freire, Canclini, Deloria and [add your own influential authors here] as well as musicologists Agawu and McClary-among others. But we also read the work of our colleagues and our students, which stimulates us to think in new ways too. Even though ethnomusicologists tend to stress the importance of their fieldwork as informing their thinking, most of us spend many more hours reading the work of others than doing field research.

Field research does change our understanding of how music and movement are conceptualized and used, and ethnomusicology is eventually changed by publications based on those field work experiences. This may be clearest in places that have become war zones and the sources of refugees fleeing conflicts and hunger. Ethnomusicologists' reflections on music and conflict were certainly stimulated by the conflicts in the Former Yugoslavia (Pettan 1996), the wars in Afghanistan (Daughtry 2015), the Palestinian conflict (Brinner 2009, McDonald 2003), the disasters in Haiti (Dirksen 2015 ) and the numerous minority groups that have been dislocated by these and other 
conflicts. The desperate plight of musicians with whom ethnomusicologists have worked, or who suffer censorship and imprisonment (FreeMuse 2018) lends an added dimension of urgency to our activities. Situations we encounter in the field force us to reflect differently on our roles as researchers and encourage us to reconsider earlier ideas.

Colleagues and students sometimes speak to me of Ethnomusicology's historical turn, ontological turn, phenomenological turn, ecological, and archival turns. But many kinds of interdisciplinary engagement as well as social, sonic, and technological changes are leading us to rethink what we do. I am not at all sure the field is turning in one direction or another. Perhaps it is dancing around in its ferment.

\section{What is ethnomusicology good for?}

It is not good for everything, and I don't believe it is good for "absolutely nothing," to paraphrase the song. Rather than pronouncing ethnomusicology to be either absolutely good or bad, I think it is more fruitful to look at its successes, its improvements and new directions, and at some things it is not doing particularly well.

Successes

Here are some things I think ethnomusicologists have been fairly successful at achieving over in the past 70 years:

1. Convincing conservatories and schools of music that there is much more to music and its study than the history and performance practices of European music. Ethnomusicologists research many kinds of music and movement, performed by many peoples in many kinds of communities-from face-to-face to virtual. The willingness of departments of music to hire ethnomusicologists has been a major factor in the expansion of ethnomusicology in the United States and some other countries.

2. Exposing large numbers of people to sounds and performance styles they never imagined. Ethnomusicologists have done this through teaching, publishing audiovisual recordings, hosting visiting artists, producing concerts or festivals, and sometimes performing ourselves.

3. Exposing large numbers of people to cultural diversity through music and dance. Diversity is sometimes easier to understand and appreciate when no language is involved and where emotions are engaged—as in music, movement, or food.

4. Developing a method for doing ethnographic research on specific musical tradi- 
tions through field research and multi-musical learning leading to book-length publications. While it is possible to criticize them, single studies of individual traditions based on an ethnographic model have been a hallmark of our discipline and we continue to address new issues in the long-form of ethnographic research and writing. We are less good at comparative work, though that, too, is changing.

5. Learning the value of working collaboratively with and respecting the rights and opinions of the people whose music we study. This is expected in contemporary ethnomusicology, but the kind of collaboration considered to be the norm today was not always practiced in the past.

6. Critically examining music and dance, and the methods used to study them, through perspectives suggested by other fields and the traumas of the communities in which we do research. Ethnomusicologists seem to have developed a healthy dose of self-criticism, and internal debate about our objectives, methods, and directions is the norm rather than the exception.

7. Diversifying the approaches to the study of music and dance. The larger professional associations like the ICTM (founded in 1947) and the Society for Ethnomusicology (SEM, founded in 1955) are constantly evolving, as are many of the national associations. They continue to establish new sub-groups to address special interests. The SEM has "sections," "interest groups," and regional "chapters" while the ICTM has "study groups," some of which are regional in focus. Among the largest are the Popular Music Section in the SEM and the Applied Ethnomusicology groups in both organizations. There are also ICTM study groups in ethnochoreology, music and gender, music and minorities, and regional studies that highlight contemporary issues and document the developing interests of the membership and give people a place to discuss emerging issues in depth.

Some improvements

There are some subjects about which early ethnomusicologists were little concerned that I think the field is getting better at addressing, though not everyone will agree with me. This volume also contains examples of new directions and critical approaches to music and dance. But here is my list.

1. We are getting better at applying lessons we and our predecessors have learned through our research to benefit the individuals and communities whose music we have studied or admire. Often called "applied ethnomusicology," our activism is based on our detailed understanding of specific musical communities as well as our readings and multi-community experiences. Many of us are doing something we consider to be applied ethnomusicology broadly defined. But we still must en- 
gage seriously with critical examinations of applied ethnomusicology and reflect not only on success or failure, but on the correctness and ethics of our actions and interpretations.

2. The ethics of research, publication, and our obligations to the agencies that fund or otherwise support our research and other activities are a complex issue that demands careful and repeated reflection. Changing methods, technologies, and objectives require more thorough and nuanced consideration of ethics than was required for most of the early ethnomusicologists (Shelemay 2013). Applied ethnomusicology requires special attention to some ethical issues that may be different from other kinds of activities, and professional organizations need to address which ethical issues need to be considered by their members (Shelemay 2013: 794-798). In 2018 both the SEM and the ICTM were engaged in revising codes of ethics; it might be a good idea to introduce students to ethical issues beyond those required by standard research ethics certificates, and to revisit professional ethics statements regularly.

3. Audiovisual archives are changing. Recording technology and audiovisual archives were important in the establishment of ethnomusicology and they continue to play roles today. We are getting better at returning audiovisual recordings and other data from personal and archival collections to artists and communities for their use and benefit. Returning archival collections is not as simple as it appears (Seeger 2018; Shelemay 2013). Field recordings of music and dance are often surrounded by important ethical and political restrictions, and the sound and documentation in them was certainly shaped by power relations and prejudice (Garcia 2017). But despite these shortcomings, archival recordings can sometimes be important for individuals and communities. The increase of publications on "repatriation," or the return of recordings to circulation in communities indicates that we are improving our approach and methods. ${ }^{7}$ In spite of improved access to many archival materials, many ethnomusicologists continue to have ambivalent feelings about depositing their own recordings and field journals in archives. Changes in technology and mission have transformed many audiovisual archives, but many personal collections are not in them and may well be lost to deterioration and obsolescence. On the positive side, the ease of copying born-digital materials allows most researchers to leave copies of their recording with the people they have recorded. On the negative side, most born-digital materials could be inaccessible

7 I highlight this activity partly because Vienna, Austria (where the ICTM Symposium was held), will always be for me an audiovisual archivists' pilgrimage site. Like many others, I began my introduction to archiving with visits to the Phonogrammarchiv in Vienna and to the Berlin Phonogram-Archiv as well as the U.S. Library of Congress. 
when digital platforms and software change or the hardware becomes obsolete or damaged. If the materials could be of future benefit to someone, what is the ethics of not taking steps to ensure the future availability of our research recordings and data?

4. For a long time, teaching the diversity of musics and dance found in the world was limited to colleges and universities. Ethnomusicologists collaborating with music educators and policy makers are slowly increasing the exposure of elementary and secondary students to diverse musical traditions, but there is a long way to go.

5. Ethnomusicologists are increasingly playing active roles in policy debates on music, culture, and heritage policies in different countries and in organizations like UNESCO and the World Intellectual Property Organization (WIPO). We are, however, sometimes marginalized in these discussions because our views are not shared by the hegemonic institutions where these discussions take place. It is essential that ethnomusicologists take an active role in these policy debates and also study and write about heritage and other cultural policies. The UNESCO 2003 Convention for the Safeguarding of the Intangible Cultural Heritage has had a very large impact on cultural polices around the world. Ethnomusicologists must fight to continue to be participants in the debates over cultural policy at the national and international levels.

\section{Not much progress}

There are things at which we do not seem to have improved. Some of these have a long history. Let me return to Willard Rhodes' article on the scope, objectives, and methods of ethno-musicology. Over 60 years ago he wrote:

In the single-minded pursuit of our narrow interests we have failed to communicate with our colleagues outside our bailiwick [specialized field]. Our contributions to anthropology and musicology are not as significant as they might have been. We have been lax in convincing the administrations of universities, foundations, and governments that we have a real contribution to make to the understanding of man through music. By our over-zealous trusteeship of the discipline and its tradition we have alienated potential students and patrons. (Rhodes 1956: 6-7)

1. Ethnomusicologists continue to struggle with the conflict between the singleminded pursuit of establishing a distinctive field called "ethnomusicology" and enlisting the active involvement of other disciplines in our activities and presentations of the field. This is changing, but all too often ethnomusicology can still 
seem defensive and insular (our "overzealous trusteeship of the discipline"). This impression, however, is contradicted by the amount of transdisciplinary work being done by ethnomusicologists everywhere, although not always read and referenced by people in other disciplines.

2. Although Rhodes considered dance to be an important subject for ethnomusicologists to study, the integration of the study of music and movement is still somewhat problematic. Dance often does not receive the recognition it deserves in studies of music. Ethnomusicologists and dance ethnologists may both do research in the same communities, but there are still not enough publications that deal with both as integral parts of the same events. ${ }^{8}$

3. The word "ethnomusicology" still troubles us after 70 years. Is it a unified field or a hyphenated field? Does the word have damning patriarchal and colonial associations? Is it too narrow to encompass what its practitioners do today? Should we replace the word "Ethnomusicology" with another one? This is more of a problem for the Society for Ethnomusicology than it is for the International Council for Traditional Music. The ICTM is not the International Council of Ethnomusicology. Though many members may consider themselves to be ethnomusicologists, the Council is not associated with any single academic field but instead with a subject matter.9 Should all disciplines studying music call themselves "musicology" or "acoustemology" or "sound studies?" These terms would certainly be useful for some kinds of research, but they might inhibit some others. What is the role of dance and movement studies within sound studies, for example? The definition of ethnomusicology may be a "branding" issue. Many commercial companies have changed their brand names to a symbol because their old names seemed confining. Consider the example of Kentucky Fried Chicken, which renamed itself KFC. The restaurant chain hopes to dissociate itself from a single menu item and cooking technique. Would a similar move help ethnomusicology? At the same time, we see certain brands multiplying their sub-brands to occupy more shelf space-are we doing this with a multiplication of names for perspectives on music and dance, like "sociomusicology" and "ecomusicology?" If we renamed ethnomusicology "EM" with a striking graphic, could we maintain the

8 I must include myself in this criticism, as I have not done the work I should have on the analysis of movement in my own research. My failure to consider song and dance as a single object is partly the result of the technological limitations during my early fieldwork. There were no portable video cameras for a long time and there was no way to charge batteries (or even to purchase them) in the field until the 1990s. I could not review in-motion song/dances with members of the community. I should, however, have done more.

9 The ICTM has its own terminological challenges with the word "traditional" and with the absence of the word "dance" in its name, however. 
positive aspects of ethnomusicology and avoid the negative connotations the word has for some people? Possibly not. "Ethnomusicology," like the word "music," is associated with a particular place and time. Perhaps using the word "ethnomusicologies" would enable us to open the field to a greater diversity of approaches (Pettan suggests this [Pettan 2015: 337-40] and other authors have used the plural as well; but like "musics," the word "ethnomusicologies" is not widely used today.)

4. Ethnomusicologists may not have been as successful at reducing intolerance as we hoped. Viewing the terrible increase of intolerance and hatred in many parts of the world during the past few years, many of us realize we haven't been doing as well as we thought at teaching respect for difference and the recognition of the advantages of diversity. Music and food are apparently insufficient in the face of other incentives to maximize self and family and to denigrate difference. With attacks on institutions of higher learning and culture in the United States and elsewhere in the world, this is the time to rethink and refine our communications and activities. It is also a time to strengthen our professional institutions, like the ICTM, SEM and our national organizations to make them even more effective.

\section{Conclusion: Good for Something}

In this paper, I have discussed what music is good for and asked what the study of music might be good for. I presented Willard Rhode's 1956 essay defining ethnomusicology and then addressed some of its current directions. I have suggested that ethnomusicology may not be good for everything, but that it has been good at some things and is getting better at many more of them. While many of us work with specialists in other disciplines, there are benefits to getting together to discuss our work and our vision for the field. We continue to learn from one another in conversations, shared meals, shared liquids, and other experiences at world conferences and specialized symposia. It is still a pleasure to be in a room with people whose work one admires, and with those whose work one has yet to discover.

The ICTM was founded in the troubled aftermath of World War II in part to enable scholars to communicate across the largely European political borders that kept them apart. The ICTM in the $21^{\text {st }}$ century has broadened its mission, is changing its praxis, and now includes many more countries, scholars, and approaches than ever before. But we still strive to overcome the borders and practical issues that isolate us from one another. In the light of this history of approximation, and in anticipation of important initiatives to further develop ethnomusicological activities, I am delighted by the move of the ICTM Secretariat to Vienna. I thank the University of Music and Performing Arts Vienna for agreeing to host the Secretariat. The new Secretary Gen- 
eral's activist work with European minority groups and her establishment of the Music and Minorities Study Group (Hemetek et al.) suggest that the importance of applied ethnomusicology will continue to grow in the coming years. The changes the ICTM has made in first two decades of the $21^{\text {st }}$ century will surely be debated and accelerated in the coming years, but it has been and probably will continue to be an important organization for the conceptualization of our discipline.

I conclude with a final quotation from Willard Rhodes. He wrote: "What of the future of ethno-musicology?" He responded "The answer lies with every worker in the discipline. We can make of it what we will" (Rhodes 1956: 7). We shall continue to do so. There will be a future for ethnomusicology, if it matters, and for the ICTM because it matters.

\section{References}

Araujo, Samuel et. al. 2006. "Conflict and Violence as Theoretical Tools in Present-Day Ethnomusicology: Notes on a Dialogic Ethnography of Sound Practices in Rio de Janeiro." Ethnomusicology: 50(2): 287-313.

. 2008. "From Neutrality to Praxis: The Shifting Politics of Ethnomusicology in the Contemporary World." Muzikološki Zbornik/Musicological Annual XLIV/1, 13-30.

Bohlman, Philip. 2002. World Music, A Very Short Introduction. Oxford/New York: Oxford University Press. . ed. 2013a. The Cambridge History of World Music (The Cambridge History of Music). Cambridge: Cambridge University Press. . 2013b. "Introduction: World music's histories." In The Cambridge History of World Music (The Cambridge History of Music), P. Bohlman ed. Cambridge: Cambridge University Press, 1-20.

Brinner, Benjamin. 2009. Playing across a divide: Israeli-Palestinian musical encounters. Oxford/ New York: Oxford University Press.

Daughtry, J. Martin. 2015. Listening to war: sound, music, trauma and survival in wartime Iraq. Oxford/New York: Oxford University Press.

Dirksen, Rebecca. 2015. "Surviving Material Poverty by Employing Cultural Wealth: Putting Music in the Service of Community in Haiti." Yearbook for Traditional Music 45: 43-57.

Ellis, Alexander. 1885. "On the Musical Scales of Various Nations." Fournal of the Royal Society of Arts 33: 485-527.

FreeMuse, Defending Artistic Freedom. 2018. "The State of Artistic Freedom 2018." https:// freemuse.org/resources/item/state-artistic-freedom-2018/ (29.03.2019).

Garcia, Miguel A. 2017. "Sound Archives under Suspicion.” In Historical Sources of Ethnomusicology in Contemporary Debate, Suzanne Ziegler, Ingrid Åkesson, Gerda Lechleitner, and Susana 
Sardo, eds. Newcastle upon Tyne: Cambridge Scholars Publishing, 10-20.

Harrison, Klisala, and Svanibor Pettan. 2010. "Introduction." In Applied Etbnomusicology: Historical and Contemporary Approaches, Klisala Harrison, Elizabeth Mackinlay, and Svanibor Pettan, eds. Newcastle upon Tyne: Cambridge Scholars Publishing.

Hemetek, Ursula, Anna Czekanowska, Gerda Lechleitner, and Inna Naroditskaya, eds. 2004. Manifold Identities: studies on music and minorities. International Council for Traditional Music Study Group Music and Minorities. Amersham: Cambridge Scholars Press.

Hemetek, Ursula. Personal communication. Emails of 30 November 2016 and 26 June 2017.

Hesmondhalgh, David. 2013. Why Music Matters. Chichester and Malden: John Wiley \& Sons Ltd.

ICTM Applied Ethnomusicology Study Group. https:/www.ictmusic.org/group/applied-ethnomusicology (26.03.2019).

Jackson, Travis. 2006. "Rearticulating Ethnomusicology: Privilege, Ambivalence, and Twelve Years in SEM." Ethnomusicology 50/2: 280-286.

Kurath, Gertrude. 1956. "Dance." Ethno-Musicology Newsletter 7: 10-13.

McDonald, David. 2003. My Voice is My Weapon: Music, Nationalism, and the Poetics of Palestinian Resistance. Durham: Duke University Press.

Loza, Steven. 2006. "Challenges to the Euroamericentric Ethnomusicological Canon: Alternatives for Graduate Readings, Theory, and Method.” Ethnomusicology 50/2: 360-371.

Merriam, Alan P. 1960. "Ethnomusicology: Discussion and Definition of the Field." Ethnomusicology 4: 107-114.

1969. "Ethnomusicology Revisited." Ethnomusicology 13: 213-229.

Mugglestone, Erica and Guido Adler. 1981. "Guido Adler's "The Scope, Method, and Aim of Musicology" (1885): An English Translation with an Historico-Analytical Commentary." Yearbook for Traditional Music 13: 1-21.

Nettl, Bruno. 2013. "On world music as a concept in the history of music scholarship." In The Cambridge History of World Music (The Cambridge History of Music), P. Bohlman ed. Cambridge: Cambridge University Press, 23-54.

Pettan, Svanibor. 1996. "Making the Refugee Experience Different: 'Azra' and the Bosnians in Norway." In War, Exile, Everyday Life. Cultural Perspectives, K. Jambrešić and M. Povrzanović, eds. Zagreb: Institute of Ethnology and Folklore Research, 245-255.

. 2008. "Ethnomusicology and Empowerment Strategies: Views from Across the Atlantic.” Muzicaloški Zbornik/Musicological Annual XLIV/1: 85-99.

2015. "Applied Ethnomusicology in the Global Arena." In The Oxford Pages. Oxford/ New York: Oxford University Press, 29-53.

Pettan, Svanibor and Jeff Titon, eds. 2015. The Oxford Handbook of Applied Ethnomusicology. Oxford/New York: Oxford University Press.

Post, Jennifer ed. 2006. Ethnomusicology: A Contemporary Reader. New York: Routledge. 
2018a. Ethnomusicology: A Contemporary Reader Volume II. New York:

Routledge.

.2018b. "Introduction: Redesigning and Redefining Ethnomusicology." In Ethnomusicology: A Contemporary Reader Volume II, Jennifer Post, ed. New York: Routledge, 1-13

Rhodes, Willard. 1956. "On the Subject of Ethno-Musicology." Ethno-Musicology Newsletter 7: $1-9$.

Rice, Timothy. 2014. Etbnomusicology: A Very Short Introduction. New York: Oxford University Press.

2017. Remodeling Ethnomusicology. Oxford/New York: Oxford University Press.

Seeger, Anthony. 1992. "Ethnography of Music." In Ethnomusicology: An Introduction, Helen Myers ed. New York: MacMillan, 88-109.

2006. "Lost Lineages and Neglected Peers: Ethnomusicologists outside Academia." Ethnomusicology 50/2: 214-235.

. 2018. "Archives, Repatriation, and the Challenges Ahead." The Oxford Handbook of Repatriation, F. Gunderson, R. Lancefield and B. Woods, eds. Oxford/New York: Oxford University Press.

Shelemay, Kay K. 2013. "The Ethics of Ethnomusicology in a Cosmopolitan Age.” In The Cambridge History of World Music (The Cambridge History of Music), P. Bohlman ed. Cambridge: Cambridge University Press, 786-806.

Star, Edwin. 1970. "War, What is it good for?" written by Norman Whitfield and Barrett Strong. Motown Records. https://www.youtube.com/watch?v=-dKAX7Jp8w (29.03.2019).

Titon, Jeff T. 2015. "Applied Ethnomusicology: A Descriptive and Historical Account." In The Oxford Handbook of Applied Ethnomusicology, S. Pettan and J. Titon, eds. Oxford/New York: Oxford University Press, 4-29.

Wong, Deborah. 1998. "Ethnomusicology and Critical Pedagogy as Cultural Work: Reflections on Teaching and Fieldwork." College Music Symposium 38: 80-100.

2006. "Ethnomusicology and Difference." Ethnomusicology 50/2: 280-286.

Abstract

Music has been recognized as a potent force in many societies over the centuries. Sometimes it has been praised as good and sometimes reviled as leading to evil thoughts and deeds. But what about the study of music-does it matter? If so, in what ways does it matter? Do our analyses simply reproduce the power structures from which we undertake them or do they challenge them? Do our activities enable individuals or communities to empower themselves or do they disempower and discourage? Does anyone read what we write or listen to the music we enable, or are they the material artifacts of irrelevant activity? This paper discusses the socio-political relevance 
of ethnomusicology with an emphasis on the $21^{\text {st }}$ century. It begins with a reflection on what ethnomusicology has been and may become. It continues with a discussion of research, documentation, and analysis and how and whether they have mattered in the past or may matter in the future. And it concludes with reflections on things ethnomusicology has learned to do well, things it is still working to improve, and things at which it has not yet improved much. Music will go on and on; will ethnomusicology? It may if it matters. 
Adelaida Reyes

\section{The Beneficence and the Tyranny of Paradigms: Kuhn, Ethnomusicology and Migration}

\section{Introduction}

The 1960s were turbulent times. In the United States, the Cuban Missile Crisis (1962), triggered by the discovery of missile launch sites in Cuba, raised fears of nuclear war. The decade saw the assassination of President John F. Kennedy, his brother Senator Robert F. Kennedy, and the Nobel Peace Prize winner and prominent leader of the Civil Rights Movement, Martin Luther King, Jr. Massive public demonstrations, violent and non-violent, protesting such issues as the escalation of the Vietnam War, or supporting causes such as racial and ethnic equality, marked the decade which came to be called "the "60s" with no need to specify the century in question.

Against this background, the publication of a small book referred to as an essay by its author, a historian and physicist who at the time was virtually unknown outside academia, could easily have gone unnoticed. The book's concerns did not have the immediacy of the issues that were then gripping the nation. As it turned out, however, the book created its own turbulence. Shortly after it appeared, Thomas S. Kuhn's The Structure of Scientific Revolutions began to stimulate and provoke debates and controversy, interpretations and re-interpretations: in print, at conferences, and in a variety of other venues. It has continued to do so intercontinentally and in a number of languages. ${ }^{1}$

Two editions of Structure or SSR (as the book is often referred to for short) followed, one in 1970, the other in 1996. Looking back some twenty-five years after the publication of Structure's 1970 edition, the eminent physicist Steven Weinberg, a thoughtful critic of Kuhn's work, observed that the book had had "a wider influence than any other book in the history of science" (1998: 48). A fourth edition, celebrating the book's $50^{\text {th }}$ anniversary, was published in 2012. What the philosopher, Howard Sankey, describes as a "massive literature relating to Kuhn" has come into being, nurtured not only by scientists, but notably by historians and philosophers, attesting to Kuhn's "profound and enduring influence on historical, philosophical studies of science" (1995: 467).

1 "Since the book's publication, over one million copies have been sold, including translations into sixteen different languages.” (https://en.wikipedia.org/wiki/The_Structure_of_Scientific Revolutions). 
Not unlike the protest movements of the 1960s, the book was a bold challenge to long-standing, widely-held beliefs. Structure was a call for radical change. In this respect it reflected the temper of the times in which it was born. Repeated at the beginning of every edition of the book, what has been called Structure's "signature statement" (McCrum 2016) gave a concise but powerful view of the then-current situation, its need for a corrective, and the book's plan for one. Suggestively using the word "possessed" to describe the attachment of scientists to the view of science prevalent at the time, and explicitly stating that they have been "misled" in their attachment, Kuhn called for "transformation."

History [...] could produce a decisive transformation in the image of science by which we are now possessed. [...] This essay attempts to show that we have been misled [...] in fundamental ways. Its aim is a sketch of the quite different concept of science that can emerge from the historical record of the research activity itself. (Kuhn 1996, 1970 [1962]: 1)

Even a sketch of such an undertaking would require a huge canvas that can accommodate a large cast of characters-science practitioners well-known and anonymous; people from the past and those still laboring in the present. The picture should be able to depict or at least suggest the dynamics between individual and community, between constancy and change, between the anomalous and the normative. Structure, in the richness of its ideas and the possibilities they raise, makes an overview extremely difficult if not impossible in a work as limited in size and scope as this. I will therefore focus on one of the concepts that became the most prominent and provocative among those that Kuhn presented in Structure: the paradigm. This will serve as a key or gateway to areas of Structure that are applicable-potentially or actually - to ethnomusicology. I will then take two ethnomusicological situations: one that is mostly if not wholly past, and another that is wholly present to raise two fundamental questions: 1) What insights might be gained by looking back at events in ethnomusicology's history from a Kuhnian perspective? And 2) What, if any, effects could such insights have on the way we approach and meet the challenge of a contemporary and future situationone such as migration, for instance, that has strong effects on the musical lives of ever larger populations in today's world?

The following summary review of Kuhn's concept of science provides a contextual frame for his views on the paradigm. 


\section{Kubn and his concept of science}

Rejecting a linear view which takes scientific progress to be cumulative-one achievement building upon another-Kuhn proposed an episodic view in which periods of what he called "normal science" are disrupted by crises before being returned to a new "normalcy" by a paradigm shift.

Rejecting a static view of science that consists of accounts of the accomplishments of its outstanding practitioners, Kuhn proposed one that is dynamic-one that emerges from a "record of activity." Kuhn would include not just the activities of outstanding scientists whose achievements science already celebrates. His conceptualization of science would assign to human agency-both as individuals and as members of a scientific community — an indispensable and observable role.

At the time of Structure's writing, scientists and philosophers of science saw this as a "threat to the rationality of science" (Wray 2015: 167). It endangered the scientific method that held objectivity to be concentration on the object of study undisturbed by first-person references-a standard to which science was then held. Believed to guarantee value neutrality, objectivity, seen in the above terms, was considered requisite to and a hallmark of good scientific work.

As a safeguard against the intrusion of the personal into scientific work, objectivity had, in effect, made sciences and the humanities mutually exclusive. In contrast, Kuhn's insistence on the inclusion of human agency in accounts of scientific work, with all that that implies, made the boundary between the sciences and the humanities permeable. It made disciplinary interaction possible, useful, and under certain circumstances, necessary. ${ }^{2}$

Further enhancing the broad applicability of Kuhn's ideas is the fact that he drew no clear boundaries to delineate the terrain that he called "science," even as he acknowledged its difference from as well as its overlaps with other fields. His usage is thus closer to one of several attributed to "science" by the Oxford English Dictionary_-"knowledge acquired by study; acquaintance with or mastery of any department of learning" - than to contemporary academic usage that divides science and its study into academic fields or disciplines and distinguishes them from the humanities. ${ }^{3}$

2 By the end of the century, the permeability of the boundary separating the sciences and the humanities had become acceptable or at least arguable. The distinguished paleontologist, Stephen Jay Gould, implies that disciplinary interaction is unavoidable if not essential: "I would [...] reject any claim that personal preference, the root of aesthetic judgment, does not play a role in science" (1994: 1; emphasis added).

3 Similarly, Mugglestone, in her 1981 article on Guido Adler's Umfang, Methode, und Ziel der Musikwissenschaft uses the term science in the "'original sense of the English word [...]' systematized body of knowledge." It is in this sense of the term "science," she points out, that Guido Adler "consistently relates the science of music to the science of art in general" (Ibid.: 19, footnotes 2 and 4). 
From a Kuhnian perspective, science becomes a more inclusive terrain where diverse disciplines can draw insights into themselves from one another. It is a terrain where ethnomusicology's claim to being part of both the humanities and the sciences can find a receptive, if not a natural, environment.

The paradigm...

Aware of the extensive discussions provoked by his use of the term, Kuhn admitted to some twenty-two different senses in which he had used "paradigm" (1977: 294). The usage that proved definitive for Kuhn's purposes evolved through the years. But certain attributes held firm even as Kuhn elaborated on the concept or re-considered previous usages.

In one of the more categorical passages in Structure, Kuhn describes a paradigm as a prior scientific achievement that is: 1) "sufficiently unprecedented to attract an enduring group of adherents away from competing models of scientific activity;" and 2) "simultaneously [...] sufficiently open-ended to leave all sorts of problems for the redefined group of practitioners to resolve" (1970: 10). ${ }^{4}$

The first characteristic that Kuhn attributes to a paradigm takes it to be an exemplar or a model, one that has proven to be the fittest (in the Darwinian sense) among "competing models." It has superior problem- or puzzle-solving qualities, ${ }^{5}$ as a consequence of which, it can "replace explicit rules" (1970: 175). But, as Kuhn points out, such models are not for mere replication. Paradigms are to be treated like an "accepted judicial decision in the common law, to be an object for further articulation and specification under new or more stringent conditions" (1970:23). Hence, the open-endedness of a paradigm and the promise it carries for articulating, ${ }^{6}$ testing and re-articulating "those phenomena and theories that the paradigm already supplies" (ibid: 24 ).

Kuhn's concept of science goes beyond problem-solving practices and research tools; it implicates human agency in important ways. As the paradigm's superior puz-

4 In the 1970 edition, Kuhn wrote: "Achievements that share these two characteristics I shall henceforth refer to as 'paradigms'” (p. 10).

5 "Puzzles are [...] that special category of problems that can serve to test ingenuity or skill in solution" (1970: 36). "[I]ntrinsic value is no criterion for a puzzle, the assured existence of a solution is" (ibid.:37).

6 Hacking clarifies the sense in which Kuhn uses the term "articulation:" it is "the process of bringing out what is implicit in the theory" (2012: xvi). 
zle-solving qualities attract adherents, and as more and more practitioners gravitate toward the paradigm, a consensus view takes shape, binding practitioners into a scientific community. The paradigm, by providing the basis upon which are determined "what phenomena are relevant and what constitutes an explanation of those phenomena" (Weinberg 1998: 48), lays the foundation for what Kuhn calls "normal science," lending it its stability and normative power even as normal science in turn sustains the life of the paradigm itself.

Kuhn thus insists that a paradigm is "what the members of a scientific community share and conversely, a scientific community consists of men [sic] who share a paradigm" (Kuhn 1970: 176). ${ }^{7}$ Anticipating charges of circularity, he clarifies by characterizing members of the scientific community as both "producers and validators of scientific knowledge" (Kuhn 1970: 178). It is the community's active role in paradigm choice as much as the puzzle-solving attributes intrinsic to the paradigm that propels the transition from pre-paradigm period to normal science. The interplay between paradigm and practitioner consensus is recognizable in its effects. By functioning as a model or exemplar, the paradigm offers practitioners methodological economy-the scientist need no longer try "to build his field anew, starting from first principles"' (Kuhn 1970: 19). By facilitating communication and mutual support, consensus among practitioners facilitates the dissemination of research results. Constant use as a constant test of the paradigm's efficacy in problem-solving enriches both the paradigm and its users through new insights into, and a better understanding of the theories and/or principles that underlie the work of the scientific community. In this respect, normal science, sustained by a paradigm and practiced by a scientific community, takes on the force of the mainstream with its dynamism and its power to influence research activity over long periods of time.

The period when a paradigm prevails can thus be a period of great beneficence. Research activities abound. Findings and insights are disseminated, boosting support for the paradigm among a widening circle of users. "So long as the tools a paradigm supplies continue to prove capable of solving the problems it defines, science moves fastest and penetrates most deeply through confident employment of those tools" (Kuhn 1970: 76).

But what has proven most attractive about a paradigm-its problem-solving power-can also become one of the greatest risks to the continued efficacy of the paradigm. Over time its use as a standard set of procedures by a sizeable scientific community gets the paradigm so internalized that it becomes difficult to bring it to consciousness and to subject it to critical appraisal. Normal science then becomes

7 In a chapter dedicated to a discussion of Kuhn, Clifford Geertz is categorical about the essential relations between a paradigm and human agency: "A paradigm governs [...] not a subject matter but rather a group of practitioners" (2000: 163). 
self-limiting, tending more toward validating rather than challenging established practice. Kuhn observes: "Perhaps the most striking feature of [...] normal research problems $[\ldots]$ is how little they aim to produce major novelties, conceptual or phenomenal" (1970: 35).

...tearing it down

Almost by definition, normal science puts its emphasis on the normative, the patterned, the rules that govern a system. But just as important to the acquisition of new knowledge is the anomalous. To the patterned and the normative, anomalies pose the challenge in the face of which paradigms must justify their findings. The recognition of anomaly, Kuhn asserts, is the "prelude to discovery" (Kuhn 1970: 57).

That recognition presupposes judgment, for not all anomalies-“discrepancies between theory and data" as Hacking puts it—are significant. Some require no more than "a simple refutation" (2012: xxvi). But when "the paradigm cannot cope with a cluster of anomalies" (ibid: xxiii) and when "over longer periods unresolved anomalies accumulate to the point where some scientists begin to question the paradigm itself" (Naughton 2012), discontent becomes explicit; consensus is disrupted, crisis results. And crisis, as Hacking notes, calls for a departure from normal science, a period of extraordinary [...] research" (2012: xxvii). Innovation no longer suffices; change, or in Kuhnian terms, a paradigm shift, looms ever larger on the horizon. ${ }^{8}$

... and making it whole.

A paradigm, therefore, is a double-edged sword that deepens, probes and reaffirms knowledge even as it creates the conditions for challenging that knowledge and hence for coming up with new knowledge. In the exercise of this dual capacity-creating and reaffirming knowledge on the one hand and challenging and (in)validating it on the other-a paradigm offers valuable insights into opposition, the dynamic process that allows the members of an opposing pair-the normative and the anomalous; tradition and innovation, for instance- to illumine each other even as it holds them in a state of both conflict and cohesive tension. ${ }^{9}$

8 The linguist Michael Shapiro's distinction between innovation and change is particularly useful here. Change, he notes, is the adoption of innovation "by the broad membership of the [...] community." [cf. Kuhn's "consensus"] "[T]nnovations are produced by individuals, whereas change is a social fact" (1991: 8-9).

9 The importance of these issues not only to science but to the acquisition of knowledge in general 
In his essay, "The Essential Tension: Tradition and Innovation in Scientific Research" (1977), Kuhn underscores the point:

$[\mathrm{O}]$ nly investigations firmly rooted in the contemporary scientific tradition are likely to break that tradition and give rise to a new one. That is why I speak of 'an essential tension' implicit in scientific research [...] Since these two modes of thought are inevitably in conflict, it will follow that the ability to support a tension that can occasionally become almost unbearable is one of the prime requisites for the very best sort of scientific research. (Kuhn 1977: 226)

Paradigms, therefore, harbor both constancy and change, keeping the paradigm both resistant to and restless for change. " $[\mathrm{B}] \mathrm{y}$ ensuring that the paradigm will not be too easily surrendered, resistance [to change] guarantees that scientists will not be lightly distracted and that the anomalies that lead to paradigm change will penetrate knowledge to the core" (1970: 65). Resistance to change or a reluctance to let go of the normative thus cannot just be charged to obstinacy or short-sightedness. It can be a careful guardianship of knowledge gained during periods of normal science's beneficence, ensuring that they can be further probed, tested and refined (Hacking 2012: xvi). In serving these functions, Kuhn argued, resistance to change is part of scientific progress.

This view of resistance to change finds support from both the nature of human perception and the nature of normal science. Both lead us to see what we expect to see. As Hacking reminds us, normal science "tends to discover what it expects to discover. We have a tendency to see what we expect even when it is not there. It takes a long time for an anomaly to be seen for what it is, something contrary to the established order" (Hacking 2012: xxvi).

Normal science and its paradigm(s) can thus enrich knowledge with its beneficence just as it can stultify the drive for new knowledge. The powerful embrace of a paradigm's certainties and the consequent resistance to recognizing anomaly with its call for change can turn into straitjackets that tyrannically deny the openness that the acquisition of knowledge requires. As a double-edged sword, the paradigm underscores the importance of opposition as a dynamic force that powers both conflict and cohesion, for the potential explanatory power of opposition can escape notice, overshad-

finds expression in a variety of fields. Both the linguist Ferdinand de Saussure and the philosopher Charles Sanders Peirce "considered opposition to be the essential dyadic relation. Indeed for Peirce, 'a thing without opposition ipso facto does not exist', hence it is the study of oppositions which underlies the understanding of the mode of being of things" (Shapiro 1983: 7). And Gould, underscoring the fundamental function of opposition, wrote: "Among the organizing dualities of our consciousness, change and constancy stands out as perhaps the deepest and most pervasive" (1994: 12) 
owed by a practice that automatically assigns a higher value to the normative at the cost of the new knowledge, the gateway to which is held open by anomaly.

\section{Ethnomusicology: a backward glance}

Musicology bypassed that open gateway, taking instead a trajectory that favored familiar certainties over the potential anomalies that may lie beyond the gateway. Looking at the consequences of taking that historical turn with the above discussion of Kuhn in mind can be instructive.

Towards the end of the $19^{\text {th }}$ century, as German and Austrian scholars sought to establish "modern musical scholarship" as an autonomous academic discipline (Mugglestone 1981: 2), musicology sheltered a variety of subjects-history, composition, pedagogy, aesthetics; European art music, "primitive" music, folk music, etc. The field was in need of "a unitary field theory" - to the search for which Guido Adler's article Umfang, Methode und Ziel der Musikwissenschaft, (1885) became a prominent and influential contribution (Ibid.: 18).

Organizing musicology into two "subdivisions," historical and systematic, Adler placed vergleichende Musikwissenschaft or comparative musicology in the systematic subdivision along with other "branches of tonal art" such as harmony, aesthetics, and pedagogy. (op cit.: 15). He saw the task of comparative musicology as "the comparison of works - especially folk songs — of the various people of the earth for ethnographical purposes and the classification of them according to their various forms" (1885: 14). ${ }^{10}$

In an article that analyzes forty-two definitions of comparative musicology and ethnomusicology from 1885 to 1976, Alan P. Merriam makes three "major points," of which two are particularly relevant: First: "[the definitions] define comparative musicology unanimously in terms of certain musics to be studied, namely, either 'non-Western' [...] or orally-transmitted musics." Second: "[the definitions] do not deal with what is meant by 'comparative method' or what the aim of comparison is; indeed, they seldom stress anything comparative at all” (1977: 192).

The second point, being the more straightforward in its manifestations and indisputable in its outcome, needs only a brief account. Throughout the period of its use from the end of the $19^{\text {th }}$ century to more than half of the next, scholars have called attention to the problem of what "comparative" stands for in this case. Hornbostel's critique, Die Probleme der vergleichenden Musikwissenschaft (1975 [1905]) was among the earliest, and most wide-ranging. It covered issues such as the theoretical and methodological implications of scientific comparison and the technical difficulties

10 Translated from the German in Merriam 1977. 
involved in collecting the musics to be compared so that they can be properly described, analyzed and juxtaposed for comparison. One passage is indicative:

[T] he difficulties of [comparison] increase infinitely, even for the experienced musician, when the music employs unaccustomed intervals and rhythms. And difficulties here are equal to sources of error. In this regard, we have a bardly surmountable tendency to adjust everything that is unusual to fit our concepts and to hear exotic music with European ears. (translation from the German by Richard Campbell in Hornbostel 1975: 251; italics added)

Others-Curt Sachs, George Herzog, Jaap Kunst and Willard Rhodes among many more ${ }^{11}$ —echoed Hornbostel and raised questions of their own into the 1960s. Kunst proposed replacing "comparative musicology" with "ethno-musicology" in 1950. In 1955, with the creation of the Society for Ethnomusicology in the United States, the hyphen was permanently removed. In 1961, Curt Sachs wrote: "[C]omparative musicology has lost its usefulness. [...] Walter Wiora is certainly right when he emphasizes that comparison can denote only a method, not a branch of learning" (quoted in Merriam 1977: 193). In the same year, Merriam wrote that "the use of "comparative musicology' as a label had disappeared except in historic references [...] it was no longer applied to the field in general" (1977: 192).

Merriam's first "major point" addressed a more complex issue. The "musics to be studied" had anomaly threaded through it from the moment it was proposed as general label for the subject matter of comparative musicology. It was "defined" largely in terms of what the subject matter of musicology, its parent discipline, was not: not Western music (often referred to as non-Western or exotic although, as Merriam noted, "the 'non-European' aspect of the definition [...] received the greatest play" (1977: 192); not art music but-based on the ranking of cultures that followed from the evolutionary thinking common at the time- "primitive" and orally transmitted or folk music. Yet the same conceptual and methodological tools-Western European theoretical frameworks, musical terminology, musical notation, etc.-were to be used for describing, analyzing, and explaining what for the most part were incommensurable musics (see the Hornbostel quotation above).

The methodological anomaly inherent in the lack of fit between tool and task may have been either missed or ignored. ${ }^{12}$ But its persistence can only be understood in the light of an assumption so deeply rooted that it was taken for granted.

Shared by comparative musicology and its parent discipline, the assumption holds that music, regardless of cultural origin, is principally if not strictly an acoustic phe-

11 See Merriam 1977.

12 See Reyes 2006 for more detail on the task-tool relation in ethnomusicological method. 
nomenon, and as such responds in the same way to Western European descriptive and analytical tools. The term "extra-musical" powerfully implies that assumption, not infrequently implying also the insignificance and dispensability of things outside music's acoustic realm.

It was not until comparative musicology lost its usefulness (see Curt Sachs above) and the "music to be studied" by comparative musicology was challenged in the 1950s that the question of how to study a kind of music ethnomusicologically was addressed. What is the nature of the object of study? From what perspective should it be described and analyzed? Questions of this kind became important theoretical issues as ethnomusicology marked its "subject to be studied" with labels such as "world music," or the "music of the world's peoples." Categories of difference were based not only on sound and/or culture of origin but on the nature of music as more than sound. Music as a cultural product was first proposed by Merriam in 1960 (see Merriam 1977). Subsequently, the cultural component became essential to the definition. Emphases differ, but whether expressed in terms such as music as human behavior, music as a social act, music as expressive culture, or as a symbolic system, the essential relations between music as sound and the culture that shapes it and from which it draws meaning became central to ethnomusicology's definition.

The resulting substantive change in the way music was regarded as an object of investigation made crossing disciplinary boundaries inevitable. One result has been what is commonly referred to as a "bifurcation" into an anthropologically-oriented ethnomusicology and a musicologically-oriented ethnomusicology. ${ }^{13}$ Often taken to stand for the mutual exclusivity of the two prongs of the bifurcation or for privileging either music or culture, ${ }^{14}$ the bifurcation could alternatively be thought of as an opposition that calls to mind Kuhn's "essential tension," - one that, on one level, pits resistance to change against innovation and, on another level, has one member of the opposition clarifying the other through contrast and the dialectic that is inherent in opposition. The dynamics of the opposition embedded in the interplay between the two "orientations" can thus provide a cohesive tension that supports the oneness and autonomy of ethnomusicology as a discipline that belongs to both of the fields that academia differentiates as the sciences and the humanities.

Was this the only road to ethnomusicology's autonomy? Kuhn suggests anotherthis time, one that deliberately goes through the gateway held open by anomaly.

13 See, for example, Nettl 2006 and Wade 2006.

14 Wade recounts discussions with Merriam at UCLA over whether the bifurcation means setting priorities: "music first or culture first" (2006: 192). She also cites the article, "Ethnomusicology Revisited" where Merriam wondered if ethnomusicology might be not one but two disciplines (1969: 213). 
In his contribution to Kubn's Structure of Scientific Revolutions: 50 Years On (2015), K. Brad Wray notes Kuhn's belief "that not all crises in science are resolved by a revolutionary change of theory. Some crises are resolved by dividing a field into two separate specialities [sic], each responsible for a sub-set of the phenomena for which the parent field was originally responsible" (2015: 178).

Wray describes the consequences. As the specialty devotes more and more of its time to the phenomena specific to it, its conceptual framework begins to diverge from that of the parent discipline to the point where communication between them becomes less effective if it does not in fact break down. As a result, "[s]cientists in the parent field are no longer held back by the persistent anomalies that led to the creation of the new specialty in the first place" (ibid.: 179). At the same time, scientists in the new specialty dedicate more and more of their attention to what has always been their normal subject of study.

Wray's projection of what happens when the alternative route is taken, i.e., when instead of trying to unify highly disparate subdisciplines they are made into separate specialties, reflect what did happen when comparative musicology finally gave way to ethnomusicology. Ethnomusicology claimed the prerogative of defining its subject matter, not merely by negating that of its parent discipline but by positively characterizing what it studies, making explicit the perspectives from which it is to be investigated, thus laying the groundwork for the construction of an appropriate theoretical and methodological framework.

\section{Ethnomusicology and (forced) migration}

The past yields insights that are often attributed to the proverbial clarity of hindsight. Temporal distance opens up new ways of seeing and reveals details previously missed, allowing for a revision of the remembered picture or narrative. Changes in assigning significance become possible and justifiable. What might or should have been suddenly becomes indisputable.

The contemporary, however, is not so accommodating. Its very presence is a demand for attention. Events are expected to be reported with the utmost fidelity to perceivable reality. So it is, for instance, with migration, particularly forced migration, and its currently incessant coverage by the media. It is a here-and-now phenomenon 
and promises to be such for the foreseeable future. In its many forms, ${ }^{15}$ in its global reach, and in its immediate as well as far-reaching effects on human life, migration has become part of contemporary life. It holds the power to transform both the migrants and the society within which they live.

In the United States, interest in migration was re-ignited by the passage of the Hart-Celler Immigration Act of 1965 which, with the Voting Rights Act of the same year and the Civil Rights Movement of the '60s, had focused public attention on issues of racial and ethnic discrimination. The Hart-Celler Act, by abolishing the national-origins quota system that had restricted immigration into the United States from southern and eastern Europe and "maintained formidable barriers against immigration from Asia and Africa" (Kammer 2015), opened the nation's doors to populations that had been previously discriminated against. The resulting influx of migrants "quickly transformed the ethnic portrait of the United States" (ibid., quoted from FitzGerald and Cook-Martin 2014: 121).

Studies of ethnic groups (often conflated with migrant groups) began to proliferate in a wide range of fields, from the health sciences to the social sciences and the humanities. "Ethnicity" (though not "Migration") appeared as a category of "Membership Interest" in the 2002 Membership Directory of the Society for Ethnomusicology "Ethnic, Ethnicity" as well as "Migrants, Migration" in the 2005 ICTM Directory of Traditional Music.

Most, if not all of the studies, however, were modeled on the experiences of voluntary migrants-those who, of their own volition, left their country of origin or place of habitual residence, with a measure of control over such matters as destination and how or when they would make the move. Compliance with the laws of the host country are a pre-condition.

To all intents and purposes, migration was assumed to be an orderly process. The term stood for a general category with the broadest possible application and without regard for circumstances of departure from habitual place of residance. What would come to be known as forced or involuntary migration was believed to be a temporary phenomenon. Refugees would return home and resume their interrupted life once the hostilities had ceased or the environmental catastrophe that had caused them to flee had somehow found resolution.

Once migrants had settled into groups, they were believed to be amenable to study using an approach that Fredrik Barth described as "isolationist." The group under

15 Migration is here used in its generic sense. It subsumes voluntary and involuntary migration, immigration and emigration. Migrants include asylees or asylum seekers, displaced persons, refugees, immigrants and emigrants. Each category has its own rights and entitlements under the law of the nation-state which has jurisdiction over the migrant(s). 
study is taken as an independent variable, "isolating" it from other groups and institutions and proceeding as though what has been isolated has an "internally shared culture," one that is an extension of the pre-migration forms that made the group distinct from both the host society and other ethnic groups (Barth 1998: 5). "[W]e are led to imagine each group developing its cultural and social form in relative isolation [...] through a history of adaptation by invention and selective borrowing. This history has produced a world of separate peoples [...] each organized in a society which can legitimately be isolated for description as an island in itself" (1998: 11).

Reminiscent of the enclave model familiar to ethnomusicology, the isolationist model has persisted in studies of migrant groups despite the mass displacements of the $20^{\text {th }}$ century and today's stark realities. "Today's conflicts burn on for an average of thirty-seven years, making return for the uprooted an ever distant prospect" (Milliband 2016: 23). "[R] efugees are displaced for an average of seventeen years and those displaced within their own country for an average of twenty-three years" (ibid.: 24). "Fewer than 1 percent of the world's refugees were able to return to their countries of origin [in 2015]. [...] Protracted conflict is the new norm.” (ibid.: 25).

In 1951, recognizing the continued presence of refugees on the world stage and the "persistent emergency" (Smyser 1987: 2) they represent, the United Nations established a permanent office, the UN High Commissioner for Refugees (UNHCR), to deal with refugee issues. A "global definition" of the refugee was formalized, its terms and a list of refugee rights intended to be binding on all signatories. ${ }^{16}$ The features of the definition most relevant for the present purposes are: the fear-driven flight from the migrants' country or place of habitual residence, and the problematic relations with the "home" country indicated by refugees' unwillingness to return.

Smyser's description, from the particularity of Khmer refugees who were "unsure whether any country would accept them [...] powerless to control their future, afraid to return home," to his summary generalization that refugees "have fled danger to accept uncertainty" (1987: xiv) effectively underscores the anomaly that is forced migration in the context of voluntary migration as the norm. Smyser's observations throw a harsh light on the striking lack of fit between a theoretical and methodological framework that treats forced migrant groups as an independent variable and the reality of the forced migrants' situation—as groups whose experience of forced migration begins

16 The UN 1951 Convention on Refugees (see: https://www.unhcr.org/3b66c2aa10) defines a refugee as a person who as a result of events occurring before 1 January 1951 and owing to a well-founded fear of being persecuted for reasons of race, religion, nationality, membership of a particular social group or political opinion, is outside the country of his nationality and is unable or, owing to such fear, unwilling to avail himself of the protection of that country; or who, not having a nationality and being outside the country of his former habitual residence as a result of such events, is unable or, owing to such fear, is unwilling to return to it. 
with the status of escapee, a status that brings with it statelessness and an inevitable dependence on others, individuals as well as institutions. ${ }^{17}$ The dangers of statelessness last for an indeterminate period of time as the forced migrants seek a nation-state that would give them asylum. Once achieved, asylum and resettlement shift the migrants' dependence and necessary interaction to the host country, its institutions and other groups within it. The kindness or hostility encountered in these inevitable and often mandatory interactions impede or advance the reconstruction of migrant life.

It is under these conditions that they must also create new emblems of peoplehood or individual identities, rejecting elements of what has been left behind or clinging to them as part of who they are. Here, expressive culture plays an important role. As the anthropologist Sidney Mintz notes, music and expressive culture in general are among the most easily transferable of human creations and are thus sensitive and vulnerable to changes in environment and to modes and circumstances of transmission (1970). Music goes where its creators and performers go, crossing boundaries, appropriating influences and having their own musical ideas appropriated by others, as everyonemigrants and their hosts alike-adapts to new and changing conditions. Musics cross over, blend with, sample from other musics, or are kept protectively hidden. ${ }^{18}$

Thus the relative orderliness of voluntary migration evaporates as forced migrants, often for reasons as elemental as survival, take on the pressures of meeting "the expectations of others-host governments, international organizations, relief officials, donors, the media. [All] condition adaptation" (Needham 1994: 18).

The necessity and inevitability of interaction between migrants and host society double-underlines the anomaly that is the use of the isolationist model for studies of forced migrants. That use foregrounds the power of even a spent paradigm. And they remind us of Kuhn's emphasis on human agency, which, in all its implications, strongly suggests the scientist's need for self-knowledge.

What used to be objectionable when Structure first came out has now become acceptable. Stephen Jay Gould expresses it succinctly: "Reality does not speak to us objectively and no scientist can be free from constraints of psyche and society" (Gould 1989: 276). Teilhard de Chardin is a bit more expansive:

[Scientists] are now beginning to realize that even the most objective of their observations are steeped in the conventions they adopted at the outset and by forms or habits of thought

17 Strictly speaking, migration involves crossing geo-political boundaries. Those who flee their homes but do not leave their country are designated "internally displaced."

18 We see some of this in the interaction between the refugees in the Jungle, the refugee settlement in Calais (France), and the UK visitors who have come to record music there (See Lucas-Smith 2016). See also Reyes 1999. 
developed in the course of the growth of research [...]. Object and subject marry and mutually transform each other in the act of Knowledge [...]. [M]an willy-nilly finds his own image stamped on all he looks at. (2008: 32)

What awaits the self-aware scientist/ethnomusicologist is a growing population of forced migrants. During World War II, "an estimated 27 million were displaced" (Smyser 1987: 7). In 2015, according to the UNHCR, there were 63.3 million "uprooted from their homes by conflict and persecution. [...] On average, 34,000 people were forced to flee their homes every day of 2015" (Milliband 2016: 23). The nature of contemporary conflicts and environmental changes virtually guarantee that forced migration will be with us for a long time. It is a global phenomenon of which musical life is a part and to which ethnomusicology has yet to respond. David Milliband, president of the International Rescue Committee, ${ }^{19}$ makes a plea that can be easily translated into ethnomusicological terms. Noting that "it is crucial to bring into alignment the interests of refugees and host communities," he underscores "the power of effective research to define needs and to meet them with the means best suited to the needs" (2016:23).

The challenge is clear. The indigenous, the native, have loosened their grip on the ethnomusicological imagination, giving way to the migrant, the border-crosser, the displaced. And migration, as the major instrumentality by which these statuses come into being, deserves closer examination. If what stands in the way of a critical look is what Stephen Jay Gould called the conceptual lock of the taken-for-granted, then migration — and especially forced migration — as the anomaly that in Thomas Kuhn's sense violates paradigm-induced expectations - may indeed turn out to be, again in Kuhn's words, "a prelude to discovery" (1970: 57).

Ethnomusicology is thus confronted with virtually unexplored territory that has a population large enough to people nation-states, a growing population that must interact with international institutions as well as a host society as it constructs an expressive culture that incorporates the distinctive experience of forced migration. Is the discipline up to and willing to meet the challenge?

At this juncture, the past comes up to the present. Will past events be used as precedents to justify repeating history's mistakes? Or will they be used as points of departure for exploring new possibilities? Opting for the certainties of the familiar, one could avoid confronting the anomalous. Or taking on the risks of innovation, one could walk through the gateway that anomaly is holding open.

19 The International Rescue Committee was founded in 1933 on the suggestion of Albert Einstein, to help Germans suffering under Hitler. It is now is a non-profit, international, non-governmental organization dedicated to humanitarian aid. It is a quick responder to forced migrant situations all over the world and helps resettle refugees. 
Kuhn has described resistance to change and its function in the context of normal science. He has described the resistance to confronting anomaly until it reaches a critical mass and begins to undermine the confidence of the scientific community. The demise of comparative musicology is illustrative.

Kuhn has also described circumstances under which crises created by anomaly finally lead to innovation and change. "As in manufacture, so in science-retooling is an extravagance to be reserved for the occasion that demands it. The significance of crisis is the indication they provide that an occasion for retooling has arrived" (Kuhn 1970: 76). Will ethnomusicology take the forced migration crises and the inevitable (re)creation or (re)construction of musical life no longer as an extravagance that we can do without, but as an occasion for much-needed retooling?

References

Adler, Guido.1885."Umfang, Methode, und Ziel der Musikwissenschaft." Vierteljahrschrift für Musikwissenschaft 1:5-20.

Barth, Fredrik. 1998 [1969]. "Preface" and "Introduction." In Ethnic Groups and Boundaries. The Social Organization of Culture Difference, Prospect Heights: Waveland Press, 5-38.

FitzGerald, David S., and David Cook-Martin. 2014. Culling the Masses. The Democratic Origins of Racist Immigration Policies in the Americas. Cambridge: Harvard University Press.

Geertz, Clifford. 2000. Available Light. Anthropological Reflections on Philosophical Topics. Princeton: Princeton University Press.

Gould, Stephen Jay. 1994. "In the mind of the beholder." Natural History 103/2: 14-23. 1994a. "Lucy on the earth in stasis." Natural History 103/9: 12-20. 1989. Wonderful Life. The Burgess Shale and the Nature of History. New York: W. W. Norton.

Hacking, Ian. 2012. "Introductory Essay." In The Structure of Scientific Revolutions, Thomas S. Kuhn, ed., [4 $4^{\text {th }}$ ed.]. Chicago/London: University of Chicago Press, vii-xxxvii.

Hornbostel, E. M. von. 1975 [1905]. "Die Probleme der vergleichenden Musikwissenschaft/ The problems of comparative musicology.” Translation by Richard Campbell. In Hornbostel Opera Omnia, vol. 1., Klaus P. Wachsmann, Dieter Christensen, and Hans-Peter Reinecke, eds. The Hague: Martinus Nijhoff, 247-270.

Kammer, Jerry. 2015. "The Hart-Celler Immigration Act of 1965." Report from the Center for Immigration Studies (September 15). No pagination (https://cis.org/Report/HartCellerImmigration-Act-1965) (09.04.2019).

Kuhn, Thomas S. 2012. 1996. 1970. 1962. The Structure of Scientific Revolutions. Chicago: Chicago University Press $\left[1^{\text {st }}, 2^{\text {nd }}, 3^{\text {rd }}, 4^{\text {th }}\right.$ editions]. 1977. Essential Tension. Chicago: University of Chicago Press. 
. 1993. "Foreword." In Reconstructing Scientific Revolutions: Thomas S. Kubn's Philosophy of Science, Hoyningen-Huene, Paul, ed. Translation by Alexander Levine. Chicago: University of Chicago Press.

Lucas-Smith, Vanessa.2016. "The Calais Sessions. A Musical Project with and for Refugees.” In Sounds in Europe. Bonn: European Music Council, 32-33.

McCrum, Robert. 2016. "The 100 best nonfiction books: no. 21 - The Structure of Scientific Revolutions by Thomas S. Kuhn (1962).” In The Guardian June 20 (US edition). https://www. theguardian.com/books/2016/jun/20/100-best-nonfiction-books-all-time-thomas-s-kuhnstructure-of-scientific-revolutions-paradigm-shift?CMP=share_btn_link (07.04.2019).

Merriam, Alan P. 1977. "Definitions of comparative musicology and ethnomusicology: an historical-theoretical perspective." Ethnomusicology 21: 189-204.

. 1969. "Ethnomusicology revisited." Ethnomusicology 13/2:213-229.

Milliband, David. 2016. "The Best Ways to Deal with the Refugee Crisis." The New York Review of Books, October 13: 23-25.

Mintz, Sidney. 1970. "Foreword" and "Afro-American Musical Adaptation." Afro-American Anthropology, Norman Whitten and John F. Szwed, eds. New York: The Free Press, 1-16; 219-228.

Mugglestone, Erica. 1981 “Guido Adler’s ‘The Scope, Method, and Aim of Musicology' (1885). An English Translation with an Historico-Analytical Commentary." Yearbook for Traditional Music, 13: 1-21.

Naughton, John. 2012."Thomas Kuhn: the man who changed the way the world looked at science." The Guardian (first published on 19.08.2012), https://www.theguardian.com/science/2012/aug/19/thomas-kuhn-structure-scientific-revolutions (08.04.2019).

Needham, Robin. 1994. "Refugee Participation.” In Refugee Participation Network, 17 (August) 17, Oxford, UK: Oxford Refugee Studies Programme, 17-19.

Nettl, Bruno. 2006. "We're on the Map: Reflections on SEM in 1955 and 2005." Ethnomusicology 50: 179-189.

Reyes, Adelaida. 2006. "Musicological Method: Order and Chaos." Turning Points in the Transformation of the Global Scene, Antoni Kuklinski and Boguslaw Skuza, eds. Warsaw, Poland: The Polish Association for the Club of Rome, 185-195.

1999. Songs of the Caged, Songs of the Free. Music and the Vietnamese Refugee Experience. Philadelphia: Temple University Press.

Sankey, Howard. 2016. "Fifty Years of Structure" a review of Kubn's Structure of Scientific Revolutions: 50 Years On (2015), William J. Devlin and Alisa Bokulich, eds. Metascience 25/1: 65-70.

Sankey, Howard. 1995. Review of Hoyningen-Huene, Paul. Reconstructing Scientific

Revolutions:Thomas S. Kubn's Philosophy of Science (1993), Translation by Alexander T. Levine. (Chicago: The University of Chicago Press), The Australasian Fournal of Philosophy 73/3: 487-489. 
Shapiro, Michael. 1991. The Sense of Change. Language as History. Bloomington: Indiana University Press. 1983. The Sense of Grammar. Bloomington: Indiana University Press.

Smyser, William Richard. 1987. Refugees. Extended Exile. New York: Praeger (with The Center for Strategic and International Studies, Washington, D.C.).

Teilhard de Chardin, Pierre. 2008 [1955]. The phenomenon of Man. New York: Harper Perennial Modern Thought.

Wade, Bonnie. 2006. "Fifty Years of SEM in the United States: A Retrospective." Ethnomusicology 50: 190-198.

Weinberg, Steven. 1998. "The Revolution that Didn't Happen." The New York Review of Books. November 8: 48-52.

Wray, K. Brad. 2015. "Kuhn's Social Epistemology and the Sociology of Science.” In Kubn's Structure of Scientific Revolutions: 50 Years On, William J. Devlin and Alisa Bokulich, eds. Cham: Springer International Publishing, 167-183.

Internet Sources:

https://en.wikipedia.org/wiki/The_Structure_of_Scientific_Revolutions (07.04.2019).

https://www.unhcr.org (06.04.2019).

https://www.unhcr.org/3b66c2aa10 (06.04.2019).

Abstract

Reflecting the turbulent spirit of the 1960s, Thomas S. Kuhn's The Structure of Scientific Revolutions, first published in 1962, questioned the status quo in the way science was conceptualized and taught, proposed radical change and provoked debates within the academic community. Three editions of the book and the growing literature on Kuhn in science, history and philosophy almost a quarter century after his death, attest to the continued significance of his work.

Also in the ' 60 s, shortly after it officially changed its name from vergleichende Musikwissenschaft/comparative musicology and had radically broadened its subject of study, ethnomusicology was engaged in intense efforts at self-definition and in examining the theoretical and methodological ramifications of its historical development.

The broad sense in which Kuhn used the term "science," made it a receptive environment for ethnomusicology. The scope of ethnomusicology's new concerns makes a search for new perspectives imperative.

These two factors along with developments in global population movements, the 
growing complexity of social organization as societies become more mobile and diverse, and the acceleration of these developments owing to technological development suggest the probability that Kuhn could be an ethnomusicological resource.

This article explores that probability by applying Kuhnian perspectives to historical events in ethnomusicology as well as to migration phenomena which ethnomusicology has yet to fully confront. 
Open-Access-Publikation im Sinne der CC-Lizenz BY-NC-ND 4.0 


\section{The Position of University-Based Ethnomusicology from an Interdisciplinary Perspective}

I can still recall how I first came across a comprehensive description of Musicology as a discipline during my penultimate school year in the late $1980 \mathrm{~s}^{1}$ — it was a brochure about Musicology (Mahling 1987) that had been commissioned by the German Bundesagentur für Arbeit ["Federal Agency for Employment"] as part of an anthology of university disciplines and related job opportunities. The job prospects were described as so extremely difficult that anyone reasonable would have followed the suggestion the Agency's advisor-who admitted that he had no idea what "Musicology" actually meant - to not study that discipline, but to go into natural sciences. The indication that future job perspectives strongly depended on self-organization likewise appeared discouraging within an educational system that was increasingly oriented towards immediate applicability. ${ }^{2}$ And yet, I nevertheless had to study this "exotic" discipline, because I was not only already interested in the actual subject, ${ }^{3}$ but rather because the text depicted Musicology as an intersection of a fascinating range of different disciplines. This included Philology, History, Literature, and Theatre Sciences, as well as Physics, Sociology, Psychology, and Anthropology (Mahling 1987: 2). Looking back on it in 2019 , we can read this description as another indicator of how strongly music matters with regard to nearly all areas.

However, the reality of my first years as a student was rather sobering: having consequently decided for Historical Musicology as a major, ${ }^{4}$ I—still with the initial description in mind-was quite disappointed, as the curriculum was basically shaped by Philology and a mono-cultural musical perspective in my major. The fact that I did switch to Ethnomusicology later on was not because of a lack of interest in music history or the (actually fascinating) sub-disciplines, but because I found this (predominant) vision

1 At the time of my graduation, the German Gymnasium ["High School"] was completed after 13 years with the Abitur [equivalent to high school diploma in the US].

2 Needless to add that many who decided for positively described job options (teacher, lawyer) at that time later actually struggled more-not only due to large student numbers, but also due to the lack of perspectives regarding self-organized careers.

3 Interested in early music as a recorder player, I had already received an insight into work with manuscripts at that point.

4 With Systematic Musicology and Philosophy as minors (complemented by Ethnomusicology during my study year in the United States and Anthropology during my Ph.D). 
of the discipline too strongly limiting for me at that time. I do not want to go into the debate on the sometimes still difficult hierarchical relationship between the different musicological disciplines, because the situation has been increasingly changing with the new academic generation in the new millennium. However, this initial disappointment led to a constant questioning of the social relevance of Musicology during my student years. The answers I received at that time seemed only vaguely helpful at first sight, because Hamburg-like many other German universities-still reflected the so-called Humboldtsche Bildungsideal ["Humboldtian educational ideal"]. This ideal emphasized university as a place of academic freedom, independent of any political or state-related restrictions, and, education-wise, as a place of individual education and self-realization (Tenorth 2013). I nevertheless wondered then whether the related consequence, that university-based education was not a job-related education shaped by economic considerations, was really a shirking of any broader responsibility. The latter likewise with regard to the apparent lack of interest regarding students' job options outside academia. These early doubts were not only shared by many fellow students, but also further fuelled by my broader, extremely practically oriented social environment that viewed Musicology as something rather obscure. Looking back on this period of study in the early 1990s, I wonder whether this unease was nevertheless already an indication of an educational-political transformation that should have been responded to proactively at that time. Instead, the discipline has been drifting into a strong invisibility within educational and also academic discourses.

At the time of writing (2018/19), Musicology ${ }^{5}$ with all its sub-disciplines is in a complex situation. It might still maintain a useful position within music conservatoires or (to remain within a German-speaking context) the so-called Musikbochschulen ["Universities of Music"], but often has to defend its position within the universities, which have been increasingly shaped by economic and political pressures. Nevertheless, it might not be without reason that, while having seriously stagnated until the first decade of the new millennium in the German context (Sweers 2000; 2008), Ethnomusicology has been receiving growing interest. This is not only reflected in a rising demand for intercultural music education in the face of the refugee crises in Europe, but also in an increasing number of requests for interdisciplinary collaboration, as I have been experiencing at the University of Bern (Switzerland) since 2009.

In the following, I thus would like to specifically focus on not only a) Ethnomusicology and its unusual position within an interdisciplinary context, but also discuss b) its relevance within a context of a transforming situation at many universities. The latter especially set against a background of the humanities being under constant po-

5 With the use of the term "Musicology" I mean the discipline as a whole (including all different subdisciplines) and not "Historical Musicology." 
litical attacks, particularly since the 1990s, and even more significantly in the era of Neoliberalism (Giroux 2014).

\section{Ethnomusicology within a Broader Educational Context}

In the German-speaking areas, this critical situation has been further fuelled by the so-called Bologna Process. ${ }^{6}$ Having been realized since the 1990 s in order to homogenize different degrees to form a comparable system, the Bologna Process has been meant to facilitate international movement for students, especially within the EU. Elements of this standardization process have been, for instance, the establishment of a so-called European Transfer System (ECTS) to facilitate a comparison of the courses, the transfer of the diploma/ Magister system ${ }^{7}$ of the German-speaking countries to a BA/MA system, and a Europe-wide accreditation system for universities.

Yet, as critics have pointed out, the initially well-intended process has resulted in an extremely bureaucratic, cost-intensive and regulatory system. In the case of the German-speaking countries, it has, for instance, restricted the previous flexibility of the structurally relatively free Magister system that had been viewed as important for the humanities and cultural studies (Winter 2015). ${ }^{8}$ The still ongoing cost-intensive accreditation processes were paralleled by a constant questioning of established structures and disciplines, particularly of the humanities and cultural studies that were increasingly viewed as questionable within the transforming political-economic situation.

As is evident from heated debates in international newspapers and journals of higher education, two broader segments in particular have been under regular attack on an international scale - the classical humanities (particularly Literature Studies), as well as Sociology, Anthropology, and Psychology. ${ }^{9}$ As, for instance, a Guardian article (Preston 2015) remarked with regard to the situation in Great Britain: "A war is being waged within the cloistered world of academia" - that has increasingly been shaped by

6 Ratified as the Magna Charta Universitatum (cf. Observatory Magna Charta Universitatum 1988) in 1988, it was further formalized in the Lisbon Convention of 1997 (cf. Council of Europe 1997), followed by the Bologna Declaration in 1999, aimed at a comprehensive realization by 2010 (cf. European Associations in Higher Education 1999 and 2010).

7 These were the first academic degrees, obtained after 4-5 years of study plus a thesis.

8 It is likewise evident in that many students have reduced their study year abroad to a much shorter timespan, especially outside Europe-due to the highly controlled program structures, but it also made free experimental seminars outside clearly formulated teaching units extremely difficult.

9 Islamic Studies, which until 9/11 was viewed as a Literature discipline, has been under heavy attack, particularly by conservative parties. 
economic considerations-also of professional qualifications. Very often, criticism has been initiated by conservative political parties-a process that is subsequently exemplified in the case of Switzerland.

In Switzerland, a central wave of criticism was initiated by the strongest party of that time, the nationalist-conservative SVP [Schweizerische Volkspartei; (Swiss People's Party)]. ${ }^{10}$ For instance, as was elaborated by Birrer (2015) in the newspaper tagesanzeiger, given that disciplines such as Anthropology, Psychology, Sociology, and History had been highly popular among students, ${ }^{11}$ the SVP had drafted a concept to limit the number of students in these disciplines. This was also connected with the suggestion of halving the overall number of students within the humanities. As was argued from a strongly economically oriented perspective, it was unfair against students to offer programs that did not directly lead to employment. As SVP member and historian Peter Keller further complained (in Aebischer 2015), "Too many students choose disciplines for self-fulfillment, while we have a dramatic shortage of engineers, computer scientists, and natural scientists." 12 As was also criticized (in Aebischer 2015), while there was a lack of employees in the private sector, most graduates from the humanities entered public sector employment (61\%). A comment even pointed out that, for the SVP, graduates of the humanities were the new foreigners: "There are too many of them. They do not find jobs and don't make any contribution. Humanities scholars are the new foreigners for the SVP." 13

It is likewise exemplary that a suggested parliament interpellation to limit student numbers within the humanities was especially criticized by left-wing and Green parties-a position held by related parties that can also be observed in other countries. As these parties argued, students of the humanities contribute flexible skills that are in demand on the job market, with most of them being in jobs two years after graduation (ibid.). Yet, given that support has mostly come from the political left, the humanities have experienced an increasingly negative image in wider society—very much in contrast

10 The SVP obtained $29.4 \%$ of the votes in the elections to the Nationalrat ["national council"] in 2015 (Schweizerische Eidgenossenschaft/ Statistik Schweiz/ Wahlen 2015: http://www.politik-stat.ch/ nrw2015CH_de.html).

11 The articles were centered on the number of 45,000 students who were enrolled in these subjects in 2013, yet without exact reference. The statistics of the SAGW [Swiss Academy of Humanities] listed 33,930 students at the end of 2012. Sabina Schmidlin (2014), Grundlagenbericht: Förderung der Geisteswissenschaften in der Schweiz im Zeitraum 2002-2012. Im Auftrag der Schweizerischen Akademie der Geistes- und Sozialwissenschaften (Swiss Academies Reports 9 (3), 2014). Zenodo. http:// doi.org/10.5281/zenodo.889479

12 " $\mathrm{Zu}$ viele Studenten belegen Selbstverwirklichungsfächer, während wir einen dramatischen Mangel an Ingenieuren, Informatikern oder Naturwissenschaftlern haben."

13 "Es gibt zu viele davon. Sie finden keine Jobs und leisten nichts. Für die SVP sind die Geisteswissenschaftler die neuen Ausländer" (in Lampart 2015). 
to the earlier standing of the humanities within the Humboldtian educational framework. A recurring discursive issue has also been the dominance of female students, which further devalues the related disciplines that had been tied to a classical bourgeois education and had thus been much later in admitting female students than medicine, for instance.

Given this impact and increasingly political entanglement, leading humanities organizations saw the need to respond in a visible manner. In 2016, the Swiss Academy of Humanities and Social Sciences [SAGW] created a comprehensive website on the role of the humanities. Entitled "It's the humanities, stupid!" (SAGW 2016), it emphasized that:

On a daily basis, all humans realize more or less intensively what the humanities investigate: social behavior, language, symbols, customs, institutions, pictures, buildings, music, literature, theatre, art, ways of life and practices, and also science itself as something created by humans. They thus have been practicing for a long time what the exact sciences have discovered as "translational research" for themselves just recently. ${ }^{14}$

Pointing to the relevance of the humanities for everyday life, the text emphasized the all-over human aspect:

The humanities deal with the thinking, acting, and production of humanity in their whole variety. This includes everyday culture, language, history, law, social, political, and religious life, the arts, but also the practice of all the sciences and their mindsets. (ibid.) $)^{15}$

At the same time, the pages point towards the socio-political relevance of the humanities:

The humanities investigate and mediate social values and rules and thus facilitate communal living of widely differing people. They support the understanding of other languages and cultures and thus facilitate a peaceful coexistence and nonviolent conflict resolution. (ibid.) $)^{16}$

14 "Täglich leben alle Menschen mehr oder weniger intensive, was die Geisteswissenschaften untersuchen: soziales Verhalten, Sprache, Symbole, Bräuche, Institutionen, Bilder, Bauten, Musik, Literatur, Theater, bildende Kunst, Lebensweisen und Praktiken, und auch die Wissenschaften selbst als etwas vom Menschen Geschaffenes. Dadurch tun sie seit Langem, was die exakten Wissenschaften als 'translationale Forschung' neuerdings für sich entdecken."

15 "Die Geisteswissenschaften beschäftigen sich mit dem Denken, Handeln und den Hervorbringungen der Menschen in ihrer ganzen Vielfalt. Dazu gehören die Alltagskultur, die Sprache, die Geschichte, das Recht, das soziale, politische und religiöse Leben, die Künste, aber auch die Praxis aller Wissenschaften sowie deren Denkweisen."

16 "Die Geisteswissenschaften untersuchen und vermitteln gesellschaftliche Werte und Regeln und 
— thereby creating orientational knowledge (“Orientierungswissen”, ibid.) in politics or as a storage place of knowledge. I have sketched this line of argument in such detail, because it clearly illustrates how closely it parallels, for instance, Merriam's (1960) concept of Ethnomusicology as the study of music in/as culture. Further highlighting the potential of the humanities (that care, mediate, validate, revise, actualize norms, symbols, values and add practically relevant general knowledge), the SAGW response thus summarized the humanities as a key contribution to human culture and civilization.

This clearly parallels the UNESCO line of argument regarding its peace policy and the corresponding concept of democracy, as well as its Intangible Cultural Heritage policy. As becomes apparent from a historical perspective evident in the UNESCO constitution (UNESCO 2018: 5), UNESCO drew clear lessons from the devastating consequences of war and destruction after 1945. More specifically, it concluded that mankind will only achieve a truly intercultural coexistence by the designing, training, and development of a humanitarian sprit. This was, as further outlined in the Preamble of the UNESCO constitution from 1945, strongly shaped by the experience that peace cannot solely rest on political and economic governmental agreements. Rather, it needs to be actively practiced and implemented as spiritual and cultural solidarity (ibid.). The humanities and cultural studies take on a major role here. With their intercultural and interdisciplinary orientation, these disciplines in particular are able to emphasize that which is common rather than that which separates. The Preamble continues, "That since wars begin in the minds of men, it is in the minds of men that the defences of peace must be constructed" (ibid.). This line of argument about a democratic coexistence that emphasizes variety and plurality combined with artistic creativity is also a central basis of the Intangible Cultural Heritage.

Meant as a justification for the large numbers of humanities students, the statement likewise emphasized the search for a meaningful activity as an essential characteristic of the related disciplines. However well-meant, relevant and correct, the SAGW paper thus actually added further fuel to the fire of the critics by using a completely different argument strategy, which also applies to the UNESCO policy. Aiming at a more relativist-integrative and human-personal perspective within an environment shaped by mechanistic/efficient and strategic thinking based on seemingly hard facts and figures, the SAGW text had little force in that specific situation: As one university vice-rector told me in 2014, however well-constructed, these arguments were weak in a political discourse that mostly asks for financial figures (e.g. regarding the financial

erleichtern damit das Zusammenleben von höchst unterschiedlichen Menschen. Sie fördern das Verstehen von anderen Sprachen und Kulturen und erleichtern so ein friedliches Zusammenleben und gewaltfreie Konfliktlösungen.” 
gain of the Canton Bern from students; the absolute costs of programs; the status and visibility of scientific research fields in an international context). This was also one reason why the University of Bern had already started to follow the demands for broader inter- and trans-disciplinary education and structures to which I will return below. This difficult, actually mismatched discursive situation that I consider to be exemplary for many related debates-also with regard to the musicological disciplines and/or department closures-calls for a further analysis of argumentative strategies for the disciplines under attack. Furthermore, it is an indicator that a solution will need broader social and public support. As it seems, a mere reference to humanitarian issues, as evident in the UNESCO policy, is not sufficient in an environment increasingly shaped by neoliberal considerations - unless the related disciplines and their research are also visibly and audibly put into practice and recognized as significant by the related communities and governing institutions.

Where is Ethnomusicology in this debate? As a cultural science, i.e. Kulturwissenschaft, ${ }^{17}$ it does not completely fit into the humanities target that is mostly represented by the literature and broader social sciences, but it is, due to its interdisciplinary framework, included here. ${ }^{18}$ Yet, given these connections, it might even offer the possibility of new solutions, particularly with regard to the above-mentioned demand for more interdisciplinarity that has become a key issue in research since the first decade of the new millennium. Viewed positively, Ethnomusicology might thus be of great relevance by being able to offer many new possibilities within this context. This calls for a closer look at the interdisciplinary context within university structures-also as an indicator of how strongly Ethnomusicology matters or could matter.

\section{Ethnomusicology within an Interdisciplinary Context at the University of Bern}

When the Faculty of the Humanities of the University of Bern had the opportunity to create new research centers during the first decade of the new millennium-including new professorships, such as mine-it acted. As interdisciplinary research had been an innovative keyword at that time, different centers (the Center for Cultural Studies and the Center for Global Studies-both merged into one Center for Global Studies in 2013-, and a Center for the Study of Language and Society) ${ }^{19}$ were deliberately imple-

17 In German there is a slightly different wording: Geistes- and Kulturwissenschaften), which is not always the same as humanities and cultural studies.

18 Systematic Musicology: as I could observe in Hamburg, being much closer to natural sciences, it appears to have a completely different legitimation.

$19[\ldots]$ that encompassed linguists from the different language degree programs. 
mented in 2008 in order to enhance interdisciplinary education and research within the faculty. The newly established professorships of Cultural Anthropology of Music, World Art History, and World Literature were initially connected to the old Center for Cultural Studies (2008-2013) that addressed broader key topics such as inter- and transculturality, mediatization/ intermediatization, the formation of values within the global cultural sector, as well as cultural memory and transmission processes. At the same time, these new professorships were physically and administratively localized within the classical institutions. They thus also contributed to a transformation of the established programs, such as Literature Studies or Historical Musicology, while likewise carrying out an exchange with disciplines such as Social Anthropology, Religious Studies, and Islamic Studies within the interdisciplinary center context.

The interdisciplinary formation and collaboration process was connected with the introduction of new interdisciplinary MA programs, such as World Arts \& Music and World Literature (at the Center for Cultural Studies), as well as specific Ph.D. programs such as global studies. While thus based at the Institute of Musicology (and gradually integrated into the BA and MA Musicology programs $)^{20}$, the new focus of Cultural Anthropology of Music 1 became a significant core of the study program World Arts \& Music that combines non-Western and popular musics, arts, performance, and literature with a specifically global perspective. Quoting from the program's website:

The Master's programme in World Arts and Music offers insight into Western and non-Western traditions of music, art, and literature, studying them from perspectives such as globalisation, intercultural and transcultural studies, and cultural anthropology. [...] Transcending the established, predominantly Western canon, World Arts and Music views any kind of cultural expression from across the globe within its individual context. The programme pays particular attention to popular, traditional, and non-Western art forms which are side-lined in the West, scrutinising artistic expressions and their medial dissemination within the overarching framework of cultural studies. As a matter of course, such analyses include sociological, political, economic, and historiographical considerations, questioning and aiming beyond the established boundaries between individual disciplines. ${ }^{21}$

Given its interdisciplinary perspective, the program has been designed around the core team of Cultural Anthropology of Music and the-likewise newly establishedprofessorship in World Art History (with a specialization on Islamic art) ${ }^{22}$ that added

20 Apparent in that the study plans were transformed into a broader musicological education.

21 http://www.philhist.unibe.ch/studies/study_programs/master_s_in_world_arts_and_music/index_eng. html

22 This specification is shaped by Swiss-wide university politics that coordinate the focus areas of the

60 
further challenges within this highly experimental situation; first of all with regard to the naming of the ethnomusicological position: as an indication of the new orientation towards global perspectives, but also of the requirement for a high degree of openness towards all social and cultural-geographic layers for the collaboration with Art History, the professorship and related thematic musicological focus was named "Cultural Anthropology of Music." 23 This situation is still unique in a Swiss context, also with regard to the presence of Ethnomusicology: the Bern position is the only full-time professorship in this field at the time of writing (2019). ${ }^{24}$ This likewise relates to the World Arts \& Music program, including the international level. While there are other programs of the same name, they are, with a few exceptions, centered on artistic education. $^{25}$

This interdisciplinary situation also required a re-thinking of the classical teaching curriculum. For example, it soon became apparent that the World Arts \& Music program, which had been established before the professorships had been filled, initially only consisted of a patchwork of uncoordinated courses. These were, due to the lack of sufficient interdisciplinary teaching staff, first designed for the classical BA/ MA programs and then "recycled," i.e. also opened up for interdisciplinary students. ${ }^{26}$ While the differences in background levels of majors and non-majors was reflected in a highly differentiated grading system, the lack of a common basis and an identification reference point for the interdisciplinary students became an increasing challenge during the first semesters. We thus realized that we needed introductory courses that

universities in a relatively small country. The University of Bern has thus set a focus on Islamic Studies, rather than, for instance, Asian Art.

23 The name was also intended as a parallel to the Social Anthropology department in Bern. Furthermore, as the position is actually based at the Institute of Musicology, the term "Ethnomusicology" had been viewed as too conflict-based from a historical musicological perspective (for further details see Ross and Sweers 2012).

24 While the Universities of Geneva (Unité de Musicologie) and Neuchâtel (Institut d'ethnologie) and the Geneva Haute école de musique offer a joint MA program, none of these locations has a full professorship in ethnomusicology, which would actually be needed.

25 Approaches similar to the Bern program can be found in the Global Arts Studies Program at the University of California Merced (https://gasp.ucmerced.edu), which also includes performative and artistic elements. However, these programs that combine the study of arts, music and theatre/ dance with a theoretical emphasis are, generally speaking, still comparably rare. Most programs of that name are practically oriented, often with an emphasis on art. For example, the Canadian program World Arts Organization (http://www.worldartsorg.com) combines arts (with a focus on so-called Western arts) with applied social, communal and therapeutic work. The same focus on arts, rather than musicology, art history, or theatre sciences, also applies to other World Arts programs, such as the cross-culturally oriented MA program at Dallas International University (https://www.diu.edu/cewa/ma-world-arts/) or the programs at the UCLA World Arts and Culture department (https://www.wacd.ucla.edu).

26 For further discussion of related challenges see Schier and Schwinger (2014). 
would combine the different disciplinary segments, set the basis for students to undertake interdisciplinary work, and would serve as common ground for an (inter-) disciplinary identity. We consequently established an introductory course in World Arts \& Music which addresses and explores potential research themes and methods within the core tropes of the different arts. A particular focus was set on themes such as the tension between regionalism and globalism, intercultural encounter processes, value building and canon formation within a globalized context, as well as cultural memory and transmission. This confronted us with the additional challenge of having to address a wide range of themes for which we were not always specialists. We thus decided to offer the course in an alternating rhythm from a musicological or an art perspective ${ }^{27}$ by establishing, here also in tune with the reflections of Neumann and Nüning (2012), a theoretical basis taken from Cultural Studies. With regard to the latter, we likewise set up a second core course on "Cultural and Media Theory." This, however, also required a large amount of preparation and adaption from our side, as we had to establish this background ourselves. Nevertheless, the additional work has clearly paid off, as both courses have become successful beyond the World Arts \& Music program. They are also attended by students of the classical humanities and cultural sciences, as well as by other disciplines, such as Latin American Studies, Geography, and Biology.

Besides clearly posing-often time-consuming-challenges, the interdisciplinary context nevertheless also brought out the specifics of Ethnomusicology more clearly. The latter, for instance, by being mirrored by the different situation in Art History. As the World Art History professorship, which is physically based in the Art History department, had been set up as an assistant professorship without tenure track, it has to be re-filled every five years. This not only poses problems with regard to personnel continuity, but particularly with regard to actually finding suitable candidates. In fact, it has turned out to be extremely difficult to recruit a suitable Fine Arts lecturer with a non-Western specialization-not to speak of someone outside Social Anthropology working outside the 'high art' canon. Having often been viewed as part of the anthropological domain, non-Western and popular non-musical art forms are still slow to arrive in the classical, often comparably conservative and 'high art' oriented disciplines-not only in Art History, but also in Theatre Sciences, for instance. Within an interdisciplinary context, the formation of specific fully developed globally oriented co-disciplines is amazingly often still viewed as extremely unusual within other disciplines. As it appears from this perspective, a small discipline like Ethnomusicology that can fall back on a broad range of institutions, large networks such as the International Council for Traditional Music or intra-disciplinary collaborations, e.g. between

27 The courses also alternate between German and English.

62 
Historical Musicology and Ethnomusicology, as well as being able to address popular and contemporary themes or migration, is rather exceptional.

We nevertheless soon felt that the early interdisciplinary collaboration among colleagues within the research center was also difficult. Despite common interests in contemporary developments, we found that we actually employed different academic languages cf. Frodeman (2010) and Neumann and Nüning (2012). This was even more evident in our context than between the classical predominantly mono-cultural (i.e. Western oriented) Historical Musicology, Art History, and Literature Studies that not only shared Western high art as a main focus, but also common methodological elements taken from History, Philology, and Literature. ${ }^{28}$

However, viewed positively, these so-called problems actually point to centralexciting-challenges of interdisciplinary work, including the negotiation of accepted ways of speaking and writing styles, as well as different methodological starting points. ${ }^{29}$ This was also apparent in our complete disagreement on the role of methodology and the position of theory: While, from an ethnomusicological perspective, I insisted on qualitative empirical work (e.g. fieldwork and related methodological self-reflection), this was only marginally accepted by my first World Art History colleague, and completely rejected by my World Literature colleague, who set an emphasis on hermeneutic interpretation (and, for instance, did not accept the voice of the author as part of the research). Interdisciplinary work is thus not only intertwined with a constant process of negotiating concepts or methods, but also requires an awareness of potential pitfalls.

While besides some common thematic interests, (critical) theory thus increasingly emerged as the Center's common academic communicative basis, it soon became apparent that neither Ethnomusicology nor Art History had a say in this context. Neither did other, even less theory-oriented disciplines, such as Religious Studies and the smaller Literature disciplines (Hispanic, French, and Italian Studies)—or even Historical Musicology. Within this context, it helped that the major body of ethnomusicological publications was in English and could thus be approached by international students who have constituted a central part of the interdisciplinary programs. At the same time, the increasing focus on English as a common academic language, partly likewise in teaching, clearly excluded not only theoretical approaches, but also other disciplines dominated by, for instance, German/ French/ Spanish discourses. We thus

28 The same applies to the Center for the Study of Language and Society that has never had any of these problems to the same extent.

29 Including the usage of terminological concepts within an international context. As "Künste" [arts] signifies all artistic disciplines in German, the study program was named "World Arts" — which, however, was read by students as "Kunst" [fine arts]. We thus changed the title of the program to "World Arts \& Music." 
noticed that the dominance of and orientation towards (English) literature theorythat had shaped the cultural studies discourses with authors like Gayatri Chakravorty Spivak (e.g. 1988) or Homi Bhabha (e.g. 2004) —particularly affected students if we did not counter-argue or intervene otherwise. This occurred partly to the extent that some Literature students occasionally simply refused to even experiment with ethnomusicological or empirical approaches—even though other predominant theorists like Michel Foucault (e.g. 1969) or Pierre Bourdieu (e.g. 1979) had also developed their approaches on the basis of empirical sociological research.

This attitude is nevertheless a reminder to the discipline of Ethnomusicology that a major body of currently popular theoretical models has mostly been taken from larger disciplines such as Literature, Sociology, and Anthropology. This also became apparent during an interdisciplinary research project on Theory and Practice of Authenticity in Global Cultural Production (2013-2017) ${ }^{30}$ — which, as an outcome of the center-related exchange, combined research teams from Literature Studies, Sociology, Ethnomusicology, and Art History from the Universities of Bern and Lausanne. The reception of theoretical approaches developed outside Anthropology, Sociology, and Literature Studies remained rare. One of the few exceptions, which we started to apply more comprehensively in our context, was reflection on a possible framework of the construction of the evaluation of authenticity by art historian Denis Dutton (2003), who had developed a broader conceptual framework of authenticity discourses on the basis of juxtaposing case studies from art and music.

This situation also applies to ethnomusicological research. Despite the stunning international publication output in recent years, few of these excellent studies and observations will ever enter interdisciplinary discourses, which could contribute to a different level of visibility. Looking at the discipline's general paradigm of studying all "musics in/ as culture" (Merriam 1960; 1964) and the initial comparative musicological search for a broader understanding of human music making, I wonder why the broader reception of ethnomusicological research has remained comparably marginal—despite its promising potential. Moreover, ontologies of musical works are predominantly written by philosophers of art who are mostly trained-if at all—in Western art music and accordingly argue from that perspective (see, for instance, Davies 2003). This situation is likewise reflected within the university context. For example, even representatives of the "smaller" disciplines at our faculty often prefer to look for a sociologist, anthropologist, or literature scientist for the interdisciplinary distinguished lecture series. This raises the question of how Ethnomusicology (and

30 The project was financed by the Swiss National Foundation (SNF) as part of the interdisciplinary Sinergia program (see also http://www.cgs.unibe.ch/content/forschung/drittmittelprojekte/authenticity/ index_ger.html). 
the other musicological sub-disciplines) could enter these debates-that are also significant public platforms-more strongly and audibly. It is happening, but there is still work to do.

The professorship of Cultural Anthropology of Music had also been attached to the Center for Cultural/ Global Studies, because it offered, by touching on contemporary themes, excellent suitability for interdisciplinary and faculty projects, and for teaching, which has been strongly supported by the University in Bern. Given the relatively open curriculum structures (notwithstanding the Bologna Process) that continue to include a large number of thematically free modules, interdisciplinary co-teaching has been highly popular in Bern. For example, Ethnomusicology has been requested as a partner for co-taught seminars with the departments, e.g. of Law, Latin American Studies/History, or English/ American Literature, to name just a few, by which it was even further tied into the broader university structure. ${ }^{31}$

However, within these teaching contexts I have noticed that one further challenge for Ethnomusicology in an interdisciplinary context has been our actual object of study-music. While many other disciplines seem to be more easily approachable at first sight, talking about music seems to scare many interdisciplinary students and colleagues alike. I had the impression that they were actually afraid of approaching music as a sound(ing) experience at all. This too results in dominant voices on music often actually avoiding talking directly about music. Apparently, there is not only a gap between ethnomusicological work and broader discourses, but one can also observe avoidance strategies when it comes to the musical substance. This is much less the case with regard to the fine arts and points to further challenges that need to be tackled for a stronger presence within interdisciplinary contexts. One possible approach utilized in Bern is a strong integration of soundscape issues that have proven helpful in bridging fears. Developing the lack of music-related language on the basis of sound perception and training requires little initial expertise (see below).

Good interconnection with the non-academic sector has been a further major factor for the broader visibility, and thus acceptance, of the discipline. Journalism is just one of the many examples here. However, a glimpse at the context of the English-speaking world music scenes shows that the relationship to journalism sometimes still appears (as evident from earlier magazines like Songlines and FRoots) as a battlefield of authority of interpretation. As caricatures likewise indicate, Ethnomusicology is still (at least oc-

31 "Law, Justice, Crime and Punishment in Folk and Popular Music" (with Martino Mona, Department of Law, autumn semester 2015), "Music and Politics in North and South America in the 1960s and 1970s" (with Christian Büschges, Latin American/ History Department, autumn semester 2017) or 'Da Blues:' The Blues in Music, Society, Literature and Film" (with Thomas Claviez, English/American Literature Department, spring semester 2018). 
casionally) shaped by stereotyped colonial images. This is particularly apparent in satirical cartoons, whose overdrawn stereotypes reveal the as yet existent outside image of our discipline. Illustrations, as evident in Songlines, utilize, for instance, male bearded figures in tropical outfits and with thick glasses, sitting and recording with impressive technical devices. ${ }^{32}$ Yet also the highly original FRoots-BIFF series, created by Guardian cartoonists Chris Garrett and Mick Kidd, gives us an insight into commonly understood stereotypes-be it the "ethnomusicologist" (BIFF 2007), the "professor" (BIFF 2005), the "Dean of Social Sciences" (BIFF 2006b), as well as "the folkie" (BIFF 2006a) or the "digital talent scout" (BIFF 2006c). In addition, women do not appear in leading positions, nor are they presented as discussants-they only occur as (sharp) commentators. Similarly, many photographic images follow these specific male stereotypes that are often tied to colonial-related gender stereotypes. While there has clearly been a transformation in recent years, we might also take this as an indicator for further reflection on the outside reception and awareness of our discipline.

I never experienced this distance to journalism so strongly in the German-speaking countries, where students, due to the almost complete lack of job opportunities inside academia, had to address the issue of job careers outside university from very early on. In the most positive cases, where careers and independent scholars outside academia are valued on an equal level, this has resulted in a highly productive university-based journalism network in which both sides profit from each other. ${ }^{33}$

\section{Ethnomusicology in Local Application}

While it thus seems that smaller disciplines are often overlooked or disadvantaged within the larger cultural and political theoretical discourses, Ethnomusicology can nevertheless become a strong focus of public interest that can attract (positive) attention within the broader political and institutional context. However, within the previously sketched political framework, communication of what ethnomusicologists do remains a major issue, and I regard the field of Applied Ethnomusicology as a major factor within this context. Not only that it contributes to a stronger visibility of the discipline in general, it is also here that Ethnomusicology clearly connects to the UNESCO line of argument and is likewise able to counter neoliberal discourses on a similar argumentative level.

32 See David Arditti`s cartoon for Meadley (2003), "Bête Noire: Ethnomusicologists."

33 In all of these debates, it is also apparent that Ethnomusicology is viewed as a kind of "queer" discipline-when it is based on a university context it often lacks the infrastructure for the practical side; and when based at a university of music, it is often marginalized because it is practical (art) music and not research that matters there. There are exceptions, of course, but I have also heard similar complaints from Historical Musicology colleagues. 
While roughly described as putting "ethnomusicological scholarship, knowledge, and understanding to practical use" (Titon 2015: 4), Applied Ethnomusicology is often more strongly limited to the concept of "a music-centered intervention in a particular community whose purpose is to benefit that community-for example, a social improvement, a musical benefit, a cultural good, an economic advantage" (ibid). As is apparent from the articles published in the Oxford Handbook of Applied Ethnomusicology (Pettan and Titon 2015), a key mode of engaging with local communities has been through world music performance ensemble activities in the English-speaking world (cf. Solis 2004).

However, the concept of "Applied Ethnomusicology" actually contains a much broader range of practical approaches with regard to what Pettan (2008) differentiated into action, adjustment, administrative, and advocative ethnomusicology. This becomes clearly evident from a global perspective that includes, to just name a few examples, agency within an archival context, strengthening the acceptance and tolerance as well as the self-determination of minority cultures, mediation in tourism and political contexts, specifically in conflict situations. Particularly with regard to the latter, musical knowledge of "other" cultures is not only conveyed through performance, but also through education (cf. Krüger 2009) as well as through lectures and public displays (see Pettan and Titon 2015 for a detailed overview).

Ethnomusicology mirrored in an interdisciplinary context at university sometimes reveals the astonishment of colleagues, and partly even envy of how many of us actually perform music (our Theatre Sciences colleagues rarely ever act in plays, for instance) —as well as amazement about the range of practical applications of the discipline in society. Notwithstanding any claims of the ideals of Humboldt-related education, and of science independent of any political or trends, I could always see a transition from initial confusion when I described my deeper interest in my favorite genres (folk rock-that was clearly considered to be a superfluous occupation) to fascination and respect when I talked about my applied work. This especially related to the intercultural Polyphony of Cultures project which I had undertaken as a local conflict resolution approach at the Hochschule für Musik und Theater Rostock ["University of Music and Theatre Rostock"] between 2005-2008. ${ }^{34}$

Moreover, once an applied project mattered to the (local) community, the visibility and social acceptance of the related discipline (in this case Ethnomusicology) increased almost automatically on all levels. As is apparent from the German-speaking countries, applied work has strongly focused on intercultural music education in a

$34 \mathrm{~A} \mathrm{CD/CD-ROM} \mathrm{project} \mathrm{aimed} \mathrm{at} \mathrm{raising} \mathrm{tolerance} \mathrm{through} \mathrm{music,} \mathrm{connected} \mathrm{with} \mathrm{a} \mathrm{didactic} \mathrm{teaching}$ aid supporting teachers who had to deal with right-wing extremist music in the classroom. (Fassnacht and Sweers 2006/8; see also Sweers 2015). 
schools and broader communal context in recent years, which is also evident in the implementation of related degree programs. ${ }^{35}$ This was particularly expanded during the second decade of the new millennium, when work with migrant communities clearly became a major issue. As music has been widely regarded as a major element in related projects, musicological perspectives are clearly in demand, as I experienced during the annual meeting of the Swiss Theological Society in 2017. This meeting had specifically requested an ethnomusicological insight into the role of music in interreligious encounters. ${ }^{36}$ Yet, as I noticed in that context too, there is often a clear helplessness within other disciplines with regard to whom to contact, which might point to a further area where improvement is needed for the discipline in general.

\section{Soundscape Research in Application}

As an example of what can happen if the discipline reacts to public demands and areas of interest, I would like to illustrate the potential of a deeper local and social impact of Ethnomusicology by sketching the interconnectedness of academic research and local communities in the case of soundscape research. While soundscape research has been strongly emerging within Ethnomusicology during the second decade of the new millennium, related academic research has also been paralleled by a growing public interest in that theme. While still a rather unusual focus in the applied canon, soundscape research in particular seems to provide a broad range of options for connecting academia with the community on an easily accessible level. For example, from 20142017 the University of Bern, together with the Universities of Ljubljana and Belgrade, conducted a soundscape project on City Sonic Ecology: The Urban Soundscape of Bern, Ljubljana, and Belgrade. ${ }^{37}$ In the case of Bern, this was accompanied by several seminars, including an applied seminar, undertaken together with Bern Tourism and Cristina Urchueguía (Historical Musicology). Here, student teams developed six different soundscape tours through the city that also included interaction with local communities, such as instrument makers, during the autumn semester 2015. These tours were

35 See, for instance, the University of Hildesheim, which has been offering an MA program in Kulturelle Diversität in musikalischer Bildung ["Cultural Diversity in Musical Education"]: https://www.unihildesheim.de/studium/studienangebot/weiterbildung-berufsbegleitend/kulturelle-diversitaet-in-dermusikalischen-bildung-master-of-arts-ma-zertifikatsstudium/.

36 Jahrestagung der Schweizerischen Theologischen Gesellschaft (SThG): Musik in interreligiösen Begegnungen. September 21-23, 2017. Landgut Castelen, Augst (Switzerland).

37 SNF SCOPES Project City Sonic Ecology: Urban Soundscapes of Bern, Ljubljana, and Belgrade (Britta Sweers, with Ivana Medic, SASA Belgrade, and Ana Hofman, Slovenian Academy of Sciences, Ljubljana as co-project leaders): http://citysonicecology.com. 
subsequently synthesized by Bern Tourism into actually realized soundscape tours (Sweers 2017), while Bern Tourism, in turn, provided students with constant feedback regarding the practical realization of their ideas.

Journalists had been strongly interested in issues of soundscape research anyway, and we were subsequently partly contacted by former students who now, as journalists (working at the Swiss Public Radio), still followed the themes offered at our institute. How strongly the network to journalism could make an impact again became apparent in the context of this soundscape project. For example, after the seminar had been featured in two local newspapers (e.g. Bürgi 2016, Matti 2016) and a radio documentary (Marti 2016) —both of which were contacts that basically emerged by word of mouth-I was requested to give a public lecture in the series Buch am Mittag ["Book During Lunchtime"] in March 2016. Organized by the University Library, it was attended by a large Bernese audience. The theme apparently mattered, because the strong emotional reactions of the audience to my descriptions were quite striking. Many listeners subsequently added many more examples of affective sound perception with regard to the locality, and also their views about main sound hot spots-partly in lengthy e-mails after the presentation.

This immersion in soundscape issues then started to interconnect with broader communal and governmental structures, indicating that ethnomusicological work was being increasingly noticed outside the academic context. For example, the Buch am Mittag lecture resulted in a request for collaboration by the Amt für Umweltkoordination und Energie AUE ["Department of Environmental Coordination and Energy"] during summer 2016. Employing engineers and chemists, this public institution focuses on a wide range of noise and sound protection regulations (including industrial noise restrictions and architectural regulations). While it was easy to measure noise and sound according to medically and physically determined standards, i.e. fixed decibel measurement values, the engineers had reached a problematic point, as the perception of sound and noise also seemed to be shaped by highly subjective human factors. As these could not be tackled physically, the department had requested help from the humanities, which among others resulted in a joint city fieldwork exploration.

However, the need for expert knowledge stratified to further sociocultural areas, as evident from two other invitations that had likewise been the result of the soundscape work. In October 2017, I was invited to teach a soundscape class at Bern's Kinderuniversität ["Children's University"]. Unlike other children's universities, this institution is highly inclusive. Rather than requiring entrance exams, it allows anyone to register his or her children. ${ }^{38} \mathrm{I}$ had been specifically requested to teach the children-aged between $8-12$ - how to listen in the age of mobile phones. The segment consisted

38 See also Kinderuniversität Bern: http://www.kinderuni.unibe.ch/ 
of two parts - a lecture on Friday evening and a practical class during the following morning. As I noticed during the lecture, which was attended by approximately 70 children, these children - still at an age before puberty-were extremely attentive, almost eagerly soaking up any information, yet also clearly keen to reflect on sensory experiences, such as hearing observations. I had been falling back on a version of Murray Schafer's ear cleaning exercises (Schafer 1969) which had been adapted by a Staten Island-based children's project. ${ }^{39}$ More specifically, it followed the pattern of sound recollections ("Which were the first three sounds you heard this morning?"), self-observations ("Which sounds do you (dis)like?"), and environmental observations ("How do leaves / approaching cars, etc. sound?"; "What can you hear in this room?"; "What can you hear at the front of the room, and what at the back?"). I was amazed by the children's input, yet also by their extreme curiosity and creativity, which became particularly apparent when we created sound maps of the area during the following morning. Given that these kinds of subjects are rarely ever taught at regular school (and few school teachers have a background in this field), it pointed to an elementary human need in education - another area where Ethnomusicology could be stepping in more clearly.

The latter examples indicate the interconnectedness of soundscape research with environmental issues and reveal an issue which is highly accessible to the public (soundscape research can easily also be undertaken by "amateurs" who are unable to read or to perform music). At the same time, the work with soundscape provided a connection to religious and political discourses. On an academic level, the need for broader exchange with the discipline became apparent at a panel discussion at Bern's so-called Haus der Religionen [a sort of ecumenical center]. Founded in 2002, the location has hosted eight religious communities within one building at Bern's Europaplatz since $2014 .{ }^{40} \mathrm{I}$ had been invited to a panel discussion on "What does Bern sound like?" during a theme day "Tag der Klänge" ["Day of Sounds"] on October 24, 2017. Sound has been a major element in denoting religious spheres-be it with regard to Christian church bells, the call of the muezzin, processions, etc.- -which has been taken so much for granted that a more differentiated reflection on them only started in connection with the soundscape debates. Again, Ethnomusicology was requested to provide a broader perspective, because, as it became apparent, the audible proximity of the respective different religions had made it necessary to re-negotiate terms with regard to the interior, due to difficulties regarding sound insulation that had been

39 N.A. "Clean Your Ears." Sounds Like Staten Island." (Retrieved Dec. 1, 2012 from http://www. soundslikestatenisland.com. Link is disfunct).

40 See website Haus der Religionen—Dialog der Kulturen: https://www.haus-der-religionen.ch 
too costly. ${ }^{41}$ The need for ethnomusicological reflection also related to sounds from outside. As I could observe within the audience, the conscious reflection of what bells represent was a revelation for many. This likewise applied to the discussion on how to negotiate a parallel existence in terms of sound between the different religions, also as a reflection of the modern situation of migration. The complex political situation had particularly become apparent in the Minarettstreit ["minaret debate"] in Switzerland. ${ }^{42}$ Speaking from the perspective of soundscape: by banning the construction of minaret towers, the authorities had basically been forcing Muslim communities into a sounding interior. As became apparent here, the Jewish community, due to century-long persecution, had moved to the interior of the building anyway, a situation which was even further aggravated due to ongoing threats in the current international political situation. Yet the discussion also revealed surprising adaptation strategies. For example, the Hindu community had reduced its loud processions to one outdoor event per year and had adapted to using the sound of Christian bells. As one Hindu priest indicated, they had started to pray at the sound of any bell, particularly Christian church bells, which have been integrated into their system as symbolic representatives of the universal OM sound. Within this public event, the ethnomusicologist might be described as a synthesizing figure who brings out all these different positions to broader public knowledge-and acceptance. As is evident here, ethnomusicological knowledge stratifies deeply into any society and its expertise is highly in demand-if the existence of the discipline is visible. Maybe I am too optimistic, but there are many ways to integrate academic ethnomusicological work even more deeply into society, as these examples indicate.

\section{Outlook}

Musics matter, and Ethnomusicology is a small discipline that matters. In fact, it matters so much that it is actually deeply interconnected-sometimes to the extent that I occasionally feel overwhelmed by the numerous requests for contribution or collaboration. This not only includes university-based interdisciplinary teaching and research or trans-disciplinary academic requests for cooperation. It also relates to recurring requests for applied activities within the broader regional community. With regard to this specific example of applied soundscape research, there are further indicators that

41 For example, it proved extremely difficult for the Buddhist community to meditate at the same time as Hindu rituals were going on one floor below.

42 See Eidgenössische Volksinitiative «Gegen den Bau von Minaretten». Schweizer Eidgenossenschaft Bundeskanzlei BK. https://www.bk.admin.ch/ch/d/pore/vi/vis353.html 
this work might have a deep impact in the community. Soundscape has become a recurring theme not only in the media, but also in the local community in general. It is still too early for any further long-term conclusions here, but is seems that this specific development is intertwined with, for instance, stronger environmental awareness and a concern with human well-being and local conflict resolution, including the perception of the situation of migrant communities in the city.

While this is truly an indicator of the importance of the discipline, it is difficult to manage due to the small number of ethnomusicologists within a department-and, as a minority, this is connected with recurring negotiations regarding ethnomusicological perspectives within existing dominant structures. Nevertheless, if it works-as I have been experiencing at the University of Bern since 2009-it is a highly satisfying experience, even if it "just" relates to drafting cultural-political responses together with Historical Musicology colleagues. However, moving towards a sustainable future for the discipline, it will be necessary to continue addressing the challenges indicated in this article of which we need to be aware in the current economic and political situation.

References

Aebischer, Christoph. 2015. "SVP knöpft sich die freie Studienwahl vor." Berner Zeitung (28.9.2015). https://www.bernerzeitung.ch/schweiz/standard/svp-knoepft-sich-die-freiestudienwahl-vor/story/14058933 (07.04.2019).

Bhabha, Homi. 2004. The Location of Culture. London: Routledge.

BIFF. 2005. “... with Professor Max Reinlegen.” FRoots 265 (August/ September), 90. . 2006a. "One Evening in May ..." FRoots 275 (May), 90. 2006b. "It‘s World Cup Mania Again," FRoots 276 (June), 82. .2006c. No title. FRoots 277 (July), 82. 2007. "Beyond the glass ceiling." FRoots 285 (March), 90.

Birrer, Raphael. 2015. "Die SVP sticht in ein Wespennest: Ein Numerus clausus für die Ethnologen und Soziologen" (12.3.2015). https://www.tagesanzeiger.ch/schweiz/standard/DieSVP-sticht-in-ein-Wespennest/story/15282770 (07.04.2019).

Bourdieu, Pierre. 1979. La distinction. Critique sociale du jugement. Paris: Les Éditions de Minuit.

Bürgi, Zarah. 2016. "Heimatgefühle. Die Klangwelten vor unserer Haustür.” BrunneZytig (June 17, 2016): 2-5.

Council of Europe. 1997. "Convention on the Recognition of Qualifications concerning Higher Education in the European Region.“ https://www.coe.int/en/web/conventions/fulllist/-/conventions/treaty/165 (07.04.2019). 
Davies, Stephen. 2003. "Music." In The Oxford Handbook of Aesthetics, Jerrold Levinson, ed. New York/Oxford: Oxford University Press, 489-515.

Dutton, Denis. 2003. "Authenticity in Art." In The Oxford Handbook of Aesthetics, Jerrold Levinson, ed. New York/Oxford: Oxford University Press, 258-274.

Eidgenössische Volksinitiative "Gegen den Bau von Minaretten." Schweizer Eidgenossenschaft Bundeskanzlei BK. https://www.bk.admin.ch/ch/d/pore/vi/vis353.html (07.04.2019).

European Associations in Higher Education. "The Bologna Declaration of 19 June 1999." https://www.eurashe.eu/library/modernising-phe/Bologna_1999_Bologna-Declaration.pdf (07.04.2019).

European Associations in Higher Education. 2010. "2010 Vienna Bologna Policy Forum Statement.” http://www.ehea.info/media.ehea.info/file/2010_Vienna/83/2/Vienna_BPF_Statement_597832.pdf (07.04.2019).

Fassnacht, Lena and Britta Sweers. 2006/8. Polyphonie der Kulturen CD/ CD-ROM. Rostock: Bunt statt braun/HMT Rostock. (LC 01795).

Foucault, Michel. 1969. L'Archéologie du savoir. Paris: Gallimard.

Frodeman, Robert. 2010. The Oxford Handbook of Interdisciplinarity. New York/Oxford: Oxford University Press.

Giroux, Henry A. 2014. Neoliberalism's War on Higher Education. Chicago: Haymarket Books.

Krüger, Simone. 2009. Experiencing Ethnomusicology. Teaching and Learning in European Universities. Farnham: Ashgate.

Lampart, Lukas. 2015. "Die neuen Ausländer.” Basler Zeitung (26.3.2016). https://bazonline.ch/ schweiz/standard/Die-neuen-Auslaender/story/29730282 (08.04.2019).

Mahling, Christoph. 1987. Musikwissenschaftler/ Musikwissenschaftlerin (Blätter zur Berufskunde 3, 3-XL01). Bielefeld: Agentur für Arbeit.

Marti, Leonie. 2016. "In Bern kann man die Geräusche noch auseinanderhalten." Radio SRF 1 (2.4.2016, 17:30). https://www.srf.ch/news/regional/bern-freiburg-wallis/in-bern-kannman-die-geraeusche-noch-auseinanderhalten (07.04.2019).

Matti, Sheila. 2016. "Bern klingt nach Landleben.” Der Bund (21.3.2016). http://www.bernerzeitung.ch/region/bern/Bern-klingt-nach-Landleben/story/23862875

(07.04.2019).

Meadley, Phil. 2003. "Bête Noire: Ethnomusicologists." Songlines 17 (May/April), 18.

Merriam, Alan P. 1960. "Ethnomusicology: Discussion and Definition of the Field." Ethnomusicology 4/3: 107-114. 1964. The Anthropology of Music. Evanston: Northwestern University Press.

Neumann, Birgit and Ansgar Nünning. 2012. Travelling Concepts for the Study of Culture. Berlin: De Gruyter.

Observatory Magna Charta Universitatum. “Magna Charta Universitatum.” 1988. http://www. magna-charta.org/magna-charta-universitatum/read-the-magna-charta/the-magna-charta (07.04.2019). 
Pettan, Svanibor. 2008. "Applied Ethnomusicology and Empowerment Strategies: Views from Across the Atlantic." Muzikološki Zbornik / Musicological Annual 44 (1): 85-99.

Pettan, Svanibor and Jeff Todd Titon, eds. 2015. The Oxford Handbook of Applied Ethnomusicology. New York/Oxford: Oxford University Press.

Preston, Alex. 2015. "The war against humanities at Britain's universities." The Guardian (29.3.2015). https://www.theguardian.com/education/2015/mar/29/war-against-humanitiesat-britains-universities (07.04.2019).

Ross, Sarah and Britta Sweers. 2012. "A Blank Field of Musical Traditions? (Re-)Constructing Ethnomusicology in Contemporary Switzerland.” In Musical Traditions: Discovery, Inquiry, Interpretation, and Application, Richter, Pál, ed. Budapest: HAS Research Centre for the Humanities, 116-134.

SAGW. 2016. It's the humanities, stupid!' https://abouthumanities.sagw.ch/ (07.04.2019).

Schafer, Raymond Murray. 1969. Ear Cleaning: Notes for an Experimental Music Score. New York: Berandol Music Limited. 1977. The Tuning of the World. New York: Knopf.

Schier, Carmen and Elke Schwinger, eds. 2014. Interdisziplinarität und Transdisziplinarität als Herausforderung: Innovative Konzepte für die Lebre and Hochschulen. Bielefeld: transcript Verlag.

Schmidlin, Sabrina. 2014. Grundlagenbericht: Förderung der Geisteswissenschaften in der Schweiz im Zeitraum 2002-2012. Im Auftrag der Schweizerischen Akademie der Geistes- und Sozialwissenschaften. Swiss Academies Reports 9, 3 (2014). Zenodo. http://doi.org/10.5281/zenodo.889479 (07.04.2019).

Schweizerische Eidgenossenschaft. "Statistik Schweiz/ Wahlen 2015.” http://www.politik-stat. ch/nrw2015CH_de.html (08.04.2019).

Solis, Ted. 2004. Performing Ethnomusicology: Teaching and Representation in World Music Ensembles. Oakland, CA: University of California Press.

Spivak, Gayatri Chakravotry. 1988. "Can the Subaltern Speak?" In Marxism and the Interpretation of Culture, Cary Nelson and Lawrence Grossberg, eds. Chicago: University of Illinois Press. 271-313.

Sweers, Britta. 2000. "Ethnomusicology in Germany." SEM Newsletter (May 2000). 1, 4-5. 2008. "Ethnomusicology at Germany's Musikbochschulen." European Meetings in Ethnomusicology 12, 125-145.

2015. "The Public Display of Migrants in National(ist) Conflict Situations in Europe:

An Analytical Reflection on University-Based Ethnomusicological Activism." In Oxford Handbook of Applied Ethnomusicology, S. Pettan, and J. Todd Titon, eds. New York/Oxford: Oxford University Press, 511-550.

2017. "Soundscape Research Put Into Practice: The Exploration of Soundwalks in the City of Bern.” Musicology (Fournal of the Institute of Musicology Sasa) 22 (1/2017): 15-37.

Tenorth, Hans-Elmar. 2013. Bildung: Zwischen Ideal und Wirklichkeit. Bundeszentrale für politische 
Bildung (9.9.2013): http://www.bpb.de/gesellschaft/kultur/zukunft-bildung/146201/bildungsideale (07.04.2019).

Titon, Jeff Todd. 2015. "An Introduction to Applied Ethnomusicology. Section 1. Applied Ethnomusicology: A Descriptive and Historical Account." In Oxford Handbook of Applied Ethnomusicology, S. Pettan, and J. Todd Titon, eds. New York/Oxford: Oxford University Press, 4-29.

UNESCO. 2018. "Constitution of the United Nations Educational, Scientific, and Cultural Organization." In UNESCO. Basic texts: 2018 edition; including texts and amendments adopted by the General Conference at its $39^{\text {th }}$ session (Paris, 30 October-14 November 2017), 5-18. https:// unesdoc.unesco.org/ark:/48223/pf0000261751.page=6 (07.04.2019).

University of Bern, Faculty of Humanities, "Master in World Arts and Music." http://www. philhist.unibe.ch/studies/study_programs/master_s_in_world_arts_and_music/index_eng. html (07.04.2019).

Winter, Martin. 2015. Bologna: Die ungeliebte Reform und ibre Folgen. Bundeszentrale für politische Bildung (31.3.2015). http://www.bpb.de/gesellschaft/kultur/zukunft-bildung/204075/ bologna-folgen? $\mathrm{p}=$ all $(07.04 .2019)$.

Online Sources

City Sonic Ecology: http://citysonicecology.com (07.04.2019).

Dallas International University: "World Arts." https://www.diu.edu/cewa/ma-world-arts/ (07.04.2019).

Haus der Religionen. Dialog der Kulturen. https://www.haus-der-religionen.ch (07.04.2019).

Kinderuniversität Bern. http://www.kinderuni.unibe.ch/ (07.04.2019).

Sounds Like Staten Island. http://www.soundslikestatenisland.com (retrieved 01.12.2012, link is disfunctional).

University of Bern, Center for Global Studies (CGS), Theory and Practice of Authenticity in Global Cultural Production (2013-2017) http://www.cgs.unibe.ch/content/forschung/ drittmittelprojekte/authenticity/index_ger.html (07.04.2019).

University of California, Los Angeles: "World Arts and Culture" https://www.wacd.ucla.edu (07.04.2019).

University of California Merced, "Global Arts Studies Program” https://gasp.ucmerced.edu (07.04.2019).

Universität Hildesheim, "Kulturelle Diversität in musikalischer Bildung." https://www.unihildesheim.de/studium/studienangebot/weiterbildung-berufsbegleitend/kulturelle-diversitaet-in-der-musikalischen-bildung-master-of-arts-ma-zertifikatsstudium/ (07.04.2019).

World Arts Organization and European Graduate School, World Arts Organization: http:// www.worldartsorg.com (07.04.2019). 
The popularity of Cultural Studies promises a broad interdisciplinary exchange and maybe even the formation of new disciplines in which ethnomusicology could play a central role. However, major public discourses are still dominated by the larger disciplines, such as English/ American Literature, Sociology, or Anthropology. This not only applies to key themes such as globalization, postcolonial issues and gender, but also to arts and music. Drawing on experiences gained while directing the Center for Cultural Studies and the Center for Global Studies at the University of Bern, this presentation first analyzes the presence of smaller disciplines, such as ethnomusicology, within the interdisciplinary university context, yet also from a broader sociocultural and sociopolitical perceptive.

While it thus seems that smaller disciplines are often overlooked within the larger discourses, ethnomusicology can nevertheless become a strong focus of public interest. This is particularly evident with regard to applied work. For example, recent urban and environmental soundscape projects in Bern not only drew the attention of newspaper and radio journalism, but also led to requests by groups as diverse as the Environmental Department, the House of Religions, the Children's University, and Bern Tourism. How far are these two contrasting situations coincidences-and to what extent do they provide an insight into broader mechanisms behind the perception of university-based ethnomusicological work? To which degree can these situations be influenced by the ethnomusicologist—and is this necessary at all? 


\title{
Music, Research and Public Interest
}

\author{
A Dialogical Praxis for Social Justice
}

\section{Rehearsal as Sound Praxis (I)}

The sounds heard as an introduction to a public presentation related to this paper ${ }^{1}$ were recorded in 2013, during a rehearsal of a head arrangement, as early jazz players used to call an arrangement of a tune consisting of direct learning of interrelated sonic phrases and spoken clues, all of which were worked out in performance by one or more of the participating musicians rather than through a score. In the example mentioned, four musicians were heard, each of them contributing a distinct part to the overall performance:

1 - a flute player, creating a contrasting melodic material to the arrangement's main object, a topical song about the murdering of a young boy by the police in a Rio de Janeiro favela (slum or shantytown) during the 2006 national elections. At the time, she was pursuing a music education degree while holding an undergraduate diploma in flute performance and having extensive professional experience in popular music;

2 - an undergraduate student in mathematics, also an accomplished guitarist in a local heavy metal band, providing a kind of response to the melodic elaboration on the flute;

3 - an undergraduate major in social sciences who used to play acoustic guitar in an experimental band called Café Frio (Cold Coffee), and, in this example, playing the supporting harmony in between bossa-nova and samba styles (e.g., he orally mentioned he was using $9^{\text {th }}$ chords typical of bossa nova, played on a tamborim ${ }^{2}$ rhythmic pattern commonly used as a time line in samba);

1 Symposium "Music Matters! Ethnomusicology and its Socio-Political Relevance Today," 28-30 September, 2017, on behalf of installation of the new ICTM Secretariat at the University of Music and Performing Arts, Vienna. The author thankfully acknowledges the financial support by the local organizers, making his participation possible.

2 Hand-held, no-cymbal tambourine, played with a stick. 
4 - the songwriter-also author of this text-shortly demonstrating the opening vocal part with non-lexical sounds, and providing clues to the different sections of the song.

Ready to sing and/or play additional instruments, four other people did not have a chance to participate in the recording due to an unexpected and closing contribution eventually imposed on the arrangement, the sounds of machine guns and grenades of just another routine battle between two rival groups involved in some way ${ }^{3}$ with the retail drug business within one of the largest favelas of Rio, Maré, with approximately 150,000 inhabitants. In the face of the regular absence of the police as a law-enforcing agency as well as the lack of more significant and systematic state action in favelas, the already mentioned forces struggle to impose their armed authority on residents in many ways. These may range from controlling certain services such as illegal cable TV connections (locally known as gatonet) to threatening the lives of passers-by who happen to come from an area "belonging" to a rival group, which in some cases means walking a few yards away from "one's community." Accordingly, such armed groups also impose their authority on the sonic space either through gunfire, such as in the event in the recording, or through relatively safer initiatives such as patronizing music and dance events within favelas.

Examining in more detail the agents, context and space of the rehearsal is equally important to this discussion. All of the intended participants in the sample performance under analysis are members of Musicultura, a research group working according to participatory protocols in social sciences research. The group consists of local residents with ages ranging from 16 to 30 years, comprising students enrolled in high schools and universities, as well as a smaller, ad hoc number of volunteers. As consistently reported in the ethnomusicological literature in Brazil and abroad (Araujo et al. 2015, 2006; Araujo and Cambria 2013; Cambria 2012; Araujo 2013, 2012, 2008; Grupo Musicultura 2010), such experience was initiated in 2004 as a result of relatively long negotiations between the Ethnomusicology Laboratory of the Federal University of Rio de Janeiro (LE-UFRJ) and the directorship of a non-governmental organization (NGO) founded and run by local activists in Maré. This organization had been engaged for a number of years in work stressing educational and cultural issues based on bottom-up perspectives as a way to fight exploitation, discrimination and political disenfranchisement among the local population. In the initial contacts, the university was represented by myself, another colleague in a post-doctoral posi-

3 Two such groups are major retail drug-selling factions in Rio, but the shooting may also be attributed to any of two other sources, the State military police or private militiamen generally consisting of either former or off-duty policemen, all four possible groups involved in extortion schemes. 
tion and two master's students in the field of ethnomusicology. ${ }^{4}$ This working group listened carefully to and kept systematic records of the NGO's previous experience as voiced by its directors and some other activists participating in the initial talks. These interlocutors were visibly curious about this, to them, exotic idea of integrating what the NGO already did into an apparently unknown category, music research (an often asked question: What, in the world, is music research?!). The NGO's more sought after activity, on the other hand, mainly comprised structured courses offered to the local student population aimed at reinforcing contents of formal education through a more horizontal approach and also offering cultural opportunities perceived as otherwise non-available otherwise to local residents. Formal music and dance classes, ranging from classical to popular styles, plus video making, hip hop, storytelling workshops etc. were common activities developed by the institution. As also stated in previous publications, this was consistently justified by the NGO's representatives by invoking Bourdieu's classic titles such as Distinction (Bourdieu 1984) or Rules of Art (Bourdieu 1996), the first of which has been quite influential in Brazil since its first Portuguese translation was released in the late 1960s. In time, this is by no means surprising, given that a number of the NGO representatives had university degrees in the humanities.

For about four months, university representatives and the organization's directorship engaged in conversations, watching videos on the NGO's cultural and educational activism, and participating more directly in local events, including full-weekend seminars to reflect upon the institutional performance in general. This joint brainstorming collective finally had the idea of starting a collaborative initiative through the constitution of a group of local residents consisting of both university and high school students. Such an unorthodox research team would be progressively introduced through practical activities to the principles of dialogical pedagogy (associated with the work of Brazilian educator Paulo Freire and followers) and later to those of participatory action-research (associated with the work of Colombian sociologist Orlando Fals Borda and followers), which are in many aspects convergent (see Freire 2005; Fals Borda 2010, 1979) with the former. It is very interesting to look back at this foundational moment, since both parties of the joint initiative-the university team and the NGOs - had their respective interests and perspectives horizontally negotiated before they could be more or less agreed upon in a jointly conceived project design. From scratch to practice, the initial group of participants started its regular activities in April

4 Respectively, Dr. Luiz Fernando Nascimento de Lima (Ph.D. University of Helsinki, 2001), Vincenzo Cambria (Ph.D., Wesleyan University, 2012), today an Adjunct Professor of Ethnomusicology at the Federal University of Rio de Janeiro State (UNIRIO), and Virginia Barbosa (M.M., Federal University of Rio de Janeiro, UFRJ), currently a doctoral student in ethnomusicology at UFRJ. 
2004, comprising 28 people altogether: three non-residents (two graduate students and myself) plus 25 local residents, including one local music teacher in the public school system, ${ }^{5}$ four undergraduate university students ${ }^{6}$ and 20 high school students.

As described in later publications either authored collectively (e.g., Araujo et al. 2006; Grupo Musicultura 2010; Araujo and Cambria 2013) or individually (Cambria 2012, Araujo 2013) by participants of Musicultura, the initial research procedures left residents visibly surprised if not intrigued since the outsiders, i.e. non-residents, made a systematic effort towards not presenting them with any aprioristic and unnegotiable concepts, goals and/or premises, but only open questions such as: What is music for you? Why? Do you think your definition of music is shared by other people within or outside Maré? By whom and why do you think so? Such questions hardly sounded like standard questions previously asked by researchers in other fields such as anthropology or sociology. The latter, since their first interlocutions with residents, usually made a point of showing in advance that they knew something, if not a great deal, about the culture and way of life of the community they, the academic researchers, had single-handedly chosen to research.

However, this procedure might very well be still a clever strategy of the outsiders just to open up a more fluid conversation with and to earn the trust of the local residents, but which would soon be replaced by a more conventional, top-down mode of only apparent or limited participation, in which community members end up acting mostly or entirely as providers of access to information an outsider would find hard to obtain through other means. Looking retrospectively, this was not the case. On the contrary, since then the group has deepened its autonomy in assuming the authorship of the research, and deciding for its continuity over these more than 13 years, as well as in favor of its own self-determination in defining the goals, methods and multifaceted forms of public diffusion of results and sociopolitical intervention.

But what exactly then constitutes Musicultura, considering it has had about 150 changing participants over its 13 years or so of existence, each averaging an 18-month participation period? Is it a coherent collective with a recognizable identity despite

5 Eduardo Antonio Duque, music teacher in Rio de Janeiro State's public system and later Master of Music in Ethnomusicology (UFRJ, 2007).

6 Among which, respectively, Alexandre Dias da Silva, later a Master of Music in Ethnomusicology (UFRJ, 2011), and today a history teacher in the City of Rio de Janeiro's public system; Erica Cristian Reis dos Santos, later a Bachelor in both Dance (2009) and Physical Education (2011), and currently a physical education teacher in the City of Nova Iguaçu's public system as well as a student at the Master's Program in Education (PROPED, UERJ); Mariluci Correia do Nascimento, later a Bachelor in History (UFRJ, 2010); and Sinésio Jefferson Silva, history teacher in the City of Rio de Janeiro's public system and later Master of Music in Ethnomusicology (UFRJ, 2005) and Ph.D. in Urban Planning (UFRJ, 2016).

80 
the changes in its composition or, otherwise, multiple collectives with identities as different as the life histories and specific interests of its specific participants at a given time? Does it follow some rigidly institutionalized principles and guidelines to a point that its variable human constituency does not affect its overall identity, revealing then a conservative and top-down structure disguised under discourses on dialogism, autonomy and direct democracy, rather than running the risk of having to reinvent itself as new members keep coming in?

These being obviously questions which can be properly answered only through the participation of the subjects themselves, I will only suggest here that, no matter what the answer is, a number of principles, methods and issues have constantly been at stake in the collective debates over the pertinence or not of the group's continuity, as highlighted below:

1. Critically Acknowledging the Political Dimensions of Knowledge Production;

This is an important and extensive line of debate in the philosophy of knowledge, so I will just stress here briefly its main claim that no intellectual enquiry is possible in itself apart from human interests forged through specific life histories, material conditions, sociopolitical contexts, and linguistic constraints, including translation problems, to mention just a few of the conditions involved.

Accepting this basic premise, the admission of biases against and constraints to notions of neutrality in the production of knowledge requires the addressing of issues such as knowledge for whom, produced by whom, for what purposes, etc.

\section{Always Problematizing Public-Private Relationships}

Interests in society are developed and shared along a continuum from the more narrowly private to the more encompassing or public ones tending to form conflicting sociopolitical pressure forces, according to their mutual commonalities. Institutions such as universities or research centers are of key importance in establishing the kind and degree of legitimacy some forms of knowledge may claim or not. Not rarely, however, each of the opposing forces in the public-private continuum may accommodate a considerable space for internal conflicts, contributing to the complexity of conflict mediation at any level or scope, from local to global. ${ }^{7}$

3. Interrelating Difference, Inequality and Exploitation;

As an offspring of the previous discussion, we have the relations between current policies toward difference and the aggravating patterns of inequality and exploitation, taking different shapes in each regional context of the planet. In the case of Brazil,

7 Here it is worth highlighting the debate on how and to what extent nation states today are able or not to carry out mediatory action on behalf of the public interest in times where the accumulation of income and power are globally structured and concentrated to a degree that weakens and often bypasses existing forms of compensatory local legislation. 
this ranges from some indigenous peoples being forcibly removed from their ancestral lands in the rainforest previously guaranteed by law, and having to move into the shanty towns (favelas) in metropolitan areas, to the recent state coup orchestrated by several anti-public interests forming a successful lobby, despite its internal contradictions, against the reformist Workers' Party which, while in power from 2003 through mid-2016, elected income distribution as its main target, producing significant and globally acknowledged results.

4. Concretely Experiencing Knowledge Production From-The-Bottom-Up, Autonomy, and Praxis.

It is beyond the aims of this paper to adequately summarize the close relationships of the Workers' Party in Brazil and other successful electoral efforts by reformist political parties and fronts in Latin America from the late 1990s onwards with the praxis resulting from innovative alliances between academics and bottom-up social movements ranging from indigenous and black rights activist groups or rural workers' unions to industrial workers' unions and LGBTQ activist collectives. This innovation largely resulted from experiments which had been in the making since the 1960s struggles against imperialism, internal military dictatorships and oligarchical political regimes, such as the participatory action-research and dialogical pedagogy mentioned above. These currents had a precious musical attribute as a converging aspect, a deep, affective and sensitive listening to the oppressed sectors of distinct national societies, identifying through horizontal dialogue how this experience of the oppressed led to relatively autonomous concepts, codes, knowledge and practices (let us not forget musical ones) contrastingly distinctly with and often contradicting top-down ones. Their methodologies also shared common approaches such as: 1- the idea of action-research as a collective praxis based on participatory decision-making processes, encompassing the definition of issues to be prioritized in the research, developing into the choice of approaches to be applied in seeking for answers to research problems, and also into singular forms of application and diffusion of the work done; 2 - the constitution of unorthodox collectives and institutions comprising academics and non-academics; and 3-deep immersion of all researchers, including the academic ones, into the reality being more closely investigated, encompassing not only participant observation but, more importantly, reflexively outspoken cultural and political activism on locally important matters.

\section{Politico-Epistemological Dimensions in the Ethnography of Music-Making}

The preceding discussion and its suggested implications present a further, twofold challenge. First, to call into question ethnomusicology as an interdisciplinary field fo- 
cused on phenomena and ideas related to music and sound, whatever definition or genealogy we may attribute to such a field, leading towards too many and not necessarily similar intellectual dialogues pursued by either individual researchers or research groups in distinct socio-historical contexts. The second is a long-standing and pervading issue in the field, namely the pertinence of the object "music" itself. As posed by Alan Merriam (1964), among others, such a notion might not be as universal as many people in the field might think, but, on the contrary, the term "music," even in its broadest sense, was not quite fit to be applied to most sound-based social phenomena, oftentimes in inseparable association with other sensorial phenomena studied by ethnomusicologists the world over and in contexts which may be hardly comparable to one another.

In other words, "music," a term so many people still use today as universal, might be a context-specific and oftentimes precarious Europe-derived translation, imposing different degrees of conceptual violence on other practices and forms of knowledge, leading to a reduction of given cultures, perceived as subaltern, to the terms of other cultures viewed as "superior" or "dominant." Consequently, even the apparently generous semantic expansion of the term "music" to allow applications to a broad range of sound phenomena not only implies mistranslations, but eventually and more seriously aids the establishment of value hierarchies and even the intellectual and material erasure of significant differences between social groups of all sorts and their respective worldviews, in a process established by force, even if eventually travestied through language and masked by largely unquestioned dominant perspectives.

The negative legacy of this erasure of different worldviews has been, therefore, a theme in ethnomusicology since its infancy, even if not perceived or acknowledged as such by researchers. Today, however, problematizing the ethics of ethnomusicology in the face of the imposition and erasure of diverse worldviews has been made more than obvious in the field's increasing self-consciousness of itself as having been established and legitimized under varied kinds and degrees of both political and epistemological violence (Romero 2001, O'Connel and Castelo Branco 2010, Koskoff 2014, Rice 2014, Luhning and De Tugny 2016, LaMadrid 2017, Mapaya 2018). One blatant effect, by the way, of such processes of imposing and erasing is the silencing of the debate about this subject in academic forums, and particularly in the largest academic congresses, as well as through the silencing of attempts at articulating both training and research in ethnomusicology with extra-academic initiatives to conceive more negotiable and sustainable coexistence models on local to global scales.

The predatory effects of this triple silencing and erasure certainly resonate with events happening in many parts of the world. In the Brazilian case they are outwardly notable, as the opening case study above suggests, and I use them here as my point of departure to deal more narrowly with the training in ethnomusicology within and 
outside universities, integrating knowledge socially produced and accumulated by academics and extra-academic individuals and groups. Considering such a framework, this paper investigates what ethnomusicology's stance would be in the face of what some (and hopefully many) of us have pursued as the necessary construction of a socially just, democratic, and sustainable world, three adjectives which remain as empty words if they are not made thoroughly explicit and open to criticism in public debates. This is not meant, however, to present any sort of retrospective view of ethnomusicology's pathways in Brazil or elsewhere, but to offer a picture of contemporary problems in the field regarding politics and the various forms of struggle for the right to diversity today, issues which pervade what in the work of Grupo Musicultura has been termed sound praxis, i.e.:

[...] the articulation of interrelated discourses, actions, and policies concerning sound, as it appears, quite subtly or unnoticeably, in the daily experience of individuals, that is, for professional and amateur musicians, cultural agents, entrepreneurs and legislators, among others; for groups such as musicians' collectives and organized audiences; and for institutions such as school systems, corporations, labor unions, and both governmental and nongovernmental policy agencies. (Grupo Musicultura 2010: 219-220)

It seems appropriate to articulate such a notion here with a seminal essay by Celso Furtado, world renowned economist and former Culture Minister of Brazil, titled "Cultural creativity and dependent development," originally written in the 1970 s (later republished as a chapter in Furtado 2012). In this paper Furtado presents an impressive synthesis of the Brazilian socio-historical saga, couched in a continuous while necessarily imprecise emulation of European industrialization models. He locates the center of this lasting mismatch between local history and imported socioeconomic models in the submission of alternating Brazilian ruling classes' projects of society and culture to an emphasis on what Max Weber termed once "the logic of means"-in other words, rational, quantitative dimensions of human knowledge-to the detriment of what the German sociologist termed the "logic of ends"-i.e. sensitive, qualitative dimensions sensitive to public interest. This situation, as argued by Furtado, may have not only reinforced the more-than-evident domination of the socalled hard sciences and technology over the arts and humanities under the framework of capitalist relations. Its more pernicious effect, suggests Furtado, has been subsuming every societal project or alternative human identity to notions of productivity anchored in the superiority of the so-called "male-white-Christian rational being in command," leading invariably to domination, violence, and human, intellectual and environmental devastation. It does not require great effort to realize that the bulk of what Furtado classified as dominance, violence and devastation are moving vectors in 
the current neoliberal drive being imposed on both social and political life in Brazil and elsewhere. A quick look at daily national newspapers will reveal the aggression and murdering of "dysfunctional" sectors of society both in the cities and in rural areas, from individual to mass killings. The most perverse aspects of such processes are certainly the systematic attempts to delegitimize and annihilate some of these sectors' respective lifestyles and worldviews, particularly when they are seen to present any resistance to the generally racist, fundamentalist, hetero-normative ideals of "progress," or to offer forms of resistance to or threaten the approval of legislation which may be humanly and environmentally harmful, to measures in favor of speculation and to measures conducive to the concentration of land ownership by big businesses of many sorts, in all cases guaranteeing the privilege of the few at the expense of the criminalization and even decimation of many.

In the historical experience accumulated by humanity in different times and places, continues Celso Furtado, this somber scenario only offers one way out: the exercise, as intensely as possible, of politics, understood here as both micro and macropolitics, and consequently the debate of ideas, a fundamental source of human creativity, and of socio-economic development. On the one hand, politics, debate, reflection, and action; on the other hand, domination, violence, and both human and environmental devastation. Here we seem to have a good—albeit quite challenging — demand for new forms of training ethnomusicologists in the study of sound praxis in the sense stated above, as well as a good script for not only new kinds of conferences and symposia but also for establishing other forms of dialogues both within the field of ethnomusicology as well as with other academic and extra-academic knowledge-producing individuals and groups.

In a previous paper (Araujo 2014), I highlighted with a more optimistic undertone not only ethnomusicology's long history of more horizontal dialogues between researchers and their interlocutors, but also joint political activism in favor of the interlocutors' aspirations, all of this generating groundbreaking scholarship (see, for instance, the case of Alice Fletcher in the $19^{\text {th }}$ century US) way beyond the due and commendable respect for other knowledge and worldviews. ${ }^{8}$ In the same paper, I also commented on the growing number of intercommunication channels available today among relatively specialized areas of academic knowledge and public administration institutions and agents in areas such as education at large (elementary, high school, special needs etc.), public health, human rights, communications and even relatively surprising ones such as production engineering or urban planning, a few of which

8 See, for instance, Fletcher and LaFlesche (1911), Fletcher (1994 [1893]), Ellis (1994), Shelemay (1988), Londoño Fernandez (2000), Lassiter (1998), Impey (2002), Hemetek (2006), Rodgers (2012), Wood (2018a, 2018b). 
have gone through some degree of relativistic turns in their approach to their respective subject matters, particularly taking into account not entirely measurable variables such as human satisfaction, health standards etc., seeking dialogues with—why not? music scholars.

However, this path leads us simultaneously to critically reconsider how far and how alienated training programs in ethnomusicology have been from these new emerging realities, and also from the new types and standards required of productive dialogues with other academic fields of knowledge, with public sector institutions and agents, and particularly with extra-academic knowledge-producing individuals and social groups. The much acclaimed emphasis on interdisciplinary studies, for instance, still privileges objects (such as "music"), very narrowly defined in terms of themes, modes of production and validation of knowledge which is still conditioned and controlled by the academic milieu, reflecting age-old Eurocentric and colonial values still seen as hegemonic despite decades of critique of this kind of centralization of power emanating from within and outside the academic environment. The defense of conventional and pro-status quo views about the particularity and necessity of a knowledge-producing social field relatively immune to social, economic and political pressures, understood by some as the privilege of the academic milieu, usually rests on ideals, and quite often not more than ideals, of distancing, neutrality and objectivity, today profoundly called into question by several post-currents (Marxism, structuralism, modernism, colonialism), as well as by feminism, lesbian-gay-bisexual-transgender studies and several other theoretical stances. ${ }^{9}$

On the other hand, and this is one central purpose of this paper, ethnomusicologists in many places-if not everywhere-are developing or seeking to develop new research frameworks, such as the one exemplified by Musicultura, involving different manners and degrees of horizontal collaboration, sometimes involving joint activities in formats other than conventional participant observation models, co-authorship with or full authorship by their extra-academic interlocutors. Regarding the formats, a parenthesis should be open here, recasting how many times ethnomusicologists have taken advantage of the non-verbal aspects of sound praxis to create new notions of fieldwork rarely if ever available to ethnographers working in other domains. ${ }^{10}$ Such processes allow the repositioning of immemorial issues in the field such as, for in-

9 It is interesting - though highly problematic - to see that the conservative viewpoints just mentioned emphasize the distancing from the socio-economic-political pressures of everyday life precisely at a point in time in which the academic field as a whole, and the world over, is increasingly being pressured to accept interference from private interests and private research funding ever more conditioned by market-dictated productivity parameters to which many if not all of us here are somehow subjected.

10 See, for instance, Hood (1960), Nettl (1987), Seeger (1988), Turino (1993), Slawek (1998), Sautchuk and Sautchuk (2014), Justice and Hadley (2015), Graber (2107). 
stance, the divide between particularity and universality, since these processes benefit enormously from a profoundly accumulated knowledge on local processes paralleled by their filtering through a common, open-ended and often enduring dialogic process in which differently originated knowledges are contrasted, negotiated and co-produced.

In this sense, the field of ethnomusicology, but also other fields of music scholarship, have an enormous task ahead of them in confronting the persisting dominance of Europeanized conservatory models and self-reproductive myths of origin which still affect music training in universities as well as perceptions of music in other fields of knowledge. Even so, in my view (but also as illustrated by other colleagues in Brazil; see Luhning and De Tugny 2016), the training of researchers, teachers and other professionals with reference to some sort of ethnomusicology in Brazilian academic programs has taken promising steps. These have involved deeper levels of self-criticism toward the issues raised above and toward the necessary social commitment to engaging in new forms of dialogues among different and not exclusively academic knowledge-producing individuals, social groups and institutions, more finely tuned with a world that demands solutions to coexistence beyond blind obedience to unilateral forms of rationalism and ideals of progress dictated by the socio-environmentally predatory self-reproduction of capital at the expense of everyone and everything.

In a national context such as Brazil's, it is crucial to come to terms with situations such as the systematic killings of indigenous peoples and the systematic disrespect of age-old indigenous rights, a situation of ethnocide which is mirrored in all the poorer sectors of society or among groups perceived as dysfunctional in or threats to the hegemonic models of wealth accumulation both in rural and urban areas (and let us not forget that these are the sites of most if not all of our research). Likewise, it is important to notice here the important role that can be played by academic societies such as the ICTM or the Brazilian Association for Ethnomusicology in mobilizing academic knowledge beyond actions of recognition and valuing of diversity toward more impactful institutional actions to ensure the right to coexistence of worldviews. In order to accomplish that, an academic society will certainly find too many obstacles in its way. But on the other hand, it may find here and there accumulated experiences, such as conceding space to these discussions in different formats and forums, establishing special interest groups to increasingly define as well as publicize issues relevant to societal discussions perceived as crucial, to launch or co-participate in campaigns with other societies and similar organizations. Obviously we will not be reinventing the wheel, but let us hope that the ideals of struggle, emancipation and change (the logics of ends) which have been recently animating real life in Brazil and other parts of the world will prevail over the subsuming of all living forms to the sole objective of increasing the prosperity of capital accumulation. 
After the first frustrated attempt by Grupo Musicultura members to rehearse the song mentioned at the beginning of this paper, the occurrence of an intense and relatively prolonged conflict between the two rival parties disputing the control of illegal activities in Maré stopped Musicultura from meeting for a whole week. As soon as the regular biweekly meetings resumed, rehearsing the song was established as a priority. When it finally happened, more or less ten days after the first attempt, the difficult memories of the gunshots and bombs were still fresh among participants. The head arrangement had, however, become somewhat clearer and the group progressed a bit further. A triangle, played by a local video maker and volunteer in the group, was added from the start, the solo electric guitar seemed a bit more comfortable, while another vocalist (a social work major) attempted to follow the singing of the non-lexical sounds. The first strophe of the text could be finally and precariously sung by the songwriter for the first time, eventually accompanying himself on a five-string guitar, as a way of making the different sections clearer and teaching the harmony to the bass player (a high school student who regularly played that instrument in a Pentecostal church he attended) as well as the right beat to the bass drummer (with a similar background but who played the trumpet in church services). Significantly, he does not play at all on the second beat, the stylistic heartbeat of samba performance, and keeps playing on the first one, which, in a more idiomatic sense, should remain silent.

The Latin roots of the term culture stem from the memory of collective work in agricultural fields, a sign of the imposition of human needs and rationality on resistant matters such as the soil, pests etc., colonized for such purpose. Cultivating the land and consequentially its resultant culture tends to be conservative in favour of the maintenance of the status quo in terms of early European notions of private property, but in most cases due to either ignorance or fear of alternatives. Therefore, the processes, results and memory of cultivation, which inherently amount to the configuration of a culture, simultaneously comprise the imposition of and resistance to a rational order, in other words, violence and conflict.

Musicultura's political activism, in a continued but tense dialogue with the academic field, is perhaps more clearly defined by this complex praxis, continuously negotiating and not always resolving conflict and disjuncture between sonic referents. These may range from speeches, sounds and music to gunshots and bombs, always involving the reciprocal relationships those sonic realities maintain with the reflexive effort that pervades the group's activities as well as with the different and not rarely contradictory macro-political and institutional goals and practices impacting the group's praxis. Such examples may be challenging to ethnomusicology's standard research 
principles and protocols of non-interventionism. On the other hand, if there is a positive legacy in ethnomusicology and its multifarious, far from linear development, such legacy will have to be sought in something embedded in the experience briefly analyzed here: its continuous self-questioning on deeper and deeper grounds, and mainly in its rethinking of and re-engagement in a real world demanding increasing socio-political awareness to contend newer, more sophisticated and ever more predatory forms of dominance, exploitation and decimation.

\section{References}

Araujo, Samuel. 2008. "From Neutrality to Praxis. The Shifting Politics of Ethnomusicology in the Contemporary World." Muzikološki zbornik 44/1: 13-30.

2012. "Etnomusicologia e debate público sobre a música no Brasil hoje: polifonia ou cacofonia?" Música \& Cultura 6. http://musicaecultura.abetmusica.org.br/index.php/revista/ article/view/161 (03.12.2017).

2013. "Entre muros, grades e veículos blindados; trabalho acústico e práxis sonora na sociedade pós-industrial.” El Oído Pensante 1/1. ppct.caicyt.gov.ar/index.php/oidopensante/ article/download/2199/1979 (03.12.2017).

2014 "Dimensiones político-epistemológicas del diálogo intercultural. Patrimonios de conocimiento y luchas sociales.” In El valor del património: mercado, politicas culturales y agenciamientos sociales, M. Chaves, M. and M. Montenegro, eds. Bogotá: ICAHN, 359-386.

Araujo, Samuel and members of Grupo Musicultura. 2006. "Conflict and Violence as Conceptual Tools in Present-day Ethnomusicology. Notes from a Dialogical Experience in Rio de Janeiro." Ethnomusicology 50/2: 287-313.

Araujo, Samuel and Vincenzo Cambria. 2013. "Sound Praxis, Poverty, and Social Participation: Perspectives from a Collaborative Study in Rio de Janeiro." Yearbook for Traditional Music 45: 28-42.

Bourdieu, Pierre. 1984. Distinction; a Social Critique of the Fudgement of Taste. Translation by Richard Nice. Cambridge: Harvard University Press. . 1996. Rules of Art. Genesis and Structure of the Literary Field. Translation by Susan Emanuel. Stanford: Stanford University Press.

Cambria, Vincenzo. 2012. Music and Violence in Rio de faneiro: A Participatory Study in Urban Ethnomusicology. Ph.D. Dissertation. Wesleyan University, Middletown.

Ellis, Catherine. 1994. "Powerful Songs: Their Placement in Aboriginal Thought." The World of Music 36/1: 3-20.

Fals Borda, Orlando. 1979. "The Problem of Investigating Reality in Order to Transform it: The Colombian Experience." Dialectical Anthropology 4/1: 33-56. 2010. Antología. Bogotá: Universidad Nacional de Colombia. 
Fletcher, Alice. 1994 [1893]. A Study of Omaha Music. Lincoln: The University of Nebraska Press.

Fletcher, Alice C. and Francis La Flesche. 1911. The Omaha Tribe. Washington D. C.: Government Printing Office.

Freire, Paulo. 2005. Pedagogy of the Oppressed. 30th ed. Translation by Myra Bergman Ramos. New York: Bloomsbury.

Furtado, Celso. 2012. Ensaios sobre cultura e o Ministério da Cultura. Rosa Freire D’Aguiar, ed. Rio de Janeiro: Contraponto.

Graber, Katie. 2017. "Francis La Flesche and Ethnography: Writing, Power, Critique.” Ethnomusicology 61/1: 115-139.

Grupo Musicultura. 2010. "Sound Praxis: Music, Politics, and Violence in Brazil." In Music and Conflict, J. Morgan O'Connell and S. El-Shawan Castelo Branco, eds. Urbana: University of Illinois Press, 217-231.

Hemetek, Ursula. 2006. "Applied Ethnomusicology in the Process of the Political Recognition of a Minority: A Case Study of the Austrian Roma." Yearbook for Traditional Music 38: 35-57.

Impey, Angela. 2002. "Culture, Conservation and Community Reconstruction: Explorations in Advocacy Ethnomusicology and Participatory Action Research in Northern Kwazulu Natal” Yearbook for Traditional Music 34: 9-24.

Justice, Deborah and Fredara M. Hadley. 2015. "Collaborative Fieldwork, 'Stance,' and Ethnography." Yearbook for Traditional Music 45: 64-81.

Kartomi, Margaret. 1997. "Catherine Ellis (1935-1996).” Musicology Australia 20/1: 3-5.

La Madrid, Alejandro. 2017. "Diversity, Tokenism, Non-Canonical Musics, and the Crisis of the Humanities in U.S. Academia.” Fournal of Music History Pedagogy 7/2: 124-130.

Lassiter, Luke Eric. 1998. The Power of Kiowa Song: A Collaborative Ethnography. Tucson: University of Arizona Press.

Londoño Fernández, María Eugenia. 2000. La música en la comunidad indígena ebera-chamí de Cristianía. Antioquia (Colombia): Editorial Universitaria de Antioquia.

Lühning, Angela and Rosangela Pereira De Tugny. 2016. "Ethnomusicology in Brazil: Introductory Reflections." The World of Music 5/1: 7-21.

Mapaya, Madimabe Geoff. 2018. "Dipsticking the Study of Indigenous African Music from the John Blacking Era into the $21^{\text {st }}$ Century." In Fobn Blacking and Contemporary African Musicology; Reflections, Reviews, Analyses and Prospects, M. Mapaya and N. Mugovhani, eds. Cape Town: Centre for Advanced Studies of African Society, 113-128.

Merriam, Alan. 1964. The Anthropology of Music. Evanston: Northwestern University Press.

Nettl, Bruno. 1987. The Radif of Persian Music; Studies of Structure and Cultural Context. Urbana: Elephant \& Cat.

O'Connel, John Morgan and Salwa El-Shawan Castelo Branco, eds. 2010. Music and Conflict. Urbana: University of Illinois Press. 
Rice, Timothy. 2014. "Ethnomusicology in Times of Trouble." Yearbook for Traditional Music 46, 191-209.

Rodgers, Victoria. 2012. "John Blacking: Social and Political Activist." Ethnomusicology 56/1: 63-85.

Romero, Raul. 2001. "Tragedies and Celebrations: Imagining Foreign and Local Scholarships.” Latin American Music Review 22/1: 48-62.

Sautchuk, Carlos Emanuel and João Miguel M. Sautchuk. 2014. "Enfrentando poetas, perseguindo peixes; sobre etnografias e engajamentos." MANA 20/3: 575-602.

Seeger, Anthony. 1988. Why Suyá Sing. A Musical Anthropology of an Amazonian People. Cambridge: Cambridge University Press.

Shelemay, Kay Kaufman. 1988. "Together in the Field: Team Research Among Syrian Jews in Brooklyn, New York.” Ethnomusicology 32/3: 369-384.

Slawek, Stephen. 1998. "Keeping It Going: Terms, Practices, and Processes of Improvisation in Hindustani Instrumental Music." In In the Course of Performance; Studies in the World of Musical Improvisation, B. Nettl and M. Russel, eds. Chicago: The University of Chicago Press, 335-368.

Turino, Thomas. 1993. Moving Away From Silence; Music of the Peruvian Altiplano and the Experience of Urban Migration. Chicago: The University of Chicago Press.

Wood, Anna L. C. 2018a. "'Like a Cry from the Heart': An Insider's View of the Genesis of Alan Lomax's Ideas and the Legacy of His Research: Part I." Ethnomusicology, 62/2: 230-264. 2018b. "'Like a Cry from the Heart': An Insider's View of the Genesis of Alan Lomax's Ideas and the Legacy of His Research: Part II." Ethnomusicology 62/3: 403-38.

Abstract

Debates on social justice have highlighted the difficult and sometimes irreconcilable tensions inherent in public-private relationships, whatever the respective definition for each of the terms may be. In an assumedly reductionist perspective, some of the major forces at play nowadays are, on one hand, issues of worldwide dimensions such as the growth of resource privatization, the commodification of social life, and a structural job crisis, all of which are generating more social inequality plus an unprecedented level of concentration of income and, consequentially, of power. On the other side of this equation, as argued by Fraser (2002) among others, rests the need or urge for effective responses by bottom-up collective action in defense of the public interest in both local and global arenas. Half way from both sides and mediating such disputes are state policies ideally aimed at maintaining a balance between private and public demands, in not a few cases hindered by the power of capital in dictating the destinies of politics worldwide. Music, soundscapes, and imaginaries around them are, 
as they have been in previous sociohistorical contexts, an integral part of this process, constituting a rich field of enquiry aimed at political action in defense of concepts of public interest and social justice against the more somber prospects of deepening socioeconomic inequality.

Since 2003, and having to cope with many of these issues on a local level, a small academic unit based on the School of Music at the Federal University of Rio de Janeiro has been carrying out action-research initiatives jointly conceived with residents of Rio's second largest favela area, Maré, home to a total population nearing 150,000 people, as well as the site of a high degree of both institutionalized and criminal violence. Since the beginning, the residents' participation in these activities has differed from conventional roles usually defined in the social sciences as informants or collaborators, terms that usually signal a limited, if existent at all, interest on the part of the subjects in the aims and results of the research, usually defined and controlled by outsiders to the contexts under investigation who are positioned in the academic field. In this long-term experience-based on principles derived from fields such as dialogical anthropology/ethnomusicology, critical pedagogy and participatory action-research-the residents, as majoritarian members of this heterodox research collective (self-named Musicultura), maintain autonomous control of the goals, methods, and forms of diffusion of the research results. All of these steps have taken shape in regularly held open discussions leading to a consensus through some sort of agreement or, under the most difficult circumstances, vote.

This article critically reflects upon the work of the Musicultura collective, addressing the potentials of and obstacles to participatory initiatives not only in redefining goals and strategies in the political struggles around the public-private continuum, but also in radically redesigning the contexts of knowledge production beyond the academic/extra-academic dichotomy. 


\section{Bridging the Racial Divide in Malaysia: Crossing Borders through Research and Process Theatre}

This essay is a reflective account about my journey as a scholar activist, one who conducts rigorous research with the intention of bringing about socio-political and cultural changes in society. Activist research is an offshoot of Participatory Action Research (PAR), an approach that emphasizes the participation of communities in the processes of research. PAR was created by non-government organizations, mainly in the Global North in the 1970s, to help solve development problems such as poverty, public health and education in the Global South. Nevertheless, these PAR projects have been criticized for moving in a top-down manner from the First World to the Third World, from the developed to the underdeveloped, and from the university to the local people (Reason and Bradbury 2008). Latin American scholar activists such as Fals Borda (2008) stress that PAR undertaken by many universities are top-down and often detached from the political issues that affect the local communities. The collaborations in these vertical approaches are often unequal, as the research subjects are treated as research assistants, and their local knowledge and concerns are not given priority.

Consequently, scholar activists such as the anthropologist Charles Hale (2004, 2006) and his colleagues have called for the direct involvement of ordinary people in every step of the collaborative research projects that academics undertake, including the formulation of objectives, collection of data, analyses and dissemination of data. This type of collaboration not only gives us a better picture of the grounds for the injustices and inequalities that occur in society, but empowers ordinary people to find ways to bring about transformation in their society. In this regard, the collaborative project conducted by Samuel Araujo and students from the Universidade Federal do Rio de Janeiro Ethnomusicology Lab, together with young people of the Grupo Musicultura, has been inspirational. The latter is an NGO created by the residents of Mare, a slum area in Rio de Janeiro where problems pertaining to violence, drugs and joblessness occur. The university researchers devised collaborative methods with the residents to document the music of Mare and its meanings. The process of research and the creation of a local music resource centre led to increased self-esteem among the youths involved, as well as new knowledge in music and other related performing arts in the area (Araujo and the Grupo Musicultura, 2006).

Even so, activist research can take many forms and approaches so as to cater to the needs of the specific communities that researchers work with. In the developing coun- 
tries of the Global South, where large sections of the population still live in poverty and authoritarian rule occurs, research on music and musicking often intersects with the struggle for basic rights such as indigenous identity, equality, peace, health, education, housing, land, and other issues. This has led many activist scholars in the Global South, including the author, to be engaged in social action research that is practice-related (Reason and Bradbury 2008). This paper focuses on a kind of practice-based collaborative approach that uses musical theatre in efforts to create a more inclusive society in the racially polarized nation of Malaysia.

In that respect, I have been influenced by the practice of 'theatre for development' or 'process theatre'. As the names suggest, theatre for development aims at the personal growth of the participants as well as the development of the community; process theatre implies the making of drama, dance and music by the participants themselves, where the process of making theatre is as important as the final product. This type of theatre evolved about 50 years ago as a dialogical method for educating communities in Latin America, Africa and Asia regarding the development issues affecting them (Eskamp 2006, Van Erven 1992). Collaborative research and the use of various media such as music, drama, visual arts, photography, or video, provide avenues to initiate discussion and promote the understanding of critical issues. In Southeast Asia, theatres for development groups have created their own participatory methods to address issues in relation to conflict resolution, peace building, gender sensitization, social inequality and heritage conservation; they also help children and adults cope with trauma caused by war or natural disasters such as the tsunami. Some of the exemplary theatre for development groups in Southeast Asia include the Philippines Educational Theatre Association (PETA) and the Philippines Theatre Network, Teatre Arena and Studio Puskat in Yogyakarta, Maya and Makhampom in Thailand (see Tan 2013). ${ }^{1}$

I have also been moved by the 'interventionist' approaches and strategies for community music-making in peacebuilding contexts that have emerged in the United Kingdom and Ireland (Higgins 2012). These interventionist approaches promote the advancement of musical skills as well as the personal growth of the participants. As a case in point, the cultural activist Bill Mullen (2018: 5) has shown that community music-making workshops in Ireland provide safe spaces for musicking and developing 'friendship', 'trust' and 'respect' among participants who are in conflict. In these workshops, music making is made available to all participants. Consequently, by gen-

1 See van Erven's (1992) seminal study on the Philippine, Korean, Indian, Indonesian, Thai and Japanese theatre for liberation networks in the 1970s and 1980s. Based on research in these countries, he wrote about the practitioners, methodologies and content of the theatre for liberation workshops and the scripts of plays performed by the prominent groups in these countries in that period. According to van Erven, the impact of these theatre programmes has been so powerful that theatre practitioners in some countries have been threatened with guns and even imprisonment. 
erating their own styles of music, the participants experience a sense of collective ownership of the music created.

The activist researchers that I referred to above stress that regardless of the approach used, there is a need to recognize that political convictions and social positioning affect our work. It is within this context that I share these visions and strategies in my attempts to build bridges among ethnically segregated young people in Penang, Malaysia, where I was born, live and work. I collaborate with and train young people in Penang to conduct their own research on the history of cultural interaction in Penang, to learn their traditional art forms and to present their findings using contemporary and local forms of theatre, music or movement. Specifically, recreating local musical theatre that investigates cultural multiplicity, cross-cultural identities, and the fluidity of cultural boundaries can offset state policies that emphasize cultural homogeneity and exclusivity.

The article begins with a personal honest reflection on how I have been socialized politically and culturally in Penang and how this has guided my academic research and writing. This is followed by an explanation of why crossing borders and collaborative approaches in process theatre can help to promote intercultural interaction. The final section explicates some practical and methodological lessons that can be drawn from this.

\section{Socialization in an Ethnically Divided Nation}

Situated along one of the major sea routes in Asia, Penang attracted Chinese, Arab, Indian, European and other traders from the region from the sixteenth century. The formation of a free port by the British in the late eighteenth century saw the arrival of a greater diversity of people including the Siamese, Burmese and Achehnese. In the late nineteenth century, Chinese and Indians landed in large numbers in Penang before they moved to other places to work in the tin mines, rubber estates, farms or to run businesses. By then, Penang had become a cosmopolitan city. ${ }^{2}$ In many of my research publications, I have shown that the people of Penang (and Malaysia) were and have been open to outside influences; folk theatre and social dance music such as the bangsawan and ronggeng and Peranakan Chinese music were inclusive of the diverse cultures of the Malay archipelago, China, India, the Middle East and Europe.

2 Malaysia's population of 28.3 million comprises 67.4 per cent Bumiputera (translated as 'sons of the soil' consisting of the Malays and other indigenous groups such as the Orang Asli, Kadazan, Bajau, Bidayuh, Melanau, Penan, etc.), 24.8 per cent Chinese, 7.4 per cent Indian, and 0.7 per cent Other (including Arabs, Eurasians, Thais, Burmese and Indonesians [Department of Statistics, 2010]). 
Performers in these syncretic theatre and musical forms were ethnically mixed; they adapted stories, dances and music from different parts of the world to attract multiethnic audiences (Tan 1993, 2000, 2016). ${ }^{3}$

As a local-born Hokkien Chinese living in multicultural Penang in the period after the British granted independence in 1957, I also crossed cultural and ethnic borders in the early days of my childhood. I interacted with children of other races in my neighbourhood and spoke the localized Penang Hokkien (the Hokkien dialect from Fujian Province mixed with Malay and English words) with my family and friends. I communicated in Malay with the Malay and Indian street vendors who passed by my house daily to sell ice cream and cakes. Some of these vendors also spoke Hokkien to me. My grandparents took me to watch Chinese Opera, Malay ronggeng and other parades during the various religious street festivals where we interacted with friends of different races. We delighted in the multiethnic cuisine available in the coffee shops and visited one another during Malay, Chinese and Indian festive occasions such as Hari Raya (celebration marking the end of the Muslim fasting month), the Chinese New Year (celebration of the first 15 days of the Chinese lunar calendar) and Deepavali (festival of light marking the beginning of the Hindu new year).

This moving in and out of cultures and languages was disrupted when I went to primary school in the 1960s. This was a period of transition when the different races experienced the complexities of independence, nationhood and the search for a national identity and culture. The nuns at the Convent Light Street, the earliest missionary school for girls set up in Penang in the nineteenth century, taught me to speak, think and write in English. I was also introduced to western classical music and was fortunate to have a cousin who gave me piano lessons at a discounted rate. Even though English education and European musical training distanced me from the local mixed cultures, they provided the avenue to further my studies overseas and the tools to conduct in-depth research on the local cultures when I was older. For this I am thankful.

Like everyone else in the school, I had to choose one of the following racial identifications: Malay, Chinese, Indian or Others. Before this, I was oblivious of the meaning of these racial categories and of race. These ethnic boundaries had been demar-

3 Bangsawan is a type of commercial popular theatre that emerged during the British colonial period. To attract multiethnic audiences, it incorporated stories, dances and music from Europe, the Malay Archipelago, China, India and other parts of Asia. Bangsawan engendered the first popular music and Malay orchestra in the Malay Peninsula. Ronggeng is a form of Malay social dance-music genre that incorporates syncretic music such as asli, inang, joget and dondang sayang. Dancers move to the singing of quatrains without touching one another. The Chinese Peranakan are local-born Chinese who have acculturated to Malay and other forms of local cultures and language. They are known for intercultural mixing particularly in their food, performing arts, costumes and language. See Matusky and Tan (2017) and Tan (1993 and 2016) for descriptions of the various forms. 
cated by the British colonialists in their attempt to 'divide and rule' and were later absorbed into postcolonial politics. The official categories of Bumiputera (literally meaning 'sons of the soil' comprising the Malays and indigenous peoples of Sarawak, Sabah and Malaysia), Chinese, Indian and Others imposed strict racial, religious, cultural and language borders and allowed for the implementation of a political system that privileged the indigenous Bumiputera (particularly the Malays) (Kahn and Loh: 1992). Mixed cultures that had occurred in Malaysian history from cross-border interactions, specifically those of the Chinese Peranakan (meaning 'local-born') and minority cultures had accordingly been marginalized. In school, we were taught to emphasize our differences rather than blur the boundaries as we did in our daily lives.

The introduction of racial categories and the privileging of the Bumiputera in the 1960s led to an increase in racial segregation and the conflict that broke out in 1969 in the country. Affirmative action policies that were introduced in the 1970s for the purposes of restructuring society and the inculcation of loyalty to the nation further resulted in racial anxieties and compartmentalization. The non-Bumiputera felt that the New Economic Policy introduced in 1971 to restructure society discriminated in favour of the Bumiputera (comprising Malays and other indigenous people) with regards to admission into universities and public service, scholarships, the issuing of licenses for operating businesses and so on.

In addition, the National Culture Policy of 1971 that called for the formation of one national culture based on cultures indigenous to the region, the incorporation of elements from other cultures, and Islam as an important element, reinforced the polarization of the performing arts into separate Malay, Chinese and Indian streams. The policy saw the implementation of state intervention in the arts and cultural production that resulted in the recreation and streamlining of selected forms of Malay dance, music and theatre and some forms from Sabah and Sarawak. A special culture ministry was set up to implement the changes in all the states and schools (Tan 1990). Other so-called 'non-indigenous' ones that included the Chinese, Indian, Siamese, Burmese and Peranakan forms were not only sidelined, but were not given any funding or promoted. In turn, for fear of being assimilated, the non-Bumiputera communities began to promote their own art forms; they played to audiences that were divided ethnically. For instance, Chinese music, dance and theatre were staged for the Chinese-educated, Malay forms for the Malay-educated and Tamil ones for the Tamil-educated (see Tan 1990, 2000). ${ }^{4}$

4 The national culture policy created much controversy among the minority groups, in particular the Chinese who formed the second largest ethnic group in the nation. To many Chinese, the policy was assimilationist and would lead to the demise of those cultures which the government identified as 'nonindigenous'. Chinese cultural groups consolidated further to preserve their culture and to assert their 
When I received scholarships to study music for my BA and MA degrees at Cornell and Wesleyan Universities respectively in the late 1970s, like the rest of Malaysia, Penang society with its blending of cultures that I once knew as a child had been divided by politics. Nevertheless, ethnomusicology programs in the American universities challenged me to cross borders again; I began to study and perform the cultures of the world. Doctoral research at Monash University in Australia in the 1980s on the syncretic bangsawan theatre showed that before the creation of national borders and policies, people of the Malay Archipelago were open to mixing cultures and interacting with one another (Tan 1993, 2016). I myself was exposed to the blending of cultures before I went to school.

When I returned to work in Penang in the 1990s, another national culture narrative had emerged. Government leaders emphasized that "culture cannot be imposed but rather it has to be adapted, adopted and practiced. Multicultural diversity is the country's strength" (New Straits Times, 8 Sept. 2002). However, the state's multicultural events focused on spectacular dance and musical performances, particularly for the National Day Celebrations, Visit Malaysia campaigns, Citrawarna- Colours of Malaysia, and the Malaysian Festival of Arts. They superficially juxtaposed stereotypical music and dances that were representative of the different ethnic groups that catered to the tourists. Light and firework displays accompanied the parade of hundreds of performers donning colourful multiethnic costumes with scarves, fans and hats. While the expression of multiculturalism appears to be promoted by the State, the kinds of cultural differences that can be portrayed are defined by cultural administrators (Tan 2000). As Kirshenblatt-Gimblett (1998: 65, 72, 77) writes, through these cultural shows "diversity is harmoniously integrated" but issues of "conflict and marginalization" are suppressed. These shows have a "neutralizing effect of rendering difference (and conflict) inconsequential."

To sum up, national policies regarding culture and rights have caused intense racial divide in the country. The non-Bumiputera including the author felt a sense of injustice about not being treated equally with the Bumiputera. Racial categories have been woven into the fabric of everyday life so that they influence how people conceive their identities, which in turn perpetuates stereotypical assumptions about culture and religion. Although an opposition coalition has taken over the government since mid2018, no new policies have emerged.

Chinese identity. They held on to their Chinese music, dance, opera, and festivals as symbols of ethnic identity and promoted their own cultural associations despite the lack of government support (Tan 1988, 2000). 


\section{Bridging the Racial Divide through Process Theatre}

In the past three decades, I have actively advocated for change in the socio-political and cultural systems in Malaysia. Together with other non-governmental groups, I have spoken out and written about how cultural centralization, the national culture policy and shows for tourism have homogenized and standardized the performing arts. But this was to no avail.

What can ethnomusicologists do to ease the ethnic anxieties in society, especially since ordinary people do not have the power to change national policies, and conventional methods of speaking and writing are not effective? How can we use our research findings, performance skills and resources to mediate intercultural dialogue so as to promote racial harmony? In an attempt to bring young people of different ethnicities together, I turned to process theatre. I searched for and initiated alternative participatory methodologies to empower young people to bridge intercultural gaps and learn their multiethnic traditions that are crucial for the development of a more inclusive Malaysian nation. Like the community music facilitators in other parts of the world, I believe that racial harmony will emerge when ordinary people, including the younger generation who are separated by race, begin to work and communicate with one another in the safe space of the music and theatre workshop.

Based on the multiethnic traditions of Malaysia and promoting inter-cultural dialogue and ensemble work, this type of process theatre can provide appropriate platforms for performers to engage with issues of race. By crossing stylistic and ethnic boundaries, the performers develop perspectives that are more inclusive; they also challenge the prevalent narratives of ethnicism. Moreover, audiences can also watch the complexities of ethnic relationships on stage.

Additionally, by learning the traditional performing arts with veteran artists, the participants can help to revitalize the traditions that are being neglected by the government, national institutions and universities. They also begin to pose questions and suggest alternatives to the State's version of performative multiculturalism that emphasizes the production of stereotypical ethnic performance styles.

\section{Process Theatre as a Method}

Process theatre is based on the ideas and pedagogy of Brazilian educator Paolo Freire. In Pedagogy of the Oppressed, Freire criticised the Western pedagogical principle that he called "The Banking Concept of Education," in which knowledge is "a gift bestowed by those who consider themselves knowledgeable upon those whom they consider to know nothing" (Freire 1972: 164). For Freire, a pedagogy for liberation 
requires a new kind of teacher who believes in the creativity and knowledge of the oppressed. By analogy, a theatre of liberation also requires a new kind of actor/facilitator who activates the inherent creativity of his or her target group. Freire also emphasized that communication in the form of dialogue between teachers and the students is crucial in empowering the latter to be in control of their own development. His concept of "conscientization" is widely used in participatory development and community theatre to refer to the process of raising awareness though collective enquiry, dialogue, and action that can lead to social change and justice.

Process theatre has also adapted the participatory approaches of the Brazilian theatre director Augusto Boal (1979), who created 'forum theatre' as a place where the oppressed or disadvantaged can express their issues of concern about the unequal power relations in society. Boal drew from Freire's ideas of 'conscientization' or 'raising awareness' for change. In Boal's forum theatre, the community is invited to see the workshop performances and to discuss or even act out their problems.

In Asia, theatre for development usually combines contemporary theatre techniques and the traditional or popular music, dance, drama, puppetry and visual arts of the place where the workshops are held. Guided by the facilitators, participants collectively develop the plays based on issues that concern them. They use the characters, music, imagery, games, movements and props from their own diverse traditional performing arts. This way, the participants gain ownership of the process, content and the play itself. The plays are often performed for the community members, whereby a discussion about the issues raised takes place after the performance. With the advent of media technology, some groups have begun to use video and photography to advance certain community concerns (see Tan 2009). ${ }^{5}$ In a way, the workshop performances are akin to contemporary socially engaged plays that have emerged in different parts of the world. For instance, the American playwright Susanne Lacy uses participatory and collaborative methods in her plays that require interaction and exchange with the audiences (Schlemmer 2017).

The process theatre projects in Penang cater to mostly teenagers and young artists andy usually last from three to five months. Facilitators comprise contemporary and traditional artists, university students, teachers, videographers and photographers. Games and group dynamic activities at all sessions help the participants and facilitators to get to know one another and establish a sense of ensemble. Participants undergo training in improvisation, role-play, mime, movement, voice, and visual arts as

5 As part of my research funded by the Asian Public Intellectuals (API) Award, Nippon Foundation. I studied some of the best practices of community outreach programmes in Southeast Asia and Japan. Two of the projects about peace building in Okinawa and the issue of forced marriages used video as the form of communication. For my report for the API, see Tan 2009.

IOO 
well as selected traditional music, dance and theatre with the traditional artists of the area where the workshop is held. Creative exercises encourage participants to explore certain themes and experiences. Field trips to specific locations where the stories are based provide the participants with the opportunity to experience everyday activities, talk to others, observe the movements and listen to the sounds of people and the environment in those spaces.

The participants then put together what they have observed, learnt and collected from the field trips in the form of songs, music, movements and short stories that they create themselves. They then perform their pieces in a workshop showcase. Members of the community that the young people obtained their stories from as well as their parents and friends are invited to see the showcase. During the closure, feedback is obtained from the participants regarding the workshop (see Tan 2008, 2013, 2018 for descriptions of the methodologies for specific projects).

This essay stresses the importance of the crossing of all kinds of borders through the production of localized plays; multiethnic casts negotiate the stage using multiple accents, languages and performance idioms. By so doing, the play becomes accessible to all of the ethnic groups in the audience, as everyone can understand the languages and identify with the scenarios in their daily lives. Crossing boundaries and hybridity also helps participants to move beyond cultural and racial stereotypes and break ethnic blinders.

What are the different ways for crossing borders? I share some of the methods used in previous community musical-theatre projects that have been conducted in the past decade with young people, namely Kisab Pulau Pinang (The Penang Story, 2006, 2017, 2018), Ronggeng Merdeka (Independence Ronggeng Dance, 2007), Kotai Penang (Penang Kotai or Song Stage, 2009), Opera Pasar (Market Opera, 2008), Wayang Chulia (Shadow Theatre about Chulia Street, 2015), Wayang Potehi (Potehi Puppet Theatre, 2015-2016).

\section{Strategies for Crossing Boundaries}

\section{Collaborating with Multiethnic Artists, Stakebolders and Participants}

As the national universities are restricted by government regulations and policies, most of the advocacy work needs to be done outside. A group of concerned artists (including the author) formed a non-governmental organization known as OmbakOmbak ARTStudio (Ombak in Malay means 'waves'); we are a collective of artists from different ethnic backgrounds who try to create cutting-edge performances with a Malaysian identity. We experiment with traditional and contemporary arts media to 
create relevant and accessible forms of theatre that can express the experiences of the local communities. We collaborate with other tradition bearers and community stakeholders of all ethnic groups. By working with an independent non-governmental organization outside of the university, we are not bound by State policies and authority.

Ombak-OmbakARTStudio runs community theatre projects (known as Ombak Muda referring to 'Ripples') that cater to children, teenagers and young adults who come from different class and ethnic backgrounds. The main objective is to educate a new generation of Malaysians who can appreciate the diverse musical and theatre traditions of all ethnic groups and to instil in the young the need to cross borders in order to break ethnic barriers. This is crucial, as the formal school education system promotes the essentialized racial particularities and cultural homogeneity as defined by the authorities. The university students who help out in these projects volunteer as facilitators so that they can gain experience working with the young people and communities.

We are also supported by other stakeholders: schools provide the students and teacher facilitators, cultural associations offer spaces for rehearsals and performances, banks and other companies give funding, and members of the multiethnic communities open their houses and shops to the young people and willingly share their personal stories and experiences.

The plays devised encourage crossovers by incorporating diverse adult facilitators and young performers. Audiences comprise young people and adults of all races, ages and social groups. For instance, Ronggeng Merdeka's cast included three co-directors-a Malay dance choreographer, an Indian dramateur and a Chinese musician. A group of children of different ages and races played the scenes about children's lives during the Japanese Occupation and pre-independence periods. Another group of young adult university students re-enacted the lives and problems of the ronggeng dancers. In the past, these dancers attracted multiethnic audiences at their performances at the amusement parks, but were looked down upon by Malay conservative circles as they danced with men and worked at night.

Interethnic mixing is further encouraged during the workshop, as the participants from diverse ethnic and social backgrounds have to interact intensively with one another for 3-5 months and to negotiate with one another in the improvisation and learning process. If they had problems with one another, they had to resolve them so that the play could go on. Enjoyment in being involved in the production also helped to ease any tensions that arose during the rehearsals. 


\section{Learning by Experience, Observation, Research and Fieldwork}

Oral interviews, observing, recording, and executing the movements or playing the music of another ethnic group helped the participants to learn more about the 'other'. Participants were taken on field trips by adult facilitators and researchers who introduced them to the history and cultural background of the sites. They were also provided with research skills and taught how to interview community members using different languages. Following that, they went out to observe and interview community members about their festivals, crafts, rituals, performing arts, food and any socio-economic issues of concern. In Kisab Pulau Pinang, the apprentices interviewed the people about what Penang was like a century ago that is not found in the history books. Intercultural mixing occurred amidst the lively spice trade, street festivals, and pilgrims stopping by on their way to Mecca, secret society fights and entertainment for all at the amusement parks. In Ronggeng Merdeka, the young people questioned families about their experiences during the Japanese Occupation and their role in the journey to independence. In Kotai Penang, the participants found out that many families including craftsmen had to move out of their homes because of the sharp increase in rents after the repeal of the Rent Control Act in 2000.

The young participants also discovered how the communities in specific streets were connected historically to specific trades, many of which no longer exist today. Through the research for their stories, the young people discovered that Carnarvon Street was known for the funeral parlours and the making of paper effigies for funeral rites; Campbell Street was bustling with activities of an old wet market and shops selling jewellery, cloth and other goods; Chulia Street thrived on festival parades, bars where sailors went for entertainment, hawker stalls that lined the streets and the 'Cheapside' alley where cheap tools and house accessories were sold.

In an attempt to bring attention to the heritage market known as the Campbell Street Market that was in danger of being closed down, Ombak Muda participants put on a play called Opera Pasar. The young participants investigated the history of the heritage market, interviewed the market vendors about their lives and how they ran their businesses and put these stories into song and dance. Through this experience, the participants learnt to appreciate the wet market, as some of them had never been to one, as they do their shopping with their parents at the modern hypermarkets today.

In all the plays, the methodology of 'Music of Sound' that I pioneered was used. The children were taken to the different sites where the story was based to collect sounds and objects for making music as well as to observe the movements of the people. At the coffee shop, for example, they recorded dialogues in different languages that they heard, sounds of people cooking and making drinks, and combined them to 
create percussive movement pieces. At the market, they observed the movements and recorded conversations of people buying and selling things and the sounds of clogs that people wore to the wet market; they then created a movement piece from the materials collected.

Learning through research in local settings allowed the participants to experience reality outside the school and home; they could experience how local communities of different races communicated with one another and how cultural borders were blurred on the ground.

\section{Analysis of the History and Concerns of all Ethnic Groups}

After collecting data from the communities, the participants came together to discuss their findings; they looked for ways to combine their interviews, sounds and movements with the music and theatre skills they had acquired to create short musical skits. The musical plays emphasized accessibility to all and sundry, as the content and forms were grounded on the lives of the local people and street performance genres belonging to the various ethnic communities. Ronggeng Merdeka highlighted the hardships encountered by the ronggeng performers of different ethnicities during the Japanese Occupation in Penang and the period leading to Independence. The multiethnic young participants in this play portrayed the challenges that children faced in the Japanese school that they had to attend.

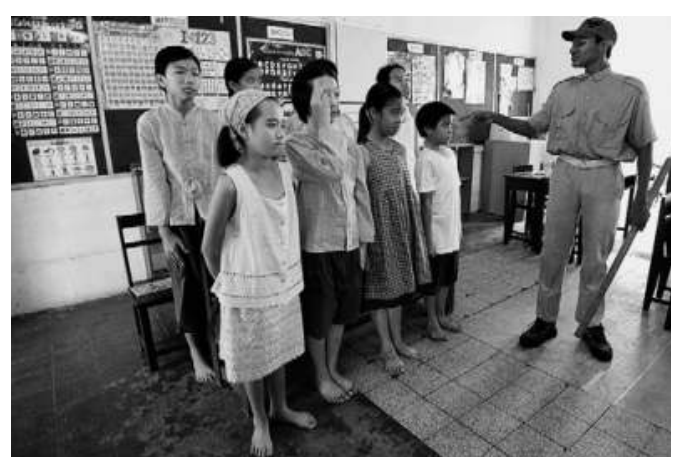

Figure 1: At the Japanese School, a scene from Ronggeng Merdeka. Photo by Tan Sooi Beng, 2007.

Conversely, Kotai Penang highlighted the issue of traditional communities being moved out of the city because of the repeal of the Rent Control Act in 2000: they could no longer afford the high rents and were being replaced by modern cafes and boutique hotels. The displaced included craftsmen who stopped practicing their art forms when they lost their spaces in the heritage city. 
These plays allowed the participants to portray their understanding of historical and present-day issues in the multiethnic society and to cross borders in a variety of ways. First, the participants had to create new plays using the dialogues, movements and sounds of the multiethnic society. Second, they also built close relationships with people of other races, especially those they interviewed and the traditional artists they apprenticed with. Third, the communities shared their common experiences and learnt about one another through the multiple stories enacted by the young participants of the workshops. Fourth, the young participants began to experience the Other by playing the roles of the multiethnic people they interviewed.

The plays celebrated difference and diversity in everyday life in the past in Penang, as they allowed the various voices to intermingle with one another within particular historical contexts.

\section{Mixing Languages and Musical Elements}

Malaysians have always mixed languages and switched codes in their daily conversations. In our musical plays, the newly-composed songs incorporated Malay, English, Hokkien, Cantonese and Tamil words. The following rap created by young performers about the streets of Penang in Kisab Pulau Pinang (2006) exemplified the mix of languages:

Rap on the Streets of Penang (italics $=$ Malay; CAPS $=$ Hokkien, ordinary font $=$ English $)$

Penang ah Penang

Banyak jalan banyaklah nama

Itu nama mana datang?

AH KONG AH MA brother sister kamu semua CAI EM CAI

Dulu-dulu nama jalan diberi kerana nama bangsa orang-orang di Penang

Malay Street, Acheen Street

Bangkok Lane, Swatow Lane

Yahudi Road, Burmah Road

Ceylon Lane, Amoy Lane

Kampung Jawa, Kampong Malabar.

ANG MO LANG EH MIA pun ada

King Street, Queen Street, Campbell Street, Victoria Street 
Tan Sooi Beng

Translation:

Penang oh Penang

There are many roads with many names

Where did the road names originate?

Grandfather, grandmother, brother, sister, do you all know?

In the past, many roads were named after the nationality of the people in Penang

Malay Street, Acheen Street

Bangkok Lane, Swatow Lane

Yahudi Road, Burmah Road

Ceylon Lane, Amoy Lane

Village of Java, Village of Malabar.

There were also European names

King Street, Queen Street, Campbell Street, Victoria Street.

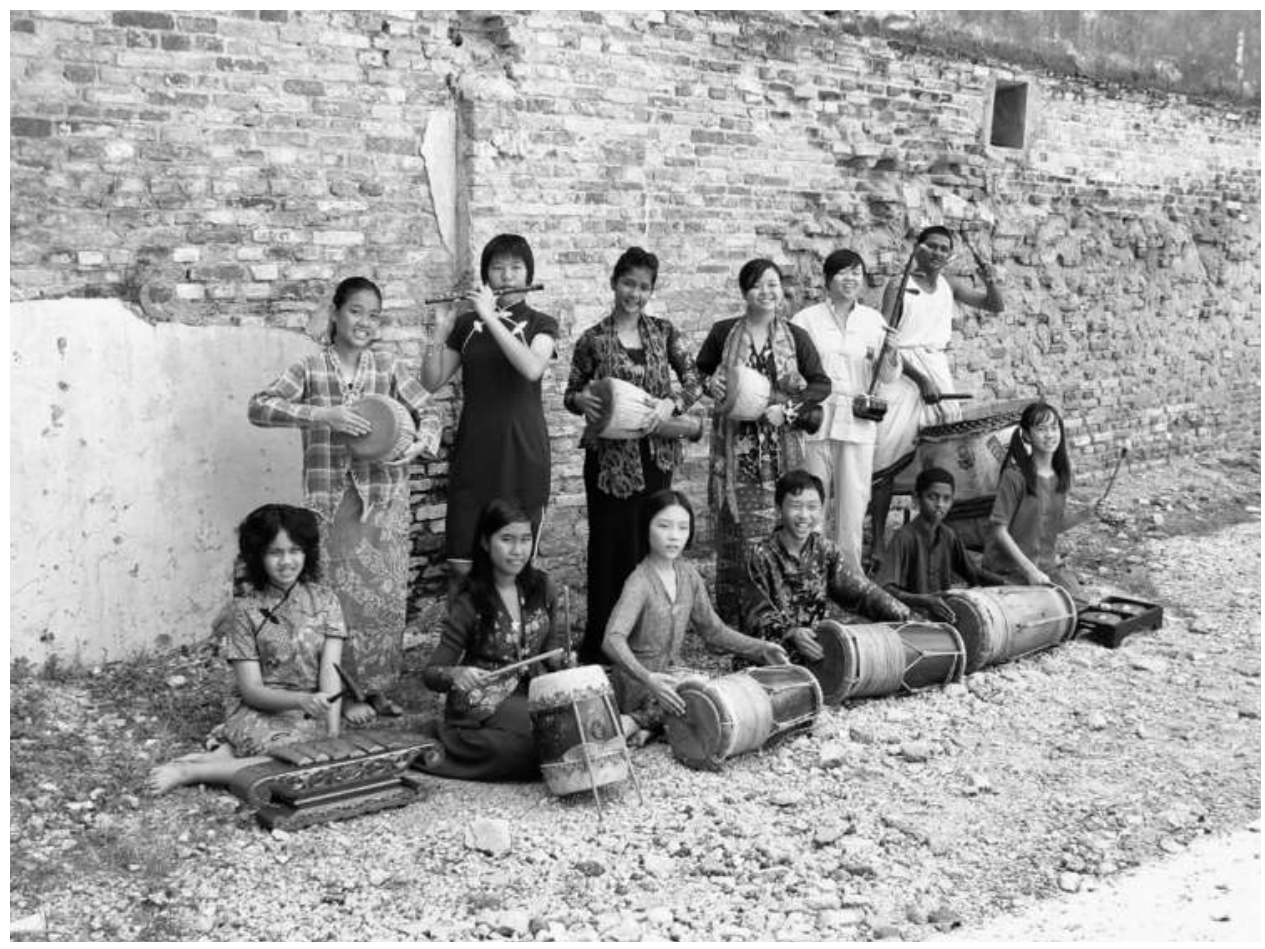

Figure 2: Chinese, Malays and Indians playing each other's instruments, Ronggeng Merdeka. Photo by Tan Sooi Beng, 2007. 
Moreover, the plays juxtaposed the musical elements of the diverse ethnic groups. Chinese and Malay melodies and modes were employed in the singing and instrumental music. Percussion was provided by Chinese, Indian and Malay drums played side by side. Yet the diverse sounds and styles were framed by rhythmic cycles and interlocking rhythms found in Malay, Chinese and Indian music. The music was eclectic and did not privilege any of the three main ethnic categories; rather it was Malaysian in content and form. For example, the melody of the folk song Dayung Sampan [Row the Boat] that was employed by the late Chinese pop star Theresa Teng in her hit song Tian Mi Mi [Sweet Sweet] was played by the gamelan players in gamelan style to accompany the Chinese migrants arriving by boat in Kisab Pulau Pinang (2006).

By crossing borders in the use of diverse musical forms, languages and instruments as well as returning to the particularities of multiethnic traditional musics of Malaysia, the new music embodied inclusion and challenged the official constructs of national identity that adhere to stereotypical ethnic, cultural and linguistic categories.

\section{Recreating Traditions that Crossed Boundaries}

The participants also crossed borders by learning, performing and experimenting with the traditional cultures of other communities. Ronggeng Merdeka combined the ronggeng ensemble (comprising the Malay rebana, gong and western violin) with gamelan instruments, wayang kulit drums, and the Chinese erbu (two-stringed spiked fiddle), flute and lion dance drums. Wearing Malay, Chinese and European clothes, the ronggeng girls dance to the eclectic tunes and rhythms of the joget, inang, cha-cha-cha, and rhumba dances as they entertain the men in the amusement parks.

In 2016, Ombak Muda learnt the traditional shadow play (wayang kulit) to tell the stories of the people living on Chulia Street, one of the busiest streets in Penang in the past. New puppets representing the different races were carved by the participants for the show entitled Wayang Chulia. They included Indians celebrating Thaipusam (an Indian festival), Chinese watching the lion dance and Malays dancing boria (a type of Malay street theatre) in shadow form.

In 2017, a group of young people apprenticed with a professional potehi glove puppet troupe to learn the art of puppet manipulation, narration and music. Calling themselves Ombak Potehi, the apprentice group recreated Kisab Pulau Pinang (2017) using the traditional glove puppets dressed in local costumes, speaking and singing in the Penang dialects to tell the people's history of Penang. The premise here is that in order to conserve any culture or recreate it for multiethnic audiences, one needs to understand the roots of the culture. 


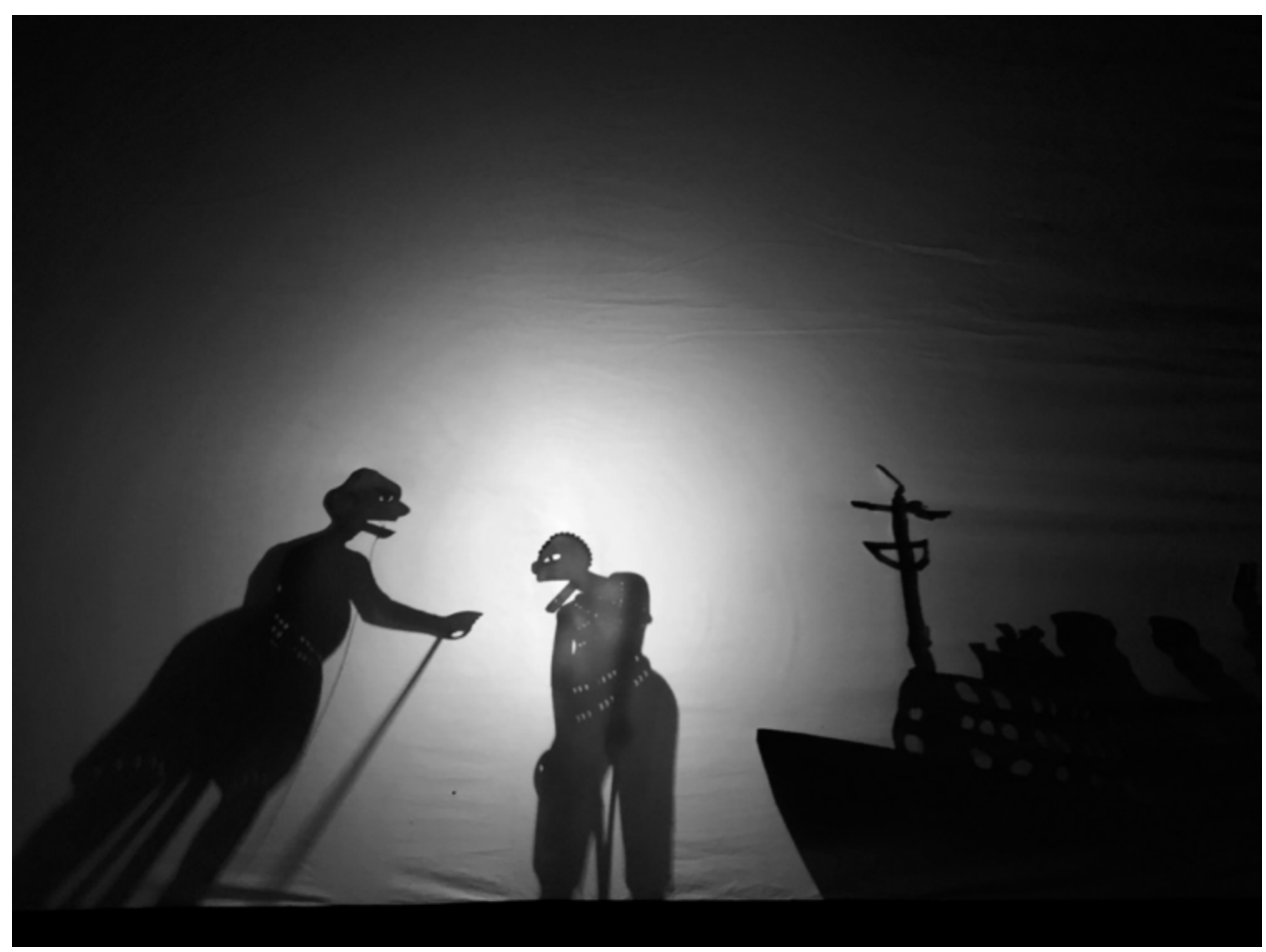

Figure 3: New localized multiethnic characters set at the port of Penang in the Malay shadow play Wayang Chulia. Photo by Tan Sooi Beng, 2016.

6 New Sites and Locations

The performances were free of charge and located in neutral local sites where all ethnic groups met, such as a street in the city, a market place, or a park or open space. The communities from whom the stories were collected were invited to the shows. Audiences also crossed boundaries by going into other spaces outside their own. These plays emphasized the intertextuality of cultures in the daily lives of the communities and cultural encounters in the parks, at street festivals and in other public spaces in the city. Even though the ronggeng performers were of various ethnic origins, they interacted and worked together in the tua se kai (Hokkien term for the Great World Park), an amusement park that featured multiple types of entertainment such as music, theatre, dance and comedy, acrobatic acts and games for the general public in the past.

Sometimes, residents living in the selected spaces were able to make their grievances heard through the oral interviews and shows. For instance, in Opera Pasar (2008), Om- 


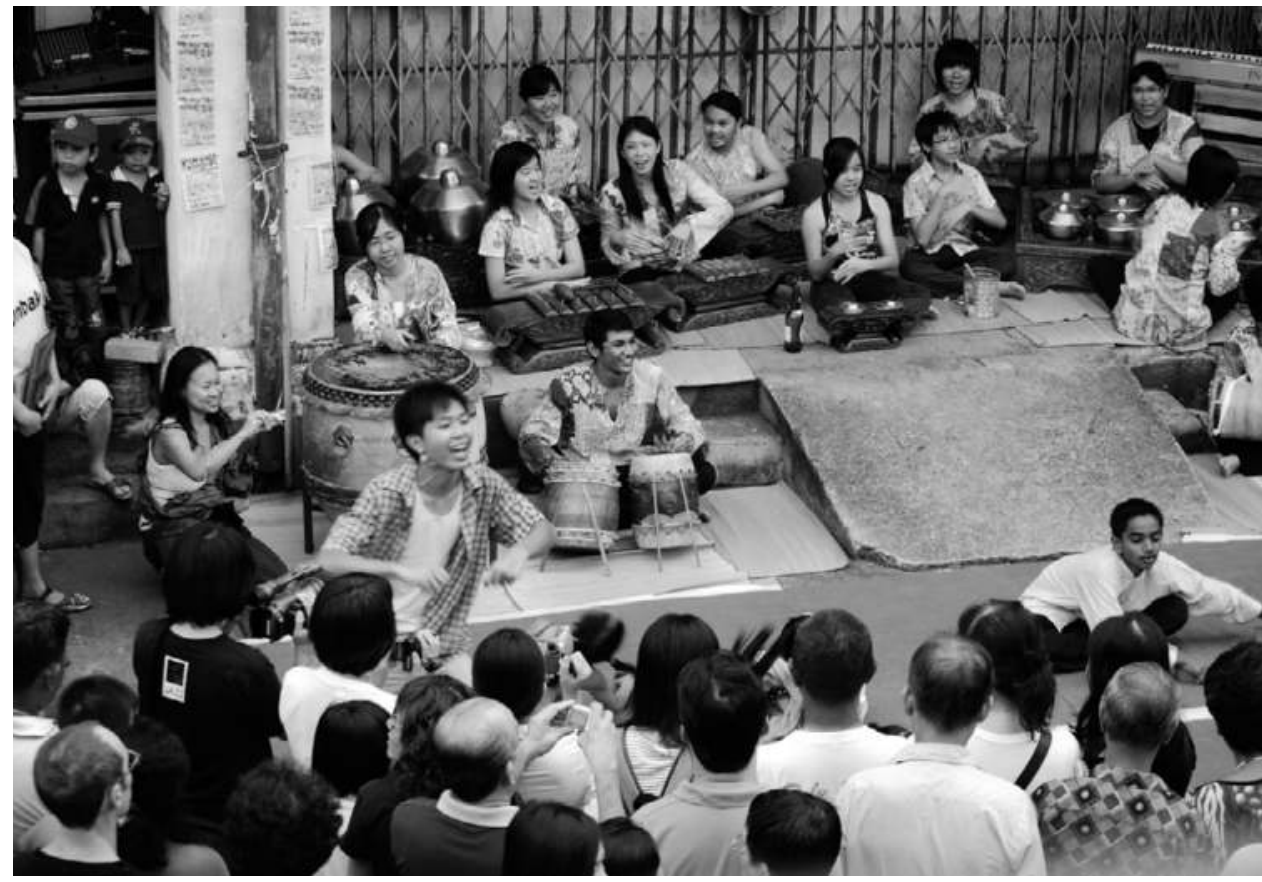

Figure 4: Performing to the market community in front of closed shop houses at Campbell Street Market. Photo by Tan Sooi Beng, 2008.

bak Muda performed in front of a row of shop houses that were closed to make way for cafes and restaurants. The performance in front of closed doors was a statement in itself. The performers also added lines about people moving out of their homes and shops in the course of the play. Additionally, through the research and performance of Opera Pasar, there was increased interest in the heritage Campbell Street Market; the market has now been earmarked for restoration and will not be closed down.

\section{Collective and Bottom-up Methods}

The facilitating team formulated bottom-up participatory approaches that emphasized dialogue, collective work and people-centred knowledge production. As in the projects in Brazil, Ireland and Southeast Asia described at the beginning of this chapter, dialogue among the members of the team and the workshop participants regarding the objectives and methods, activities and fieldwork was carried out from the beginning till the end of the workshop. 
The members of the facilitating team worked as a collective (each one had a distinct task and networked with other community members). When one person was not available, another one in the collective took over the particular job. Through participation, the participants took possession of the outcomes that could be useful for their own development. They were empowered to question and voice their opinions about their own cultural development and transformation.

\section{Evaluations and Lessons Learnt}

Evaluations carried out with the participants and audiences show that the Malaysian identity which is articulated in the process theatre workshops challenges the politics of the ruling elites. The plays do not fall into any of the country's official ethnic categories-they are not specifically 'Chinese, Malay, Indian or Others', but Malaysian. As one 16 year old participant says in her evaluation, "when we create the music, movement or drama, we focus on making the piece together; we do not think of the play as Malay, Chinese or Indian but something that we composed ourselves." A member of the audience told me that "the music and plays cross ethnic, cultural and stylistic boundaries. Local folk and popular Malay music using Chinese, Malay and Indian instruments embrace the cultural diversity of our multiethnic people."

In the process of constructing process theatre, the young participants learn to understand other cultures and lose any preconceived notions they have of those cultures. The plays, dialogues and song texts that they create disassemble stereotypes that each ethnic group is linguistically and culturally monolithic, and that one's identity is fixed and unchanging. As they blur the boundaries of race by blending languages, song styles, instruments or movements, and represent themselves in ambiguous ways in the musical productions, the performers began to appreciate that intercultural mixing takes place on the ground.

In fact, the performers were of the opinion that the whole process of making musical theatre "changed their thinking about other races" and their perceptions about Others. A 16 year old Indian girl stressed that, "interaction with others opened my mind. I learnt the music of other races that I never knew before." A 14 year old Chinese participant from a Chinese language school said, "This was the first time I entered a mosque and I learnt how Muslims pray." Another 17 year old Malay boy said, "I interacted with people of different ethnic backgrounds and religions with more confidence; my perceptions regarding the other races changed; this is because I did not know their cultures prior to the workshop."

By crossing borders, the plays promote intercultural mixing and help to generate bonds among the participants who come from different ethnic, social and gender 
backgrounds. They serve as alternatives to the communal divide that is the everyday reality. As another fifteen year old Chinese participant declared: "For the first time, I am able to mix with other Malays and Indians. In the Chinese school that I go to, I only mix with Chinese people. Through this workshop, I made new friends who have similar interests." The participants added that they could communicate with Others by making music together and interacting intensively in the workshops. They pointed out that the collaborative working style encouraged them to "exchange ideas with one another in order to create the music, scripts and song texts;" they "learnt to listen to other people's ideas;" and that "group work inspired creativity and understanding." The participants remain good friends and keep in touch with one another via social media and continue to meet one another after the workshops. Many have continued to join other similar workshops where they have gradually been given the tasks of facilitating by leading the smaller group activities. In this way, the multiethnic workshop team has been able to build capacities for future work.

By encouraging the multiple expressions of Malaysian culture, the performers underline that all creative forms and languages are equally valid. The young people learn to perform the diverse traditions and use them in their new creations. In this way, community musical theatre promotes understanding among the performers and audiences that difference is central to being Malaysian, that identity changes according to the historical and social contexts, and that multiplicity is inherent in all aspects of Malaysian life.

Nevertheless, after many years of practice, problems of sustainability persist. The numbers of young people taking part in the projects are small: twenty to thirty students a year. The young people today tend to multitask and have to attend many supplementary tuition classes outside of school so that they can no longer spend three to five months on a single project. Others seem to be glued to their computer and hand phone games. Funding for the projects is also scarce, as these projects are not part of formal education and are of no commercial value to corporate sponsors.

For the alternative theatre projects to be sustainable, much work remains to be done to convince education policy makers, schoolteachers and private corporations of the values of experiential learning in the field and the process theatre workshop as a venue for cultural interaction. The training of school teachers and the incorporation of the methodologies of process theatre into the school curriculum would be a great leap towards sustainability. 
For me, being an ethnomusicologist means being an engaged activist researcher who not only conducts detailed ethnographic research or writes about how ordinary people use music and the arts to contest power structures and national ideologies, but one that dynamically advocates for change in the education and political systems. The methods of recording, archiving, performing and analyzing music and interviews with performers remain vital and are consistent with my personal vision. However, I strongly believe that we can no longer stay neutral in our research and shy away from politics if our research subjects are being marginalized, are divided by race or suffer from social injustice.

After twenty years of practising activist research, I have found process theatre, theatre for development or community theatre to be an effective educational tool that can stimulate change in society and individuals. As Goldbard (2006: 52), an advocate of community cultural development, suggests, "Culture is an effective crucible for social transformation, one that is less polarizing and creates deeper connections than other social change arenas."

What are the main principles and concepts in the methodology of theatre for development? As in other community music-making projects, particularly those for peacebuilding in Ireland (Mullen 2018), the workshop provides a safe space for the participants who are separated by ethnicity and class; it allows them to express their differences and similarities. To run the workshops effectively, it is important to create a cross-ethnic and inter-disciplinary team of facilitators who continually reflect on their individual identities, positionality and their roles as facilitators. Besides teaching skills in the various types of theatre and music, the facilitators should be able to engage the young people in collaborative activities that can lead to mutual respect and trust; they need to balance the needs of the participants while trying to achieve the objectives pertaining to social change. They must be flexible in adjusting their methods depending on the social and cultural situation. The facilitators also need to know how much to intervene in the creation of art works so that the outcome is of a certain quality.

The adoption of participatory and collaborative strategies is crucial in the conceptualization of this type of community theatre. Dialogue is generated through collaboration in research, reflection, analysis, evaluation and planning. Through dialogue and collaboration, different kinds of local knowledge can be ascertained and disseminated. This process blurs the boundaries between the facilitators/communities/ participants; it promotes inclusion among the multiethnic participants. In the peacebuilding context, making art together (which is seen to be a fun activity) allows the participants 
to go into dialogue with one another even if they do not do so in everyday life; the mutual exploration of shared histories and musics allows the participants to see one another in novel ways.

Additionally, workshop principles in the Global South also highlight research (such as oral interviews, participant observation and making audio-visual recordings) and the dissemination of knowledge using the creative arts. Research that is required in process theatre privileges the perspectives and the analyses of the participants and communities regarding the socio-political issues that affect their music, culture and lives. Through oral interviews, the participants recover history based on the people's views besides the views of those in power. As Arjun Appadurai (2006: 175-177) writes, research and documentation are essential tools for social intervention. Based on the experiences of the Partners for Urban Action and Research in Mumbai, he emphasizes that learning to "document, inquire, analyze and communicate results" can help the bottom billions "speak up as active citizens on matters that are shaping their city and their world." Process theatre may also be viewed as a step towards the democratisation of cultural research and learning where alternative media such as photography, drawing, creating videos, singing and acting can be used to communicate research findings and analysis to the public.

Moreover, in the praxis of theatre for development in the Global South, holistic theatre that combines the visual and performing arts and oral traditions of the diverse communities themselves is employed. The cultural traditions of the community become tools for communication. In this way, theatre for development emphasizes the awareness of a 'sense of place'. Moser (2018: 226-227) suggests that in post-colonial countries in particular, there is a need to look for one's "traditional cultures" and to "make new cultural experiments" for social transformation to occur. As stated in the United Nations' Universal Declaration of Human Rights, 1948, everyone has the 'right to culture' and no one culture should dominate over the other. But there is also a need to find ways for the different cultures to come together.

What is the role of the activist ethnomusicologist in these workshops? Besides facilitating, I have played the role of mediator between the community, traditional practitioners, students and young people in the projects, funding agencies, the state government, university and the outside world. However, I have to be mindful that I may be seen as someone who has the power to say which data is important to collect and what the music/theatre composition should be like. The activist research approach therefore requires that the scholar activist facilitates a collective as a model of running the project and transfers research and performance skills to the people involved in the project. To promote power sharing, there should be consensus within the collective with regard to the objectives, ownership, distribution and other decision matters related to the project. This approach suggests a type of engagement where 
knowledge flows horizontally across communities and stakeholders; it moves power relations away from the scholar.

Nevertheless, the process of dialogic intervention takes time as it involves negotiation, reflection and creating trust among those involved. These methods do not resolve problems such as inequalities, racial tensions or problematic representations completely, but they help to illustrate and expose the issues. In the context of community development, creative participatory processes are vehicles for participation and a forum for raising and analyzing local problems. Group evaluations pose challenges that can lead to further action. A major outcome is the empowering of young community members who, prior to participating in these projects, had little or no say in decision-making.

The principles and methodologies for theatre for development claim relevance for nation building and cultural citizenship in the present era where international and internal conflicts have resulted in high migratory flows and a global flood of refugees. Host countries facing anxieties related to integration may find that the participatory and dialogic praxis of this type of theatre that highlights community forms of art and research is applicable as a means of intervention.

References

Appadurai, Arjun. 2006. "The Right to Research." Globalisation, Societies and Education 4/2: 167-177.

Araujo, Samuel and Members of the Grupo Musicultura. 2006. "Conflict and Violence as Theoretical Tools in Present-Day Ethnomusicology: Notes on a Dialogic Ethnography of Sound Practices in Rio de Janeiro.” Ethnomusicology, 50/2: 287-313.

Bartleet, Brydie and Lee Higgins, eds. 2018. Oxford Handbook of Community Music. New York: Oxford University Press.

Boal, Augusto. 1979. Theatre of the Oppressed. New York: Urizen Books.

Department of Statistics, Malaysia. 2010. https://www.dosm.gov.my/v1/index.php?r=column/ cthemeByCat\&cat=117\&bul_id=MDMxdHZjWTk1SjFzTzNkRXYzcVZjdz09\&menu_id= L0pheU43NWJwRWVSZklWdzQ4TlhUUT09 (07.04.2019).

Eskamp, Kees P. 2006. Theatre for Development, An Introduction to Context, Applications, and Training. London: Zed Press.

Fals Borda, Orlando. 2008. "Participatory (Action) Research in Social Theory: Origins and Challenges.” Journal of Consumer Research 35/3: 423-439.

Freire, Paolo. 1972. Pedagogy of the Oppressed. England: Penguin.

Goldbard, Arlene. 2006. New Creative Community: The Art of Cultural Development. Oakland: New Village Press. 
Hale, Charles R, ed. 2004. Engaging Contradictions, Theory, Politics, and Methods of Activist Scholarship. Berkeley: University of California Press.

Higgins, Lee. 2012. Community Music: In Theory and in Practice. New York: Oxford University Press.

Kirshenblatt-Gimblett, Barbara. 1998. Destination Culture: Tourism, Museums and Heritage. Berkeley: University of California Press.

Kahn, Joel S. and Loh Kok Wah, eds. 1992. Fragmented Visions. Sydney: Asian Studies Association of Australia with Allen and Unwin.

Matusky, Patricia and Tan Sooi Beng. 2017. The Music of Malaysia, the Classical, Folk and Syncretic Traditions. Burlington: Ashgate.

Moser, Peter. 2018. "Growing Community Music through a Sense of Place." In The Oxford Handbook of Community Music. B.-L. Bartleet and L. Higgins, eds. New York: Oxford University Press, 213-228.

Mullen, Phil. 2018. "Community Music." Music and Arts in Action 6/2: 5-15.

New Straits Times, 8 September, 2002.

Reason, Peter and Hilary Bradbury. 2008. The Sage Handbook of Action Research, Participative Inquiry and Practice. London: Sage Publishing.

Schlemmer, Ross H. 2017. "Socially Engaged Art Education: Defining and Defending the Practice." In Handbook of Research on the Facilitation of Civic Engagement through Community Art, Chapter 1, 1-20. https://www.researchgate.net/publication/312010009_Socially_Engaged_ Art_Education_Defining_and_Defending_the_Practice (28.02.2019).

Tan, Sooi Beng. 1988. The Phor Tor Festival in Penang: deities, ghosts and Chinese ethnicity. Clayton: Centre of Southeast Asian Studies, Monash University.

1990. "The Performing Arts in Malaysia: State and Society." Asian Music, XXI/1: 137171.

1993. Bangsawan: The Social and Stylistic History of Popular Malay Opera. Singapore: Oxford University Press.

2000. "The Chinese Performing Arts and Cultural Activities in Malaysia." In The Chinese

in Malaysia. Lee Kam Hing and Tan Chee Beng, eds. Kuala Lumpur: Oxford University Press, 316-341.

2003. "Multi-Culturalism or One National Culture: Cultural Centralization and the Recreation of the Traditional Performing Arts in Malaysia." Fournal of Chinese Ritual, Theatre and Folklore 141: 237-260.

2008. "Activism in Southeast Asian Ethnomusicology: Empowering Youths to Revitalize Traditions and Bridge Cultural Barriers.” Musicological Annual, Ljubljana, XLIV/I: 69-84.

2009. "Participatory Arts and Creative Media in Asia: Engaging Communitiesand Empowering Youths for Change." In Confluences and Challenges in Building the Asian Community in the Early 21st Century. The Work of the 2009/2009 API Fellows. Tokio: The Nippon Foundation. 
http://www.api-fellowships.org/body/international_ws_proceedings/year8.pdf (27.05.2019).

2013. "Cultural Engagement and Ownership through Participatory Approaches in Applied Ethnomusicology." In The Oxford Handbook of Applied Ethnomusicology, Svanibor Pettan and Jeff Todd Titon, eds. New York: Oxford University Press 2013, 109-133.

2016. "Cosmopolitan Identities: Evolving Musical cultures of the Straits-born Chinese of pre-World War II Malaya.” Ethnomusicology Forum, 25/1: 35-57.

2018. "Community Musical Theatre and Inter-Ethnic Peace Building in Malaysia." In The Oxford Handbook of Community Music. B.-L. Bartleet and L. Higgins, eds. Oxford/New York: 243-263.

Van Erven, Eugène. 1992. The Playful Revolution, Theatre and Liberation in Asia. Bloomington and Indianapolis: Indiana University Press.

Abstract

In the past two decades, I have been engaged in activist research advocating for social justice and change in the education, cultural and political systems in Malaysia. Through musical-theatre community and festival projects, I have devised participatory dialogic approaches and provided safe spaces for peace-building among young people and communities of different ages, races, religions, income levels, and gender. These projects have also raised the awareness of young people of all races about their diverse cultural heritage and a passion to keep their musical traditions alive. This paper is a reflexive attempt to elaborate on the strategies and challenges encountered in these projects. Central to the strategies is the collaboration and partnership of the ethnomusicologist with the tradition bearers, students, and the young people of the community in all aspects of research, documentation and performance. This type of people-centred collaborative research approach strives for more horizontal and equal relations between the researcher and the research subjects and emphasizes the voices of the communities themselves. It also calls for the localization of ethnomusicological methodologies in the research and teaching of the traditional performing arts and music. Nevertheless, the collaborative dialogic process takes time and creates anxieties, as it involves negotiation, reflection, and power sharing among those involved. 


\section{Affect, Ontology, and Indigenous Protocol: Encounters in Canada}

When you are teaching songs you're teaching not just the song, but a lot of etiquette, talking about power and how to channel power. There's a lot of spin off from regarding your place in the world. (Vaughen Doucette, Mi kmaq from Eskasoni, Cape Breton, as quoted in Sable and Francis 2012: 92)

For government negotiators, schooled in Western political thinking and law, treaties were secured and made legitimate by touching the treaty pen or signing an ' $\mathrm{x}$ ' on documentsnot by smoking a peace pipe, giving gifts, or engaging in prayers, songs, or feasting. They tended to see participating in sacred ceremonies as a preliminary nuisance, a token gesture rather than Native treaty-making protocol. (Regan 2010: 102)

Indigenous forms of social interaction and diplomacy with other First Nations as well as settler colonizers ${ }^{1}$ in Canada have a long history, but old patterns (such as those Regan notes) that fail to engage with the performative protocols of intercultural diplomacy have persisted. There are, of course, serious ontological differences between ways of being and interacting in the world. ${ }^{2}$ With regard to sound and song, Indigenous and Euro-centred conceptualizations are particularly incongruous as the epigrams above imply. While many ethnomusicologists and Indigenous studies scholars have addressed song and sound as Indigenous ways of worlding, the ontological differ-

1 My focus in this article is Canada, but Indigenous/settler encounters in other countries bear many similarities in my experience. The use of "settler" (including at times its capitalization) has become common practice in North America since the surge of publications on "settler colonialism." I have, however, followed practices in Indigenous studies where capitalization is used for Indigenous institutions (e.g., governments, religions) or specific rights. Earlier literature sometimes used the term "newcomer" (see, e.g., Trigger 1985, Miller 2004) to reference settlers, and while the alliteration of "Native and newcomer" was memorable, the differences among settlement at different historical moments were also elided.

2 Social scientists have debated the term "ontology" extensively in recent years. Blaser (2014) cautions that it is not simply new language for what we used to call "culture" with reference to social difference as well as human/non-human interaction. Rather he suggests that "ways of worlding" is a better formulation in Indigenous studies. Expressive cultural practices, and song in particular, are among the human communication forms that are conceptualized and practised very differently. 
ences that cause misapprehension in intercultural contexts have received little attention to date. In this article, I want to examine different uses and responses to performative protocols at contemporary inter-Indigenous and Indigenous-settler meetings, some involving disputes or disagreements. My focus is not on what is done as much as the affect of what is done. ${ }^{3}$ How do participants and other listeners engage-sensorily, emotionally—with contemporary Indigenous performances, especially in a period of dramatic Indigenous resurgence in Canada, where there are partial indications that governments and other institutions want to enact the 94 Calls to Action of the Truth and Reconciliation Commission in Canada (TRC) ${ }_{4}^{4}$ recommendations that would transform child welfare, education, health, language/culture programs, and justice. To respond to these calls it is imperative that ontological differences be discussed. The stakes of such discussion are further intensified in a period of ecological crisis where settler colonial and Indigenous investment is often conflicted. The need to respect ontologies that understand song as law and human life as interconnected with the land and its lifeforms is urgent. But as Audra Simpson notes, Indigenous culture has often simply been described as "tradition" without regard for the "context of articulation"the message control that serves "to contain, to fetishize and entrap and distill Indigenous discourses into memorisable, repeatable rituals for preservation against a social and political death that was foretold but did not happen" (2014: 99). Such containment relates to what is apprehended-what is seen or not seen, heard or not heard. This is where ethnomusicology might have a role to play. What is apprehended, by whom, and in relation to what contemporary context of articulation when politically charged encounters involving Indigenous groups are performatively storied? What is seen and heard? What can ethically be written about what is seen and heard? What purposes might such writing serve? I will argue that the ontological framing of creative practices by Indigenous interlocutors invites all of us to attend and hence apprehend sound and image in a more intensely relational way, to think about the sort of relationality assumed or implied from different cultural and political positions

My approach is inspired, in part, by Mark Rifkin's (2011) work on "settler states of feeling" and Eva Mackey's (2014, 2016) development of that work in relation to "unsettled expectations." Rifkin observes that a dominant "state of feeling" underpinning settler colonialism is entitlement and with that comes a feeling of certainty about the

3 As Sarah Ahmed (2014: 4) notes, "emotionality as a claim about a subject or a collective is clearly dependent on relations of power, which endow 'others' with meaning and value."

4 In a CBC television interview published March 23, 2018: https://www.youtube.com/ watch?v=j2Lv21Ktz84, Senator Murray Sinclair who chaired the TRC noted that only ten of the 94 Calls to Action have been completed and less than half have been dealt with at all in the three years since their final report was issued in 2015. He was heartened, however, that there had been some action on ten of the Calls.

I I 8 
rightness of such things as property and Eurocentred legal definitions, cultural categories and other forms of boundary delimitation. ${ }^{5}$ In actuality, North Americans-Indigenous and immigrant (some recent, some long "settled")—-live in a context of what Audra Simpson calls "nested sovereignties" (2014: 10-12). The singular authority that the nation states of Canada and the United States assume is not and has never been accepted by most of the First Peoples. As an alternative to "recognition," Simpson posits "refusal" as a productive politics. Its many forms may include, for example, the refusal of a Canadian or U.S. passport, the refusal to vote, or refusal to let the state decide who belongs to her people, the Haudenosaunee. ${ }^{6}$ Other scholars, such as Paulette Regan (2010) and Eva Mackey (2016) recognize that relations between settlers and Indigenous people are (and should be) "unsettled." They argue that the state of being unsettled should be embraced since it opens hearts and minds to new conversations about how to live peaceably. Of course, Mackey (2016) acknowledges that the earth itself is also unsettled and ecological precarity is the condition in which new conversations will take place. She proposes that we should think of "treaty as a verb," a process of ongoing dialogue and renewed relations. Can "treaty as a verb" coexist with the politics of refusal? This is a key question as I consider how people meet. How different parties handle disagreement and how (or if) they try to avoid violence. I challenge myself, but also my readers, to consider the experiential and affective frames that have shaped my own ontological worlding in hopes of making good decisions while accepting unsettled relationships.

Meeting when differences are pronounced is inevitably tense. The rules of encounter are often described as "protocols." ${ }^{8}$ The word may also be used in other fields that range from medicine to military campaigns to determine procedure and authority. In these other contexts, it is not surprising that strict and consistent action is desirable to avoid loss of life and that strictness and consistency tend to be emotionless. In-

5 What Bruno Latour names systems of "purification" (We Have Never Been Modern. 1993). With specific reference to music, see also Porcello et al. (2012: 60).

6 Refusal, at one level, is part of everyone's life. We each refuse to do things, to relate to one another or to present the self in certain ways. Refusal of "recognition" is less quotidian for many settlers since they are not in the position of Indigenous people who are offered recognition within a state policy of "multiculturalism," a policy that seeks to incorporate rather than recognize nested sovereignties. Recognition can indeed be offered more easily than equitable living conditions or health services

7 Many First Nations in Canada refused the treaty process and may disagree with Mackey's suggestion on that basis.

8 A definition of Indigenous protocol and an elaboration that I find very thoughtful and clear is Cree scholar Gregory Younging's discussion in Elements of Indigenous Style (2018: 35-43) which begins as follows: "Protocols are appropriate ways of using cultural material, and of interacting with Indigenous peoples and Indigenous communities. They encourage ethical conduct and promote interaction based on good faith and mutual respect" (2018: 35). 
digenous protocols are now invoked in many Canadian contexts at present, but action has been divorced from their use in most cases and this may relate to the fact that settlers do not see either the attentive precision or the affective capacity for adapting to changing circumstances that Indigenous protocols afford. ${ }^{9}$ Land acknowledgements, for instance, that are now read at meetings and concerts that I attend, are often presented in a formulaic and disengaged manner. The purpose they serve is not widely understood. As such, these formulaic protocols are what Tuck and Wang (2012) have labelled "moves to innocence" on the part of settlers, gestures without implication, without thought about relationality. We settlers get away with this because these "protocols" are often performed in contexts where there are relatively few Indigenous attendees and hence where few have given any thought to Indigenous sovereignty.

Some of the online guides to Indigenous protocols are in point form, where, to me, they resemble rigid and formulaic etiquette. But we are hardly talking about the polite placement of a wine glass, rather people confronting serious differences. As her statement reveals, “etiquette" for Vaughen Doucette (Mi'kmaq) is about power and one's place in the world. What concerns me is what we might learn from the performance of Indigenous protocol in contexts (both inter-Indigenous and Indigenous/settler) where nested sovereignties are understood very well and where the outcomes of meeting have much at stake. In these contexts, expressive culture plays an important role-often as a way of preparing participants to open their minds and hearts. Although my knowledge of Indigenous protocols is partial, ${ }^{10} \mathrm{I}$ have been fortunate to be present

9 Good sources for Indigenous protocols in various countries world wide include: In Australia, Terri Janke's pioneering Respecting Indigenous Cultural and Intellectual Property Rights, 1999: http://www.austlii. edu.au/au/journals/UNSWLawJ1/1999/16.html,

WIPO Cultural Protocols for Indigenous Reporting in the Media: https://www.wipo.int/export/sites/ www/tk/en/databases/creative_heritage/docs/abc_cultural_protocol.pdf,

Oxfam's Aboriginal and Torres Strait Islander Protocols: https://www.oxfam.org.au/wp-content/ uploads/2015/11/2015-74-atsi-cultural-protocols-update_web.pdf,

in New Zealand "Tikanga Maori”: http://www.tetaurawhiri.govt.nz/maori-language/tikanga-maori/, Marae and Powhiri Protocol and Customs: https://www.englishnewzealand.co.nz/news/marae-powhiriprotocol-customs/,

in Sapmi (the land of Scandinavian Saami people), protocol often refers to a Sametinget agreement that differs somewhat from the aforementioned cultural protocol documents: https://www.sametinget. se/105173.

Commisceo has produced "etiquette" documents for Indigenous groups in different countries but these, like many online resources, are oriented as much to tourists and media staff as they are to people who want to build sustainable relationships. In Bolivia, for instance: https://www.commisceo-global.com/ resources/country-guides/taiwan-guide, in Taiwan: https://www.commisceo-global.com/resources/ country-guides/taiwan-guide.

$10 \mathrm{My}$ process of learning about protocol extends back to the 1970s when I did research in three Inuit communities in the central Arctic. I had studied Inuktitut for a year before I began that research 
when performances of protocol have taken place. In Haudenosaunee territory (in Ontario, Quebec, and New York State) where I have lived much of my life, for instance, meetings begin with the Thanksgiving Address that expresses thanks for the gifts of each element in creation, and asks attendees to be of good mind. Yvonne Bomberry has described the concept of a "good mind" (Ganigonbi:yob in her Onondaga language) as a searching and an understanding that is always shaped by "incorporating unconditional positive regard for yourself and your people." ${ }^{11}$ In the other contexts, a request for help from spirits or other extra-human energies, is a way to embrace being unsettled at times, to recognize responsibility, or to validate change, sovereignty, or refusal at other times. In such cases, "ceremony" may be a more appropriate term, as when a smudging, tobacco offering, or other act of thanksgiving for and acknowledgement of the various elements/energies of creation is conducted to begin (or end) meetings.

There have always been appropriate Indigenous formalities for conducting diplomatic discussions and negotiations. Creation stories of many First Nations offer guidance on these matters. In Northeastern Canada and the U.S., as Mi'kmaq Hereditary Chief Stephen Augustine explains in the first lecture that he presents in "Learning from the Knowledge Keepers of Mi'kmaqi," ${ }^{2}$ the Mi'kmaw Creation Story which narrates the emergence of various powers on earth governs conduct within and between communities. He discusses how the tobacco ceremony was a "negotiation of survival" as a means of entering into dialogue with neighbours. Diplomacy in other words. The pipe was filled with tobacco seven times to honour the elements of creation and thanks was offered in each of the seven directions. Entering into dialogue entails meeting and meeting often requires song. Among the Mi'kmaq communities (in the region where I currently live), songs are often referenced by the function they

and most Inuit were supportive of recording traditional songs and song histories known by an older generation at that time. I was not attuned to debates about "extractive" research that have subsequently emerged in both Indigenous and academic circles. My residence for a fairly large part of my life has been close to Haudenosaunee communities in Ontario. I attended many events where the broader public was welcome and sometimes was invited to less public social events, and I developed friendships, one of which (with Sadie Buck) developed into a research collaboration. In the 1980s and 1990s I turned my attention to Innu communities in Labrador and Quebec, focusing increasingly on cross-over genres and festivals but also story-telling, which was a particular priority in one of the communities. In more recent decades, my research interests have shifted to contemporary Indigenous recording artists and to arts in intercultural contexts. I try to engage as much as possible with Mi'kmaq in the region where I now reside as well as with various Indigenous associates of the local friendship centre and arts communities in my province.

$11 \mathrm{https} / /$ www.americanindigenousresearchassociation.org/wp-content/uploads/2016/11/BomberryAIRA-2016.pdf

12 An online course offered by Cape Breton University in Sydney, Nova Scotia, https:// www.cbu.ca/ indigenous-affairs/unamaki-college/mikm-2701. 
perform when meetings take place. There are several Mi'kmaw songs that begin with the word "Kwanute" or "Ikwanute" and these have been variably described as "Welcome Songs," "Gathering Songs," "Peace Songs" or "Feast Songs" indicating in each case that they mediate encounters when visitors from other Mi'kmaw Nations, other First Nations, settler communities, or international dignitaries arrive.

Like many instances of protocol, such formalized actions serve specific social purposes: when one group wants to enter the land of another group; when visitors arrive; when meetings take place; when changes in status are validated/celebrated/mourned (when someone returns after being away; ${ }^{13}$ when a new leader is put in place; when an individual is given a name; when someone dies); when offense has been given or when disputes emerges. ${ }^{14}$ Such actions are anything but formulaic. Rather they recognize dynamism and flux in the relational energies of living creatures, their histories and institutions, the legacies of settler colonialism and the land.

In the rest of this article, I want to think through the multi-sensory and multi-dimensional (political, social, spiritual) experience of public events where protocol was performed, sometimes in ways that surprised me, sometimes in ways that raised questions. The first was at the Truth and Reconciliation Commission's National Event in Halifax, Nova Scotia, where Mi'kmaw, Innu, Inuit, and Anishnabe communities in northeastern Canada testified about their experiences in the genocidal schools. While the TRC was thought by many to finally set the historical record straight on the abuses of more than a century, there were, of course, concerns about the process. Would testifying retraumatize victims? Would action ensue? Settlers such as myself participated as witnesses. High profile individuals also spoke on Commissioners' Sharing Circles panels, and groups offered Expressions of Reconciliation, one of which is the focus of my attention, after which a token of their Expression was placed in a carved bentwood box that was placed centre stage in the "theatre" of the TRC. The TRC created its own protocols for opening and closing each day in a good way; Sunrise ceremonies each morning and a procession to the venue of the hearings were followed by a Call to Gather with music from the region as well as the ceremonial lighting of an Inuit qulliq - a stone lamp that was a source of heat and light in a traditional igloo. Healing ceremonies were available to survivors at some of the national events.

13 An early classic in ethnomusicology, David McAllester's Enemy Way Music (1954), described the ceremony that Navaho use to restore balance when a Navajo returns after encountering outsiders.

14 There are, of course, localized means of resolving disputes within a single community. The drum dance songs of Inuit, for example, are mobilized as restorative justice when someone has been wronged. Those songs describe the wrong-doing, but also give voice to place names that hold the stories of the land, and use circumlocutions for animals as a gesture of respect. They don't fit into the neat categories that the Settler society I grew up in tends to use: categories that separate moral judgment from geography and social history or human interaction from human/animal interaction. 
Individual gifts or uses of speech and song at times modelled protocol in various ways.

The second occasion that I will describe was also associated with the Truth and Reconciliation Commission but organized by a local Indigenous group called Reconciliation Canada. It involved a canoe delegation in the heart of Vancouver on the West coast of Canada just prior to the TRC hearings there. There was less apparent controversy about this event (although I note some different viewpoints), and so it stands as an instance of inter-Indigenous protocol that the broader public was invited to witness.

The third set of occasions referenced below are ongoing protests that seek to stop the building of oil pipelines that would carry bitumen through Indigenous lands and areas that are ecologically at risk from the oil sands of Alberta across British Columbia to the Pacific Ocean (and on to Asian markets). There is no government consensus on this project since the British Columbian and Albertan provincial governments do not agree that the pipeline should be built. Nor is there consensus among First Nations governments. Since 2016, ${ }^{15}$ however, protests have intensified, in the city of Vancouver, Burnaby Mountain, and the encampment of Kinder Morgan, the company contracted to build the pipeline. ${ }^{16}$ Indigenous participation in the protests has been predictably active, constituting a focus for Indigenous and non-Indigenous activists that paralleled the Standing Rock protests of 2014-15 in the United States.

\section{Labrador Inuit Perform at the Truth and Reconciliation Commission}

At the time of Canada's Truth and Reconciliation Commission on Indian Residential Schools (2009-2015), Indigenous attendees of Indian Residential Schools from the province where I live, Newfoundland and Labrador, were not recognized as survivors of the genocidal system because the schools they attended were run by Moravians and not the mainstream Christian churches in Canada. They were not eligible for financial compensation, but they also suffered because they were excluded from the government apology of 2008 that had led to the TRC. They were encouraged to testify to the Commission, however, and many did that. At one TRC event, they chose to speak at a session called "Expressions of Reconciliation." A delegation of over twenty Labrador Inuit filed onto the small stage that was intended for only a handful of "rep-

15 Earlier and on-going initiatives include the Unist'ot'en camp of Wet'suwet'en people of central British Columbia which has attracted extensive international attention for its sustained opposition to resource extraction, particularly in the salmon spawning grounds of their territory.

16 The Canadian government purchased all rights to the pipeline from Kinder Morgan at the end of May, 2018, introducing new waves of protest but also signalling that Canada was "open for business" as the news commentators reported. 
resentatives" of organizations. Surprisingly (to me at least), a territorial minister of Nunatsiavut presented a copy of legal documents they had just filed in a class action suit against the Canadian Government. The message: reconciliation could never happen without justice. At the end of their presentation, they sang a Christian hymn, "Till We Meet Again," taught originally by the Moravians and translated into Inuktitut. They began tentatively but the energy of the performance grew to convey strength and confidence. It is a hymn that is used to end every meeting in their community, including social and political gatherings, some with other Inuit and some with settler participants ranging from developers to social workers and government ministers. The hymn is also used at funerals to mediate the transition from life on earth to life in the spirit world. Effectively it ensures that, however dramatic the rupture of separating after meeting (whether it is intercultural conflict or death), Inuit will pledge to a future with all involved, to meet again. It is a Labrador Inuit protocol for meeting and parting in a good way. The choice of a hymn poses a challenge to those who expect "tradition" to be uniquely "Indigenous" but indeed the Indigenized Moravian churches of Labrador have long regarded such hymns as their tradition, even though there are divided opinions about Christian colonization. The singing style is pertinent. One choir member explained her way of listening relationally when she told me that she loved the distinctive timbres of each voice in the choir. ${ }^{17}$ She could hear the family lineages in their sound, the spirits of those who had passed and hence the sonic history and continuity of her community. The hymn validated their right to justice and hence their lawsuit. It also confirmed their responsibility to engage in further negotiations. The good news for Labrador Inuit is that this case has now been settled out of court.

Prime Minister Justin Trudeau made a formal apology to Labrador survivors in 2017 during a special visit to their territory. One of the Inuit survivors formally accepted the apology. Their neighbours from the Innu First Nation in Labrador, however, who are faced with serious challenges to their caribou hunting cultures as well as recent actions by government social services to remove their children and place them in "foster care," 18 decided that refusal to accept the apology was necessary. They did not want simply to be "recognized" for their suffering but to have ongoing issues addressed. Refusal was their sovereign right.

17 This, of course, is distinctly different from the "blend" that many classically oriented choirs strive to achieve.

18 Foster care is a long lasting assimilationist strategy since it separates Indigenous families and effectively results in the loss of language and culture for the children put in homes away from their family and community. The placing of First Nations, Inuit and Métis children in foster homes was particularly intense during the what is called the "60s Scoop" (1960s), but the over use of foster care for Indigenous children has never stopped. 


\section{Vancouver, British Columbia: Canoe Gathering}

I turn next to performances of protocol at a canoe gathering on the West coast of Canada, in False Creek which flows through the city of Vancouver, British Columbia. Before describing this event, it is important to recognize that there is an extensive literature from scholars and other Indigenous leaders from this region about the elaborate, formal performance traditions such as the potlatch, that have long validated sociopolitical change such as the recognition of a new chief, or other transfers of authority.

Pacific Coast First Nations regard song, together with mask making, dance, speeches, feasting etc.) as "law." The responsibilities of song knowledge, as well as the right to wear crests or perform certain dances, are inherited by specific families, and misuses by others have serious consequences as described by many contributors to an important project on First Nations cultural heritage and law (Bell and Napoleon 2008). Indigenous contributors told how visual symbols, dance, speeches and songs enact and validate history and the social responsibilities of belonging. Some described song lineages as performances of belonging. Executive Director of the Umista Cultural Centre, Andrea Sanborn (Kwakwaka'wakw) explained:

We have our own laws through the potlatch ceremony. It includes the protocols for the use and ownership of the materials, whether it be songs, dances, stories, names, this sort of thing. [...] Anything that is conducted, any ceremonies that are conducted and information given to the people, that is the law. If a song is being identified as being passed down from a chief to his son, or from whomever, and it's done in a potlatch ceremony, that's the law. (Bell and Napoleon 2008: 51)

In another context, law professor John Borrows (Anishnabe) offered a similar explanation with regard to the Gitxan and Wet'suwet'en:

For millennia, their histories have recorded their organization into Houses and Clans in which the hereditary chiefs have been responsible for the allocation, administration and control of traditional lands. Within these Houses, chiefs pass on important histories, songs, crests, lands, ranks and property from one generation to the next. The transfer of these legal, political, social and economic entitlements is performed and witnessed through Feasts. [...] The Feast is thus an important institution through which the people governed themselves. (Regan 2010: 198) 


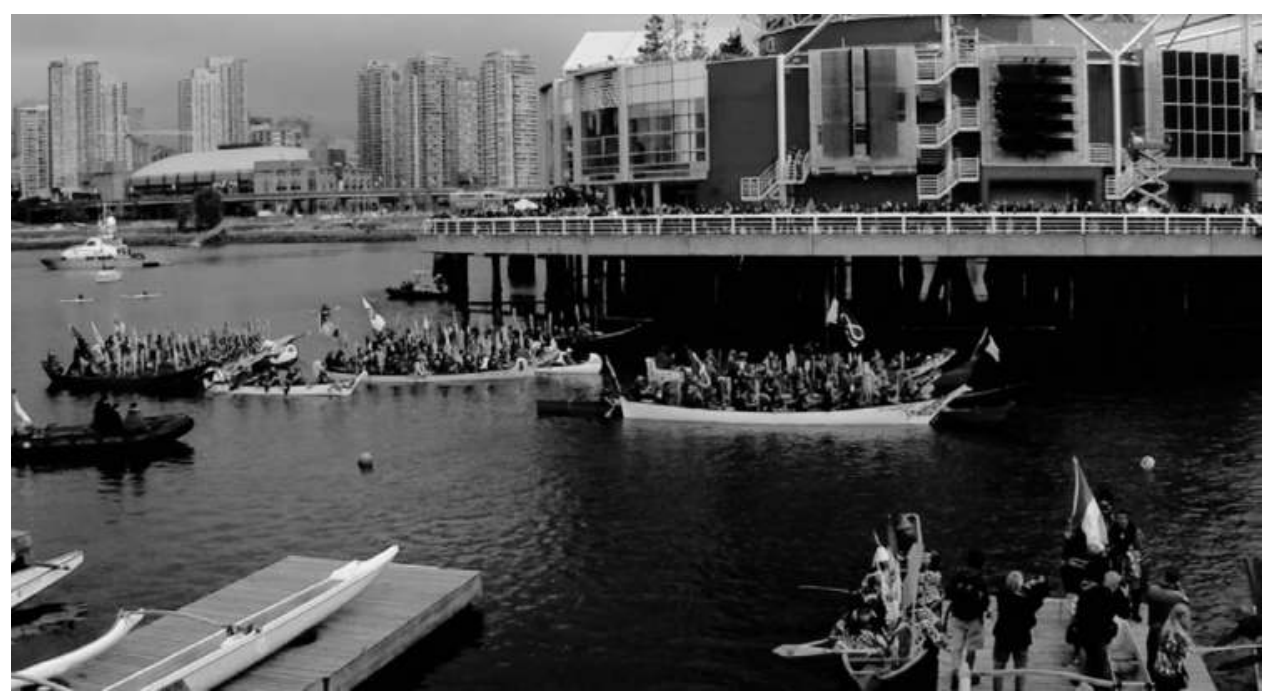

Figure 1: First Nations Canoe Gathering, Vancouver 2013. Photo by Beverley Diamond.

Performances assert the sovereignty of their own legal traditions, including clan organization, and confirm ownership of the land in traditional Indigenous contexts, but also in Indigenous-settler contexts. ${ }^{19}$

Performance as law was enacted at the highly public canoe gathering within the City of Vancouver prior to a national event of the Truth and Reconciliation Commission. I had the privilege of attending the event. The venue was a space where many people walk or bicycle to work, on unceded land of three First Nations: The Musqueam, Squamish, and Tsleil-Waututh. The canoe gathering brought over forty dugout canoes up False Creek into the heart of the province's capital city. Dugout canoes were such a rarity some decades ago that the Museum of Anthropology (at the University of British Columbia) exhibited a canoe described as the work of the last artist to carry the knowledge needed to make such magnificent vessels. But the skill has been retaught as successive fleets of dozens of canoes demonstrated on this occasion. While several hundreds of us-Indigenous and settler-staked out space at the railings all around the Science Centre and other borders of False Creek, many other

19 The Wet'suwet'en community at Unistoten in British Columbia has posted many videos documenting their responsibilities as water protectors and their stewardship of the salmon. Those responsibilities put them in opposition to companies who propose pipe lines across their territory. Some videos on their website include dance performances of individuals wearing clan symbols on the bridge that marks the entrance to their territory. This is indeed a performance of refusal on the brink of violence. http:// unistoten.camp/ (07.04.2019). 
passersby in transit were also "present" in varying degrees. The large space and disparate crowd struck me as challenging circumstances for protocols performed often in more intimate settings. How does the scale of events recast protocol, recast its affect, I wondered.

Commissioners of the Truth and Reconciliation Commission-appointed by the federal government of Canada-were in the lead canoe of the first "fleet" to approach the shore. The canoes were visually beautiful. Many of them had beautiful carved and painted artwork: clan symbols or colours that represented particular communities. Some canoes, however, had the logos of corporate sponsors. People, similarly, made autonomous choices as to how to present as Indigenous on this occasion. There were traditional button blankets and cedar hats among others who chose casual or business attire. The lead canoes were welcomed by matriarchs of each of the three host nations. The Chiefs of those nations then offered welcomes, not speaking directly, in two cases, but through an assistant who served as the speaker. I wondered whether the female energy of the matriarchs and the deflection of chiefly authority through a second speaker were protocols long used to signal peaceable encounter. The chief Commissioner, Justice Murray Sinclair, stood in his canoe, prior to landing ashore, brought greetings in his (Anishnabe) language and asked representatives of each of the three First Nations whose land they approached for permission to come ashore. In this way, he performed humbly as a guest ${ }^{20}$ but also made a strong public statement that Indigenous nations, not the nation state of Canada, were the sovereign authorities. The host First Nations welcomed the visitors to their land with many songs, both traditional and modern, and the paddlers added to the sonic energy by pounding the floor of their canoes with up-turned paddles: the emcee called out "Let's make the ocean thunder today." The host nations offered many acts of caring on the grounds where canoes came ashore: an area for elders that could accommodate wheelchairs, health workers and volunteers who were ready to assist but who also gave out information about places to get food, for instance. Caring was also evident by the very presence of so many canoes in support of the survivors who would testify in the days to follow. Among the fleets to arrive later were three international canoes who voiced their support for IRS survivors, sometimes by referencing parallel experiences of colonialism. The Aboriginal Australian canoe represented the Australian Stolen Children Association. A Mayan delegation offered a song that was very well received. The head of the Assembly of First Nations, Shawn Atleo, referenced the importance of the TRC hearings to follow:

20 There is relatively little literature on Indigenous concepts of "guesthood" in North America, although more has been published elsewhere, particularly in relation to Maori concepts. Particularly relevant to my discussion here, however, is work by Dangeli (2016). 
we've arrived here on your shores to stand with every single survivor to tell you: This is your moment for healing and for truth telling. The emcee enjoined us to "be of one mind." But the celebratory atmosphere was not appreciated by all. I overheard occasional comments such as "I don't like this. What we need to do is show our fists.

Vancouver, British Columbia: Pipeline Protests

The protocols at the canoe gathering form an interesting point of comparison with Indigenous performances at the numerous pipeline protests in the Vancouver area, protests that have intensified since 2016, and particularly in March of 2018 as a deadline for work on the pipeline was imminent. ${ }^{21} \mathrm{I}$ know these only through extensive news media and youtube videos. I thought about what was visible and what was audible at each event. How they were gendered somewhat differently from the canoe gathering, and how Indigenous cultures were positioned and presented in the many online videos.

While the purposes of the two Vancouver events might seem to be starkly contrasting, Indigenous participants at both events used similar kinds of "storied performances" to achieve their ends..$^{22}$ But there was, as I observed the first event and viewed the digital material available for the second, very different kinds of "apprehension"frameworks for and responsibilities of viewing, hearing, feeling — suggesting very different affective responses.

At both events, leaders spoke to issues of sovereignty. In the case of the canoe gathering in False Creek, Commissioner Sinclair modelled nation to nation relations among Indigenous landholders, as he asked to come ashore with humility that belied his position as the head of the federally appointed TRC Commission. During the pipeline protests it is also the nation state that is at issue. One leader parodied the Canadian national anthem by referring to the government's belief in "our home on Native land." ${ }^{23}$ In an April 2018 edition of the TV program "Nation to Nation" on the Aboriginal Peoples Television Network, Indigenous interviewee Kanahus Manuel referenced the problematic concept of "terra nullius" ${ }^{24}$ when she said "Canada is

21 In a move to deflect attention from Kinder Morgan, the Canadian government purchased the pipeline in May 2018. This, of course, evoked very strong reactions from protestors although the anti-protest movement supported the government tactic.

22 I acknowledge that Indigenous views on "development" vary in relation to many factors but there is consensus about the autonomy of Indigenous decision making.

23 The national anthem lyrics are "Our home and native land."

24 Literally "nobody's land," this phrase was used in colonial documents to assert that settlers had the right to take land for their own use.

I 28 
based on a legal fiction," one that underpinned the long history of settler colonialism.

The gendering of Indigenous political activism is distinctive. While the importance of elder women was recognized by the matriarch's greetings at the canoe gathering, that event honoured elders in particular. At pipeline protests, on the other hand, Indigenous women and youth are often in the majority on the front lines. This strategy of placing women in vulnerable positions in the hopes that police and other authorities will be less violent was also used at, for instance, the Standing Rock protests in the U.S. However, reports suggest that Indigenous protestors have been treated more aggressively than non-Indigenous protesters; they have been targeted for arrests, subjected to violence, and detained in prison to a larger extent. ${ }^{25}$ Furthermore, the highly visible position of Indigenous protestors on the front lines, wearing regalia and playing hand drums, also suggests to me that they are bearing the affective and physical burden of action, of being cast as responsible for protest, even though there are huge numbers of non-Indigenous protestors as well.

Indigenous front-line protestors sing and play frame drums and sometimes stop to dance to assert the sovereignty of their community, clan or family affiliation. Kimiko Karpoff, a member of a delegation of leaders from different faith traditions who joined the protests in the spring of 2018, wrote about the audible: "It was the singing that stood out for me. Singing as resistance. Singing as a spiritually grounding and communally uplifting practice to calm tension and support the people on the frontlines who had put themselves forward for potential arrest." ${ }^{26}$ It is not clear whether she referred to singing within the church delegation or to Indigenous singing, since the Indigenous singing is hard to hear unamplified in a noisy crowd. Drum sounds carry further. While drum beats have often been described as positive energy_-"heart beats"-in Indigenous contexts, some settler listeners (in my experience) invoke negative stereotypes of aggressivity in response to drumming, particularly without hearing singing. Many news media representations of the protests diminish or mute the audible (particularly singing). ${ }^{27}$ Several video taped news stories begin with a few seconds of Indigenous drumming but shift quickly to non-Indigenous commentary. I suggest that these media influence the public's listening practices more generally. In some cases, settler artists replicate the news media's strategies. For example, in a video of a clever protest song ("Stephen Harper Song" written in 2014 prior to the election of the current Liberal government), the song-writer shows images of Indigenous drummers but with the

25 The aforementioned APTN interview with Kanahus Mauel was one such report.

26 https://www.ucobserver.org/environment/2018/05/singing_pipeline_protest/.

27 There are increasing numbers of Indigenous news commentators and interviewers on Canadian media. At the time of writing, the Aboriginal Peoples' Television Network is available without special subscription to all Canadians as is a daily radio showed entitled Unreserved. Major networks interview Indigenous leaders often but words are privileged over the airing of performed protocols. 
sound muted, even though she does include the sound of antiphonal shouts of "Power" within a scene of non-Indigenous protestors. ${ }^{28}$ Sonic Indigeneity, then, is often referenced visually but not acoustically. Viewers do not hear the assertions of sovereignty, nor the invitation to relationality that Indigenous protocol performs.

This contrasts sharply with the canoe gathering, where paddlers responded to song by sounding back with their oars turned upright in the canoe and where even the ocean was invoked to amplify the celebration, where the participants acknowledged the way in which sonic vibration activates all bodies present, human and non-human. On that occasion, songs of welcome were very clearly audible with the fine technical support available. Repertoire was diverse, with some old songs first and later songs in more modern styles. ${ }^{29}$

I came away from the canoe gathering with a renewed sense of responsibility. On the other hand, I watched the digital media for the pipeline protest with growing anger at the way Indigenous elders were largely seen but less often heard, but where they seemed to be given the burden of responsibility that should be shared by all who believe fossil fuel development should end.

\section{Protocol and the Long Durée}

As I've described, when media report on meetings between, e.g., government representatives and Indigenous leaders, the performances are often omitted or rendered inaudible. This, I believe, reflects the mainstream non-Indigenous view that "arts" are not part of "politics" or "negotiation." Regrettably, such a miscomprehension is both disrespectful and counterproductive. The loss of the performances, feasting, and speeches (and other elements depending on the community traditions) that prepared participants for meetings or ratified their decisions are regrettable effects of settler emphases on written agreements, both past and present. Performances of protocol conducted at intra- or intercultural meetings are not fixed forever as a signature on a document is, but require regular renewal to strengthen relations. In the Northeast, for instance, earlier diplomatic relations were marked by an exchange of wampum belts, the purple and white designs of which were symbolic representations of political, social and spiritual involvement in the negotiations. The wampum beads, made from the

28 I don't mean to criticize the song writer, Alishia Fox, whose song is politically astute and clever, and who may have had little control over the video production.

29 I was a visitor in a region where I don't have personal friendships with the Indigenous participants and had no way of knowing what the specific song choices were. I do note that, in her writing about protocol of the Squamish First Nation, Dangeli notes the requirement to "acknowledge the presence of ancestors by singing ancestral songs before sharing newly composed songs" (2016: 78).

I3O 
shells of the quahog clam, were said to need renewal, to need polishing or cleaning regularly (Rath 2014). In recent years, the need for on-going work of reparations is also sometimes signalled as it was in a naming ceremony (2017) in which the Tsuu T'ina First Nation of British Columbia gave a name to the current Canadian Prime Minister Justin Trudeau: the name translated as "the one that keeps on trying." 30

Part of that on-going process will require that non-Indigenous "settlers" must think about ontologies and particularly about the invitation to relationality that Indigenous ontologies extend. Rather than the media muting of sonic expression, how might we learn to listen relationally, to listen in order to apprehend the "affect" of protocol. For each of us, which vocal sonorities signal humility or arrogance? Anger or care? Can we begin to hear family lineages in song? What does "song as law" mean for broader intercultural exchange? ${ }^{31}$ How are visual and aural expressions demanding different kinds of response and action?

Phenomenologists of sound and other music scholars (including myself) have often written about the differences of aural senses in related to other senses. Sound is inherently relational. It enters the bodies of listeners, and vibrates the total environment in what Jeff Todd Titon has called "resonance." Katherine Young notes that because sound travels through the body, the aural is "a world in motion, a world of action." 32

My central question in this paper implicates sound and voice in relation to the right of refusal as a starting point for a productive Indigenous-settler discussion in the context of unsettlement. I felt the intensity of a Christian hymn that promised futurity at the moment where Labrador Inuit were using the country's legal system to challenge the Government of Canada's problematic definition of who counts as a "survivor" of residential schools. I felt the warmth and respect for sovereignty at the False Creek canoe gathering as a witness to a meeting of First Nations, albeit an event leading to hearings in which many survivors also refused to participate. But I note with distress the ways in which sound and song are muted or ignored, particularly by the media, in contexts such as contentious environmental protests. Affective response is denied. This muting is a severe rejection of the relationality that Indigenous sonic performance in particular affords. Settler entitlement is the dominant state of feeling when settler voices are privileged. Listening, the sense that is by its very nature pervasive and action-oriented, is simply not used productively in many situations such as the

30 An excerpt is viewable online: https://www.youtube.com/watch?time_continue=5\&v=iipOsjTrGMM.

31 Dangeli (2016) has addressed how proper guesthood might be enacted and how issues of song appropriation need to be addressed. Reed (2017) and Noble (2008) write about contrasting cultural property regimes that recognize, for instance, "owning as belonging" as Noble describes.

$32 \mathrm{My}$ references here are from notes made at a recent Phenomenology and Music conference at Memorial University in June 2018 where Jeff Todd Titon and Katherine Galloway Young were presenters. An anthology from this event will appear in due time. 
pipeline protests that I described. What might be the future protocols for dispute resolution, for restoring balance when violence (actual or symbolic) is encountered? As the concept of the Anthropocene is more widely discussed, there is evidence that growing contingents of the broader society understand relationality beyond human sociality. However, the differences in new post-human worldings and particularly the responsibilities entailed are vast. How might a more intense sonic attentiveness help forge a discussion about such matters?

References

Aboriginal Peoples Television Network. 2018. Nation to Nation. "Interview with Kanahus Manuel.” April 2018. https://www.facebook.com/APTNNews/videos/10155697695208772/ (07.04.2019).

Ahmed, Sarah. 2014. The Cultural Politics of Emotions. $2^{\text {nd }}$ edition. Edinburgh: Edinburgh University Press.

Augustine, Stephen. 2017. Learning from the Knowledge Keepers of Mi'kmaqi. Sydney: Cape Breton University. On-line course. https://www.cbu.ca/indigenous-affairs/unamaki-college/ mikm-2701/ (07.04.2019).

Bell, Catherine \& Val Napoleon. 2008. First Nations Cultural Heritage and Law. Case Studies, Voices, and Perspectives. Vancouver: UBC Press.

Blaser, Mario. 2014. "Ontology and indigeneity: on the political ontology of heterogeneous assemblages." Cultural Geographies 21/2: 49-58.

Dangeli, Mique'l. 2016. "Dancing Chiax, Dancing Sovereignty: Performing Protocol in Unceded Territories." Dance Research Fournal 48/1: 75-90.

Fox, Alishia. N.d. "Stephen Harper Song. Burnaby Mountain." https://www.cbu.ca/indigenousaffairs/unamaki-college/mikm-2701/ (07.04.2019).

Karpoff, Kimiko. 2018. "A Kinder Morgan Protest in Photos and Song." In Broadview. 28 May 2018. https://broadview.org/the-kinder-morgan-protest-in-photos-and-song/ (17.05.2019).

Latour, Bruno. 1993. We Have Never Been Modern. Cambridge, MA: Harvard University Press.

Mackey, Eva. 2014. "Unsettling Expectations: (Un)certainty, Settler States of Feeling, Law, and Decolonization." In Canadian Fournal of Law and Society / Revue Canadienne Droit et Société, 29. 235-252 http://journals.cambridge.org/abstract_S0829320114000106 (12.05.2019)

2016. Unsettled Expectations. Uncertainty, Land and Settler Decolonization. Halifax: Fernwood.

McAllester, David. 1954. Enemy Way Music. A Study of Social and Esthetic Values as Seen in Navaho Music. Cambridge, MA: Peabody Museum.

Miller, J.R. 2004. Reflections on Native-Newcomer Relations. Selected Essays. Toronto: University of Toronto Press.

$\mathrm{I} 32$ 
Noble, Brian. 2008. "Owning as Belonging/Owning as Property: The Crisis of Power and Respect in First Nations Heritage Transactions with Canada." In First Nations Cultural Heritage and Law, C. Bell and V. Napoleon, eds. Vancouver: UBC Press, 465-88.

Porcello, Thomas, Louise Meintjes, Ana Maria Ochoa Gautier, and David Samuels. 2010. "The Reorganization of the Sensory World." Annual Review of Anthropology 39: 51-66.

Rath, Richard Cullen. 2014. "Hearing Wampum. The Senses, Mediation and the Limits of Analogy." In Colonial Mediascapes. Sensory Worlds of the Early Americas, Matt Cohen et al, eds. Lincoln: University of Nebraska Press, 159-75.

Reed, Trevor. 2016. "Who Owns Our Ancestors' Voices? Tribal Claims to Pre-1972 Sound Recordings." Columbia fournal of Law and the Arts. 40: 275-310.

Regan, Paulette. 2010. Unsettling the Settler Within. Indian Residential Schools, Truth Telling, and Reconciliation in Canada. Vancouver: UBC Press.

Rifkin, Mark. 2011. "Settler States of Feeling: National Belonging and the Erasure of Native American Presence." In A Companion of American Literary Studies, Caroline Evander and Robert Levine, eds. Hoboken, NJ: Wiley/Blackwell, 342-355.

Sable, Trudy and Bernie Francis. 2012. The Language of this Land, Mi'kma'ki. Sydney, NL: University of Cape Breton Press.

Simpson, Audra. 2014. Mohawk Interruptus. (Political Life Across the Borders of Settler States). Durham: Duke University Press.

Trigger, Bruce. 1985. Natives and Newcomers. Montreal: McGill Queen's University Press.

Truth and Reconciliation Commission of Canada. 2015. Truth and Reconciliation Commission of Canada: Calls to Action. Volume 3 of the Commission's Final Report. Winnipeg: Truth and Reconciliation Commission of Canada.

Tuck, Eve and K. Wayne Yang. 2012. "Decolonization is not a metaphor." In Decolonization: Indigeneity, Education \& Society 1/1: 1-40.

Younging, Gregory. 2018. Elements of Indigenous Style. N.p.: Brush Publishing.

\section{Online Sources}

https://www.youtube.com/watch?v=j2Lv21Ktz84 (07.04.2019).

http://www.austlii.edu.au/au/journals/UNSWLawJl/1999/16.html (07.04.2019).

https://www.wipo.int/export/sites/www/tk/en/databases/creative_heritage/docs/abc_cultural_ protocol.pdf (07.04.2019).

https://www.oxfam.org.au/wp-content/uploads/2015/11/2015-74-atsi-cultural-protocols-update_web.pdf (07.04.2019).

http://www.tetaurawhiri.govt.nz/maori-language/tikanga-maori/ (07.04.2019).

https://www.englishnewzealand.co.nz/news/marae-powhiri-protocol-customs/ (07.04.2019).

https://www.sametinget.se/105173 (07.04.2019). 
https://www.commisceo-global.com/resources/country-guides/taiwan-guide (07.04.2019). https://www.commisceo-global.com/resources/country-guides/taiwan-guide. (07.04.2019). https://www.americanindigenousresearchassociation.org/wp-content/uploads/2016/11/Bomberry-AIRA-2016.pdf (07.04.2019).

https://www.youtube.com/watch?time_continue=5\&v=iipOsj TrGMM (07.04.2019). http://unistoten.camp/ (07.04.2019).

https://www.ucobserver.org/environment/2018/05/singing_pipeline_protest/ (07.04.2019).

Abstract

Ethnomusicologists have, thus far, written extensively about Indigenous ontologies but less about the ways divergent ontologies shape intercultural diplomacy. This article attempts to think through several such spaces of intercultural encounter. It considers how Indigenous protocol plays a role in promoting respectful relations. But it also reflects on situations where a failure to consider the affect of protocol-related performances may be disrespectful and counter-productive. There is a need, then, for intercultural dialogue about the clashes of perspectives, and the affect of performances that surround difficult moments of meetings, when one way of being in the world (i.e., ontology, simply defined) meets another and seems utterly incomprehensible. Sometimes such incommensurability is rooted in language: that song or story are "law" for many Indigenous groups in North America (and elsewhere), for instance, is often a confusing notion for Euroamericans. This formulation is already stimulating action-oriented discussions about access to archives, and appropriations of Indigenous song. At other times, forms of relationality are at stake. For instance, many Indigenous expressive cultures assume kinship with non-humans, spirits, and other life-forms in a broad ecological system that differs fundamentally from, e.g., those who see the earth's resources as economic investments, or those promoting "creative city" initiatives that see the arts as a vehicle for prosperity while disregarding human relations with other life forms. The affect of performances that assert presence and sovereignty on the one hand or guesthood on another is an important consideration when divergent viewpoints are at issue. In some cases, a focus on "affect" may help to reduce misunderstanding, while in other cases it may encourage respect for the performers who assert their values, understandings, and sovereign rights. 


\section{Reflections on the Epistemic Foundations of Music in Modern India through the Lens of Caste: A Case from Maharashtra, India}

Within and outside academia, representations of Indian music are often reduced to or depart from classical music, whereby Hindustani and Karnatic are assumed to be the most ancient, sacred and complex traditions without much interrogation about their invention in the $19^{\text {th }}$ and early $20^{\text {th }}$ centuries. Extant scholarship on the music of India/South-Asia, particularly emerging from disciplines like musicology and ethnomusicology, seems to have not engaged enough or often overlooked caste as a valid analytical framework that can offer insights beyond a ghettoised identity of 'the oppressed' or socio-economic relations. The histories and historiographies of caste and music, their close links with race, colonialism, gender and sexuality, their contemporary manifestations in postcolonial societies and the voices that have resisted caste remain seriously underexplored. Many contemporary studies seem to confuse caste with class and have frequently used both terms interchangeably, while others have entirely avoided the use of caste-specific terms to describe musical authorship and instead used terms such as an 'educated middle-class' or 'elite population' for brahmins or 'marginalized', 'disenfranchised', 'underprivileged communities' for Dalits. Research on the so-called folk traditions and/or hereditary musicianship (of Muslim and Dalits/other oppressed caste communities) often uncritically assumes musical categories and classifications with a few exceptions (e.g. Fiol 2015, Katz 2017). Studies that have examined music and dance from the perspectives of nationalism and post-independence caste politics have to a certain extent shifted the lens towards caste (e.g. Junghare 1983, Qureshi 1986, Thompson 1991, Babiracki 1991, Bakhle 2005, Weidman 2006, Soneji 2012, Schultz 2013, Sherinian 2014, 2015, Fiol 2015, Stirr 2017, Putcha (upcoming) et.al). However, much ethnomusicological research has yet to historicise and theorise caste from the perspective of music, sound and embodiment (particularly of race, gender and sexuality). Sound/music can be a significant departure point to understand caste relations, meaning-making processes and affective politics in regional contexts. Such analyses could further help in theorising sonic epistemologies of caste. Soundscapes of anti-caste revolutions that have been thriving for centuries in different parts of India have much to offer in this regard.

In this essay, I foreground caste as an essential framework for the study of music in India/South-Asia. I locate sonic, pedagogical and epistemic bounds of music as deeply 
embedded in the intersections and hierarchies emerging out of caste, race, gender, sexuality and religious nationalism that peaked in the late $19^{\text {th }}$ and early $20^{\text {th }}$ centuries. I present critical reflections on the altered epistemic foundations of music in $20^{\text {th }}$ century India by drawing on my field research (2015-2017) with musicians in an anti-caste movement mobilised by Dalit or formerly 'untouchable' outcaste populations in the contemporary western Indian state of Maharashtra. This movement presents alternative sonic imaginings by reclaiming hereditary musicianship through the vernacular (Marathi), musical instruments, voice, performance styles and body politics. It offers literary interventions through song that can be treated as counter-epistemologies to dominant caste or brabmanical discursive and performative representations. This anti-caste movement ultimately necessitates a caste-based examination of music/ musicianship which helps in formulating decolonial interventions for the study of music in India/South-Asia.

Music/musicianship coerced as a hereditary occupation on certain Dalit communities was commonly associated with and confined to religious performance or entertainment, since Dalits were shunned from accessing any form of written or valued knowledge. In the late $19^{\text {th }}$ century, Dalit communities in western India leveraged the same coerced musical labour and aesthetic to mobilise against caste, Hindu orthodoxy, brahmanism and to put forth an equalitarian philosophy (see Omvedt 1976, 1994, 2006, Rege 2002, Thakur 2005, Patil 2017). For more than a century, this tradition has been consistently carried forward in contemporary Maharashtra. While this anti-caste musical tradition has evolved with distinct genres and subcultures, this essay will particularly look at the vidrobi shabiri jalsa (rebellious music gatherings) which emerged in the early years of the $21^{\text {st }}$ century. Vidrobi shabiri jalsa, a musical, literary and dialogical theatrical performance is designed, formulated and performed by Dalit youth in contemporary Maharashtra and has powerfully reclaimed sonic and cultural politics as well as histories and presents for nearly two decades. I will particularly focus on Shital Sathe, a shabir (songwriter/composer/ singer/drummer) and one of the authors of vidrobi shabiri jalsa to examine how she articulates liberatory politics and asserts new mechanisms of building solidarity and care in the perpetual state of coloniality for Dalits in postcolonial democratic India. The surveillance, censorship and incarceration of Shital Sathe, her partner and many others in the last decade testify to the intensifying caste apartheid at the hands of the casteist Indian democratic nation-state. It further raises concerns about Dalit musicians' right to citizenship. I therefore locate musicianship as deeply embedded in the existential politics of survival of Dalits as opposed to what is often essentialised as 'protest' music. Drawing on insights offered by Shital Sathe as well as my own experiences as a former Hindustani classical music student/practitioner, this essay will highlight how music/musicianship, when examined through the lens of caste,

136 
can offer a radical critique of the ways in which we practice, understand and examine knowledge in/of India.

\section{'A Dalit is dead, Democracy is dead!'}

Writing in Brahmin's house, grain in Kunbi's house and singing-playing

(musical instruments) in the house of Mangs and Mahars

(A Marathi proverb) ${ }^{1}$

About four months into my fieldwork in January 2016, the suicide of Rohith Vemula, a Dalit PhD student at Hyderabad Central University (HCU), sparked protests all over the country, especially on university campuses. Rohith was an activist in the Ambedkar Students Association (ASA), ${ }^{2}$ committed to the anti-caste equalitarian philosophy and democratic politics. Days after being suspended by the university authorities over his continued political differences with the ABVP (Akbil Bharatiya Vidyarthi Parishad), the right-wing nationalist student association affiliated with its parent organisation RSS (Rashtriya Swayamsevak Sangh) and the political party BJP, Rohith, along with four other research scholars from the ASA were indicted of violence by the university administration. The administrative enquiry report, however, did not show any evidence of violent behaviour on Rohith's part, also echoed by his friends and fellow activists. Rohith, along with the other accused, were evicted from their hostels, barred from entering public spaces in the university, and participating in student union elections.

These ongoing clashes prevented Rohith and his comrades from receiving their scholarship funds for about seven months. It was shocking to learn in the death proceedings about the degree of complicity of the university administration in ostracising Dalit students over student politics, especially given that there was no evidence of violence or bullying on the part of Rohith or his association. A series of letters and communication between the administration, local BJP leaders as well as the MHRD (Ministry of Human Resource Development, Government of India) later revealed that the decision for this vindictive action was taken at the directive of the combine of the right-wing student association and the local right-wing political party (BJP).

1 Brabmin, kunbi, mang and mahar are names of caste-groups in western India, traditionally known to be the knowledge producers/authors/writers; farmers; cleaners/labourers/musicians respectively.

2 Dr B.R Ambedkar was the chief author of independent India's Constitution, a civil rights activist, member of a Dalit caste and the most significant leader of Dalit communities of the 20th century. 
On $17^{\text {th }}$ January 2016, the fourteenth day of a sleep-in strike against the authorities, Rohith hanged himself using a blue protest banner (the colour of the Ambedkarite movement) in his friend's hostel room on the university campus and left a letter that shook the country to no bounds. It revealed that during the time he was ostracised from the university, he had written several letters to university authorities for a fair investigation with the students from ABVP and had appealed for a conversation, a dialogue in the preceding months. No attention was given to these letters. Shocked, bereaved and enraged university campuses all over the country protested against the administration and the vice-chancellor and demanded investigation of the obvious political influences in this caste-based atrocity.

In the following months, student movements drafted and put forth a proposition for implementing 'Rohith Act' which would ensure legislative protection for students from marginalised communities in higher educational institutions against any form of discrimination. Given all the intricacies of this matter and the conditions in which the death of Rohith Vemula occurred, the haste with which Rohith's body was sent for autopsy and cremation, the student movements rightly termed the incident an 'institutional murder' to hold the university authorities accountable for their actions. The disappearance of the university vice chancellor-among other stakeholders-following Rohith's death was testimony to their complicity in the matter. Along with students' movements across the country, anti-caste activists, including musicians, played a key role in demanding and asserting the right and access to knowledge and institutional education for Dalits. Robith is gone, a Dalit is dead, written and composed by Shital Sathe, became almost an anthem in the weeks to follow. It was extensively shared on social media and repeatedly performed by anti-caste cultural activists all over the country. 
नाही शिकायचं तुम्ही राबायचं

मनुस्मृतीनं घातली बंदी

वेद ऐकिले तर मंत्र वाचिले तर

शीस वतलय कानामंदी

पिढ्यानपिढ्यांची मक्तेदारी

विद्येची ठोकशाही

रोहित गेला दलित मेला

मरते ही लोकशाही!

करण्या संशोधन गेलं विद्यापीठी

बाबासाहेबांचं लेकरू खरं

जातीवाद्यांच्या हो दुखलं पोटामदी

नाही मनाला वाटलं बरं

हाकलून देउन अपमान करून

दाखवली गुंडाशाही

रोहित गेला दलित मेला

मरते ही लोकशाही!
You cannot be educated, You must only toil

Manusmriti banned us from learning!

If we heard the Vedas, chanted the verses

You poured molten lead in our ears

Generations of control and power

A forced rule on knowledge!

Rohith is gone, a Dalit is dead

Democracy is dead!

(He) went to the university to undertake research

An honest child of Babasaheb

The casteists felt envious

And did not like it

They insulted and threw him out

And displayed their rowdiness

Rohith is gone, a Dalit is dead

Democracy is dead!

(Selected verses; written and composed by Shital Sathe; translation by author)

The piercing words of this song invoke not only the oppressive trajectory of the brabmin's control and monopoly over educational institutions but also that of dominant castes at large in administrative structures. It points to how they collaborate to retain power through the coercive caste structure. Despite affirmative action procedures in post-independence India (known as the reservation system) to ensure equal access and opportunity for historically oppressed and marginalised castes in mainstream educational structures, democracy remains fictive and hopeless for the majority populations of India (see Omvedt 1990). ${ }^{3}$ The postcolonial Indian nation-state seems to have ensured democracy, equal rights and access for a certain class of people who define and govern institutions, society and knowledge. Rohith's right to education was violated and so was his assertive anti-caste political presence on the university campus. How could the university administration ostracise Rohith and his Dalit friends with impunity?

3 Salma Rahman's (2017) report reveals a series of eight student suicides from oppressed caste communities on Hyderabad Central University campus in preceding years. This was the $23^{\text {rd }}$ suicide of a Dalit student in India since 2007 according to this report. 
In the following months, as I performed this song with Shital Sathe on a number of university campuses across the country, I was deeply confronted with complex issues around the idea of knowledge itself: its nature, authorship, value, authenticity, the politics of merit, accessibility and representations. The Marathi proverb quoted at the beginning of this section reveals the extent to which knowledge is understood as divided and hierarchised according to caste. Through this proverb, Gopal Guru (1997) and Sachin Mali (2013) elaborate on Ambedkar's observation that caste ensures the division of labour and labourers. Rohith, a Dalit student from the Mala caste group of Andhra Pradesh in south India, was ostracised for asserting his right to freedom of expression, his right to engage in student politics. I learnt that the Mala caste group had not only been marginalised to the degree of extreme poverty, but one of their occupations apart from bonded labour was also to entertain the village during harvest season through acrobatics and performances of songs (Rajpramukh 2013).

As I increasingly reflected on the entanglement of my own brabmin caste positionality, my ease of access to public spaces and educational institutions, particularly my training in Hindustani classical vocal music and my present location within academe as an ethnomusicologist was all tragically revealing. Born and brought up in a brabmin middle-class family in urban India, I had hardly ever given a thought to the easy access I had to institutional education, when non-brahmin caste groups have had to prove their caste identity to firstly secure a seat in the reserved quota in state institutions. My smooth navigation in the public sphere, in educational institutions and the 'invisibility' of caste around me was indeed a privilege I could afford like generations of brabmins before me.

I could recognise the stark invisibility of caste in Hindustani classical music sphere that I navigated since childhood, which in retrospect was one of the most exclusionary spheres. To witness Shital, an anti-caste activist with a master's degree in Education, singing of the death of democracy while offering an ode to a bright, passionate Dalit student and Ambedkarite activist who was dead owing to unbearable ostracization, demanded profound contemplation on my part and many like me. ${ }^{4}$

4 Accessibility to institutional education in India has remained an issue deeply entangled with caste for centuries despite the struggles of Dalit leaders in drafting and recommending affirmative action policies in colonial and post-independence India. These affirmative action policies in the form of reserved seats/ quotas in state/civil services, elected bodies and educational institutions have a long history in India. Despite a long struggle, the implementation of reservations according to Article 15 and 16 (Right to Equality) in the Indian Constitution effective since 1950, was only undertaken in a substantial manner in 1993, after the Mandal commission's research and recommendations in the late 1970s. Affirmative action in the form of reserved quotas was introduced to encourage the historically disadvantaged and oppressed communities, the shudras and ati-shdras—Scheduled Castes (SC), Scheduled Tribes (ST), Other Backward Classes (OBC). It is important to understand that the reservation policy is directed 
If caste has truly ensured the division of labour and labourers, why are the specialised knowledges of oppressed castes not represented by those caste groups in the mainstream today? If music has been a caste-hereditary occupation, why is classical music, film music and mass-mediated music predominantly practiced, represented and mainstreamed by brabmins? What role has caste played in ensuring brahmin's monopoly over (musical) knowledge, music's classicisation, institutionalisation and devising a religious casteist musical pedagogy? What role has nationalism, modernity and colonialism played in classifying music? Why are caste-hereditary musical, theatrical and dance forms like tamasha, lavani, gondhal of Maharashtra placed in opposition to the classical and deemed as folk music today? What sonic cues offered by Shital can we listen to when examining the politics of caste, race and gender that have shaped epistemologies, theories, pedagogies and discourses of music today? I answer these questions firstly by looking at the politics of caste and music in modern India that will guide us in deciphering the sonic markers offered by Shital Sathe.

\section{Music, race, caste and gender in the making of Indian modernity}

The caste system vindicated on the basis of ancient religious scriptures has prevailed in India for centuries and determines a socio-economic hierarchy wherein individuals inherit status based on descent and occupation. Such a structure is preserved through endogamy and is characterised by a descending scale of ritual purity, (in)accessibility to written knowledge and education, segregation of food cultures and restrictive accessibility to public/private spaces, among other markers. Those who are at the receiving end of inhumane coercion and violence as a result of this caste apartheid are predominantly Dalits. ${ }^{5}$ Brabmins, the authors of ancient religious texts, have pre-

specifically towards identifying and acknowledging the historically perpetuated discrimination, oppression and exclusion of Dalit-bahujan- adivasi communities from learning, creating, teaching and working in the 'mainstream', which has historically been designed, created and stringently controlled by brabmins. Over the decades following India's independence, countless struggles of Dalit communities to retain the reservation system, to assert and claim their constitutional right, are a testimony to the strong hold of brabmins over knowledge and its self-proclaimed superiority. Caste remains one of the most dominant and controversial bases for reservations in India. A number of violent protests across India followed after the introduction of reservation policies, especially in the 1990s-the anti-Mandal agitations and Marathwada University agitations being the most well-known national examples. These protests led and organised by dominant castes (mostly brahmins), actively resisted and continue to resist and despise the reservation policy.

5 'Dalit', meaning ground, suppressed or broken, is derived from the Marathi language of Maharashtra. It continues to be a positive, assertive expression associated with pride, dignity and rejection of brabmanical (or dominant caste) oppression. The term 'untouchables' was introduced by the British, who also 
served their highest rank in the caste order in such a way that all other caste groups in the middle-Kshatriyas, Vaishyas and Shudras — work towards the possibility of obtaining greater power and in turn preserve caste, which principally favours brabmins, particularly the brabmin male. Women are essential to this tightly controlled endogamous heteropatriarchal structure that safeguards caste purity and are therefore doubly discriminated. Dalit women are further confronted by multiple and graded layers of oppression given their caste (Dalit), class (labourers) and gender (women) location. Coercion plays a key role in preserving caste, making Dalits the most vulnerable demographic to dominant caste violence. From 'honour killings' and lynching to brutal sexual assaults, dominant castes have historically invested in a caste apartheid that violates basic human rights and the dignity of Dalits at large and Dalit women in particular. Historical accounts (Ambedkar 1916, 1936, Patil 1982, 2005, 2006, 2010, Omvedt 1994, 2003, Chakravarti 2003, 2014, Doniger 2009, Teltumbde 2016, Viswanath 2016 et.al.) have outlined the nearly two-thousand-year old history of caste in India spanning feudal, imperial and colonial regimes and counter revolutions. ${ }^{6}$ Colonial regimes in fact leveraged racial discourses to reinforce caste in India. On the one hand, caste in contemporary India is only a continuation of a long historical legacy, and on the other prevails as one of the most invisibilised forms of discrimination in people's everyday lives.

Figueira (2002) and P.J Marshall (1970) among others show how post-enlightenment European discourses obsessed with theories of 'origin' came to India in search for justification of an Aryan myth, and in turn gave value to ancient Indian history, specifically of the Vedas during the colonial period. In so doing, a number of authors referred to ancient scriptures like the Vedas and Manusmriti and identified that the originators of Indian civilization were the Indo-Aryans, namely the brabmins, who had apparently preserved the purest Aryan strain with racial exclusivity maintained through the caste system. Arbitrary interpretations, writings and authoritative definitions of the Aryan disseminated in the nineteenth century. These were capitalised on by brahmin social reformers to mobilise public opinion that focused on the battle against modernity (Figueira 2002). In this quest, reclamation of the glorious Aryan

denoted oppressed and outcaste populations as 'Scheduled Castes', the 'Criminal Castes', 'Musician castes', 'Depressed classes' and 'Outcastes' among others while conducting the Indian census. Later, Gandhi designated the term 'Harijan' for Dalits, meaning 'the children of god', which continues to be strongly resisted by Dalit populations for its patronizing and paternalistic connotation (Doniger 2009).

6 Religious conversions have been a major part of Indian history (particularly Christianity and Islam). However, they have hardly changed caste identities, caste-based social practices and everyday cultures of people. Viswanath (2016) has strikingly shown how the persistence of caste outside of Hinduism is found in Catholic cemeteries in South India where walls are built to segregate corpses according to caste so as to avoid pollution of a fellow Christian even after death. 
past was equated with recovering an Aryan masculinity by brabmin men (Figueira 2002, Sarkar 2001, Sinha 1995 et.al.). In other words, the Aryan theory of race was interpreted as deeply rooted in brabmin masculinity, as India's subjugation was ascribed to their emasculation while attributing British colonialism to masculine superiority.

The fabrication of the Indo-Aryan was not just to establish European-Indian kin, but also to create 'the other' non-Aryans viz. outcastes and Muslims (Figueira 2002, Keating 2012). Oriental constructions of Muslims as the 'disparaged other' were presented by British colonial writers to justify colonialism (Keating 2012). The anxieties around Dalit and Muslim men in colonial India emerged also because they/their sexuality were/was viewed to be particularly dangerous, a threat to the brabmin woman, as mixing blood lines would collapse the caste order (Hasanat 2009, Gupta 2010). A number of solutions were thus presented by brabmin men to restore Aryan/brabmin masculinity. This narrative formed the basis of the nationalist ideology in the $19^{\text {th }}$ century. In this process of 'remasculinisation', the reshaping of womanhood and femininity was necessitated and reformulated through social reform (Figueira 2002). "Since identity was text-centred, the Aryanization of the modern Indian male centred on reading the Vedic canon as texts written against the female body" (ibid.: 120). Thus, caste, race and gender became inextricably entangled.

Some of the brabmin nationalists of this period are today known as the modernisers of music, particularly Vishnu Digambar Paluskar (1872-1931) a Marathi brabmin man deeply influenced by Dayanand Saraswati and B.G. Tilak, the notable voices who advocated a nationalism based on racial and territorial exclusivity, supremacy of brabmins and the Vedic religion. Featured in Bakhle's (2005) seminal work on the modernisation of music in India, Paluskar appears as one of those brabmin male figures who actively fabricated the history and pedagogy of music to hierarchise it on the basis of religion, caste and gender: music was to be rescued from the so-called ignorant classes (Muslim and Dalit hereditary musicians including devadasis, nautch girls, baijis, kunbinis and tawaifs) to reclaim what originally belonged to the Indo-Aryans/brabmins (ibid). ${ }^{7}$ The modern nation's music was classicised on the basis of religion, nota-

7 Paluskar's pedagogy, which he presented as religious or devotional (bhakti), focused on rescuing music from entertainment and transforming it into a high art form with overtly brabmanised themes. This is clear from all the different examples Bakhle (2005: 138) has investigated: reintroducing guru-shishya parampara (the tradition of lifelong subservience and loyalty of the student towards the teacher), regularly conducting poojas or worship in music schools, chanting Sanskrit prayers, singing devotional songs of Hindu deities, organising music performances at Brahmin rituals like the thread ceremony, marriage, hosting musical events on the birth anniversary of Krishna or Rama, accompanying his performances of bhajans and kirtans (devotional songs) with speeches on the Ramayana (a Hindu epic), holidays on Hindu festivals in music schools, among others. 
tion and nationalism defined by brabmins, thereby internalising and realising William Jones' (1789) oriental vision of India.

In this scheme, the aural hereditary musicianship of Muslim court musicians was blatantly co-opted and made into what is today known as Hindustani classical music. In western India, musical/theatre genres of Dalit musicians (predominantly from mang and mahar communities) like tamasha, lavani, powada were all appropriated and essentially sanitised for the consumption of the new urban brabmin middle-class through Sangeet-Natak (Marathi theatre) and placed in opposition to Victorian theatre (Rege 1995, 2002, Bakhle 2005). Brahmin middle-class women like me were actively brought into the public sphere of classical vocal music performance as proselytisers by their male counterparts (Bakhle 2005). Brabmin middle class women as singers became the saviours of culture and nation as wives and mothers who would indoctrinate their children with Hindu religious values through music (ibid.). They became the essential mark of honour and respectability. Brabmin womanhood was thus placed in opposition to the dishonourable Dalit woman who at that point was associated with an erotic form of dance and song called lavani. Brabmin women, who were stringently controlled, for whom it was unthinkable to attend school or get education until the end of $19^{\text {th }}$ century, became the mark of honour and respectability in the public sphere through their musical and gendered labour in early $20^{\text {th }}$ century. ${ }^{8}$

The performance of lavani (erotic song) by enslaved Dalit women was at peak in the preceding Peshwa empire (of brabmin rulers) of western India and formed the basis of a sustainable economy for the Peshwa state until its defeat by the British in early $1^{\text {th }}$ c. (see Chakravarti 2014, Rege 1995, 2002). Lavani composers in the Peshwa court who were mostly brabmin men fashioned womanhood on caste/gender lines. Lavanis were characterised by an overtly expressed female sexuality of the performer and a strong endorsement of the dichotomy of the whore (bateek) and the wife (saubhagyawati). ${ }^{9}$ Rege $(1995,2002)$ critically examines how the insatiable sexuality

8 Their emergence in sangeet natak and as solo artists of Hindustani classical vocal music was made possible only through the strictures that they embodied with 'proper' appearance, attire, presentation marked by an asexual, chaste and respectable affect (Bakhle 2005). Brahmin women's unapologetic, uncritical and arrogant entry into the musical public sphere while brutally marginalising Muslim and Dalit women musicians is testimony to how upper-caste women in the caste order participate in casteist projects in order to maintain their proximity to the brabmin male and preserve their power.

9 Songs included themes such as the insatiable desires of the bateek, the bateek's need for regular bodily fulfilment, her pleading to the man to visit her regularly to give her pleasure, to take her as if it was his right like he would his wife; contrasting this was the pain of separation felt by the wife (because of the husband being away at war/business or the presence of elders in the family or menstruation), the wife expressing pride in the manhood of her husband, his virility, his excessive and sometimes perverted desires, pleas to the husband to take her in her fertile period, the husband's demand for intercourse several times in a night, the wife's pleasure in motherhood, among many others (Rege 1995). 
and an inherent adulterous nature of the bateek performing the lavani was an ideological justification for the enslavement of Dalit women. Their caste-gender location enabled the Peshwa regime to usurp their sexuality in ways that were beneficial for the feudal brabmanical social and state structure. The binary construction of the wife and the whore, the brabmanic heteropatriarchal sexualities and the procurement of Dalit slaves for entertainment/sexual pleasure indicate the centrality of female bodies to the preservation of caste. Lavani performers were brutally marginalised in the following decades due to loss of patronage owing to the British takeover of the Peshwa empire and the increasing stigma around Dalit women's musicianship with the rise of nationalist ideology by the end of the $19^{\text {th }}$ century.

Dalit women in western India have traditionally been temple dancers and singers-murali, jogtin, devdasi-as part of the caste structure, and were coerced into sexual slavery or prostitution at the hands of dominant-caste men (Soneji 2012, Tambe 2008). On the one hand, hereditary music performers have been forced to follow their occupation, and on the other the caste structure allows dominant castes to utilise and appropriate this labour for any means and to any ends. The case of lavani in Peshwai, the subsequent emergence of 'honourable' brabmin women musicians and sangeet natak demonstrate how caste enables the appropriation and abandon of labour at the hands of the brahmin male/dominant caste. These processes in the $19^{\text {th }}$ and $20^{\text {th }}$ centuries are foundational to the ways in which we understand Indian music (and culture). Impacts of brabmanic nationalism similarly shaped classical Indian dance (like Bharatanatyam and Kuchipudi among others) and Karnatik music (see Weidman 2006, Soneji 2012, Putcha 2013) in other parts of India.

The history of music (and dance) is central to the reconstruction of caste, gender, sexuality and religion in the national as well as regional context. The brutal epistemic violence on Dalit (and Muslim) musicians continues to shape their lives even today (see Ajotikar 2018). Hierarchical categories of classical and folk became increasingly reinforced in this process where folk was to represent the simple, rural, exotic, authentic regional essence within the larger nationalist imagination of the 'classical' (Rege 2002). As Fiol $(2015,2017)$ and Korom (2006) remind us, equating the musical category of 'folk' with hereditary musicianship (gondhal, powada, lavani etc.) must also be read within this politics of modernity shaped by colonial authors and brabmins with the emergence of the study of folklore, an important stream of cultural nationalism. ${ }^{10}$ The construction of 'folk' further shaped colonial and post-independence regionalism in western India/Maharashtra (officially recognised as a state in 1960) and paved the way to further capitalise on it through modern technology and media. Regional and

10 I adopt the term 'popular' (meaning 'of the people') instead of 'folk' drawing on Sharmila Rege's (2002) insights on the categories of 'popular', 'mass-mediated' and loksangeet. 
national cinema and television 'reality' shows today have sanitised and repackaged lavani among other popular forms of music, dance and theatre.

Despite India's independence from the British in 1947, the formation of a new secular democratic nation-state and the eradication of untouchability and affirmative action procedures, Dalit communities nonetheless continue to experience structural inequity, violence and coercion, and are compelled to organise against the persisting caste apartheid (see Teltumbde 2010, 2016). While a number of literary and political movements (like the Dalit Panthers) have been significant in evolving anti-caste politics, cultural movements, music performances in particular, have been the vanguard of new equalitarian politics emerging out of everyday lives of people. As stated in the introduction, Dalit communities in $19^{\text {th }} \mathrm{c}$. western India leveraged their coerced musical labour and aesthetic to mobilise against caste, Hindu orthodoxy, brabmanism with Jotirao Phule's Satyashodhak Falsa (musical gatherings of Satyashodhaks or 'the community of truth seekers'). The same tradition transformed into Ambedkari falsa (musical gatherings based on Dr. B.R Ambedkar's works, activism and philosophy) in the $20^{\text {th }} \mathrm{c}$. These traditions branched out into a number of genres and subcultures (like bbimgeet, buddhageet, qawwali) within Dalit/Ambedkarite publics in post-independence India. The emergence of Marathi vidrohi sabitya sammelan (rebellious literary convention) in the late 1990s created an alternative space for Dalit and anti-caste literary voices to be heard and marked dissent from the mainstream Marathi literary conventions which for decades promoted $\mathrm{brabmin/dominant} \mathrm{caste} \mathrm{writers/poets,} \mathrm{often} \mathrm{funded} \mathrm{by}$ the state. Most of these musical trajectories largely excluded or marginalised Dalit female performers given the stigma associated with their musicianship since the $19^{\text {th }} \mathrm{c}$. Given this context, vidrobi shabiri jalsa (rebellious music gathering) in contemporary Maharashtra draws on the long musical/literary legacy of jalsas, shabiri ${ }^{11}$ and vidrobi sabitya sammelan as it represents a shift in authorship, performance and politics. It makes music one of the most crucial sites engendering counter-epistemologies as it reclaims sonic, spatial and cultural politics in contemporary India.

\section{Sonic reclamation in the vidrohi shabiri jalsa}

Shital's song about Rohith Vemula featured earlier in this essay became an important part of her vidrobi shabiri jalsa not only because it challenged and questioned the idea of democracy, equality and rights of Dalits in the Indian caste society, but also because

11 Shabiri may be understood here as an umbrella term that comprises of popular traditions of Maharashtra such as powada, tamasha, gondhal, lavani etc. Shabiri has been most prominently associated with the $17^{\text {th }}$ century 'war musical' or ballad composed for the Maratha king Shivaji of western India.

146 
caste had increasingly become a precarious issue with the rise of the BJP (Bharatiya fanata Party), the right-wing Hindu fundamentalist political party in 2014. Their nationwide popularity and electoral win followed unhindered state-legitimised violence on oppressed and outcaste groups at the hands of extremist groups. ${ }^{12}$ Previously unseen, this violence (e.g. cow vigilantism) was based on their founding ideology of Hindutva - which Wendy Doniger aptly translates as Hinduness, "a territorial, racial and fundamentalist form of Hinduism" (2009: 44). Many anti-caste activists thus termed BJP rule as 'Hindutva fascism'.

While caste discrimination was not new during the BJP tenure, its current form was certainly brazen and granted impunity to perpetrators. In the preceding rule of other political parties, mostly the Indian National Congress, caste-based discrimination in institutional settings, sexual assaults and the censorship and torture of Dalit musicians in state custody from 2005 had also proved time and again the brabmanical nature of the Indian democratic nation-state. In fact, Shital and her partner Sachin Mali (also a poet/songwriter and co-author of the vidrobi shabiri jalsa) were both accused by the Maharashtra state of having links with the Naxalite or Maoist insurgency in India and arrested in 2013 under the UAPA (Unlawful Activities Prevention Act), a draconian law that continues to be misused against Dalits. Shital was six months pregnant when arrested and was released on bail a few months later, days before she gave birth to their son. Her partner, Sachin Mali, remained in prison for almost four years to follow and was finally granted bail in 2017. Given these experiences, Shital's songs carried a strong message against the brabmanical state, especially during the tenure of the BJP.

While 'A Dalit is dead, Democracy is dead' presents a powerful commentary on the current caste politics in India, such songs/compositions shed further light on the sonic politics of caste. They show us how sound itself as an epistemology has preserved caste and how it is being employed by musicians/activists like Shital to reclaim cultural politics. While a number of sonic markers in language, voice, timbre, body politics, performance aesthetics and styles, musical instruments, lyrics/song-texts can guide us to think further about caste in a regional setting, I focus here on some of these aspects that characterise a sonic reclamation through the vidrobi shabiri jalsa (VSJ). This will also explain what makes these performances rebellious.

Like a ritual, Shital's VSJs were planned for the evening where sophisticated sound systems were set up and makeshift wooden stages were decorated with pictures of prominent leaders from anti-caste movements. After working the entire day, the tired

12 See In state after state, cow protection vigilantes pick on Dalits, Muslims by Chetan Chauhan in Hindustan Times (29.07.2016); Violence against Dalits: There is a discernible pattern to this madness by Annie Namala in Indian Express (23.07.2016) and Dalits and the remaking of Hindutva by Badri Narayan in The Hindu $(25.01 .2016)$ 
but rather excited families, the elderly, young people and children gathered for the performance. Musical instruments associated with stigmatised memories of the past were seen on stage along with electronic sounds coming out of synthesizers and octapads. Shital's announcement of the VSJ followed the assertion "we are not here to entertain you, we are here to disturb you." People applauded. All attention was directed towards her. Throughout the two-hour long performance, the song and narrative mode of presentation included consistent references to the Hindutva regime which has brought back feudalism for Dalit communities. Each reference to inflation, unaffordable food and basic necessities, the inaccessibility of schools/universities, religious violence and unemployment was followed by an applause. Shital often posed questions to which people answered in unison. She cracked jokes and mocked the brabmanism of the top leaders of the BJP and reminded people of the battles they have historically fought-many of which manifested in song that used hereditary drums, the so-called impure vernacular and poetry that resounded hope. She called for oppressed caste masses (not just Dalits) and women to critically observe their everyday lives which included casteist patriarchal exclusionary practices. After the performance, people were extremely moved and emotional, and gathered in groups around Shital to talk to her. A number of women were able to meet her and often directly shared their personal experiences and their willingness to take concrete actions within their everyday social contexts. Many young people approached her to ask how they could organise and form new VSJ troupes and whether they could learn song writing, singing and performance tactics from her. VSJ as an affective force marked by participatory listening thus creates a sense of belonging, 'channels personal memories into interpersonal experience and mobilizes people to reconnect experience, memory and possibility' (Hofman 2017). One of the key aspects of this affective force, as identified by Shital, was words/song lyrics and their employment in musical composition.

While citing the $17^{\text {th }}$ century Marathi poet and saint Tukaram, Shital explained to me some of the key features of the VSJ during an interview: ${ }^{13}$

आम्हा घरी धन शब्दांचीच रत्ने

शब्दांचीच शस्त्रे यत्य करू

शब्दची आमुच्या जीवाचे जीवन

शब्दची वाटू जन धन लोका

\author{
Words are the wealth in our house \\ Words, our jewels, words, our weapon \\ Words are what give our lives meaning \\ We can only distribute the wealth of words \\ among people
}

13 Abhang (verse) number 320, translation adopted from Omvedt (2003: 203). 
Who are the creators of popular arts and music? The oppressed castes: the ones at the margins. They created their own music, their own poetry—a reflection of their lives. Our music (mostly the dholki and genres like lavani and powada) is the only thing appropriated and sensationalised by the contemporary mass-mediated brabmanical capitalist culture, but they have completely ignored the words, the poetry. Our words are significant to understand the history of aural cultures and caste groups at the margins. We cannot imagine anything without words. (Interview Shital Sathe)

In his book, The Consciousness of a Caste-ending Cultural Revolution, Sachin Mali (2013) further explains through an example of the halgi (a frame drum played with sticks) how sonic meanings are flipped with poetry that liberates the musician, the artist from performing, embracing and embodying the same action that had imprisoned them for generations.

We have composed a song with the use of the halgi, a drum traditionally played for the goddess (Lakhabai, Mariaai, Mandhardevi). The rhythm of the balgi works as a catalyst for women to trance. The fast tempo of the halgi, resembling lightning, transfers itself into the woman's body. The ex-mahar community, after their conversion to Buddhism, threw away the Hindu shrines from their homes and also their musical instruments associated with the religion. During our performances at Ambedkarite events, a number of activists have asked us not to play the halgi as it is associated with the Hindu religion. It is not their fault. The sound of the halgi is so embedded in their conscious and sub-consciousness that they are immediately reminded of their caste [...] But the same halgi which was confined to brahmanical culture when played like lightning for the end of brahmanical culture, makes them feel relieved. This means, whether it is the halgi of the mang-mahar community, or the dhol of the Dhangar community, unless and until these instruments are brought into the field of ending caste-patriarchy-class, it will not be possible to dissociate them from their caste [...] Today, the halgi is not the drum of mang-mahar communities, but has become a ranhalgi (drum of the battlefield). (Mali 2013: 100) $)^{14}$

The song that has transformed the meanings associated with the balgi is 'Jai Bhim Mhannyaadhi' or Before you Say jai bhim ('victory to bhim' is a common greeting in Maharashtra among Dalit/Ambedkarite communities in remembrance of Dr. B.R Ambedkar, whose first name is Bhim).

14 Translation by author; Sachin's reference to the ritual performances of goddesses like Mariaai and Lakhabai can be found in songs such as 'Lakhabai, please meet me, I put you under an oath, my life is yearning', 'The green bangles of Kaalubai', 'Kaalubai has entered my body' (to trance) among many others. These titles present yearning for the goddess as a way of obeying caste duties. 
समतेचा तो रथ भीमाचा मागं कुणी न्हेला मागं कुणी न्हेलात्याचा लिलाव कुणी केला हंबारतो भीम बाई गहिवरतो भीम राजा अन जयभीम जयभीम म्हणून त्याचा घात कुणी केला, केला ना?

जुलमी जात गेल्याशिवाय घटना बिनकामाची म्हणतो

घटना जाळीन म्हणतो, नवा मार्ग दावीन म्हणतो

पण सत्तेसाठी आज भाडं कोण कोण खातो संसदेच्या जनानखान्यात कसा तोग्यानं

मिरवतो, मिरवतो ना

कसेल त्याची जमीन आता व्हता व्हत न्हाई

शिवताशिवत जातीवाद जाता जात न्हाई अजून का वं दलितांच्या रोज वस्त्या जळत्यात मारपीट बलात्कार राजरोस घडत्यात घडत्यात ना
Who pulled back the chariot of equality given to us by Bhim Who retreated it? Who auctioned it?

Bhim is bellowing, Bhim is choked with emotion

Who killed him by repeating 'Jai

Bhim', over and over again?

(He says) the Constitution is useless if the oppressive caste-system isn't eradicated

(He says) the Constitution must be burnt and a new path must be carved

But lusting for power, look at all those who have sold out And showing off their swagger in the sacrosanct Parliament

Where is that promised 'land to the tiller'? There is still no end to untouchability and casteism Why are the ghettos of Dalits still set on fire every day? Why are we being lynched and raped in public (with impunity)

(Select verses; written by Sachin Mali, composed by Shital Sathe; translation by the author)

'Jai Bhim Mhannyaaadhi' clearly illustrates the link between caste, words and musical instruments. The social meanings of the drum traditionally associated with castebased hereditary performance confined to obligatory religious ritual find a new meaning through words. The technique of playing the balgi and the players themselves remain the same, but the performance context, the players' politicised subjectivity and the new political subjectivities of the audience are completely changed through the words. The words facilitate not only an imagination of a new dignified musicianship, but also a liberatory politics of claiming history, critiquing the present and imagining a future with new political understandings. Liberation from caste is thus imagined through a process of reclaiming sound. Halgi is a significant example of what makes VSJ rebellious. 
Similarly, language, utterance, accent and voice are critical locations of this sonic reclamation. The sonic apartheid of caste begins in the spoken language of everyday life: the accent, the pronunciation, the vocabulary and so on. The dawn of the Dalit Panthers movement in Maharashtra in the 1960s and 70s marked a significant period of literature produced by Dalit writers and poets that changed the literary landscape of Maharashtra. From poetry and short stories to women's autobiographies and testimonios, the narratives from the experiential world of Dalit communities were hard-hitting. The use of specific (previously unheard) sounds in Marathi, the 'slang' that emerged in localities inhabited by Dalit communities appeared in published literature which until that time was stigmatised given that it did not fit in with brabmanic literary standards. In Maharashtra, despite the Ambedkarite and Satyashodhak jalsas, the literature in the 1960s, 70s and beyond radically reclaimed a space for language. The reason behind this could also be that the songs remained within the domain of aural culture and dissemination, while the poems, stories and autobiographies emerged in the public sphere in print, marking a mainstream presence and opposition to the dominant brabmin middle-class literature.

Language must be examined as a place of resistance to the brabmanical sanskritised dominance of literature and spoken language. The sonic aesthetic of literature of Dalit writers and poets "strips language of its hygienist rules of propriety and correctness which have often been ways of concealing violence" (Zecchini 2016: 68). The 'crude', exposed vocabulary, often admittedly incomprehensible to writers from dominant castes ${ }^{15}$, "refuses to decorate, neutralise or camouflage its subject" and the contexts as a way of subverting the values of respectability, morality and properness associated with classical Hindu language and literature (ibid). What Tamil writer Bama terms as the "superficial orderliness of the status-quo"- the rules of grammar, syntax, standards-must be disturbed by the language of Dalit writers (ibid). The violence concealed in the ideals of hygiene and purity is reclaimed as a site of self-determination, the site of resistance. The long legacy of this sonic self-determination is especially underlined by Marathi poets like Namdeo Dhasal, Daya Pawar, Arjun Dangle, J.V. Pawar, Hira Bansode and Pradnya Pawar, among many others.

There are also clear markers indicating the shuddha or pure Marathi despite several Marathi dialects and accents. Discrete categories of sound are associated with (and reveal) the rural/urban, brabmin/non-brahmin and lower-class/upper-class divides. All these categories by and large point towards caste, since the notion of purity is essentially associated with caste. To illustrate this in the Marathi language, the phonology

15 The example of the renowned brabmin writer Vijay Tendulkar must be noted here. In the preface of Namdeo Dhasal's collection of poetry, Golpitha (1975), Tendulkar writes extensively on how he had to sit Dhasal down and have him explain the meanings of a number of words in his poems. 
of the consonant ' $\mathrm{N}$ ' is crucial. In Marathi, ' $\mathrm{N}$ ' is pronounced dominantly in two ways (न, ण). Using न instead of ण, becomes impure to the brabmanical ear (for instance in the words पाणी, बाण, पण, pani, ban, pan). The retroflex ' $\mathrm{n}$ ' is associated with brabmins and the dental ' $\mathrm{n}$ ' with non-brahmins. The impure sound continues to be mocked or used for comic purposes in brabmin homes, social conversations and mass-mediated cultures. The words व्हता, हाय, न्हेला, न्हाई (होता, आहे, नेला, नाही in brabmanical usage respectively) featured in the songs in this essay reflect how impurity in language is reclaimed in the VSJ.

The voice also underlines and brings together many elements of language, utterance and musical instruments. While expressing her deep concern for the increasingly selective co-optation of elements of popular traditions in film, television and other mainstream cultures during a conversation Shital, pointed to some crucial aspects about the voice.

Every musical instrument and genre has had its own history and legacy. Mainstream music today has taken many of these and accommodated them for the taste of all. You can be anywhere or anyone and listen to songs like 'Aai Bhavani' (song of the goddess composed by the famous Marathi film music director duo Ajay-Atul) which has adopted elements of sambal (a drum of the gondhalis) and essentially purified them for the taste of upper classes and castes. If you want to use these elements, why not ask the actual (gondhali) singer to sing it? Why do you need these mainstream singers who have no idea about these genres? Would you invite us to sing a classical song or a song from Sangeet Natak? They are marginalised because their voice may be too raw or loud for the elite audience. (Interview Shital Sathe)

Shital's indication of the 'raw', 'loud' voice here points to the established meanings associated with trained and untrained voices, a dichotomy reiterated by the ways in which classical and "folk" categories are also understood. Her use of the word "purified' is revealing since it exposes from her point of view how mass-mediated culture primarily serves the brabmin middle class audience. She addresses how the separation of the voice from the genre's history is in itself objectifying, sensationalising popular arts: a form of selective co-optation. ${ }^{16}$ It is striking then how voice becomes a site of

16 The voices of mainstream film singers are not discarded by Shital or others in the movement for their vocal quality, but often because of whom they represent—brahmanical capitalist figures like Lata Mangeshkar and Asha Bhosale are often criticised. The voice of these singers is not necessarily seen as something to aspire to, something that I experienced actively in my vocal training, where Lata Mangeshkar was presented as possessing an "ideal female voice" (see Srivastava 2004, Booth 2013). The voice becomes a site of subjective identity situated as part of a genre having its own history and context. Lata Mangeshkar and Asha Bhosale, who have often sung lavanis for films, also complicate the gender-

I 52 
"collectively recognized meanings" within a cultural and socio-political structure and carries meanings that eventually decide the socio-economic and cultural capital it may afford (Weidman 2014: 38).

During a time when violence on Dalits in public spaces is normalised as part of the Hindutva ideology, musicians such as Shital dare to perform the VSJ despite their own subjective experiences and the constant threat of violence/death/incarceration. VSJ not only reclaims sounds, performances and listening practices, but also reclaims public spaces. While news channels and social media broadcast the videos of Hindutva perpetrators thrashing or lynching Dalit bodies in broad daylight in public spaces as bystanders watch in fear, the musicians and listeners of the VSJ occupy public spaces to assert their passionate politics of hope. The VSJ represents a physical and sonic location of occupying historically unmarked inaccessible public spaces in a physically marked manner whereby sound contests hopelessness, exhaustion, fear and political incapacities. The voices and drums mediated through sound systems reverberate in ways that make the surrounding dominant caste neighbourhoods uncomfortable as they complain about the loud noises and chaos.

Shital's VSJ in particular also marks a new intersectional politics whereby young Dalit women can claim a performative space in the male dominated anti-caste movement. Dalit women who are still perceived as carrying the embodied stigma associated with musicianship and dance from the $19^{\text {th }} \mathrm{c}$. can be rebellious, perform, write songs, and become the target of brabmanical repression. They can challenge Hindutva forces and add to the anti-caste political discourse from a standpoint that remains on the margins even in the mainstream feminist discourse. Shital's presence on stage enables a sense of inclusivity and serves as a reference point for Dalit female audiences of all age groups. Although not all Dalit communities are hereditary musicians, the oppressed castes are aware of the turbulent history of Dalit musicianship. To witness the VSJ as an intergenerational listening practice also creates sonic memories and familial bonds as reported by a number of listeners. Such bonds created through shared listening and witnessing of the VSJ is then a testimony to the lack of structural absence of care and belonging. The rebelliousness of the VSJ is not only the reclamation of a sound to organise and protest against brabmanism and engage in critical dialogue, but a way to preserve each other, to preserve histories, to care for oppressed castes, women and the subjectivities within.

By naming these performances vidrobi, the VSJ has further underlined the importance of vernacular and the underlying caste-based sonic structures. VSJ thus consciously offers new meanings to sounds and music where Dalit communities use their

caste assumptions. Brabmanical imaginations of the lavani singer/performer in the mind of the playback singer, music director and filmmaker have shaped the voice in specific ways. 
caste's hereditary sonic knowledge to invoke cultural memory, reclaim histories, musical knowledge and meanings associated with sounds to present counter-narratives that have been crushed by the caste structure. It offers a new sonic and spatial imagination that breaches the extant soundscape of caste apartheid in Maharashtra. Music and musicianship thus become sites of caste annihilation and the struggle over survival, histories and cultural meanings.

Shailaja Paik (2016: 21) has analysed how struggles towards the access to knowledge and equal rights of Dalits in the $20^{\text {th }}$ century departed from leaders invoking the "formation of a personhood," a process of Dalit humanization. From actively embracing a gendered body politic, gaining education, reclaiming a sonic politics through new lyrical and performative representations, Dalit communities, particularly women, continue to define their personhood and what constitutes the conditions under which they can have a dignified existence. In this sense,VSJ facilitates a space where dignity and personhood come to be asserted and redefined. VSJ performed by Shital Sathe occupies a significant space in this legacy, as she brings together performative, theoretical, aesthetic, affective and personal spheres. Her VSJ underlines music, sound, texts as caste and gendered epistemologies and brings them into political spheres that further question postcoloniality, democracy, equality and the right to citizenship.

In many of her performances in recent years, Shital has highlighted the experience of coloniality - living under caste apartheid — by critiquing India's struggle for freedom from the British and how it hinged on casteism. Her songs question the work of Gandhi and other dominant caste 'mahatmas' (great souls) who overshadowed radical anti-caste leaders like Dr. B.R Ambedkar. While emphasising the fractures within Indian democracy, Shital questions the very idea of the postcolonial, as modernity and freedom have been defined by and in the interest of brabmins and other dominant castes (particularly the brabmin-baniya alliance). Although colonialists and nationalists contested the function of knowledge in colonial India, for both, the nature of the knowledge of India was essentially brabmanical - and continues to be the case today.

Caste inherently stands in opposition to the idea of democracy, which Waghmore (2013: 199) aptly terms the paradox of "high democracy and low civility". It is characterised by a concomitance of violence and democracy and stands in opposition to how citizenship is conferred in independent India (Waghmore 2013: 201). "Democracy has preceded civility, civil society" and thus, "continues to reproduce caste by breeding new and sinister ways that perpetuate exclusion" as well as new forms of protest and alternative imaginations (2013: 17). Shital's surveillance and incarceration among many other Dalit musicians like her, the custodial torture of some of them as well as Rohith's institutional murder are the contradictions of (Indian) democracy.

Shital thus reminds people that the country will truly be free when we address how caste has taken over our everyday psyche. She challenges the theoretical cate- 
gory of the 'postcolonial' as it seems limited to the experiential world of dominant castes. Some of the key contributions from South-Asian postcolonial and subaltern theorists (Chakravorty Spivak 1999, Bhabha 1994, Chakrabarty 2002, 2009 et.al), although valuable in exposing colonial-imperial-oriental constructions of India, lack an understanding of the local hegemonic structures of which they are key representatives. It has also been recently pointed out that the popularity of postcolonial theories in Euro-American academia can be contrasted with Dalit and adivasi (indigenous communities) intellectual tradition in India where the postcolonial has no referential value, a perspective emerging out of what is being conceived as 'critical caste studies' (Ayyathurai 2018).

These observations and analyses are in no way exhaustive and aim to foster a generative dialogue. I have attempted to listen to the sounds of an anti-caste movement in contemporary Maharashtra which present critical insights about the epistemic foundations of music in India, specifically the complex history of hereditary musicianship, caste, race, gender and sexuality in the wake of modernity and nationalism. Drawing on the VSJ conceived and performed by Shital Sathe among others, I have traced how hereditary musicianship is leveraged to present liberatory politics and counterepistemologies. I have attempted to listen to how embodied sounds and spaces are reclaimed in the VSJ, (particularly by women like Shital) that defy the stigma and baggage imposed upon Dalit communities throughout the $19^{\text {th }}$ and $20^{\text {th }}$ centuries. I have ultimately argued for a caste-based examination of music and sound in modern India/ South-Asia as it aids us to think further about the ways in which knowledge at large is constructed and represented.

\section{Concluding thoughts}

It was hardly a coincidence that I, a brabmin middle-class woman, born and brought up in Pune, a city that prides itself on Peshwa heritage, turned to Hindustani classical music. It was not an autonomous choice, but one that was made long ago. It was no coincidence that I easily navigated the spheres of music education as well as academia without any active reflection on caste or gender. It all unfolded through systemic control. The choice was already made, like most 'choices' about caste are. That caste is invisibilised in everyday life is true to a certain extent, as suggested by Chakravarty (2003). But it is also true that only dominant castes can afford to ignore it and invisibilise it, as they can get away with impunity.

Classicisation of music in India as one of the central projects of modernity was achieved through brutal violence on Dalit and Muslim communities. Pedagogies and aesthetics of classical music as we understand them today are entangled with the apart- 
heid of caste, gender and sexuality. Ideal and honourable brabmin womanhood has been achieved by discarding Dalit women and appropriating their hereditary knowledge. The reason why the VSJ has had to flip sonic and cultural meanings, reclaim histories, theorise and perform new liberatory philosophies is because of the sonic apartheid of caste that has proved to be a threat to Dalit communities' survival, dignified existence and equal citizenship. The VSJ teaches us to reinterpret and rewrite a reparative history of music in India. It challenges the authenticity and foundations of all knowledges, including music that are sold to us as 'ancient Indian' or 'Hindu traditions' which are but modern inventions emerging out of the nationalist ideology of dominant castes/brahmins. This is particularly important given that the rise of the Hindutva regime in contemporary India is a stark reminder of the same nationalist narratives in colonial India of which the 'moderniser' of music V.D Paluskar was a product and agent.

As I increasingly travelled with Shital, singing about Rohith and other songs in the VSJ, I was able to challenge as well as transgress my own boundaries of caste, gender, musical knowledge and performance. Witnessing the paradox in Rohith's struggle and demand for access to critical education and democratic debate within a brabmanical educational structure on the one hand and Shital's mobilisation through musical performance in the same social structure on the other, profoundly revealed to me how caste and gender can be enabling and disabling at the same time. The more I reflect on the politics of caste, music, gender and sexuality and listen to the voices of anti-caste activists and musicians, I am motivated to trace the history of my own positionality instead of only capitalising on critiques put forth by Dalit musicians.

I realise the urgency to decolonise ethnomusicological approaches, theories and methods at large in India and South Asia as I navigate brabmanical and Euro-American academic spheres. I use the term 'decolonising' drawing on bell hooks (2003) to not only mean liberating epistemologies, performance traditions, instruments, sounds, voices, bodies, memories, affect and meaning-making processes from the colonial/ imperial, logocentric regimes, but also from the local brabmanical regime that has colonised minds for centuries. This would require not just a critique of knowledge, but also of the ways of knowing.

Sherinian (2015) rightly points out how the analysis of classical music reinforced the long-standing local hierarchies of musical and social identity until the late $20^{\text {th }}$ century. Indian musicologists like Ashok Ranade (1986) and I E N Chauhan (1973), while questioning the applicability of western models to Indian music, have reproduced the nationalist, brahmanical ideal and located (complex) classical music at the apex while promoting (simple) binaries of classical-folk, classical-tribal among other forms of music. Some noteworthy shifts in ethnomusicology in the last three decades have been significant with a focus on people, their context and the processes that evolve from

I 56 
sound making, the shared experience of performance, and the relationships that evolve through fieldwork processes, the focus on feminist ethnomusicology as well as music's political-social-cultural process of production, transmission, and reception.

While these developments are significant, the full potential of a caste-based examination of sound, music and musicianship is yet to be undertaken. For instance, the histories of dominant castes, particularly brabmins and their involvement in musicianship, the history of caste hereditary musical instruments in specific regions, sonic, musical and lyrical specificities of sub-caste groups, musical pedagogy, local economy and politics. This would further enable a dialogue about contemporary caste-class relations and how only certain forms of musicianship find a place in mainstream capitalist market. Ultimately, an examination of caste would not only ensure decolonising epistemologies of music, but decolonising knowledge itself and its representation.

Most importantly, the analysis of caste would entail an investigation of race, gender, and sexuality. It would bring to fore women's positionality as musicians and address issues with regard to sexuality and heteronormative patriarchy. Such an approach would also help us to nuance the understanding of cultural movements as emerging from the everyday experiences of oppressed communities which cannot be reduced to 'protest music' or 'political music', which imply that all other performances (of dominant castes) are less or apolitical. The dominance of written sources on music by European colonial legacies, later internalised by brabmins (particularly the invention of the notation system) must also be challenged, since aurality has been one of the central modes of expression and communication of majority populations, given that they were excluded from acquiring formal institutional education. Finally, the concern around under-representation of local scholarship on music, gender and caste, especially in vernacular authored by Dalit scholars, musicians and intellectuals, must be a central agenda of decolonising ethnomusicology. The erasure, denial or ignorance of caste and gender would only reproduce colonial relations and perpetuate caste apartheid. A decolonial ethnomusicology of India/South-Asian has yet to be fully claimed and this essay is a limited attempt in the same direction.

\section{References}

Ajotikar, Rasika. 2018. Music and the politics of caste and gender: women's voices of liberation in western India. $\mathrm{PhD}$ dissertation, SOAS, University of London.

Ambedkar, Babasaheb R. 1916. "Castes in India: Their Mechanism, Genesis and Development.” Indian Antiquary, Vol. XLI (May 1917). Reproduced in Dr. Babasaheb Ambedkar: Writings and Speeches, Vol. 1. Bombay: Education Department, Government of Maharashtra. 1979: 3-22. 
1936. The annihilation of caste; speech prepared for the annual conference of the Jatpat-todak Mandal of Lahore, but not delivered. Bombay: B.R. Kadrekar.

Ayyathurai, Gajendran. 2018. “Towards Critical Caste Studies.” Lecture, Dalit History Month, Berlin, Germany, May 9, 2018.

Babiracki, Carol, 1991. "Tribal music in the study of great and little traditions of Indian music." In: Comparative Musicology and Anthropology: Essays on the History of Ethnomusicology. Chicago and London: University of Chicago Press, 69-90.

Bakhle, Janaki. 2005. Two men and music: nationalism in the making of an Indian classical tradition. Oxford: Oxford U Press.

Bama. 1999. "Dalit Literature." Indian Literature 197: 97-98.

Bhabha, Homi. 1994. The Location of Culture. New York: Routledge.

Booth, Gregory. 2013. "Gender, Nationalism, and Sound: Outgrowing 'Mother India.” In Senses and Citizenships: Embodying Political Life, S. Trnka, C. Dureau, J. Park, eds. New York, London: Routledge, 136-158.

Burckhardt Qureshi, Regula. 1986. Sufi Music of India and Pakistan: Sound, Context and Meaning in Qawwali. Cambridge: Cambridge University Press.

Chakrabarty, Dipesh. 2002. Habitations of Modernity: Essays in the Wake of Subaltern Studies. Chicago: University of Chicago Press.

- 2009. Provincializing Europe: Postcolonial Thought and Historical Difference. Dipesh Chakrabarty. 2000. Princeton: Princeton University Press.

Chakravarti, Uma. 2014. Rewriting History: The life and times of Pandita Ramabai. New Delhi: Zubaan.

Chakravarty, Uma. 2003. Gendering Caste through a feminist lens. Calcutta: Stree.

Chakravorty Spivak, Gayatri. 1999. A Critique of Postcolonial Reason: Toward a History of the Vanishing Present. Cambridge: Harvard University Press.

Chauhan, Chetan. 2016. "In state after state, cow protection vigilantes pick on Dalits, Muslims.” Hindustani Times. July 29, 2016. https://www.hindustantimes.com/india-news/instate-after-state-cow-protection-vigilantes-pick-on-dalits-muslims/story-F1CFAkyduCopAY5IYIN4LL.html. (04.07.2018).

Chauhan, IEN. 1973. Ethnomusicology--Tribal Music: A Directory of Tribal Musicians of Kinnaur. Controller of Publications: Government of India.

Dhasal, Namdeo Salubai. 1975a. Golpitha. $2^{\text {nd }}$ ed. Pune: Nilkant Prakashan.

Doniger, Wendy. 2009. The Hindus. An Alternative History. New York: The Penguin Press.

Fiol, Stefan. 2015. "One Hundred Years of Indian Folk Music: The Evolution of a Concept." In: This Thing Called Music: Essays in Honor of Bruno Nettl, V. Levine and P. Bohlman, ed. Lanham: Rowman and Littlefield, 317-329.

. 2017. Recasting Folk in the Himalayas: Indian Music, Media, and Social Mobility. Campaign: University of Illinois Press. 
Figueira, Dorothy. 2002. Aryans Jews Brahmins. Theorizing Authority through Myths of Identity. New York: SUNY.

Guru, Gopal. 1997. Dalit Cultural Movement \& Dialectics of Dalit Politics in Maharashtra. Mumbai: VAK Publication.

Hofman, Ana. 2017. "“All in one voice”: Politicness of Music and Sound in a Time of Uncertainty.” Lecture at Symposium: Musics Matter! Ethnomusicology and its Socio-political Relevance today, Vienna, Austria, September 30, 2017.

hooks, bell. 2003. Rock my Soul: Black people and self-esteem. New York: Atria Books.

Jones, Sir William. 1792 [1984]. "On the Musical Modes of the Hindoos.” Asiatick Researches 3: 55-87.

Junghare, Indira. 1983. "Songs of the Mahars: An Untouchable Caste of Maharashtra, India." Ethnomusicology 27/2: 271-295.

Katz, Max. 2017. Lineage of Loss: Counternarratives of North Indian Music. Connecticut: Wesleyan University Press.

Keating, Christine. 2011. Decolonizing Democracy: Transforming the Social Contract in India. University Park: Penn State University Press.

Korom, Frank J. 2006. South Asian Folklore: A Handbook. Connecticut: Greenwood Press.

Mali, Sachin. 2013. Jaatiantak Saanskrutik Krantiche Atmabhan. Aurangabad: Com. Chandragupta Chaudhari Smruti Samiti.

Marshall, P. J. 1970. The British Discovery of Hinduism in the Eighteenth Century. Cambridge: Cambridge University Press.

Omvedt, Gail. 1976. Cultural revolt in a colonial society: the non-Brahman movement in western India, 1873 to 1930. Bombay: Scientific Socialist Education Trust.

. 1990. "Twice-Born" Riot against Democracy." Economic and Political Weekly 25/39: 2195-2201.

1994. Dalits and Democratic Revolution: Dr. Ambedkar and the Dalit Movement in Colonial India. New Delhi: Sage Publications.

- 2003. Buddhism in India: Challenging Brahmanism and Caste. New Delhi: Sage Publications.

- 2006. Dalit Visions: The Anti-caste movement and the construction of an

Indian Identity. Hyderabad: Orient Blackswan.

Namala, Annie. 2016. "Violence against Dalits: There is a discernible pattern to this madness." The Indian Express, July 23, 2016. https://indianexpress.com/article/blogs/dalit-violencegujarat-gau-rakshaks-2930876/ (04.07.2018).

Narayan, Badri. 2016. "Dalits and the remaking of Hindutva." The Hindu. Last modified October 18, 2016. https://www.thehindu.com/opinion/op-ed/Dalits-and-the-remaking-of-Hindutva/article14018125.ece (01.05.2018).

Paik, Shailaja. 2016. "Forging a New Dalit Womanhood in Colonial Western India: Discourse 
on Modernity, Rights, Education, and Emancipation.” Journal of Women's History 28/4: 1440. https://doi.org/10.1353/jowh.2016.0034 (01.05.2018).

Patil, Sharad. 1982. Dasa-Sudra Slavery. Mumbai: Allied Publishers.

- 2005. Caste-ending Bourgeois Democratic Revolution \& Its Socialist Consummation. Shirur: Mavalai Prakashan.

- 2006. Caste Feudal Servitude. Pune: Mavalai Prakashan.

- 2008. "Lived-in Experience." Economic and Political Weekly 43/28: 4 and 194.

- 2010. Primitive Communism, Matriarchy-Gynocracy \& Modern Socialism. Shirur: Mavlai Prakashan.

- _ 2017. Abrahmini Sahity ani Kalanche Saundaryashastra. $2^{\text {nd }}$ ed. Pune: Mavalai Prakashan.

Putcha, Rumya. 2013. "Between History and Historiography: The Origins of Classical Kuchipudi Dance-" Congress on Research in Dance 45/3: 91-110.

—_. (upcoming). Mythical Courtesan I Modern Wife: Feminist Praxis in Transnational South Asia.

Rahman, Salma. 2017. "Rohith is the 23rd Dalit student suicide in institutes like AIIMS and IITs." Catchnews, February 14, 2017. http://www.catchnews.com/national-news/ blood-on-books-rohith-vemula-s-is-the-23rd-dalit-student-suicide-in-under-a-decadebandaru-dattatreya-abvp-bjp-rahul-gandhi-thorat-committee-caste-1453210563.html (25.04.2018).

Rajpramukh, K.E. 2013. Satellite Castes and Dependent Relations: Dalits in South India. New Delhi: Partridge.

Ranade, Ashok. 1992. Indology and ethnomusicology: Contours of the Indo-British relationship. New Delhi: Promilla \& Co.

Rege, Sharmila. 1995. "The Hegemonic Appropriation of Sexuality: The Case of lavani performers of Maharashtra." Contributions to Indian Sociology 29/1-2: 24-38.

—. 2002. "Conceptualising Popular Culture 'Lavani' and 'Powada' in Maharashtra-" Economic and Political Weekly: 1038-1047.

Sarkar, Tanika. 2001. Hindu Wife, Hindu Nation: Community, Religion and Cultural Nationalism. London: Hurst \& Company.

Schultz, Anna. 2008. "The Collision of Genres and Collusion of Participants: Marathi 'Rasț̣̂ya Kirtan' and the Communication of Hindu Nationalism.” Ethnomusicology 52/1: 31-51.

- 2013. Singing a Hindu Nation: Marathi Devotional Performance and Nationalism. Oxford: Oxford University Press.

Sherinian, Zoe. 2014. Tamil Folk Music as Dalit Liberation Theology. Bloomington: Indiana University Press.

- 2015. "Activist Ethnomusicology and Marginalized Music of South Asia." In: S. Pettan, J. Todd Titon, eds. The Oxford Handbook of Applied Ethnomusicology. New York: Oxford University Press: 348-376.

I60 
Sinha, Mrinalini. 1995. Colonial Masculinity: The 'Manly Englishman' and The 'Effeminate Bengali' in the Late Nineteenth Century. Manchester and New York: Manchester University Press.

Soneji, Davesh. 2012. Unfinished Gestures: Devadasis, Memory, and Modernity in South India. Chicago: University of Chicago Press.

Srivastava, Sanjay. 2004. "Voice, gender and space in a time of five-year plans: The idea of Lata Mangeshkar." Economic and Political Weekly 39/20: 2019-2028.

Stirr, Ana. 2017. Singing Across Divides: Music and Intimate Politics in Nepal. New York: Oxford University Press.

Tambe, Anagha. 2008. "Different issues/different voices: Organization of women in prostitution in India." In: Prostitution and Beyond: An Analysis of Sex Workers in India. R. Sahni, V. K. Shankar and H. Apte, eds. New Delhi: SAGE Publications: 73-97.

Thakur, Bhagwan. 2005.Ambedkari Jalse. Pune: Sugava Prakashan.

Thompson, Gordon R. 1991. "The Cāraṇs Of Gujarat: Caste Identity, Music, And Cultural Change." Ethnomusicology 35/3: 381-391.

Teltumbde, Anand. 2010. The Persistence of Caste: India's Hidden Apartheid and the Khairlanji Murders. London: Zed Books.

- 2016. Dalits: Past present and future. London and New York: Routledge

Viswanath, Rupa. 2016. "Caste and Untouchability." In: Hinduism in the Modern World. B. Hatcher, ed. New York and London: Routledge: 257-275.

Waghmore, Suryakant. 2013. Civility against Caste: Dalit Politics and Citizenship in Western India. New Delhi: SAGE Publications.

Weidman, Amanda. 2006. Singing the Classical, Voicing the Modern: The Postcolonial Politics of Music in South India. Durham, NC: Duke University Press.

- 2014. "Anthropology of Voice." Annual Review of Anthropology 43: 37-51. https://doi. org/10.1146/annurev-anthro-102313-030050 (15.03.2019).

Wolf, Richard. 2009. Theorizing the Local: Music, Practice, and Experience in South Asia and Beyond. Oxford: Oxford University Press.

Zecchini, Laetitia. 2016. "'No name is yours until you speak it': notes towards a contrapuntal reading of Dalit literatures and postcolonial theory.” In: Dalit Literatures in India. J. K. Abraham, J. Misrahi-Barak, eds. New York: Routledge: 58-75.

\section{Abstract}

Music as a knowledge system in India is deeply embedded in the structure of the caste system which continues to determine its nature, authorship and value even today. The heteropatriarchal and graded caste structure has determined not just the epistemic foundations of music but of knowledge at large, predominantly controlled by the 
Brabmins or dominant castes. The caste system has persisted through pre-colonial, colonial and post-independence eras in different forms and manifestations implying the hegemony of the Brabmins on the ways in which knowledges in and of India are assumed today. Ethnomusicological studies in India largely representing the "classical" music traditions have rarely engaged with caste as a valid framework that can offer insights beyond class and socio-economic analysis. In this article, I foreground caste as an essential framework for the study of music in modern India while locating the sonic, pedagogical and disciplinary bounds of music as deeply embedded in the intersections and hierarchies emerging out of caste: gender, sexuality and religious nationalism. I present critical reflections on the epistemic foundations of music in $20^{\text {th }}$ century India by drawing on my field research with oppressed caste (known as Dalit communities) musicians and activists in the contemporary anti-caste cultural movement mobilised in the western Indian state of Maharashtra. While this movement continues to present incredible alternative sonic imaginings through caste-hereditary musicianship (specifically through musical instruments, vocal and performance styles), in this essay I highlight the literary interventions in song as counter-epistemologies to dominant caste discursive and performative representations that help formulate new theoretical ideas for the study of music in contemporary India. 


\section{Politics of Women Dancing in Madagascar: Relating Critical Perspectives on Gender}

Awaiting the arrival of locally beloved politician fean-facques during his campaign in July 2011, several groups of women were dancing through the village of Belamoty. They were singing various songs to their synchronized steps including the song from the circumcision ceremony about the maternal family arriving as 'numerous mothers'- "bereny" (see Video 1). ${ }^{1}$ This procession-like group locomotion through the village, which some call manao carnaval, literally 'doing a carnival', is typical for various occasions. To attract attention and to inform others of the goings-on, one or several groups of people specific to the event move in visual and audible synchronicity of stomping, clapping and singing, thereby transforming different parts of a village into the festival space. Later that day, preparing for fean-facques' arrival, the attendants of the event encircled a large space in front of the town hall, with the local orikesta, an electric guitar-, bass- and drum set-based live music group, playing tsapiky, a popular music style from Southwest Madagascar, in the shade of the central tamarind tree. To further shape the space, an organizer of the event beckoned one of the three women's organizations that performed that day to dance through to the other side of the town hall, where other women's associations had already congregated (see Video 1). The majority of the members performed in matching shirts and, or matching 'wrappers' (lambahoany) worn around their waist as skirts, and danced as a dense group whilst directing their bodies in one direction, moving through space as a single, united group (see also Figure 1). In front of the group, some five to eight members performed more loosely apart from that formation. They wore their wrappers in specific ways around their chest, and their hair in talim-bilo braids, which is known to be a form of prayer and protection worn during the bilo healing ceremony, whilst dancing the bereny (lit-

1 Video 1 is accessible online: www.mdw.ac.at/ive/ethnomusicologymatters

This article is based on research in Madagascar in 2008 (for my MA thesis on music and dance in the context of the circumcision ceremony), 2011, 2012, 2014, and 2015 (for my doctoral thesis on dance and gender in Madagascar), and 2017 (during an excursion with students from the University of Vienna to Île Ste Marie). I want to mention and thank José Razafinarivo Maminiaina, Lodwine, and August Schmidhofer for their support on many levels during this time and far beyond, and particularly the women's associations and the many individual women who were open to talking to me and sharing and discussing their experiences, thoughts and my recordings with me. The names of the interviewed women were changed. 


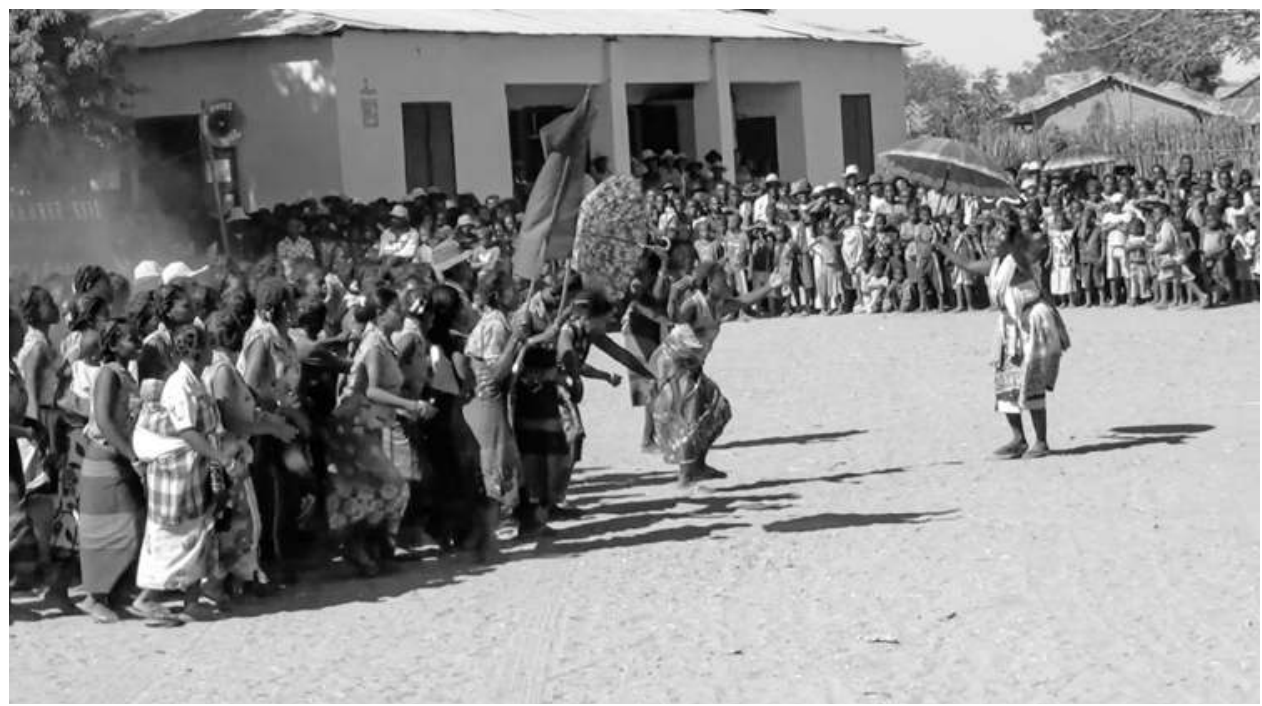

Figure 1: The Beadabo women's association during the visit of a Minister. Screenshot, Belamoty, 2011.

erally: 'numerous mothers'). The dancers flex their knees, lean their upper bodies forward, turning their heals in- or outward on every step, alternating the right and left foot to each beat of the music, whilst holding up the palms of their hands and an umbrella, rotating them regularly. Like the songs, this combination of embodied signs and dance acts are all signifiers of the circumcision ceremony in the central Onilahy Valley, particularly of the figure of the mother within this context.

This event was one of the first, and turned out to be one of the most indicative moments within my doctoral research on the meaning, significance and effect of dancing and the negotiation of gender through dancing within various contexts. Having only seen actual circumcision ceremonies during my previous research in the central Onilahy Valley, I had not been aware that these specific songs and dances were performed out of context. Moreover, the significance of this particular day only really became clear to me a year later, when I found out that the number of women's associations had grown from those three groups from three different communes to 22 groups in just this one commune of Belamoty. During his visit, fean-facques ${ }^{2}$ had prompted

2 In Madagascar, politicians are frequently known and referred to by their first name. Therefore, I only found out later that the politician Jean-Jacques Rabenirina was the anthropologist who had coincidentally written his doctoral thesis on the circumcision ceremony which I had drawn from extensively. He was the Minister of National Education at the time, campaigning to later become Deputé of the Betioky region, which includes the central Onilahy Valley. 
mayors to offer the option to register women's associations on the local administrative level of the commune, which comprises two to several villages. Before then, women had had to endure a day trip by taxi-brousse to the district capital Betioky for official registration, at great cost for any person from the general population.

This stark increase in official women's associations is an intriguing trend that I investigate from several perspectives. What are the politics behind initiating the local registration of women's associations? Why did so many women welcome this initiative so willingly? And how are the specific modalities of action the women's organizations employ, their performances of dancing and singing, linked to being so popularly accepted? First, I contextualize my questions within the particular political climate, my field research and local concerns at the time of my fieldwork. Before looking at discourses on and experiences of women's associations, I question the universalist perspective of the concept of "woman" by showing how gender is a complex, interdependent category. I then examine and critique how women's issues are discussed within the context of two national and regional development reports in which women's associations count as one of several numeric indicators of the overall status of women. I further focus on the meaning and significance of the women's choices in singing and dancing as modalities of representation and gender performativity, and their first hand accounts of their own motivations to found and participate in the associations. In this chapter, I focus on gender as an analytical lens to trace the various factors and discourses I attribute to contributing to the increase in official women's associations, as it mirrors the complexity of entangled politics. By relating different levels of gender politics, gendered practices, and gendered experiences to one another, I also question my own position as a white, European feminist scholar and emphasize that I do not speak for anyone, but see this discussion as a work in progress and as my current individually informed perspective.

\section{The Crisis and the Increase in Women's Associations}

In the national and international press and in online representations of influential partners of Madagascar such as France (the official colonial power from 1896 to 1960) and the USA, the time between 2009 and 2013 is known as the five years of crisis in Madagascar. This started with Andry Rajoelina overthrowing President Marc Ravalomanana and becoming the President of the High Autbority for the Transition (HAT) until the first official elections, in which a new President of the Republic of Madagascar, Hery Rajaonarimampianina, was elected. During my doctoral research on the meaning, significance and effect of dancing within various contexts in the central Onilahy Valley in Southwest Madagascar (2011-2015), which overlapped with this time period, the crisis 
was often mentioned in everyday life, and was certainly not "solved" by the elections in 2013. Frequently, a kind of powerlessness was perceived in relation to self-serving politicians, as the crisis was experienced in terms of a simultaneous increase in poverty and in organized crime. During and beyond the time of crisis, parts of the South including the central Onilahy Valley were at times officially designated as zone rouge - an absolute danger zone - due to organized groups of zebu-cattle thieves, referred to as malaso or dabalo, being in a war-like state with the military and gendarmerie.

During my research stays, I lived with several families in their private homes, having initially been brought together through my master's thesis advisor's family, particularly through the contacts of my long-term research assistant José Razafinarivo Maminiaina. I was invited to "float" through their networks, meeting more and new people and was thereby invited to attend and record various festivities, which were often guarded by family members from the military for safety. Simultaneously, particularly during my second stay in 2012, the significant rise in the number of women's associations caught my attention, as their attendance during various festive contexts was quite impressive due to their outstanding group presence, visually recognizable with their t-shirts in matching colors.

The performance described at the beginning of this contribution is one of but three ways in which official women's associations organize which are regulated by official bylaws clarified at registration. First, the members pool money on a regular basis in order to act as a savings and loans association to support each other economically and in sudden crisis. Second, as in the event described above, the entire association is invited to attend and perform at commune festivities such as the $26^{\text {th }}$ of June (Malagasy Independence Day), New Year's Day, the $8^{\text {th }}$ of March (International Women's Day), or other events organized by local political-administrative representatives. For these types of events the associations receive a small amount of money from the mayor's office and monetary offerings from the audience called basimena for dancing. Third, the associations accompany members who have been invited to specific social and ceremonial events, to which they arrive and perform as a united group. This united arrival, mostly in a danced modality, is typical for weddings, circumcision or mortuary ceremonies. Like any group of guests, the women's associations bring monetary and material offerings such as drinks in more or less the same way as other invited groups. Yet, whereas the majority of arriving groups are defined through family relatedness and are headed by male representatives (who do not dance), women's associations only include female members (including trans* women) over the age of 14 . Their appearance of group unity by wearing 'matching outfits,' manao tenue or kômpile (from the French word complet; see Figure 2) 3 was often emphasized to be very important by women's associations.

3 This may include an entire attire of matching wrappers and blouses sewn by the members themselves, 
Pooling money to support each other, demonstrating strength in unity, singing and dancing, and representing themselves in speech uniquely as women are thus key issues to being a women's association, as will be further discussed in this chapter. Moreover, the women's associations also openly connected to the experience of crisis in several of their songs as they sang about protection, wealth and new laws: about young men protecting the villages from thieves, about wealthy men owning several guns and having several women, and about the local convention ${ }^{4}$ introduced in 2014.

\section{Woman as an Interdependent Category}

Though the existence of and the lively participation in women's associations suggests a homogenous, autonomous category called 'woman', the process of talking to the members of the women's associations, of analyzing participants' actions within different ceremonial and everyday spaces, of conducting feedback interviews on my recordings, and of conducting biographical interviews with individual women from the central Onilahy Valley or/and of self-identified Tanosy 5 ethnicity made it clear that gender, or being a woman is, as anywhere, not conceived as a single-layered issue. The various gendered practices, structures, and personal experiences prove to be inseparably interconnected with access to resources, generation, age, ideas of reproduction, and ancestral relations.

The experience of being (categorized as) female, particularly when considering ancestral practices, is always understood in connection to various positionalities in rela-

often with matching scarfs or hats, or t-shirts with the association's name printed on them in various colors, so every association has its specificity—a suggestion attributed to the politician Jean-Jacques himself (Interview Zafy 2012).

4 The dinabe convention against (zebu) theft was introduced in several villages and communes in the central Onilahy Valley starting in 2014. It proved to be a success, as its central method was holding entire communities responsible for individual thieves.

5 The categorization of the 18 groups currently recognized as ethnicities in Madagascar has gone through a long process of $19^{\text {th }}$ and $20^{\text {th }}$ century discussions and works written by missionaries, "adventurers," travelers, colonialists, and ethnographers. Today, Tanosy people of the central Onilahy Valley, the overarching ethnic identity of the majority population there, trace their ancestors back to kings and princes that had fled from the Southeast of Madagascar during Merina rule, a united kingdom in the $19^{\text {th }}$ century that gained unequal power through the support in terms of military strategy of the British and other individual European nations. Central to this collective identity defined as 'ethnic' are ancestral images and practices in which gendered experiences play a central role such as weddings or circumcision ceremonies. These images and practices forming ethnic realities include specific 'ways of doing things,' called fomba, following certain taboos connected to nutrition, sexuality and spatiality, speaking a common dialect, and a common history of colonial ethnic categorization and fixation. 
tion to other people one interacts with in different spaces. Whereas the three women's associations performing during the political event in 2011 all named themselves according to their villages and were constituted as diverse groups of women from entire, mostly larger villages (such as Belamoty or Salobe), the six women's associations I worked with a year later offered a greater diversity of chosen names according to other positionalities. Some named themselves according to their common workspace such as 'market place' bazary, others by the name of their village quarter, and again others according to their common 'ancestral name' raza, such as Takarana. Consequently, some women are part of several women's associations.

As some of these names imply, gendered experiences are particularly connected to family affiliations, which are established within cultural practices connected to ancestry, living spaces, and labor. This includes different levels of ancestral lineage affiliation and relatedness, defined through birth to a specific mother, and may potentially be changed through one's mother's, or one's own wedding(s) or adoption. Lineage affiliation furthermore most frequently intersects with a village or quarter identity due to virilocal and patrilocal practices; many smaller villages or quarters of larger villages are made up of a majority of members of one ancestral lineage with few individual exceptions, such as merchants or teachers, or from related lineages through partnership or blood-oath siblinghood.

Within these ancestral lines, troke, literally 'stomach', which are defined by the head of the family, the common living ancestor who is the most senior male person of the oldest generation, gender is experienced in a relational way to different family members, particularly marked by age and generation, real and potential sexuality and reproduction, and to family members of related ancestral lines. Whereas male children become heirs and potential successors of the head of the family through circumcision, female children do not, which is legitimized due to their potential change in ancestral line after marriage. For women who become pregnant and give birth to a child, their ancestral affiliation potentially changes through marriage after having given birth to their child, unless it is a case of marriage within a family fanambalia amin'ny troke. By practicing a wedding ceremony including a blessing from her and her partner's elders, the mother and existing or any potential future children become descendants of the male partner's ancestors.

In addition to potentially changing ancestral affiliations through reproduction and ceremonies particularly for women, ancestry and family relatedness intersect with access to social, cultural and monetary wealth and property of an entire lineage, which includes land, zebu cattle, and the number of descendants. Weddings are frequently arranged by elders (commonly not against the partners-to-be's will) for wealth to stay within the given network of relatedness. Some also trace their ancestry to royalty, a category that was abolished and instrumentalized within the introduction of local po- 
litical administrators through French colonial rule, who instated the last kings of the central Onilahy Valley to govern the colonial project at the beginning of the $20^{\text {th }}$ century, thereby destabilizing their legitimacy among local people (Behariva de Moussa 2008: 87-88, 91). This also links to the fixed gendered administrative and political practice today, that for example in Belamoty there has never been a woman in formal politics.

Ancestral practices and discourses of ancestral "ethnic" or royal belonging that take place within ceremonies are thus also at the heart of gender. For the women I was in contact with, being female is intrinsically interdependent, ${ }^{6}$ by which I mean that it is always experienced in relation to other issues of differentiation and to other gendered people. Though being male or female in the central Onilahy Valley is conceptualized as a gender duality associated with specific reproductive expectations, specific 'ways of doing things', labor practices, imageries, values and emotional ideas, and is sometimes experienced as an unequal binary, being male or female in the central Onilahy Valley is a duality simultaneously experienced in a plural way.

In interactions on a daily basis and within ancestral contexts, one is never merely a woman, but a sister to a male sibling, sister to a female sibling, mother, daughter, a female child, a partner, a young woman, an older woman, or one of the elders in general. In matters of categorization, gender is always relational, situational, as frequently used generic terms to address others are interdependent gendered categories in themselves related to age in specific age group categories such a somondrara for a young woman or rakemba for an older woman, or related to generation, such as the

6 In current academia and activism concerning gender issues, the terms interdependent, intersectional, or interlocking have been applied to express this notion of interconnectedness of experience, categories, identities or belongings. This concept can be traced back to Women of Color, Black Women in the USA, and Postcolonial Feminists since the 1970s, among other scholars such as Patricia Hill Collins, bell hooks, Audre Lorde, Trinh T. Minh-ha, Chandra Talpade Mohanty and Anne McClintock. Though various in their theoretical approaches, whether from a more structural level of critique, from a standpoint of individual experience or identity, or from a representational level, the various metaphors and perspectives all have in common a feminist critique of oppression and inequality. Influential concepts in this context have been: double or multiple jeopardy (coined by Frances Beal 1970 and by Deborah King 1988), matrix of domination (Patricia Hill Collins 1990), doing difference (Candice West and Sarah Fenstermaker 1995), double/ triple oppression (Nira Yuval-Davis 2006, Helma Lutz 2007) and axes of difference (Gudrun Axeli Knapp and Cornelia Klinger 2005). Currently, the two terms intersectionality, coined by Kimberly Crenshaw in 1989, and interdependency, though not unique to the issue of gender, have become the most established and most frequently applied. As discussed by Katharina Walgenbach et al. (2012), interdependent offers the meaning of gender of always being experienced simultaneously with other factors, as is the case in Madagascar. Walgenbach et al. point towards the difference of seeing gender in intersection or in interdependency with other categories and thereby still separating them analytically, to seeing gender in itself as an inherently interdependent category, inseparable from other experiences of unequal power relations. 
term sister to all female siblings from either a female positionality, rababavy, or from a male positionality, anabavy; or related to age, such as zoky to address someone of the same generation who is older, or zainy for someone who is younger.

In this sense, though women's associations are defined within a binary gender concept by applying the term 'woman' vehivavy in their title, this term must be understood as an interdependent category. It is intrinsically connected to local networks of labor and ancestral practices, and relational positions created in interaction. However, as discussed in the realms of ancestral succession and inheritance, and of the formal political system as passed down from colonial structures, female and male are not equal. Though impactful, these are but two tropes of agency, and women's associations have been critical of them-by applying other forms of agency.

\section{Development Discourses on Women in Madagascar}

To date, my research on women's associations in Madagascar has shown that there have not yet been rigorous academic treatments of this topic. What can be found on official women's associations in Madagascar is situated within the trope of development. The problem therein lies in the political agenda within development discourse, and as I will show, the lack of acknowledgement of the complex notions of gender in Madagascar despite the existence of academic studies on the topic. ${ }^{7}$

I will now discuss two currently accessible Malagasy development reports which include the topic of women's associations. The two studies were published by official national and regional authorities of Madagascar in the context of national development, one specifically on the Southwest of Madagascar, Monographie de la Région Atsimo Andrefana (MRAA 2012?), the other specifically on the autonomy of women in

7 Over the past thirty years, many scholars have discussed simultaneous contradictory representations of gender in specific contexts (Bloch, 1989), dynamic perspectives on what it means to be born and categorized as male or as female, and have pointed out that reproduction in Madagascar is not a purely biological act, nor exclusive to women (Feeley-Harnik 1997, Middleton 2000, Astuti 1998, 2000); and have discussed discursive and interactional identity formation more generally within various areas and from differing perspectives (Larson 1995, Thomas 1995, Astuti 2009). This also includes critical perspectives on unequal access to particular practices, opportunities and resources for women concerning land-ownership and farming (Jarosz 1991, Gezon 2002), or education (Rognes 2008, Skjortnes and Zachariassen 2008, Veum 2008). Though Rognes, Skjortnes and Zachariassen, and Veum discuss how intersections with ethnic practices, class and general differences through personal situations are of immediate relevance in the daily lives of many Malagasy women, I suggest that a more interdependent approach in terms of taking the inseparable experience of class and ethnicity as a gendered person as a starting point rather than simply naming these factors as add-ons would be an impactful approach.

170 
Madagascar, Enquête nationale sur le suivi des objectifs du millénaire pour le développement à Madagascar: Promouvoir l'égalité des sexes et l'autonomisation des femmes (ENSOMD 2012-2013). Both reports open the topic of women with the United Nations Millennium Development Goal (MDG) to "eliminate gender disparity in primary and secondary education, preferably by 2005 , and in all levels of education no later than $2015, " 8$ and both reports include the mention of women's associations.

The report on the autonomy of women draws attention to women's associations in the following way: "The access of women to associational life is considered one of the direct indicators of the status of women, above all in the domain of participation in decision making," "L'accès des femmes à la vie associative est considéré comme l'un des indicateurs directs du statut de la femme surtout dans le domaine de la participation à la prise de décision" (translated by the author, ENSOMD 2012-2013, 35-36). The report's statistics, based on surveying women between the ages of 15 to 49 , show that $42 \%$ of the women were part of religious associations, $4.9 \%$ were part of sports associations, and $5.5 \%$ part of political or civic associations ${ }^{9}$. The small percentage of women in political and civic organizations is explained by the discriminatory political culture in respect to women in Madagascar. In addition to decision-making as an indicator of the status of women, which includes membership in associations, the other four indicators are education and literacy, salaries, participation, and domestic violence. The second half of the report focuses solely on the matter of violence against women.

Similarly, the report on the whole Southwest region of Madagascar dedicates a specific part to women under the headline "vulnerable groups," listing them together with older people, children and people with disabilities (MRAA 2012?). Throughout the entire report there are merely two mentions of women in relation to economic factors concerning labor practices and of one particular professional women's group, whereas it otherwise portrays women as often being, "victims of abuse and illiteracy, with local habits and customs often marked by polygamy and endogamy causing pitiful conditions for women," "[s]ouvent victimes de maltraitance, d'analphabétisme, avec la présence des us et coutumes locales souvent accentués comme la polygamie, l'endogamie, font, des conditions des femmes pitoyables" (translated by the author, MRAA 2012?, 219).

The foregrounding of violence against women and the victimization of women in the reports clearly relates to an outdated but pervasive image in the logic of develop-

8 http://www.un.org/millenniumgoals/gender.shtml (11.02.2018).

9 The first documented mention of women's associations in Madagascar was also in the context of the Norwegian Lutheran Missionaires in 1886, and was initiated by missionary's wives and followed gendered tasks such as collecting money and handcrafting (Skeie 2012: 155-156). 
ment - the necessity to save those vulnerable, monolithic groups of people in mostly postcolonial nations that allegedly have to yet be developed, indicating that they cannot save themselves, and equating the simplistic dichotomy of perpetrator and victim with men and women per se. Since the 1970s and 80s, with a growing involvement of women's issues in development aid, international gender studies scholars, particularly Women of Color and postcolonial feminists, have persistently critiqued these eurocentric perspectives on "Third World Women" (a.i. Trinh 1987, Mohanty 2003) and the assumed, "universal social and cultural inferiority of women," connected to Western dichotomies such as "domestic/public [..] which led [specific scholars] to the conclusion that maternal and domestic roles were responsible for the supposed universal subordination of women" (Amadiume 1987: 4).

Rather than drawing from the numerous discussions of scholars on the complexity of gender in Madagascar, UN development goals and parameters are simply taken as neutral points of reference by the authors of these reports (i.e. the Ministry of Decentralization: MRAA; Instat, The official Statistics Institution of Madagascar: ENSOMD). Though I certainly do not question the urgent matters of violence against women and the relevance of decision-making power, measuring women's autonomy according to pre-set standards, parameters, or what are considered relevant spheres of decision-making can only end in pre-set results: again reifying the necessity of saving the vulnerable from outside. The chosen indicators such as education and literacy, salaries, participation, or customs such as polygamy and endogamy must be more intensely investigated in relation to the actual conditions in Madagascar, where few rural men are literate and have formalized jobs, nor regular, reliable salaries, where young men are equally affected by endogamous arranged marriages, which are not per se experienced as violent, and where formalized polygamy commonly implies wealth and safety, and neither practice automatically results in a more "pitiful" situation for affected women.

It would, however, be interesting to question women and men in Madagascar on what they understand as decision making (beyond how the household's money is spent, as noted in the ENSOMD report). Also, specifically concerning women's associations, I would question whether it is really the access to women's associations and not their particular activities that are indicators of decision making and thereby the status of women, which again relates back to the question of which spheres of decision making are considered relevant. Whereas for example the report on development in the Southwest of Madagascar describes women's associations' activities in the form of handcrafting and fundraising for the distribution of rice and soap to those in need in the section on vulnerable groups (MRAA 2012?: 148), women's associations are no longer named under the headline of civil societies, "Les societés civiles" (MRAA 2012?: 276-277). This section does, however, mention congregations, religious soci- 
eties and organizations of minorities (particularly referring to associations of disabled and people from other regions), and even includes the head of the lineage as part of civil society, as he holds a highly important position within patriarchal practices and is influential in local politics. Women's associations were either overlooked or are apparently not considered part of civil society.

The lack of including the complexity of gender, combined with the focus on women's vulnerability, the issue of women as daily agents of decision making, and as acting in specific spheres through specific modalities, is left undiscussed as it seems to not be recognized as part of the pre-set parameters privileging certain kinds of agency and autonomy.

\section{The Performances of Women's Associations}

Civic associations in general, and women's associations in particular, are thus on the agenda of discourses on development and women's autonomy in Madagascar as the "access of women to associational life is considered one of the direct indicators of the status of women" (translated by the author, ENSOMD 2012-2013: 35-36). To further engage with the implications of the formal institutionalization of women's associations in the central Onilahy Valley in relation to questions of different modalities and spheres of gendered agency, I discuss the actual performances of women's associations and their significance in greater detail in the following section.

The performances of women's associations consist mainly of singing and dancing. Their choice of representational songs during events organized by local political-administrative representatives is either from a specific women's associations' repertoire, which talk about being women (more specifically about being "women who are arriving," as the united arrival as a group is so relevant within various important events), about their work expertise, and as mentioned above, about men who have several guns and wives, indicating great wealth, young men who protect villages from zebu thieves, and more recently, about a convention against zebu-cattle theft called dinabe that was introduced in 2014. They also sing songs drawn from the repertoire of songs of particular ancestral occasions, such as the circumcision ceremony. This specific context is also the one from which the dance and its representational meanings is taken. Like the women's associations I engaged with in other areas of Madagascar (Andranotakatse, Betioky; Maromandia, Île Ste. Marie), the groups I worked with represent themselves with specific ways of dancing which form an important part of their local cultural identity, and in which they are consequently highly competent. In the central Onilahy Valley, this particular dance associated with local identity is that of the circumcision ceremony. The dance called bereny includes various embodied material and action 
signs, ${ }^{10}$ as noted in the introductory description of the women' association's performance. The most significant aspect for the recognition of bereny is that the dancers hold their hands up at about shoulder and head height with open palms, rotating the wrist every two to four beats, or swaying their palms downwards and upwards. This action sign is called velataña or alañala, which means 'open hands.' This key dance act commonly includes holding an umbrella in one hand, equally rotating and swaying it downwards and upwards. The velataña is a sign of joy, happiness and pride and was noted by dancers to be, "what makes us Tanosy," "mahatanosy anay" (Interview performance group Petraka, Saloavaratsy 2011). This statement of marking a practice with local ethnic identity was similarly made various times about the circumcision ceremony (savatsy) itself, the context in which these dance acts are commonly performed and are central to.

\section{Dancing as a Signifying Act}

In order to understand the vast meanings of the dance, why it is considered joyful and Tanosy, I discuss it in its actual context, savatsy (circumcision ceremony), in which dancing the bereny most significantly represents female gender and motherhood.

On the third day of this typically four-day ceremony, the boy's paternal family picks up the maternal family from (a) near-by tamarind tree(s) in the forest and invites them into their village. Coming from the village, the paternal family moves in group locomotion towards the tree(s) and starts dancing in one spot, initiating an oval-shaped circle of which the maternal family forms the opposite side in front of the tamarind tree(s). The mother and all the female siblings of the parents' generation of the boy to be circumcised then dance the bereny with an umbrella and their hair in talim-bilo, whereas the older generations of women dance the bereny without those embodied signifiers. The father and all male siblings conduct the mamoban-defo, holding spears, sticks or guns while hopping on one leg. Whereas the paternal family is accompanied by a drum-flute ensemble, the entire maternal family sings the bereny song announcing their arrival (cf. Randrianary 2001: 102): "bereny izao avy izao," "numerous mothers are arriving."

10 The term action sign stems from Drid Williams' semasiological movement anthropology. In analogy to the Saussurian linguistic sign it consists of a movement image and a concept, it refers to (Williams 2002: 26); An action sign must be understood in its context, depending on the person(s), deixis, space and context and may include other embodied signs such as clothing and paraphernalia or vocal signs such as exclamations and cries. It is particularly useful in dance and movement research when the Western concept of "a particular dance" does not quite grasp the act, as it refers to a unit relevant in local movement taxonomy. 
The dominant narratives about the circumcision ceremony conveyed in interviews I conducted tell the story of two "competing" families that in the end agree upon the circumcised boy to become a legitimate heir and successor to his paternal ancestors (cf. Gruber 2015a). After this danced confrontation, which may also be interpreted as a fight (also noted in Rabenirina 1998), the two families enter the paternal village together, and a formalized speech and blessing takes place at dawn. Several of the interactions creating the four-day ceremony, such as the dance acts, the village space contrasting the "wild" forest, and the speech of the head of the paternal family at dawn, embody and verbalize gendered ideas. This includes images and ideas of male strength and ability, the norm of patrilineal descent, and patriarchal and gerontocratic structures of gendered and generational family relatedness. Simultaneously, the circumcision ceremony emphasizes the role of mothers within this idealized ancestral reproduction. In this context and beyond, motherhood, however, does not uniquely relate to female gender, but all maternal family members are considered and announced as the 'mother of the child', renin-jaza. The maternal uncle holds a particular position and is literally called 'male mother', renilahy (cf. Gruber 2015b).

Though this description of ceremonial practices risks producing a seemingly fixed structuralist imagery of what may be termed "customs and traditions," the Malagasy concept of 'the ways of the ancestors' fomban-drazana offers a more dynamic perspective of practices as ways of knowing in the Onilahy Valley. It is a decisive paradigm that indicates that which can be translated as "tradition" in the sense of a continuation of certain practices over time is necessarily something that is repeatedly done, narrated and experienced, not simply dictated. Though the model is passed on by one's living ancestors, the focus lies on the actual act of doing things, within everyday life and particularly within festivities connected to ancestral blessings such as the circumcision ceremony (cf. Gruber 2018).

These historic and discursive actions of 'the ways of the ancestors', verbal and embodied, relate to how philosopher Judith Butler conceptualizes performativity: as repetitive (gendered) acts that are marked by being self-referential and citational (i.a. Butler 1998, 2004); the way things are done continuously and recurrently becomes normalized, and legitimizes or disfavors current actions, and always includes the potential to be dynamically changed and transformed, deliberately or unaware. Relating the concept of performativity to the Malagasy concept of fomba, 'the way of doing things', was first brought up by anthropologist Rita Astuti as a way of understanding local "ethnic" and gender constructions as interactional and performative (1998). The term fomba may refer to a specific practice or ceremony, depending on the context and the way in which the term is used, or it may refer to a specific way of doing a practice, a kind of quality of doing things. Still, though fomba and thus fomban-drazana 'the ways of the ancestors' contains a dynamic notion through its action-centeredness, so 
something can become a tradition when having been done repeatedly, it is simultaneously a matter of discursive authority and potentially reproduces unequal power relations, (re)creating particular patrilineal and patriarchal structures in which women are not given the space to hold representative, formalized speech, which was also noted by a representative of a women's association (interview Zafy 2012).

In interviews in the field, I was repeatedly told that the bereny dance "means the circumcision ceremony savatsy." By dancing the bereny in other contexts, the women's associations cite particular acts indicating (ungendered) motherhood; and motherhood may be associated with a caring, loving person that not only includes the birthmother, with female gender, with younger generations and thus in turn with the reproduction of descendants, with patrilineal, patriarchal, and geronotocratic ancestral practice, and more generally with the emotions of joy and happiness, fifalia. The women's associations then apply this celebrated dance, this recognized 'ancestral way of doing things' and thereby cite the imagery and imaginary associated with its context to represent themselves as a women's association. In some cases, one of the members also danced as a man with the typical signifiers - a cloth over one's shoulder, salampy, a hat, and the spear for dancing the mamohan-defo as described above.

Dancing as a signifying gendered act, particularly, but not exclusively, for and by women during various important ancestral contexts, is an acknowledged mode of agency and must therefore be factored in as to why women chose to found and/or participate in the associations as members, and particularly why their performances are highly appreciated-recognizable by the monetary offerings they receive from the audience.

\section{Pre-existing Networks}

The modality of representation is but one reason as to why women's associations were so greatly welcomed when registration on the administrative level of commune became possible. Those members who had already been part of the larger women's association of the entire Belamoty commune which had been founded in 2008 additionally noted their content with the consequential division into smaller groups. There had been some disagreements and conflicts in the larger association. This resulted in newer, more numerous associations being more differentiated, and in some members belonging to more than one women's association. Though the reasons for membership vary from member to member, I suggest that the rapid success and approval of the associations lies in pre-existing gendered structures that were already part of everyday lived experience.

By following various invitations, and thereby networks of family relatedness to different ancestral occasions in the central Onilahy Valley throughout my research, it

I 76 
became clear to me that the local male-dominated ancestral and political-administrative practices are not the only gendered networks. These male-defined structures of relatedness and power often visible in living arrangements such as virilocal villages, particularly during ancestral events, co-exist with a more mobile network of bonds among related women, reproduced and experienced by both women and men. The female siblings (including cousins) who grew up together and their respective mothers commonly sustain important networks with each other, even though they frequently change their location of residence and labor for a partnership with a man that potentially includes having children together. These networks along a maternal line are continuously held upright through emotional, economic and financial loyalty such as assistance in various forms of labor including care work, as well as loaning and contributing money. Again, as many women live virilocally, these networks can be quite widespread. These structures are very similar to institutionalized women's associations.

Though their existence is not explicitly verbalized in (representational) research interviews or formalized ceremonial talks, they are embodied in everyday action and ancestral settings. In most cases, marriage creates a multi-positioned and potentially more precarious lineage affiliation for female partners (with the exception of arranged marriages among closer paternal cousins), as they not only move to a village that was not the one they grew up in, but also become part of a new ancestral line through marriage, an affiliation they would lose again through divorce. As a result, they often participate equally as members of both families, also within ancestral contexts. For example, in the context of a circumcision ceremony in 2008, a mother danced on her male partner's side (the paternal family) as the central mother of the child to be circumcised, yet one week later, she danced with her own patrilineal family, next to her brother as part of the paternal family. If her sister's son were to be circumcised, she and her brother would then be dancing on the maternal side of the circumcision ceremony. Also, within the context of dancing during the circumcision ceremonies, I observed that the double position the female partner retains in terms of lineage is spatially visible: in some dance spaces the birthmother is the only one to dance next to members of both sides, whereas the members of either lineage dance in spatial opposition, facing each other, and only next to their relational lineage members. This spatial aspect of dancing is generally very significant in terms of belonging to several dance spaces of various contexts.

In dance, then, the multiple relational, interdependent positioning and belongings are negotiated, embodied, publicly performed, and consolidated (cf. Gruber 2018). This effect of ancestral practices simultaneously creating gendered networks according to patrilineal descent, strong bonds among female siblings along maternal lines, and male representational bonds certainly influenced the fast acceptance of an accessible, formalized form of women's groups. 
Based on in-depth interviews with members and presidents of six women's associations, it can be stated that the motivations for founding associations vary, yet point towards several structural issues in gendered acts, practices and experience.

One aspect pointed out by members of the associations was the desire and goal to demonstrate unity and collectivity in their gendered struggles with poverty, child-rearing, death, and health issues. The head of one of the longest standing associations, for example, stated that one of their biggest successes was to find out that she and the few other original members had a common idea, "We found out that we women have a common understanding. That is what we found out. [...] The reason to start an association is that we have a common understanding, the same thoughts and poverty in common." "Hitanay tamin'izay, hôtchan miray hina zahay vehivavy. Izay le hita izy. [...] Antony hanovanay fikambanam-behivavy miray, miray hinariny [hina], rei hevitse [hevitra], miray fijaliana" 11 (Interview Rose 2012). The phrase Vehivavy Miray Hina, literally 'women of one accord' was also the phrase that was used to frame women's associations in Madagascar's Second Republic, as the promotion of women's issues was on the political agenda of President Didier Ratsiraka's Socialist Charter of 1975 (Fee 2000: 20).

Pooling their organizational and monetary resources is an essential goal, as one founder noted, "we women wanted to be an association so that when there is something that must be done, we can unite," "de hoe tianay hikamabana izany zahay vehivavy, sa laha mba misy raba azo atao dia bikambana" (Interview Zafy 2012). This support for each other is particularly needed in times of hardship, "we help each other in the many cases of death," "mifamohananay zahay mombamomba ny faharatsia maro" (interview Pela 2012). In addition to collecting money to offer on specific occasions, money is also collected regularly, which is also a goal noted in the standardized associational bylaws. The collected money is then used as an offering, or as a loan for when a child is sick, someone needs to go to the hospital, to conduct a small business, or more generally, "to save each other," "mba sôvenanay izany" (Interview Rose 2012). One group, however, also noted that some of the members were not able to bring up the regular contribution of MGA 500 per month (approx. 16 eurocents in 2014).

Apart from two groups who founded an association because they saw other groups forming and wanted to do the same, there is one particular critical idea that was relevant to almost all of the founding narratives of the associations and even caused its formation in one case: the discontent with practices in the context of mortuary cere-

11 Malagasy interviews are transcribed in Tanosy dialect.

I 78 
monies. It is common for family groups to visit the deceased's family in cases of death and to offer monetary and material gifts, famangia fahoria. In return, the organizers of the mortuary ceremony offer food and drinks, famaba. In one case, at the mortuary ceremony of their youngest uncle, some of the female members of the family, aware of the expenses this practice entails, decided not to accept this offering (tsy aferana, or tsy mandray) - this was their initiating spark to form a women's association. Some women's associations additionally do not accept offerings when visiting happy occasions such as the circumcision ceremony. Their criticism of this ancestral practice that may lead to even more poverty is, however, gendered; the head of a women's association later added that men must still accept this return offering.

As this narrative indicates, although these perspectives may be viewed as critical of the status quo, the associations were never noted to be perceived as non-conforming or threatening during my research. Their plans, demands and needs coincide with typical issues women take responsibility for: birth, health, clothing, school fees, school utensils, raising children, and feeding their household, particularly in times of hardship between harvesting seasons. Two associations also noted that they wanted to work together to make money with sewing, producing mats and baskets, and one group wanted to build a house for the association for meetings, discussions, handicrafts, or to use as a restaurant. All groups also asked me for support in the form of sewing machines, equipment for farming, a water pump, or construction material to build a house.

There were, however, also some concrete assessments of gender inequality. In two interviews, some women related female poverty to societal inequality concerning inheritance. As women generally do not inherit in Tanosy families, they do not own any property or land. They commented that this is their elders' 'way of doing things' (fomba ny raimanadreninay). Furthermore, on a representative level, one member noted that being a woman was not counted as equal to being a man, "men's rights are stronger, we [women] are still below," "manjaka ny zo mba lebilahy, zahay mbo ambany" (Interview Sedera 2012). This spatial categorization of higher and lower in a hierarchical sense is also applied in a physically embodied sense toward elders and in seating arrangements in the house. When talking to or greeting elders (particularly men), one must try to remain spatially lower than them to demonstrate respect; in a house the North and East, which are considered 'high', is where respectable guests, older men and men generally are seated, and the South and West, which are considered 'low,' is where women and children sit. The hierarchical spatial opposition of lower and higher may also be exchanged for the oppositional hierarchy of 'stronger' matan$j a k a$ and 'weaker' malemy, in relation to men and women. However, only two founders of associations specifically related their reason for organizing to not having the same civic rights, $z 0$, as men (interviews Rose 2012, and Zafy 2012). Most members 


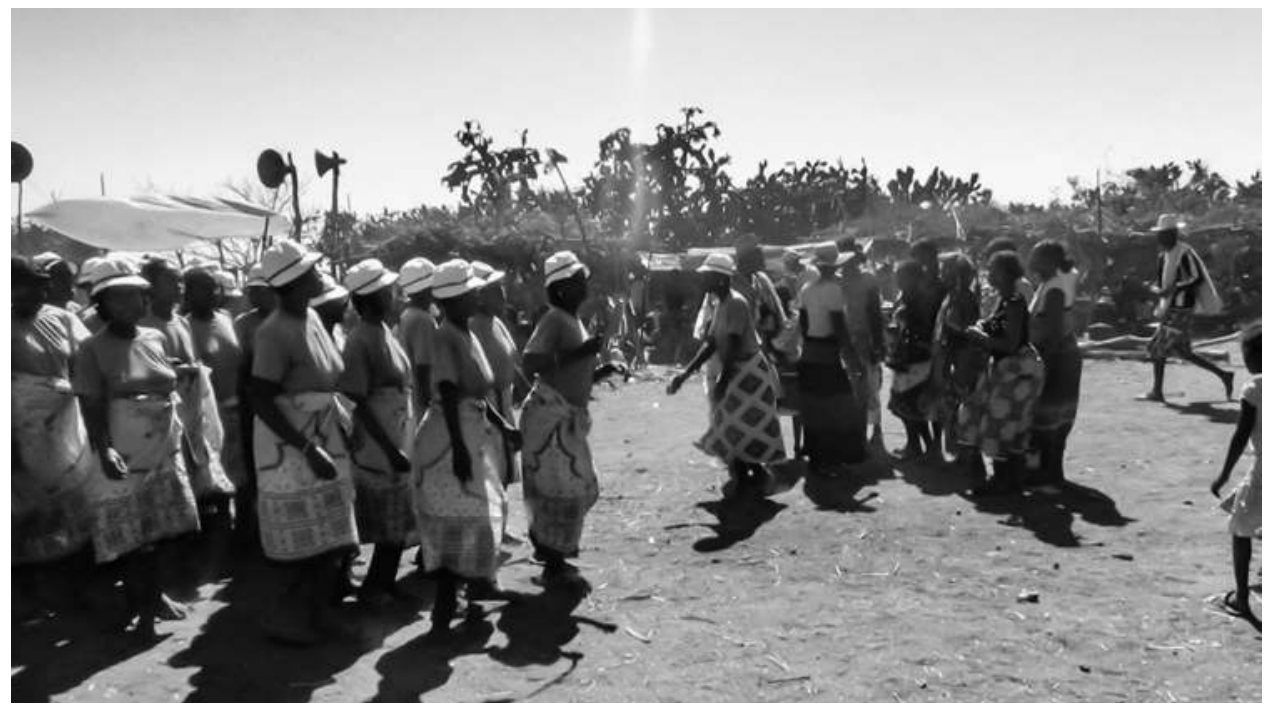

Figure 2: The Savazy II Women's association arriving at a mortuary ceremony with some money in a plastic bag on top of a stick. Screenshot, Soamanonga 2012.

of women's associations, and other women, did not voice wanting to break with their gendered roles in conversation with me.

Though potentially indicating a generally critical position toward a male-dominated society, the women's associations are spoken of highly by people of any gender. Their choice to appear as a united women's group, equally contributing to various events, is a major part of this. During most ceremonies, dancing is decisive for people to establish their particular relational positionalities. In many spaces of dancing within various occasions, the majority of dancers are female, and the relational generation, age and lineage affiliation also play a role in who dances when, with whom, creating which space. Often the idea connected to a specific dance space is then associated with female participants. Particularly during mortuary ceremonies for example, in-law women take up the emotional labor through dancing, by creating spaces of joy and happiness in contrast to sadness and mourning. And even more generally, dancing is often a signifying act of life, happiness and healing (cf. Gruber 2018).

By appearing and dancing together as a united group, the associations position themselves in respect to the organizers of the event. They conduct their singing in a particular spatial manner, in locomotion through the larger festive space-doing carnaval - and when entering ceremonial spaces as a united group to visit and contribute money, mamangy (see Figure 2), and for emotional support of the respective organizers, "in the case of a death we go there to be sad together, in cases of a joyful event, we go there to be happy together," "misy fahafatesana izany miaramiory izany tsika, misy

I 80 
bafaliana miaramfaly tsika" (interview Rose, 2012). This notion of "arriving" at important occasions, inferring support and alliance, is central to networks in the central Onilahy Valley, and is most often executed in the form of dancing.

The choice in performance and the fact that the women's associations' critical voicings concern what is for the most part considered typical women's topics adds to the general support of these associations. Particularly when the choice of topic, actions and representation offer an overall appreciation, institutionalization has its effects. Institutionalization has led to an impressive level of visibility and to some changes in terms of public speaking and self-representation.

\section{Relating Perspectives}

Though the perspective of the individuals and the women's associations as a whole give a quite positive, hopeful image of women's associations creating formalized structures that help in supporting each other, and of strategically applying acknowledged performatives to create potentially new performatives, the question relating back to the political incentive to offer local registration comes back to mind. What was the politics behind the incentive for local registration in 2012?

In the report on the development in the Southwest of Madagascar, a Madagascar Action Plan (MAP) is introduced with eight millenary development objectives, many of which relate to spheres considered women's issues in Madagascar such as health and raising children. Alongside fighting poverty and famine, offering primary education to all children, reducing child mortality, enhancing healthcare for mothers, fighting HIV/AIDS, ensuring environmental sustainability, and promoting equality and giving power to women, one of the objectives is developing global partnerships for development (MRAA 2012?: 8-9, 12).

In the context of Madagascar, which is categorized as one of the poorest countries in the world, global partnerships particularly indicate international donor politics. In his book The Politics of Institutional Failure in Madagascar's Third Republic, which contains an extensive analysis of the situation of civic society organizations in Madagascar in general, political scientist Richard Marcus notes that the Malagasy state has become highly dependent on NGOs and international donors, having been at the receiving end of development aid ever since it went bankrupt under Didier Ratsiraka in 1979 (Marcus 2016: 43), when "international donors saved the country from the abyss" (Marcus 2016: xi). Furthermore, there has been a trend by international donors starting in the 1980s, noted by Marcus, to promote civic society organizations (CSO) as they contribute to rural development: "international organizations such as the World Bank came to understand the importance of CSO mapping" (Marcus 2016: 139-the 
World Bank is, according to Marcus, Madagascar's "largest donor by far" (2016: 4). As was generally the global trend, the World Bank's development aid politics has also included the promotion of women's rights and gender equality as a central aim since the 1980s (Tripp et al. 2008). During that time, development agencies prepared several studies on women in Madagascar and several conferences on women's rights in Madagascar were held (Fee 2000: 33).

Given this discerned relevance of civic associations and of women's associations for development and donor politics, I suggest relating the politics of promoting local registration to the development discourse. The report on development in the Southwest of Madagascar includes the note that after a decline in women's associations due to a lack of finances for renewing their statutes, 2008 was a turning point when regional politicians announced their revival to be one of its priorities (MRAA 2012?: 219). This links to the statement of the report on women's autonomy discussed above, noting that the "access of women to associational life is considered one of the direct indicators of the status of women" (emphasis by the author). Registration at commune level made this process immensely more accessible for women, and they did not have to pay a fee. This incentive for local registration must be seen as part of women's policy, as for other associations such as ethnic associations or youth associations, registration at commune level had already been possible before.

To consider the positive effects of women's associations in the central Onilahy Valley, we must therefore, as feminist development scholars Sohela Nazneen and Maheen Sultan suggest, critically engage with development politics and its influence on the feminist voice in the Global South, noting " $[t]$ he epistemic power of donors to shape the feminist agenda and activism, and to influence the state gender agenda" (2014: 15 , italics in original). From a perspective of postcolonial feminist critique, we must therefore question how gender, which is understood in specific yet diverse ways, can ever be statistically represented as a marker for "development," or can ever be statistically represented period. And of course, we must question how scholars such as myself can seriously deal with gendered issues, as there is inevitably a political agenda, no matter if we are talking about cultural practices and discourses we ourselves are part of or not. Looking at gender as an interdependent category beyond an alleged binary is therefore unavoidable, and (unfortunately) nowhere near being a simple solution that would make gendered issues less complex, unless reproduced as a new automatic pre-set "toolbox" that is applicable in the same way globally (cf. Aguinaga et al. 2013: 45 , and their critique of Western epistemological preconceptions within development models). This includes viewing the politics of women's associations with caution, as many of the questions of gendered practices, formalized structures and acknowledged gendered modalities of action relate to postcolonial and neocolonial transnational power relations. This includes the introduction of women's associations within the 
missionary context, the abolition and instrumentalization of former political and cultural structures through colonization, which most likely affected the current "discriminatory political culture" that is mentioned in the report above, and the neo-colonial dependency on international donors and NGOS, which necessarily builds on and instrumentalizes pre-set indicators of "development," be they Western epistemological preconceptions or the methodology of statistics.

In the case of these particular women's associations in Madagascar, I suggest that institutionalization was particularly "successful" because the women's networks had already existed in a non-formalized ways, and they employed and further developed acknowledged forms of agency. This pre-existence in varied forms cannot be statistically represented, as it is a matter of embodied practice rather than verbally represented and institutionalized practice, in contrast to the head of the lineage who is even included as part of civil society in one of the reports. This again links back to the colonial implementation of patriarchal representatives in formal administration and politics in colonial times, which the postcolonial state was built on.

Formal institutionalization and the consequential rising number of official women's associations in Madagascar has had and will have its effects. By re-contextualizing the legitimized citational gender performative acts as a united group,-yet, of women without a male representative-the women also negotiate the chance for representative speech as they arrive during different occasions, announcing their own offerings in formalized dialogue with the organizers. During a mortuary ceremony in 2014 for example, a non-official women's group arrived and gave their offerings, and then took part in a formalized dialogue under the tamarind tree, commonly held by the male representative of a group of guests. One more outspoken representative of a women's association pointed out that otherwise women may only speak during the 'festivity of women' (International Women's Day; Interview Zafy 2012). Dancing thereby becomes a modality of women's agency with the potential acknowledged effect of taking up space and claiming the microphone during the festivities. Due to this rootedness in the ancestral context, the given gender and generational notions and structures are not overtly threatened. Rather, the citation of other contextual settings like the circumcision ceremony offers a potential performative effect to expand the opportunities for female group representatives to engage in formalized speech, and in the long run to potentially normalize new 'ways of doing things.'

Though my own position is already entangled in all of the presented perspectives, I will add some further reflections. As ethnomusicologists and ethnochoreologists, I believe that we can contribute unique discussions, because we examine forms of agency and expression that are often overlooked as they are not acknowledged as political, or dangerous, or even relevant as an analytical tool to understand other, apparently more important aspects which are actually political. This may give us the advantage of being 
able to talk about very serious issues without interrogating anyone, yet it also gives us the responsibility to discuss serious issues and to be aware of our own (political) research agenda. As a feminist researcher, I was very impressed and intrigued by the performance of women's associations from the very beginning. However, during my research process, even as an ethnomusicologist, I also noticed that in my reflections on the negotiation of gendered power relations I quickly fell into the trap of giving formalized speaking greater value than singing and dancing, which plays into my own Western epistemological framework of gender studies, in which linguistic scholars have played a directional role, and of what is considered political and non-political. Yet, working with several women and women's associations and simply listening to women I lived with gave me a better understanding of their engagement, which I consider to be political. This chapter is thus a work in progress that will change through additional long-term, multi-sited research and collaborations, as there are many questions about the political self-understanding, their actions, and the long-term effects of these associations left for further discussion.

\section{Conclusion}

On the one hand, there are several reasons why associations, and therefore the ability to form associations on the administrative level of commune, are supported by politicians, one of which is most certainly to uphold the international reputation of Madagascar as becoming more democratic (or in the Malagasy trope, decentralizing), and promoting women's rights. On the other hand, the intense poverty experienced by the greater part of the population of Madagascar, which is connected to political and economic errors and corruption, and to postcolonial-transnational power relations, makes associations attractive both for members and for the State in terms of appeasing NGO and donors' gender equality agenda. The increase of women's associations clearly connects to transnational and national politics and economics, but more importantly it relates to bottom-up socio-political strategies developed by women, who include dance and performance approaches in taking up space and being seen and heard. From local perspectives the main aims and ambitions are dealing with poverty, the necessity to make and collect money to support each other financially, with women's rights being one of many entangled issues.

Though the development reports suggest otherwise, women in Madagascar are not merely "vulnerable" victims, but people who have for a long time been organizing in socio-economic networks through everyday practice in which gender as an interdependent category comes to play; these networks are also highly relevant to discussing and negotiating experiences of violence. Women deal with the same issues as men yet

I 84 
are affected quite differently and consequently have different ways and modalities of addressing them, such as song and group action. In their presentation of being women through the means of their associations, they deal with issues of poverty, unevenly distributed wealth, labor expertise, survival, and being mothers-all topics that affect both men and women. The notion of women's rights must therefore be related to the actual reality of women's situations, what they conceive as relevant in their lives and not assumed to be universally the same.

The complexity of interdependent categories and belongings used on various different levels, and the question of relating them to one another in a critical way is a crucial aspect in ethnomusicological /-choreological research and writing. We must remain critical and culturally reflected toward gender hierarchies that create forms of violence though practices of male succession and inheritance, without reinforcing a simplistic dichotomy of domination and subordination. Positioning a 'lower' or 'softer' gender as vulnerable per se is simplistic; and tends to be a strategic tool within the international and national development discourse to seek financial aid. We must relate perspectives of gender scholarship to particular people and their national and transnational contexts-as ethnomusicologists frequently intend to do. To relate and implicate a lived interdependency and gender performative theory in order for theoretical constructs such as performativity and intersectionality to "remain $[. ..] \mathrm{dy}$ namic and generative concept $[\mathrm{s}]$, it is critical to retain the incoherent, contingent and contextual nature of such praxis" as Richa Nagar and Amanda Lock Swarr pointed out (2010: 18). That means we must examine the theory found in specific practices. Analyzing the acts of women's associations and particularly their representational choice of created and citational songs and dance must be contextualized within their aims, motivation and structural aspects beyond formal institutionalization in order to shed light on interdependent, politically relevant and entangled processes of agency and gender.

\section{References}

Aguinaga, Margarita, Miriam Lang, Dunia Mokrani, and Alejandra Santillana. 2013. "Development Critiques and Alternatives: a Feminist Perspective." In Beyond Development. Alternative Visions from Latin America, M. Lang, and D. Mokrani, ed. Quito: Transnational Institute; Rosa Luxemburg Foundation, 41-60.

Amadiume, Ifi. 1987. Male Daughters, Female Husbands: Gender and Sex in an African Society. London: Zed Books.

Astuti, Rita. 1998. “'It's a Boy', 'it's a Girl': Reflections on Sex and Gender in Madagascar and Beyond." In Bodies and Persons: Comparative Perspectives from Africa and Melanesia, M. Lambek and A. Strathern, eds. Cambridge: Cambridge University Press, 29-52. 
2000. "Food for Pregnancy: Procreation, Marriage and Images of Gender among the Vezo of Western Madagascar." Taloha 13: 173-192.

. 2009. "Revealing and Obscuring Rivers's [sic!] Natural Pedigrees: Biological Inheritance and Kinship in Madagascar." In Kinship and Beyond: the Genealogical Model Reconsidered, J. Leach and S. Bamford, eds. New York: Berghahn, 214-236.

Beal, Frances [Beale, Frances]. 1970. "Double Jeopardy: To Be Black and Female.” In The Black Woman. An Anthology, T. C. Bambara. ed. New York: New American Library, 90-100.

Behariva de Moussa, Aurélien. 2008. "Conception de l'espace dans la tradition Tanosy du Moyen-Onilahy. Essai d'endo-ethnologie.” PhD diss., Université de Toliara, Toliara.

Bloch, Maurice. 1989. "Descent and Sources of Contradiction in Representations of Women and Kinship." In Ritual, History and Power: Selected Papers in Anthropology, M. Bloch, ed. London: The Athlone Press, 153-165.

Butler, Judith. 1988. "Performative Acts and Gender Constitution: An Essay in Phenomenology and Feminist Theory." Theatre fournal 40/4: 519-531. 2004. Undoing Gender. New York: Routledge.

Collins, Patricia Hill. 1990. Black Feminist Thought: Knowledge, Consciousness, and the Politics of Empowerment. New York and London: Routledge.

Crenshaw, Kimberle. 1989. "Demarginalizing the Intersection of Race and Sex: A Black Feminist Critique of Antidiscrimination Doctrine, Feminist Theory and Antiracist Politics." University of Chicago Legal Forum 1: 139-167.

ENSOMD. 2013. "Enquête nationale sur le suivi des objectifs du millénaire pour le développement à Madagascar. Objectif: 03. Promouvoir l'égalité des sexes et l'autonomisation des femmes." Report by Instat-Madagascar and Vice-Primature chargé de l'économie et de l'industrie secrétariat général, Madagascar, 104 pp.

Fee, Sarah. 2000. "Note introductive sur le genre à Madagascar." Taloha 13: 13-35.

Feeley-Harnik, Gillian. 1997. "Dying Gods and Queen Mothers: the International Politics of Social Reproduction in Africa and Europe.” In Gendered Encounters, M. Grosz-Nga and O. H. Kokole, eds. New York: Routledge, 153-181.

Gezon, Lisa L. 2002. "Marriage, Kin, and Compensation: A Socio-Political Ecology of Gender in Ankarana, Madagascar." Anthropological Quarterly 75/4: 675-706.

Gruber, Cornelia. 2015a. "Embodied Narratives. Are we Still Fighting, or are we Dancing?" In Dance, Narratives, Heritage: $28^{\text {th }}$ symposium of the ICTM Study Group on Ethnochoreology, E. Ivancich Dunin, ed. Zagreb: Institute of Ethnology and Folklore Research, 78-83. 2015b. "(Un)gendered Mothers: Songs of the Boy's Circumcision Ceremony Savatsy." In Transgressions of a Musical Kind. Festschrift für Regine Allgayer-Kaufmann zum 65. Geburtstag, A. Brunner, C. Gruber, A. Schmidhofer, eds. Aachen: Shaker Verlag, 199-218. 2018. "Gendered Dance Spaces: The Interdependency of Gender through Dancing in Southwest Madagascar.” Ph.D. dissertation, University of Vienna, Vienna. 
Jarosz, Lucy. 1991. "Women as rice sharecroppers in Madagascar." Society \& Natural Resources 4/1: 53-63.

Klinger, Cornelia and Gudrun-Axeli Knapp. 2007. "Achsen der Ungleichheit - Achsen der Differenz: Verhältnisbestimmungen von Klasse, Geschlecht, ,Rasse“/Ethnizität.“ In Acbsen der Ungleichbeit. Zum Verhältnis von Klasse, Geschlecht und Ethnizität, C. Klinger, G.-A. Knapp and B. Sauer, eds. Frankfurt am Main/New York: Campus, 19-41.

King, Deborah. 1988. "Multiple Jeopardy, Multiple Consciousness: The Context of a Black Feminist Ideology.” Signs 14/1: 42-72.

Larson, Pier M. 1995. "Multiple Narratives, Gendered Voices: Remembering the past in Highland Central Madagascar.” The International Journal of African Historical Studies 28/ 2: 295325.

Lutz, Helma. 2007. "'Die 24-Stunden-Polin' - eine intersektionelle Analyse transnationaler Dienstleistungen." In Acbsen der Ungleichbeit. Zum Verbältnis von Klasse, Gescblecht und Ethnizität, C. Klinger, G.-A. Knapp and B. Sauer, eds. Frankfurt am Main/New York: 210-234.

Marcus, Richard R. 2016. The Politics of Institutional Failure in Madagascar's Third Republic. London: Rowman \& Littlefield/Lexington.

Middleton, Karen. 1997. "Circumcision, Death, and Strangers." Fournal of Religion 27 /4: 341373.

. 2000. "How Karembola Men become Mothers." In Cultures of Relatedness: New Approaches to the Study of Kinship J. Carsten, ed. Cambridge: Cambridge University Press, 104127.

Mohanty, Chandra Talpade. 2003. “'Under Western Eyes’ Revisited: Feminist Solidarity through Anticapitalist Struggles.” Signs 28 (3): 499-535.

MRAA. 2012?. Monographie de la Région Atsimo Andrefana. Report by the Ministry of Decentralization, PNUD - Programme des Nations Unies pour le Développement, and Cabinet Sarandra - Conseil et Développement, Toliara, Madagascar.

Nagar, Richa, and Amanda Lock Swarr. 2010. "Introduction. Theorizing Transnational Feminist Praxis.” In Critical Transnational Feminist Praxis, A. L. Swarr, and R. Nagar, eds. Albany: State University of New York Press, 1-20.

Nazneen, Sohela, and Maheen Sultan. 2014. "Introduction: Voicing Demands: Feminist Activism in Transitional Contexts." In Voicing Demands: Feminist Activism in Transitional Contexts, S. Nazneen, and M. Sultan, eds. London: Zed Books, 1-28.

Oyěwùmí, Oyèrónkẹ́. 1997. Making an African Sense of Western Gender Discourses. Minneapolis: University of Minnesota Press.

2005. "Visualizing the Body: Western Theories and African Subjects." In African Gender Studies: A Reader, Oyèrónkẹ Oyěwùmí, ed. Basingstoke: Palgrave Macmillan, 3-21.

Rabenirina, Jean-Jacques. 1998. Le rituel mobilisateur de la circoncision: savatsy ou cérémonie de circoncision chez les Antanosy de Soamanonga. Lille: ARNT.

Randrianary, Victor. 2001. Madagascar: les chants d'une île. Arles: Cité de la Musique, Actes Sud. 
Rognes, Torunn H. 2008. "Une rencontre avec la vie estudiantine à l'université de Toliara." Talily. Revue d'histoire 13-15 (Numéro special: Problème d'education des filles): 120-141.

Skeie, Karina Hestad. 2012. Building God's Kingdom: Norwegian Missionaries in Highland Madagascar, 1866-1903. Leiden: Brill.

Skjortnes, Marianne, and Heidi Holt Zachariassen. 2008. "Une perspective sexiste sur la formation supérieure et changement social dans la région de Toliara à Madagascar." Talily. Revue d'histoire 13-15 (Numéro special: Problème d'education des filles), 89-108.

Thomas, Philip. 1995. "Of houses, hearths, and granaries: Some aspects of gender among the Temanambondro of South-East Madagascar." Indonesia Circle 67: 340-358.

Trinh, T. Minh-Ha 1987. "Difference: 'A Special Third World Women Issue.” Feminist Review 25:5-22.

United Nations Official Websitee, Millenium Development Goals and Beyond 2015. Goal 3: Promote Gender Equality and Empower Women, http://www.un.org/millenniumgoals/gender. shtml, (11.02.2018)

Veum, Guro. 2008. "Idéaux de femmes à Madagascar: ont-ils changé?” Talily. Revue d'bistoire 13-15 (Numéro special: Problème d'education des filles): 109-119.

Visvanathan, Nalini. 2011. "Introduction." In The Women, Gender and Development Reader, N. Visvanathan, ed. Halifax: Fernwood Pub.

Walgenbach, Katharina. 2012. "Gender als interdependente Kategorie." In Gender als interdependente Kategorie. Neue Perspektiven auf Intersektionalität, Diversität und Heterogenität, K. Walgenbach, G. Dietze, L. Hornscheidt and K. Palm, eds. Opladen: Verlag Barbara Budrich, 23-64.

Walgenbach, Katharina, Gabriele Dietze, Lann Hornscheidt, and Kerstin Palm. 2012. Gender als interdependente Kategorie. Neue Perspektiven auf Intersektionalität, Diversität und Heterogenität. Opladen: Verlag Barbara Budrich.

West, Candace, and Sarah Fenstermaker. 1995. "Doing Difference." Gender and Society 9/1: 8-37.

Williams, Drid. 2002. "Signifying Bodies, Signifying Acts. New Ways of Thinking about Human Movement." Unpublished manuscript.

Yuval-Davis, Nira. 2006. "Intersectionality and feminist politics." European Fournal of Women's Studies 1/3: 193-209.70 


\section{List of Relevant Recordings}

All recordings can be found in the Vienna Phonogrammarchiv of the Austrian Academy of Sciences (http://www.phonogrammarchiv.at). The dates are noted as year month date: yyyymmdd.

\begin{tabular}{|c|c|c|}
\hline Date & Event and Interviews & Place \\
\hline 20110813 & $\begin{array}{l}\text { Political campaign of Minister Jean-Jacques Ra- } \\
\text { benirina, with a kiloloky set of one-tone whistles, } \\
\text { mandoliny lute ensemble with drum batera, } \\
\text { tsapiky ensemble, and women's associations }\end{array}$ & Belamoty \\
\hline 20110830 & Petraka Performance Group & Saloavaratsy (Bezaha) \\
\hline $\begin{array}{l}20120716, \\
20120716\end{array}$ & $\begin{array}{l}\text { Dancing and singing with the Takarana Belamoty } \\
\text { women's association, and feedback screening }\end{array}$ & Belamoty \\
\hline 20120716 & $\begin{array}{l}\text { Taha wedding with attending members of wom- } \\
\text { en's associations }\end{array}$ & Savazy I (Belamoty) \\
\hline $\begin{array}{l}20120718 \\
20120809\end{array}$ & $\begin{array}{l}\text { Family group performing the mandoliny lute with } \\
\text { the katsa rattle, including a demonstration of } \\
\text { songs from women's associations, and feedback } \\
\text { screening }\end{array}$ & Belamoty \\
\hline 20120723 & $\begin{array}{l}\text { Taha wedding with attending members of wom- } \\
\text { en's associations }\end{array}$ & Belamoty \\
\hline 20120807 & $\begin{array}{l}\text { Taha wedding with attending members of wom- } \\
\text { en's associations }\end{array}$ & Mahatôra (Montifeno) \\
\hline $\begin{array}{l}20120811 \\
20120812\end{array}$ & $\begin{array}{l}\text { Enga-dolo mortuary ceremony with a tsapiky } \\
\text { ensemble, the Lambo Edoara paritaky drum-flute } \\
\text { ensemble and women's associations from Savazy I } \\
\text { and Savazy II, and men's associations from Savazy I }\end{array}$ & $\begin{array}{l}\text { Analaroa near Soama- } \\
\text { nonga (Soamanonga) }\end{array}$ \\
\hline 20120816 & $\begin{array}{l}\text { Dancing and singing with the Bazary women's asso- } \\
\text { ciation, and feedback screening }\end{array}$ & Belamoty \\
\hline $\begin{array}{l}20120816, \\
20141105\end{array}$ & $\begin{array}{l}\text { Dancing and singing with the Avaradrova women's } \\
\text { association, and feedback screening }\end{array}$ & Belamoty \\
\hline 20120817 & $\begin{array}{l}\text { Dancing and singing with the Betamenaky women's } \\
\text { association, and feedback screening }\end{array}$ & Betamenaky (Belamoty) \\
\hline 20120904 & $\begin{array}{l}\text { Taha wedding with attending members of wom- } \\
\text { en's associations }\end{array}$ & Belamoty \\
\hline
\end{tabular}




\begin{tabular}{|l|l|l|}
\hline 20120907 & $\begin{array}{l}\text { Interview with the head of the Savazy I women's } \\
\text { association }\end{array}$ & Savazy I (Belamoty) \\
\hline 20150901, & $\begin{array}{l}\text { Interview with the performer Petraka and the Sa- } \\
\text { loavaratsy women's association }\end{array}$ & Saloavaratsy (Bezaha) \\
\hline 20150902 & $\begin{array}{l}\text { Dinabe festivity with tsapiky ensemble with wom- } \\
\text { en's, and kalôny associations }\end{array}$ & Salobe \\
\hline
\end{tabular}

VIDEO I: Women's associations performing at the political campaign of Minister JeanJacques Rabenirina, Belamoty 2011-08-13 (01:50)

As a result of a politician's incentive to admit the communal registration of women's associations in the central Onilahy Valley in the Southwest of Madagascar, the number of officially registered groups rose significantly. In the various occasions to which these associations are invited, they employ singing and dancing as a significant mode of representation and act in a similar way to groups structured along patrilineal lineage. By arriving and presenting themselves as unified groups through visual and audible markers, the women engage with social issues and spaces, and expand new opportunities to negotiate formalized speech through self-representation. Based on ethnographic research, this article analyses the women's associations' activities and aims and critically relates various perspectives to understand the significance of and conditions for the sudden increase in their number, including national and regional development reports, the academic gender discourse, dominant local gendered practices and structural issues, and the members' experience and their choice to act as formalized associations in particular ways. While the view of women in NGO-related reports focuses on women's vulnerable positionalities in Madagascar, I argue that it is necessary to acknowledge the lived intersectionality of the category "woman" as interdependent with age, generation and ancestral relations, and therefore connect their performances to historically situated structural practices of female networks. Only then can we appreciate their representation and participation through singing and dancing as particular modalities of agency. 


\title{
Practicing Ethnomusicology/Ethnochoreology Within Post-Socialist Realities:
}

\author{
The Case of Serbia with Some Comparative Experiences \\ from Former Yugoslav Countries
}

In most Southeastern European countries, the beginnings of ethnomusicology and ethnochoreology as distinct scholarly disciplines were inextricably linked with the state institutions of the socialist regimes after World War II. In these countries, ethnomusicological and ethnochoreological research, grounded in folkloristics, was sponsored under the ideological constraints of socialist systems, and was hence strongly orientated towards the ideological and political agendas of the state parties. In the republics of the former Yugoslavia, the break-up of the common socialist state, the war and the huge economic crisis have resulted in processes of establishing new social systems based on democracy and a market economy which did not start until the late 1990s (cf. Prica 2007: 35). In Serbia these processes began even later, after Slobodan Milošević admitted defeat in the elections of October 2000. These radical political changes have led to the commencement of broad social, economic and cultural transformations, which are generally signified in scholarly literature as post-socialist "transitions" (Hann 2004:1) or, as some anthropologists suggest, "transformations" (Erdei 2007: 78). Apart from being heterogeneous, complex and multidimensional (Humphrey 2004: 13), in the sphere of the Serbian state cultural policies, and especially policies regarding university education and academic research, it could be said that these processes are continuing and that they are far from being finalized.

Regardless of the organizational particularities in each Southeast European country, the model of hierarchical ordering of the institutions in charge of the fields of humanities and social sciences in all socialist societies was similar. Based on the notion that education and science are important vehicles for the construction and establishment of national identities, it implied two main centres of institutional settings: universities and research institutions. While universities were primarily responsible for education, the activities of research institutions were directed exclusively towards scholarly exploration of various cultural phenomena, including traditional music and dance. They were most often organized within the institution of the highest intellectual and scholarly value within socialist academic systems - the Academy of Science. 
Along with universities and research institutions or within them, archives of traditional music and dance could also be established.

Regardless of the institutional orientation, in all socialist countries ethnomusicology and ethnochoreology were considered to be subjects which should provide an intellectual foundation for the cultural politics of the ruling political system, and which should foster national ideologies. That standpoint influenced the constant tension between fundamental and applied research and also, consequently, a small number of ethnomusicologists and ethnochoreologists (in each country there were just a few of them in each disciplinary field). On the other hand, the attitude that ethnochoreological and ethnochoreological investigation should be treated as a scientific activity was also the reason why all research projects, regardless of the institution involved, were sponsored and controlled through the centralized guidance of the Ministry of Science.

After 2000, ethnomusicology and ethnochoreology generally continued to be linked with state institutions in all republics of the former Yugoslavia. In the case of Serbia those are universities in Belgrade and Novi Sad and one research institute. ${ }^{1}$ Regardless of the fact that these institutions continued to be financed by the state, during the last twenty years ethnomusicology and ethnochoreology have been subject to extensive remodelling, including disciplinary orientations, methodological approaches, the applicable domains of professional activities, and a slow increase of the financial resources available for research and work. The notion that scholarship should be market-oriented has started to be considered as one of the important aspects of current ethnomusicologies and ethnochoreologies in this part of Europe.

This article explores the views of many individual researchers (including myself) about their work with the aim of understanding the position of ethnomusicology and ethnochoreology in the contemporary society of post-socialist Serbia, and thus the socio-political relevance of these scholarly fields from the perspectives of the researchers themselves. With the aim of giving voice to the scholars who "practice" ethnomusicology and ethnochoreology as their main professional activity, I have held interviews and conversations with a number of my colleagues of different generations from Serbia, discussing the current relevance of our work and trying to understand the causes and effects of the remodelling of our disciplinary fields in a transitory post-socialist society.

With the intention of comparing the current experiences of scholars from Serbia with the attitudes and apprehensions of colleagues from the other republics of the former Yugoslavia (Croatia, Bosnia and Herzegovina, Slovenia, Macedonia and Montenegro) with whom we share a common socialist past, I also had several conversations or exchanged ideas in the form of questionnaires with some of them. Comparing

1 The Institute of Musicology of the Serbian Academy of Science and Arts.

192 
the experiences of ethnomusicologists and ethnochoreologists from Serbia with colleagues from former Yugoslavia was carried out with the aim of obtaining a broader picture of the remodelling of our disciplines with a regional perspective, and gaining a better understanding of the particular circumstances of disciplinary positions in each country.

This qualitative research approach was directed towards interpreting the context of professional ethnomusicological/ethnochoreological engagement as broadly as possible and in a multidimensional and subjective way from the perspective of the protagonists themselves. Within the set of general issues which I prepared in advance for our discussions (educational specificities, themes of ethnomusicological/ethnochoreological research, fieldwork methodology, international cooperation, strategies of scholarly writings, concepts and results of applied work) the basic questions which received our attention were: What has exactly changed in our professional orientation and work after 2000? How did it change and why? What were the main questions which occupied our discussions? Starting from those issues, further questions which emerged were: What are the potentials of our disciplinary relevance within the scholarly community in the region and worldwide, but also in the society in which we act? What are our experiences in "practicing" ethnomusicology and ethnochoreology in various educational, research and applied contexts of transitory society? What obstacles are we facing?

Our discussions revealed many particular details and difficulties which individual researchers have faced during their careers and which affect their everyday professional activities. We talked openly and our conversations were straightforward and honest. Therefore, I want to sincerely thank all of my colleagues who acted as interview partners. I do hope that I articulated our standpoints systematically and that this will help us all to understand and improve our work and scholarly positions, not only in domestic and international academic circles and various professional contexts such as primary and secondary education and the media, but also in society as a whole.

\section{Starting standpoints: the position of individual researchers and the general ideological orientation of scholarly work}

Discussing the socio-political relevance of ethnomusicology and ethnochoreology from a historical perspective, especially in Southeastern European countries, implies two general underlying standpoints which appear to be contradictory in relation to the post-socialist reality of contemporary society in Serbia and former Yugoslav countries.

The first is that scholarly disciplines exist through the work of individuals who are inevitably connected through institutions, organizations and the media where power 
relations are always hierarchically ordered according to shared interests and certain financial resources. In the case of Serbia, the existence of a significant number of ethnomusicologists and ethnochoreologists was caused by continuous academic education in ethnomusicology since 1948 (at all levels of academic degrees) at the Faculty of Music of the University of the Arts in Belgrade and since 1996 at the Academy of Arts of the University in Novi Sad (see Golemović and Rakočević 2008: 90-91), and in ethnochoreology (at Bachelor's and Master's levels) in Belgrade since 1990 and in Novi Sad since 2000 (see Rakočević 2013: 70-74). ${ }^{2}$ The establishment of the Bologna Declaration in 2006 subsequently increased the number of Master's students who graduated in both disciplinary fields. ${ }^{3}$ All that resulted in the fact that more than fifty ethnomusicologists/ethnochoreologists are professionally active today, not only in the educational system ${ }^{4}$ and research institutions, ${ }^{5}$ but also in various domains of public work such as the media ${ }^{6}$ and non-governmental organizations, which was not the case during socialist times when those domains of professional activity did not exist. ${ }^{7}$

2 Ethnochoreological courses are incorporated into the ethnomusicological curriculum.

3 The standard quota for the enrolment of students in Bachelor's degrees in Ethnomusicology at the Faculty of Music in Belgrade during socialist times was a maximum of five students before transferring to the Bologna system of higher education, while after 2006 this number was doubled. The quota at Academy of Music in Novi Sad was a maximum of four students, which has now increased to eight. Along with that, application of the Bologna system, which implies strict compliance with deadlines and fostering student progress during degree programs has resulted in greater efficiency and a higher number of graduates than was the case during socialist times.

4 Apart from the Faculty of Music in Belgrade (currently eight ethnomusicologists and ethnochoreologists and one dance anthropologist work in the degree program for ethnomusicology and ethnochoreology) and the Academy of Arts in Novi Sad (four ethnomusicologists and one ethnochoreologist work on the degree program for ethnomusicology), which cover all levels of higher education, there are a number of courses devoted to folk singing and instruments at the level of secondary musical education in Serbia, where more than ten ethnomusicologists and ethnochoreologists teach ethnomusicology and ethnochoreology as main subjects (Marjanović 2017). Apart from disciplinary oriented educational programs, many ethnomusicologists and ethnochoreologists in Serbia also teach various musical subjects in elementary and secondary schools, where they incorporate knowledge about traditional music and dance both theoretically and practically.

5 Four ethnomusicologists currently work at the Institute of Musicology of the Serbian Academy of Science and Arts.

6 It is hard to provide an exact number of ethnomusicologists who work in the media. As an illustration, approximately ten ethnomusicologists are currently employed at Radio Television of Serbia (Vitas 2017).

7 Many of the ethnomusicologists and ethnochoreologists in Serbia are active in various nongovernmental organizations which started to be founded in the 2000s. Among them are the Serbian Ethnomusicological Society and Centre for the Research and Revitalization of Traditional Dance in Serbia led by teachers from the Faculty of Music. Alongside them, new organizations have started to appear, launched by colleagues who do not work at universities. One of the first was Balkan Cultural Heritage founded by Bojana Nikolić in 2011. This organization has three main activities: education, 
Opportunities for higher education in the field of ethnomusicology and ethnochoreology also exist in neighbouring countries, although in each case the degree programs are different. In Croatia, for example, ethnomusicology is incorporated into the musicological curriculum at the Academy of Music in Zagreb as an optional subject in the degree program which integrates Bachelor's and Master's degrees, while $\mathrm{PhD}$ projects in ethnomusicology/ethnochoreology can be pursued within the Department for Ethnology and Cultural Anthropology at the Faculty of Humanities and Social Sciences and, since October 2017, at the Academy of Music in Zagreb, and also at some other universities such as the Academy of Arts in Split. Even though opportunities for postgraduate studies in ethnomusicology and ethnochoreology exist in Croatia, the absence of separate degree programs at Bachelor's and Master's levels influences the fact that there are less than ten active ethnomusicologists and ethnochoreologists in Croatia today (Vukobratović 2017, Zebec 2017). ${ }^{8}$ Despite the relatively small number of researchers in Croatia, all of them are very active in scholarly production in domestic and international spheres. ${ }^{9}$

Although both Bachelor's and Master's programs in ethnomusicology have existed in Macedonia at the Faculty of Music Arts in Skopje since the 1990s, and in ethnochoreology at the Faculty of Music Arts in Shtip since 2007, as well as opportunities for ethnomusicological/ethnochoreological research in $\mathrm{PhD}$ projects at various institutions in Skopje and Tetovo (Kostov 2016: 34), currently there are only approximately ten active colleagues in this country (Stojkova Serafimovska 2017, Opetcheska

concert production and publishing CDs of traditional music. Within the Balkan Cultural Heritage organization, Bojana was the first person in Serbia who opened a private school of traditional singing. Several years later, other ethnomusicological NGOs appeared in Serbia, such as Interkult, which has been run by Maja Krasin since 2013, and the Center for Ethnomusicological Activities founded by several young ethnomusicologists in 2014. Along with ethnomusicologists, young ethnochoreologists also started to found dance schools in various dance genres. Among them is Katarina Tomić, who founded the Street Dance Academy in 2007. Some of the young Serbian ethnomusicologists/ ethnochoreologists also work among the diaspora where they are active in folk dance and music societies (for example, Vesna Bajić Stojiljković has run the cultural-artistic society Kolo in Koper/Slovenia since 2007).

8 For more about the history of ethnomusicology and ethnochoreology in Croatia see Marošević 1995: 39-53; Ceribašić 1998: 49-65, Zebec 1996: 89-110, 2009: 136-150.

9 Ethnomusicologists and ethnochoreologists from Croatia not only actively take part in international conferences-those employed at the Institute of Ethnology and Folklore Research in Zagreb have organized several meetings of the ICTM study groups, for example, the $28^{\text {th }}$ Symposium of the ICTM Study Group on Ethnochoreology held in Korčula in 2014 or the $6^{\text {th }}$ Symposium of the ICTM Study Group on Music and Dance in Southeastern Europe which was held in Sinj in April 2018. Both ethnomusicology and ethnochoreology have a long history and are well established in this institution (more in Marošević 1995: 39-53, Ceribašić 1998: 49-65, Zebec 1996: 89-110, 2009: 136-150). 
Tatarchevska 2017, Petkovski 2018). ${ }^{10}$ While there is no ethnomusicological and ethnochoreological education in Montenegro (Marjanović 2017), the situation in Slove$\mathrm{nia}^{11}$ and Bosnia and Herzegovina ${ }^{12}$ is similar to Croatia and Macedonia: ethnomusicological/ethnochoreological education exists, but only up to ten professionals are currently active in each country (Pettan 2017; Talam 2017).

In Serbia, but also in other republics of the former Yugoslavia, all of the institutions and organizations where ethnomusicologists and ethnochoreologists work are financially supported by the State through the funds of the Ministry of Education, Science and Technological Development, and, additionally, for projects of an "applied" character, by the Ministry of Culture. Financial support from other sources is still rare and it can be said that at present it is almost non-existent. This means that the State still directly influences policies of scholarly research and cultural activities through regular funding, and project financing. However, Serbia is, according to official data from the Statistical Office of the Republic of Serbia (http://www.parlament.gov.rs), one of the European countries with the lowest investment in the university sector (less than $0.5 \%$ of the State budget for 2017) and culture (less than $1 \%$ of the State budget for 2017) $\cdot{ }^{13}$ Along with very few allocations of funding, the market crisis of the $2010 \mathrm{~s}$ led to the government's decision to ban from 2013 onwards the creation of new jobs in public services which are financed by the State, including the education system, research institutions and the media. ${ }^{14}$ During the last five years, in spite of the unbroken continuity of ethnomusicological/ethnochoreological education, young people do not

10 Some of the ethnomusicologists and ethnochoreologists from Macedonia are also very active at an international level and organized two symposiums of the ICTM Study Group on Music and Dance in Southeastern Europe (in 2008 and 2012). For more about the history of ethnomusicology and ethnochoreology in Macedonia see Stojkova Serafimovska 2008: 23-29, Opetcheska Tatachevska 2005: 94-99, 2008: 30-39, Kostov 2016: 331-336).

11 Although there are not many of them, Slovenian researchers are very active in both domestic and international contexts. In order to illustrate this, it is sufficient to mention that the ICTM Secretariat was based at the University of Ljubljana from 2011 to 2017 thanks to the efforts of the Slovenian researcher Svanibor Pettan, who ran this organisation very successfully in the position of the ICTM Secretary General in that period.

12 The degree program in ethnomusicology in Sarajevo, established in 1955, is the oldest in the territory of the former Yugoslavia and has exhibited continuity at all levels of study since its foundation (Talam 2017). For more about the history of ethnomusicology and ethnochoreology in Bosnia and Herzegovina see Karača Beljak and Talam 2014: 240-249).

13 In Macedonia the situation is the same: $0.2 \%$ of the state budget was dedicated to academic/scientific research for 2017 (Stojkova Serafimovska 2017).

14 According to this ban, a person can only obtain permanent employment to fill a post which has become vacant following retirement or for some other valid reason. This decision of the government has been renewed annually since 2013 .

196 
have an opportunity to obtain steady jobs as experts in traditional music and dance. ${ }^{15}$ In this contradictory current situation of post-socialist Serbian society, many young ethnomusicologists and ethnochoreologists succeed in making their living by "staying in the field" and finding ways to achieve their professional aspirations through engagement in the alternative cultural sector or non-governmental organizations. Although all of them are still basically linked with the State through various kinds of project financing, new funding opportunities are emerging slowly which will affect the power relations between scholars/researchers and state officials in the future.

The understanding of the socio-political relevance of any scholarly work including the broad fields of ethnomusicology and ethnochoreology is also influenced by my second starting premise: that ideologically neutral social action does not exist. The ethnomusicologist Iva Nenić indicates that one of the basic epistemic values of ethnomusicology is that it can be apprehended as "an intervention that transforms the cultural into the political (or that openly points out that the cultural is alwaysalready political in its nature and seeks social transformation from that point of departure)" (Nenić 2016: 339). The social implications of practicing ethnomusicology and ethnochoreology in Serbia have significantly expanded during the past decades in both theoretical and practical domains. They should be considered in the context of a broader cultural and political remodelling of the socialist ideology, but also as a consequence of the latest expansion of the values of the neo-liberal social system in our post-socialist, transitory society.

Even though contemporary ethnomusicology and ethnochoreology in Serbia are characterized by many individual approaches and research topics, as it is the case in other republics of the former Yugoslavia (Ceribašić 1998: 53, Marošević 2010: 25, Pettan 2015: 39, Stojkova Serafimovska 2017, Talam 2017, Zebec 2017), many domestic researchers agree that a distinct discourse of ethnomusicological "disciplinarity” has long existed in this country (Bajić Stojiljković 2017, Nenić 2015, Dumnić 2017, Fracile 2017, Lajić Mihajlović 2017, Marjanović 2017, Vitas 2017, Zakić 2017, Golemović 2018). According to many researchers, this specificity of Serbian ethnomusicology has been modelled by university education and traced along themes of research, methodological procedures based on fieldwork, and theoretical presumptions of music in/as culture. This standpoint can also be applied to ethnochoreology, which in Serbia is immanently (through methodological and theoretical orientations) and formally (through institutional connections) intertwined with ethnomusicology since their foundation (more in Rakočević 2013: 70-73, 2015: 34-35). With the aim

15 This contradictory situation occurs in some other post-socialist countries of the former Yugoslavia, for example in Slovenia, where a number of young people who have been awarded doctoral degrees have not been able to find a job for two years or more (Kotnik 2007: 160). 
of developing a discussion on the relevance of ethnomusicology and ethnochoreology in post-socialist Serbian society, their remodelling will be considered here according to changes and widening of the themes of research, understandings and realization of fieldwork, the extension of methodological orientation in the direction of interdisciplinary permeation, and ways in which professional work is carried out in the domains of applied activities. These issues of ethnomusicology and ethnochoreology in Serbia will be broadly compared with some of the specificities of "practicing" our disciplinary fields in other republics of the former Yugoslavia.

\section{Themes for research and fieldwork}

As it is well known, the folkloristic foundations of ethnomusicology and ethnochoreology which influenced their thematic orientation during the socialist era was focused on folk music and dance of rural origin, primarily of the majority population, with the aim of constructing and strengthening national identity. Although some of the scholars devoted themselves to the research of certain minorities as early as the $1950 \mathrm{~s}$ (for example, Ilijin 1953: 1-110, Ilijin and Debeljak 1953: 1-166), a significant widening of research topics that included urban and newly composed folk music and music of the ethnic groups of multicultural areas can be associated to a greater degree with the 1980s (Fracile 2017, Lajić Mihajlović 2017, Zakić 2017, Golemović 2018), as was also the case in some other republics of the former Yugoslavia, primarily Croatia (Marošević 1995: 48, Pettan 2017, Zebec 2017). ${ }^{16}$ Despite the fact that nationally oriented themes focused on structural-formal issues of music and dance were "implicitly favoured as more needed, more important and more complex," (Nenić 2017), it could be said that a gradual broadening of ethnomusicological/ethnochoreological research followed only in the subsequent decades in all former Yugoslavia republics. This process should be considered as part of the broader remodelling of related folklore-based fields of study such as ethnology and anthropology which have gradually spread in Southeast European scholarship from the late years of socialism until now. ${ }^{17}$ While these processes were much faster in some countries of the former Yugoslavia, espe-

16 One of the first articles which was devoted to so-called newly composed folk music as an urban phenomenon already appeared in the early 1960s (Dević 1963: 545-551). However, this topic became legitimate in the academic curriculum only in the late 1980s (Babić Rakidžić 1989 and Sedmak 1990). Newly composed folk music and urban music in general, however, were not further investigated in the following years until the 2000s.

17 For example, the beginnings of the gradual spreading of research interests in Serbian and Croatian ethnology and anthropology had started already in the 1970s (Kovačević 2005: 15-16 and Prica 2004: 26), and in Bulgarian folkloristics after 1989 (Rice 1999: 188).

198 
cially in Slovenia and Croatia (Pettan 2017: Zebec 2017), the real shift in ethnomusicology and ethnochoreology in Serbia occurred only in the late 2000s. This was when issues of popular music and dance, gender, identity processes, a deeper examining of the style of the performance, concepts of hybridity and interculturalism/transculturalism, cultural politics and ideology, the music industry etc. were gradually introduced into the ethnomusicological curriculum (Nenić 2015, 2017, Zakić 2017). ${ }^{18}$ This shift in the orientation of themes can be illustrated by the titles of the main research projects of ethnomusicologists from the Faculty of Music in Belgrade financed by the Ministry of Science. One of the first major five-year projects of this institution financed by the State, which lasted from 2004 to 2010, was entitled "Musical and dance dialects of Serbia," while the next one (which started in 2011) is very broadly named "Traditional music and dance of multicultural and multiethnic Serbia."19

In spite of an obvious turning point in the educational and cultural policy of the Serbian authorities after 2000 which, among other issues, involved the encouragement of multicultural dialogue and regional and international cooperation, nationally oriented themes in scholarly research are still very much favoured by the State, but also the wider community. Research topics devoted to various aspects of the safeguarding of traditional music and dance considered as national intangible cultural heritage are given preferential treatment in both academic circles and by a wider public. That implies that scholars design their research projects very broadly with the idea of embracing various ideas for their theoretical and practical work. It could be said that scholars in post-socialist Serbia have been put in a position where they-let me use the formulation of Danka Lajić Mihajlović- "make compromises between the needs and possibilities of research in Serbia and the ideas and wishes that they have on the basis of contacts with international disciplinary production in order to increase relevance" (Lajić Mihajlović 2017). Although state strategies for shaping the favoured research themes differ, and they vary according to current policies on academic research in each country of the former Yugoslavia, many researchers from former Yugoslavia republics share the attitude that they make many compromises when selecting the focus of their research.

Geographically-oriented field research could be considered as one of the hallmarks of Serbian ethnomusicology and ethnochoreology. However, after 2000 some of the

18 One of the first Master's theses devoted to ideological aspects of partisans' songs, which anticipated changes in the orientation of themes in students' papers and introduced anthropological perspectives into ethnomusicology in Serbia, was supervised by Dimitrije Golemović and defended by Ana Hofman in 2004 at the Faculty of Music in Belgrade (Hofman 2004).

19 Even though it was primarily planned that the second project cycle, which started in 2011, should end in 2015 , there is still no clear indication when it will end and how the State will organize project funding in the future. This uncertainty greatly affects all researchers in Serbia, but especially those employed by the Institute of Musicology, who are financed exclusively through project funding. 
young scholars started exhaustive fieldwork which was not primarily determined by geography, but focused on the historical features and performative qualities of the individual music or dance genres, or gender relations in musical performance. ${ }^{20}$

Regardless of the broadening of the legitimate choices for field research projects, one of the contradictions of policy on academic research in Serbia both today and before 2000 is that there has been no official funding for field research for Master's and doctoral students. Possibilities exist within the budgets of already accepted research projects, but in order to apply for funds a young researcher first has to be elected onto a project as a team member, which is, for many, a very limiting circumstance. This fact still influences the choice of research subjects in many cases based on ethnography "at home" which do not include traveling at all or are based on numerous short-term fieldwork trips (Lajić Mihajlović 2017, Nenić 2015, Zakić 2017, Golemović 2018). However, the multiplication of possible research topics is inevitably pervaded by deliberations concerning the methodology of fieldwork, which, in the last ten years, has significantly expanded-not only in Serbia, but also in other countries of the former Yugoslavia-into phenomenological and epistemological aspects in parallel with applied methods including repeated and semi-structured in-depth interviews, participation in performance, archival work and using internet and social networks as sources for investigations.

\section{Methodological orientation and international cooperation}

The fact that ethnomusicological and ethnochoreological education in Serbia are linked with higher education in music has influenced their prevailing methodological focus on structural-formal aspects of music and dance and their sonic and kinaesthetic representations. This is the reason why, along with folkloristic foundations, musicology and music theory have had a significant influence on their methodological procedures and theoretical interpretations. ${ }^{21}$ Due to the fact that older generations of eth-

20 To illustrate this, let us mention several recently defended $\mathrm{PhD}$ projects. For their $\mathrm{PhD}$ dissertations, Marija Dumnić investigated historical and performative aspects of old urban music (starogradska muzika) (Dumnić 2016), while Iva Nenić devoted her PhD thesis to various issues of historically and culturally placed gender relations in traditional musical practice (Nenić 2014). In her $\mathrm{PhD}$ project in the field of dance research, Vesna Bajić Stojiljković focused on scenic presentations of traditional dance and music through the practice of the so-called cultural-artistic societies (Bajić Stojiljković 2016).

21 The degree program in ethnomusicology at the Faculty of Music in Belgrade was offered at the Department of Musicology and Ethnomusicology from its foundation in 1961 and lasted until 2006, when two independent departments were established. Ethnochoreology has been included in the ethnomusicological program since 1990. 
nomusicologists and ethnochoreologists were mainly fluent in German and Russian, international cooperation in the 1970s and 1980s primarily involved relations with scholars from East Germany and the Soviet Union (Zakić 2017). ${ }^{22}$ Researchers' language preferences and the prevailing folkloristic orientation of ethnomusicology and ethnochoreology were grounded in the general geopolitical conditions caused by the Iron Curtain and the Cold War period (1963-73), where academic knowledge production, not only in Serbia and former Yugoslavia republics, but also in Eastern Europe in general (more in Giruschescu and Torp 1991: 2, Gore and Grau 2006), was strongly influenced by Soviet and Eastern German sources until the late 1980s.

These are the main reasons why, after the turbulent $1990 \mathrm{~s}^{23}$ which in Serbia were marked by a major economic crisis, hyperinflation, and isolation caused by international cultural and economic sanctions, the political changes from 2000 onwards had a profound impact on methodological and theoretical issues in ethnomusicology and ethnochoreology. Along with a broadening of methodological perspectives through the incorporation of semiotics and communication theories in the early 2000s (for example, Lajić Mihajlović 2007, Vukićević-Zakić 2002: 131-139, Zakić 2012: 55-66), methodological and theoretical approaches in parallel with the themes of research will

22 In this orientation of international scholarly influences during the socialist era, the work of the ethnomusicologist Radmila Petrović (1923-2003) could be considered as an exception, because she was fluent in English and was a guest lecturer at the University of Pittsburgh (http://www.music.sanu. ac.rs). As she worked at the Institute of Musicology, her ethnomusicological work was unfortunately not completely familiar to the students of ethnomusicology at the Faculty of Music, and for a long time remained on the margins of the core of ethnomusicological writings (Lajić Mihajlović 2017).

23 The war on the territory of the former Yugoslavia had a terrible influence on the last decade of the 20th century in most of the ethnomusicological traditions of the former Yugoslavia. This is the reason why Naila Ceribašić called this period of history of ethnomusicology in Croatia the "zero years" (Cerbiašić 1998: 56). Tamara Karača Beljak and Jasmina Talam have also written about radical changes in ethnomusicology in Bosnia and Herzegovina in the 1990s caused by the fact that the eminent scholar Ankica Petrović had to leave Sarajevo because of the war in 1992, and that Dunja Rihtman-Šotrić lost her home in the bombing of the city (Karača Beljak and Talam 2014: 224-248). Dragica Panić, who at that time was working on the ethnomusicological collection at the National Museum of Bosnia and Herzegovina also had to escape from Sarajevo with her family, and they lived in Serbia for several years of the war (Panić 2018). Svanibor Pettan, who completed his doctorate in the USA and returned to the Institute of Ethnology and Folklore Research in Zagreb at the time of the war, recalls the feeling of life-threatening everyday life following the rocket attacks on Zagreb by the Yugoslav People's Army in 1995, when his mother nearly became a victim (Pettan 2017). Although the war was not conducted on the territory of Serbia, and Serbian researchers were not in immediate danger, they were confronted with hyperinflation in the period from 1992-1994 and in almost complete isolation due to international sanctions from 1992 to 2000. The ethnomusicologist Mirjana Zakić vividly recalls that in 1993 she, as a teacher at the Department of Ethnomusicology at the State Faculty of Music, was able to buy just one single banana from her entire monthly earnings (Zakić 2017). 
significantly multiply in the coming years, both in ethnomusicology and ethnochoreology. The new intellectual openness of Serbian researchers has been largely caused by the start of communications with experts from Anglo-American scholarly traditions, and achievements not only in the anthropology of music and dance, but also in the broad fields of cultural and performance studies, post-structuralism, popular music theories, feminist theories, affect theories etc. (for example Nenić 2015, Dumnić 2016). Serbian ethnomusicologists and ethnochoreologists only started to be continuously active in international associations after 2000, primarily within the ICTM. ${ }^{24}$ Here, one more contradiction of the post-socialist reality in Serbia appears: the state officially not only supports international cooperation, but also favours it compared to activities within a national framework. At the same time there are no funds available for membership in international associations in Serbia. Academics are forced to cover such expenses from their own funds. There are possibilities for researchers to apply for partial cost coverage for participation in international meetings once every two years, but only for those who are involved in official projects of the Ministry of Science. Those applications are often not approved and researchers are forced to bear all the costs of taking part in international conferences themselves. While this financial situation also appears in some other former Yugoslavia republics, specifically in Montenegro (Marjanović 2017), established researchers in Slovenia, Croatia and Macedonia have more official support for international cooperation (Opetcheska Tatarchevska 2018, Pettan 2017, Zebec 2017), although students and researchers who do not have an institutional background in these countries also have to bear the costs of participation in international meetings from their own funds (Opetcheska Tatarchevska 2018, Vukobratović 2017). Regardless the fact that the initial careers of young researchers in all republics of the former Yugoslavia are characterised by difficulties regarding international cooperation, it could be said that Slovenian and Croatian scholars are generally in a better position than others, thanks to the EU membership of these countries. Slovenian and Croatian researchers, institutions and organizations can apply for various EU university exchange programs and project funds, while their colleagues, institutions and organizations from countries that are not members of the Union can only be so-called affiliated partners and have greater difficulties with complicated EU application forms and requirements. ${ }^{25}$

24 While colleagues from Slovenia and Croatia became active in the ICTM in the early 1990s and immediately after the war (Pettan 2017 and Zebec 2017), in Macedonia and Bosnia and Herzegovina these activities became possible only in the early 2000s (Stojkova Serafimovska 2017, Talam 2017), as was the case in Serbia.

25 Thanks to their professional engagement, some researchers from non-EU countries have found ways to join international projects on an individual level over the last ten years, as is the case with our colleagues Jasmina Talam and Tamara Karača Beljak from Bosnia and Herzegovina (Talam 2017). 
Intellectual openness for alternative theoretical interpretations and methodological procedures inevitably blurs disciplinary boundaries and directs ethnomusicology/ ethnochoreology, not only in Serbia but worldwide, towards somewhere in the vague field of, as Iva Nenić calls it, "transdisciplinary humanities" (Nenić 2017). However, it is not only that the Serbian Ministry of Science does not recognize ethnomusicology and ethnochoreology as distinct disciplinary fields, ${ }^{26}$ but the broad knowledge domain labelled in Anglo-American academia as the humanities was recognized only after 2008 when it started to appear in official state narratives. During the last ten years, nevertheless, "interdisciplinary" has become one of the key words in all formal recommendations for research project applications in the sense that those projects and articles which are interdisciplinary are much more favoured. This is the reason why many researchers in Serbia recognize the imperative of interdisciplinarity, which is encouraged by the State and generally accepted as a dominant source of methodological research orientation, as kind of a pressure. This attitude causes the reaction to defend disciplinary fields determined by the topics and methodology of research: most of the scholars to whom I have talked share the view (as I do) that both ethnographic and theoretical narratives about sonic and kinaesthetic representations of music and dance are specificities of the domestic ethnomusicological/ethnochoreological tradition in Serbia with which we have the opportunity to build up our scholarly relevance internationally (for example, Bajić Stojiljković 2017, Lajić Mihajlović 2017, Zakić 2017, Golemović 2018). ${ }^{27}$

\section{Between academism and applied work}

As part of introducing neo-liberal aspects into its policy on higher education and research institutes, in the early 2000s the Ministry of Science introduced a new evaluation system for Serbian scholars based on project activities. According to this highly competitive ranking system, researchers are continually forced to increase their production of scholarly writings, whereby the annual number of published works influences their status in research projects, their progression in teaching positions within universities and research institutions, and directly influences their earnings. The evaluation list of ranked publications (monographs, international and domestic journals, proceedings,

26 In the system of disciplinary fields established by the Ministry of Science, ethnomusicology and ethnochoreology are classified under "history, archaeology and ethnology" (cf http://www.mpn.gov.rs/ nauka/osnovna-istrazivanja).

27 One of the rare articles in which the standpoint that kinesthetic features of dancing should be recognized as a basic orientation of ethnochoreological research are directly expressed was published in the ICTM Yearbook in 2015 (Rakočević 2015: 36). 
and also audio and DVD publications) is far from suitable. An additional contradiction of national policy on academic research is that publications in foreign languages are far better ranked than those in Serbian. At the same time, students' papers at all levels of higher education, including $\mathrm{PhD}$ theses, must be written not only in Serbian but also in Cyrillic. ${ }^{28}$ Due to the fact that there are no funds for the costs of translation, some of the excellent publications written in Serbian remain unknown to the wider academic community. ${ }^{29}$ With the state's desire to preserve and stimulate scholarly production in Serbian as well as the Cyrillic script, but also to gain wider visibility and thus potential relevance in the international scholarly community, researchers in Serbia are constantly in a position where they have to make compromises with regard to language choices.

Along with forced academic production and teaching duties for those employed at universities, ethnomusicologists and ethnochoreologists in Serbia are very much engaged in applied work. The concept of applied ethnomusicology appeared in Serbia for the first time in the late 1990s (Litvinović 1998: 131), but it was recognised as being distinct only recently in 2010 (Dumnić 2010). In addition, the idea of applied ethnochoreology has also been discussed (Bajić 2006: 119-122). No matter when they appeared as a potential working opportunity, applied domains of ethnomusicology and ethnochoreology have been recognized by most of the researchers in Serbia as musiccentred interventions (Titon 2015: 5) to promote and safeguard traditional music, musical instruments and dance. According to the attitudes of many scholars, these activities have already been practiced for years, so according to them applied work has a long tradition in domestic scholarship (Bajić Stojiljković 2017, Fracile 2017, Lajić Mihajlović 2017, Marjanović 2017, Vitas 2017, Zakić 2017, Golemović 2018). ${ }^{30}$ They have covered a wide range of work in the organization and evaluation committees of numerous traditional music and dance festivals and competitions within the country and in the diaspora, teaching traditional music and dance not only in schools and at universities, ${ }^{31}$ but also at various seminars and workshops, publishing audio and video

28 In the universities in other republics of the former Yugoslavia, final papers at all levels of education also have to be written in the respective national languages, with the exception of Slovenia, where foreign students are free to select the language, while domestic students are expected to write in Slovenian unless the supervisor, co-supervisor, or a committee member cannot read Slovenian. Due to the rather small pool of Slovenian specialists in the increasingly specialised scholarly arena and the preference of some students for writing in English, such situations have become common (Pettan 2017).

29 Let us mention some of them: Bajić Stojiljković 2016, Golemović 2005, Dumnić 2016, Fracile 2014, Jovanović 2014, Karin 2014, Lajić Mihajlović 2014, Marjanović 2013, Nenić 2014, Radinović 2011, Ranković 2012, Zakić 2009.

30 Some colleagues from former Yugoslav republics also share this standpoint (for example, Opetcheska Tatarchevska 2017, Talam 2017).

31 Practical courses in performing traditional music and dance are an integral part of the ethnomusicological curriculum both at the Faculty of Music in Belgrade and the Academy of Art 
recordings and so on. This is the area where most of them recognize their immediate relevance within the local communities with whom they work, but also in wider society (Bajić Stojiljković 2017, Fracile 2017, Lajić Mihajlović 2017, Vitas 2017, Zakić 2017).

Despite favouring national values in official cultural, educational and research policies, traditional music and dance are marginalized in public spaces such as television, radio and printed media, which appears as yet another contradiction of contemporary post-socialist Serbian society. This is the reason why, according to most of my interview partners, one of the major causes of the lack of relevance of Serbian ethnomusicologists and ethnochoreologists in the wider community is a lack of "visibility." However, in the last few years the applied work carried out with marginalized or vulnerable social groups and individuals (such as emigrants, refugees, the poor or disabled people) organized around various musics and dance, has slowly begun to be considered as a necessity, especially among the younger generation of scholars and students, who, it could be said, consider the potential of applied ethnomusicology to be much broader (Dumnić 2017, Nenić 2015, 2017). It could be said that the so-called people-centered social interventions of ethnomusicology (Titon 2015:5) and ethnochoreology needs to be developed in future in Serbia.

While various aspects of applied ethnomusicology and ethnochoreology have yet to be evolved in Serbia, some other countries of the former Yugoslavia have much greater experience and achievements in this field. Slovenia is far ahead of the others, thanks to the dedicated activities of the ethnomusicologist Svanibor Pettan. Pettan actively took part in many and various pioneering ventures in establishing applied ethnomusicology, not only in Slovenia but worldwide (see Pettan 2015: 29-53). This was one of the reasons why Ljubljana hosted two symposia dedicated to the issues of applied ethnomusicological work: Ethnomusicology and Ethnochoreology in Education: Issues in Applied Scholarship, which took place in 2006, and the inaugural symposium of the Study Group on Applied Ethnomusicology within the ICTM held in 2008. The edited volume Applied ethnomusicology: Historical and contemporary approaches (Harrison, Mackinlay and Pettan 2010) emerged from the first meeting of this study group. Due to these achievements, a university course in applied ethnomusicology is taught at the Faculty of Arts in Ljubljana, and a university course on applied ethnomusicology has also existed in Sarajevo since 2011.

in Novi Sad. They were included in the late 1990s, first as an elective and since 2008 as obligatory subjects at Bachelor's degree level. Offering students training both in the theoretical and practical domains of performing music and dance is one of the most important aspects of ethnomusicological and ethnochoreological education in Serbia. 
The key words such as inconsistency, ambiguity and discrepancy mark the cultural, educational and academic research policy of transitory, post-socialist Serbian society. The lack of a distinct official long-term strategy for scholarly activities has meant that Serbian ethnomusicologists and ethnochoreologists are in a position where they have to hold incessant negotiations in almost all domains of their work. Without the intention of essentializing the domains of ethnomusicological/ethnochoreological activities, the issues of those negotiations could be polarized around the topics of ethnicity, nationality and cosmopolitism; multiculturalism and interculturalism/transculturalism; music and dance heritage and transnational musical and dance genres; traditional and popular music and dance, academism, and applied work.

Tensions existing between the neo-liberally oriented policy of higher education, academic research which incudes a culture of competitiveness in scholarly production, the multiplication of professional tasks both in theoretical and applied work and insecurity caused by the market orientation of all scholarly activities influence the older generation of researchers who perceived their position during socialist times as being more secure and easier, albeit with fewer opportunities for research and international cooperation. At the same time, many of the ethnomusicologists and ethnochoreologists of all generations, not only in Serbia but also in neighbouring countries, have clearly expressed dissatisfaction with their general position in society. Despite the growing number of trained ethnomusicologists and ethnochoreologists, the prevailing attitude is that this is not enough, and that only better-developed education can contribute towards improvements in the discipline itself. As Velika Stojkova Serafimovska from the Republic of Macedonia said: "Only education can make changes. If you have an army, and the army consists of students [...]" (Stojkova Serafimovska 2017).

Within intellectual circles, including academia, animosity among ethnomusicologists and ethnochoreologists also arises from the general marginalization of the field of humanities. Researchers believe that their position would be better if only the general field of their activities, broadly recognized as humanities, was considered to be more significant. Many of them thus try to improve the situation regarding the insufficient importance of ethnomusicology and ethnochoreology in both academia and state institutions via intensive and ambitious project applications, and activities in many official bodies, commissions and committees where they seek to increase the visibility of our profession.

The imperative of productivity in scholarly writings imposed by the State is also considered by many ethnomusicologists and ethnochoreologists to be burdensome for their professional activities, which are often reduced to a constant struggle to achieve 
a sufficient number of points for academic advancement. These attitudes are mostly expressed by the younger generations of scholars, who are also raising their voices against the imposition of research topics. They feel a strong resistance to project financing as the only form of professional activity, and are advocating confrontation against the established system of employment and state funding of research and cultural activities. Focusing on individual academic achievements slows down or even prevents collective action that would surely, as many researchers believe, contribute towards an improvement of the relevance of ethnomusicology and ethnochoreology at various levels. One of the causes of the absence of individual and collective action is also an attitude which was shaped during socialism, and is rooted especially among older generations of researchers, that scholarly activities should be "neutral" and "apolitical." Younger generations, however, have overcome such views. Some of them clearly express their political orientation in their writings (for example, Hofman 2008: 23-35, Nenić 2016: 334-341).

Professional endeavours to confront the rules established by the State are, nevertheless, coloured with feelings of fear and insecurity which are shared by many, especially young researchers, not only in Serbia but also in other countries of the former Yugoslavia. They feel animosity toward project financing in general, but also towards all the new forms of national interests (neo-nationalisms) which influence research topics proposed by the State and consequently the evaluation of proposed research projects. At the same time, processes of the slow withdrawal of the State from academic education and the network of institutes in the direction of liberalization of the "market" of higher education is perceived as one of the biggest threats to the development and even survival of ethnomusicology and ethnochoreology in the foreseeable future.

Despite ambivalent feelings towards all of the challenges facing the transitory societies of Serbia and the former Yugoslavia republics, it could be said that most of the scholars of the middle and younger generations generally have a positive attitude towards the future and that they feel a strong tendency towards advocacy and social engagement through their professional work. To summarise, the main aspects of the professional activities of ethnomusicologists and ethnochoreologists from Serbia and the neighbouring countries, considered as areas where we are gaining a certain degree of social relevance, are: collaboration with local communities and performers of traditional music and dance; work with students in theoretical and practical domains; carrying out dialogues with experts from other fields of social sciences and the humanities through interdisciplinary research projects; changing public awareness considering various issues of music and dance such as gender or policies of safeguarding intangible cultural heritage; and last, but not least, pointing out the theoretical and practical aspects of music and dance in the wider community as immanent and pos- 
sibly powerful tools for social and political engagements.

Starting out from the basic reason why we are remaining active in our disciplinary fields at all, which is a strong affection for music and dance, it could be said that, ultimately, what makes sense in our work is that music and dance matter!

\section{References}

Babić, Rakidžić, Ana. 1989. "Fenomen novokomponovane narodne pesme u Srbiji” [The phenomenon of newly composed folk song in Serbia]. Master's thesis. Belgrade: Department of Ethnomusicology, Faculty of Music.

Bajić, Vesna. 2006. "Od originalnog zapisa tradicionalne muzike i igre ka preradi, obradi i kompoziciji. Tradicionalna muzika i igra u kulturno-umetničkim društvima i institucijama u Srbiji" [From the original notation of traditional music and dance toward its adaptation, treatment and composition. Traditional music and dance in cultural-artistic societies and institutions in Serbia]. Master's thesis. Belgrade: Department for Ethnomusicology, Faculty of Music.

Bajić Stojiljković, Vesna. 2016. "Procesi (re)definisanja strukturalnih, dramaturških i estetskih aspekata u scenskom prikazivanju tradicionalne igre i muzike za igru u Srbiji” [Processes of (re)defining structural, dramaturgical and aesthetic aspects of stage presentation of traditional dance and dance-music in Serbia]. Ph.D. dissertation. Belgrade: Department of Ethnomusicology, Faculty of Music.

Ceribašić, Naila. 1998. "Etnomuzikološka i etnokoreološka djelatnost instituta tijekom devedesetih godina" [Ethnomusicology and ethnochoreology at the Institute during the nineties]. Narodna umjetnost 32/2: 49-66.

Dević, Dragoslav. 1963. "Nove 'narodne' pesme” [New 'folk' songs]. In Рад IX конгреса СФЈ (Mostar and Trebinje, 1962). Sarajevo: Savez folklorista Jugoslavije, 545-551.

Dumnić, Marija. 2010. "Primenjena etnomuzikologija. Istorijat, koncepti, perspective u Srbiji" [Applied ethnomusicology. History, concepts and perspectives in Serbia]. Master's thesis. Beograd: Faculty of Music, Department of Ethnomusicology.

2016. "Istorijski aspekti i savremene prakse izvođenja starogradske muzike u Beogradu" [Historical Aspects and Contemporary Performance Practices of "Old Urban Music" (starogradska muzika) in Belgrade]. Ph.D. dissertation. Belgrade: Department of Ethnomusicology, Faculty of Music.

Erdei, Ildiko. 2007. "Dimenzije ekonomije: prilog promišljanju privatizacije kao socio-kulturne transformacije" [Dimensions of economy: A contribution to the reflection of privatisation as a socio-cultural transformation]. In Antropologija postsocijalzma. V. Ribić, ed. Belgrade: Srpski genealoški centar, 76-127.

Fracile, Nice. 2016. Tragom antičkih metričkih stopa. Komparativna etnomuzikološka is208 
traživanja [In the wake of classical-antiquity metric feet. A comparative ethnomusicological study]. Novi Sad: Akademija umetnosti Univerziteta u Novom Sadu.

Giurchescu, Anca and Lisbet Torp. 1991. "Theory and method in dance research: a European approach to the holistic study of dance." Yearbook for Traditional Music 23: 1-10.

Golemović, Dimitrije. 2005. Etnomuzikološki ogledi [Ethnomusicological essays]. Beograd: Biblioteka XX vek.

Golemović Dimitrije and Selena Rakočević. 2008. "Mapping the past and the future of Serbian ethnomusicology and ethnochoreology." In Vienna and the Balkans, L. Peycheva and A. Rodel, eds. Sofia: Institute of Art studies, Bulgarian Academy of Science, 88-95.

Gore, Georgiana and Andrée Grau. 2006. "Politics of knowledge: East-West relations in the anthropology of dance." Paper presented at the CORD conference in Tempe, Arizona.

Ilijin, Milica. 1953. Slovenske l'udove tance vo Vojvodine. Petrovec: Kultura, 1-110.

Ilijin, Milica and Marta Debeljak. Madarske narodne igre iz Vojvodine. Novi Sad: Bratstvo i jedinstvo, 1-166.

Hann, Chris. 2004. "Introduction: postsocialism as a topic of anthropological investigation. Farewell of the postsocialist 'other'." In Postsocialism. Ideals, ideologies, and practice in Eurasia. C. M. Hann, ed. London/New York: Routledge, 1-12.

Harrison, Klisala, Elisabeth Mackinlay and Svanibor Pettan, eds. 2010. Applied ethnomusicology: Historical and contemporary approaches. Newcastle upon Tyne: Cambridge Scholars Publishing.

Hofman, Ana. 2004. "Uloga partizanskih pesama u kreiranju Sistema" [The role of partisan songs in creating a system]. Master's thesis. Belgrade: Department of Ethnomusicology, Faculty of Music.

2010. "Maintaining the distance: Rethinking the activist position in applied ethnomusicology." In Applied Ethnomusicology: Historical and contemporary approaches. K. Harrison, E. Mackinlay, and S. Pettan, eds. Cambridge: Cambridge Scholars Publishing, 23-35.

Humphrey, Caroline. 2004. "Introduction: postsocialism as a topic of anthropological investigation. Does the category 'postsocialist' still make sense?” In Postsocialism. Ideals, Ideologies, and Practice in Eurasia. C. M. Hann, ed. London/New York: Routledge, 12-15.

Jovanović, Jelena. 2014. Vokalna tradicija fasenice u svetlosti etnogenetskih procesa [The vocal tradition of the Jasenica region in view of ethnogenetic processes]. Belgrade: Muzikološki institut SANU.

Karača Beljak, Tamara and Jasmina Talam. 2014. "Research of the ethnomusicological context in Bosnia and Herzegovina through the work of the folklorists Mira Fulanović-Šošić, Dunja Rihtman-Šotrić, Jasna Spaić and Ankica Petrović." In The collection of papers celebrating the 110th anniversary of the birth of felene Dopude. Sarajevo: Univerzitet u Sarajevu, Muzi ka akademija u Sarajevu, 240-249.

Karin. Vesna. 2014. "Plesna tradicija Dinaraca u Vojvodini" [The dance tradition of Dinaric people in Vojvodina]. Ph.D. dissertation. Belgrade: Department of Ethnomusicology, Faculty of Music. 
Kostov, Stojče. 2016. "Implementacija na etnokoreologijata vo obrazovniot system na srbija I na makedonija" [The introduction of ethnochoreology in the educational system in Serbia and Macedonia]. Makedonski folklor 71/XXXVIII: 331-336.

Kotnik, Vlado. 2007. "Bizarre academism and science in Slovenia: elements of the anthropological study of post-socialism and transition." In Antropologija postsocijalzma. V. Ribić, ed. Belgrade: Srpski genealoški centar. Etnološka biblioteka, knjiga 34, 128-171.

Kovačević, Ivan. 2005. "Iz etnologije u antropologiju. Srpska etnologija u poslednje tri decenije 1975-2005 [Ethnology, a route for anthropology. Serbian ethnology during the past three decades 1975-2005].” In Etnologija i antropologija: stanje i perspektive. D. Radojičić, ed. Belgrade: Etnografski institut Srpske akademije nauka i umetnosti, 11-19.

Lajić Mihajlović, Danka. 2007. "Serbian epic practice in the communicology discourse: A contribution to the methodology of ethnomusicology." In Research of dance and music on the Balkans. International Symposium Brčko, December 6-9, 2007, D. O, Golemović, ed. Banja Luka: International Musicological Society \& Musicological Society of RS and Musicological Society FBiH; Brčko: Association for Fostering Serbian Cultural and Historical Heritage, Baštinar, 25-36.

2014. Srpsko tradicionalno pevanje uz gusle. Guslarska praksa kao komunikacioni proces [Serbian traditional singing accompanied by the gusle. The guslars' practice as a communication process]. Belgrade: Muzikološki institut SANU.

Litvinović, Selena. 1998. "Primenjena etnomuzikologija na delu: Falun folk music festival и Етнокамп 97” [Applied ethnomusicology in action: Falun folk music festival i Etnokamp 97]. Нови звук 11: 131-132.

Marjanović, Zlata. 2013. "Narodna muzika Boke Kotorske i Crnogorskog primorja" [The folk music of Boka Kotorska and the Montenegrin coast]. Ph.D. dissertation. Belgrade: Department of Ethnomusicology, Faculty of Music.

Marošević, Grozdana. 1995. "The influence of folkloristics on ethnomusicology in Croatia." Narodna umjetnost 32/1: 39-54.

Nenić, Iva. 2014. "Deregulacija kanona: identiteti, prakse i ideologije ženskog sviranja na tradicionalnim instrumentima" [Deregulation of the canon: identities, practices and ideologies of women playing traditional instruments in Serbia]. Ph.D. dissertation. Belgrade: Department of Ethnomusicology, Faculty of Music.

2015. "In Discipline: Talks from the European Side - Iva Nenić," SEM Student Union, April 2015.

https://semstudentunion.wordpress.com/2015/04/02/in-discipline-talks-from-the-europeanside-11/ (07.04.2019).

2016. "Envisioning ethnomusicological praxis: Theory, action-intervention and situated knowledge." In Music and dance in Southeastern Europe: New scopes of research and action, L. Mellish, N. Green and M. Zakić, eds. Belgrade: Faculty of Music, 334-341.

Opetcheska Tatarchevska, Ivona. 2005. "Macedonian traditional dances and education policy 
in Macedonia development aspects.” In Cultural policy and music education, D. Buzarovski ed. Skopje: University of St. Kiril and Metodij, School of Music, Institute for Research and Archiving Music, 94-95.

.2008. "Macedonian ethnomusicology: A problem of continuity." Vienna and the Balkans.

Papers from the $39^{\text {th }}$ World conference of the ICTM, Vienna 2007. Sofia: Institute of Art Studies of the Bulgarian Academy of Science, 30-39.

Pettan, Svanibor. 2015. "Applied ethnomusicology in the global arena." In The Oxford Handbook of Applied Ethnomusicology, S. Pettan and J. T. Titon, eds. Oxford/New York: Oxford University Press, 29-52.

Prica, Ines. 2004. "Nasljeđe jugoslavenskih etnologija i suvremeno istraživanje postsocijalizma." Traditiones 33/1: 19-34.

. 2007. "Problem interpretacije tranzicije iz 'neralnog socijalizma" [The problem of interpreting the transition from an 'unreal socialism']. In Antropologija postsocijalzma, Vladimir Ribić, ed. Belgrade: Srpski genealoški centar. Etnološka biblioteka, knjiga 34, 25-50.

Radinović, Sanja. 2011. Oblik i reč. Zakonomernosti melopoetskog oblikovanja srpskih narodnih pesama kao isnova za metodologiju formalne analize [Form and word. The laws of the melopoetic shaping of Serbian folk songs as a basis for the methodology of formal analysis]. Belgrade: Department of Ethnomusicology, Faculty of Music.

Rakočević, Selena. 2013. "Tracing the discipline: Eighty years of ethnochoreology in Serbia." In New Sound 41, M. Veselinović-Hofman, ed. Belgrade: Department of Musicology. Faculty of Music. 1/2013, 58-86.

. 2015. "Ethnochoreology as an interdiscipline in a postdisciplinary era: A historiography of dance scholarship in Serbia." Yearbook for Traditional Music 47: 27-44.

Ranković. Sanja. 2012. "Vokalni dijalekti dinarskih Srba u Vojvodini" [Vocal dialects of Dinaric Serbs in Vojvodina]. Ph.D. dissertation. Belgrade: Department of Ethnomusicology, Faculty of Music.

Rice, Timothy. 1999. "The revision of Bulgarian folkloristics and folk music research in the post-communist period (1990-1996)." In New countries, old sounds. Cultural identity and social change in Southeastern Europe. Beiträge des internationalen Symposiums in Berlin (22. -27. April 1997), Bruno B. Reuer ed. with Lujza Tari and Krista Zach. München: Verlag Südostdeutsches Kulturwerk, 187-202.

Sedmak, Biljana. 1990. "Miodrag Mile Bogdanović” (monografija jednog pevača) [Miodrag Mile Bogdanović (monography of one singer)]. Master's thesis. Belgrade: Department of Ethnomusicology, Faculty of Music.

Stojkova Serafimovska, Velika. 2008. "Macedonian ethnomusicology: A problem of continuity." In Vienna and the Balkans. Papers from the $39^{\text {th }}$ World conference of the ICTM, Vienna 2007. Sofia: Institute of Art Studies of Bulgarian Academy of Science, 22-29.

Titon, Jeff Todd. 2015. "Applied ethnomusicology: A descriptive and historical account." In The Oxford Handbook of Applied Ethnomusicology, S. Pettan and J. T. Titon, eds. Oxford \& New 
York: Oxford University Press, 5-29.

Vukićević-Zakić, Mirjana. 2002. "Znakovne funkcije određenja žanra pesama zimskog polugođa" [Sign functions of determining the genre of the songs of the winter rituals]. In Muzika kroz misao. četvrti godišnji skup nastavnika i saradnika Katedre za muzikologiju i etnomuzikologiju. Belgrade: Faculty of music, 131-139.

Zakić, Mirjana. 2009. “Obredne pesme zimskog polugođa. Sistemi zvučnih znakova u tradiciji jugoistočne Srbije" [Ritual songs of the winter season. Systems of sound signs in the tradition of South Eastern Serbia]. Ethnomusicological studies. Dissertations. Belgrade: Faculty of Music.

. 2012. "The application of semiotic theory by Ch. S. Peirce in ethnomusicology."

In Musical Practices in the Balkans: Ethnomusicological Perspectives, proceedings of the international conference held from November 23 to 25, 2011, D. Despić, J. Jovanović and D. Lajić-Mihajlović, eds. Belgrade: Institute of Musicology of SASA, 55-66.

Zebec, Tvrtko. 1996. "Dance research in Croatia," Narodna umjetnost 33/1: 89_ 110.

2009. "Razvoj i primjena etnokoreologije u Hrvatskoj" [Development and Application of Ethnochoreology in Croatia], In Zbornik radova, VI Medunarodni simpozij „Muzika u društvu." Sarajevo: Muzikološko društvo FbiH i Muzička akademija u Sarajevu, 136150 .

Interview partners

Bajić Stojiljković, Vesna. 2017. Interview made on 2 August 2017.

Dumnić, Marija. 2017. Interview made on 4 August 2017.

Fracile, Nice. 2017. Interview made on 26 July 2017.

Golemović, Dimitrije. 2018. Interview made on 30 January 2018.

Lajić Mihajlović, Danka. 2017. Interview made on 4 September 2017.

Marjanović, Zlata. 2017. Interview made on 27 July 2017.

Nenić, Iva. 2017. Interview made on 28 July 2017.

Opetcheska Tatarchevska, Ivona. 2017. Interview made on 8 October 2017.

Opetcheska Tatarchevska, Ivona. 2018. E-mail correspondence on 11 February 2018.

Panić, Dragica. 2018. Interview made on 24 July 2018.

Petkovski, Filip. 2018. E-mail correspondence on 20 July 2018.

Pettan, Svanibor. 2017. Interview made on 30 August 2017.

Stojkova Serafimovska, Velika. 2017. Interview made on 9 September 2017.

Talam, Jasmina. 2017. E-mail correspondence, 9 September 2017.

Vitas, Marija. 2017. Interviews made on 1 August and 14 September 2017.

Vukobratović, Jelka. 2017. Interview made on 30 September 2017.

2 I 2 
Zakić, Mirjana. 2017. Interview made on 10 August 2017.

Zebec, Tvrtko. Interview made on 30 August 2017.

\section{Internet sources}

http://www.mpn.gov.rs/nauka/osnovna-istrazivanja (04.04.2019).

http://www.parlament.gov.rs (04.04.2019).

http://www.music.sanu.ac.rs (04.04.2019).

\section{Abstract}

In most Southeastern European countries, the beginnings of ethnomusicology and ethnochoreology as independent scholarly disciplines were inextricably linked with the state institutions of socialist regimes after World War II. In these countries ethnomusicological and ethnochoreological research, grounded in folkloristics, was sponsored under the ideological constraints of socialist systems and hence had strong national orientations in the service of the ideological and political agendas of the state parties. After the collapse of the socialist regimes, which caused broad social and cultural transformations, ethnomusicology and ethnochoreology have generally continued to be linked with state institutions (universities and academic institutes), but at the same time have been subject to extensive remodeling, including disciplinary orientations, methodological approaches, applicable domains of professional activities, and the broadening of available financial resources for research and work.

In this article I explore the views of many individual researchers (including myself) about their work with the aim of understanding the position of ethnomusicology and ethnochoreology in the contemporary society of post-socialist Serbia, and thus the socio-political relevance of these disciplines from the perspective of the scholars themselves. Based on interviews and questionnaires I have tried to compare answers to the following questions: What are the basic attitudes concerning the realities and potentials of our disciplinary relevance within the societies in which we act? What are our experiences of "practicing" ethnomusicology and ethnochoreology in various, educational, research and applied contexts? What difficulties are we facing? How do we feel about our professional relevance? What efforts are we making to increase and widen our relevance in society?

The current experiences of scholars from Serbia are compared with the attitudes and apprehensions of colleagues from other countries of the former Yugoslavia by drawing on connections made during shared socialist pasts. This project provides a 
platform for critical reflection on the contemporary position of scholars from this part of Southeastern Europe and to reveal the difficulties and challenges they are currently facing, but also to reveal their innovative ideas and professional challenges. 


\title{
Music Archives, Identity and Democracy.
}

\author{
The Role of Archives from New Perspectives
}

In connection with the public seminar "Memories for life" in Stockholm in 2014, the Danish EAM (electro acoustic music) duo Vinyl Terror and Horror performed a work that was commissioned for this special occasion. ${ }^{1}$ Vinyl Terror and Horror consists of Camilla Sørensen and Greta Christensen, and the duo has specialized in live performances based on the fragmentation and re-use of recorded phonograms. In practice, this means using vinyl discs that are cut into pieces and put together in new forms; in puzzle shapes, as spirals, squares etc. The result is a collage of pre-recorded sounds, scratches and noise. As a listener you are thrown between the recognition of fragments from the recordings and more noise-inspired soundscapes. Sørensen and Christensen work live on stage with a large number of turntables with fixed and loose pickups that are alternately consciously and randomly dipped onto the fragmented vinyl records or pressed hard onto the disc tracks. On the website they describe their way of working:

Our approach to music starts from a visual and sculptural practice. Turntable deconstruction and rearrangement of the vinyl media in all imaginative ways is strongly influencing our sounds. [...] Cut up and mistreated records looping and creaking from dust and sloppy treatment. Pick-ups being pushed disrespectfully over grooves. Records spinning backwards and forwards while played from multiple pick-ups simultaneously. [...] Repetitive arrangements, dark sounds, neck breaking mixes, film-amateur sound effects, scratches, squeaks, vinyl's terror and horror. ${ }^{2}$

At the Svenskt visarkiv [The Centre for Swedish Folk Music and Jazz Research] we were very pleased with the performance. It exemplified very well the research project Pluralize or Polarize's intention to problematize the archive's dual role as an institution for intermediation and preservation. At the same time, we were somewhat wor-

1 "Memories for life" was a final presentation of the research project "Mixa eller Maxa" [Pluralize or Polarize], conducted at Svenskt visarkiv 2011-2014. The project addressed questions of music collecting and ideology.

2 http://www.vinylterrorandhorror.com/live.html (01.08.2019) 


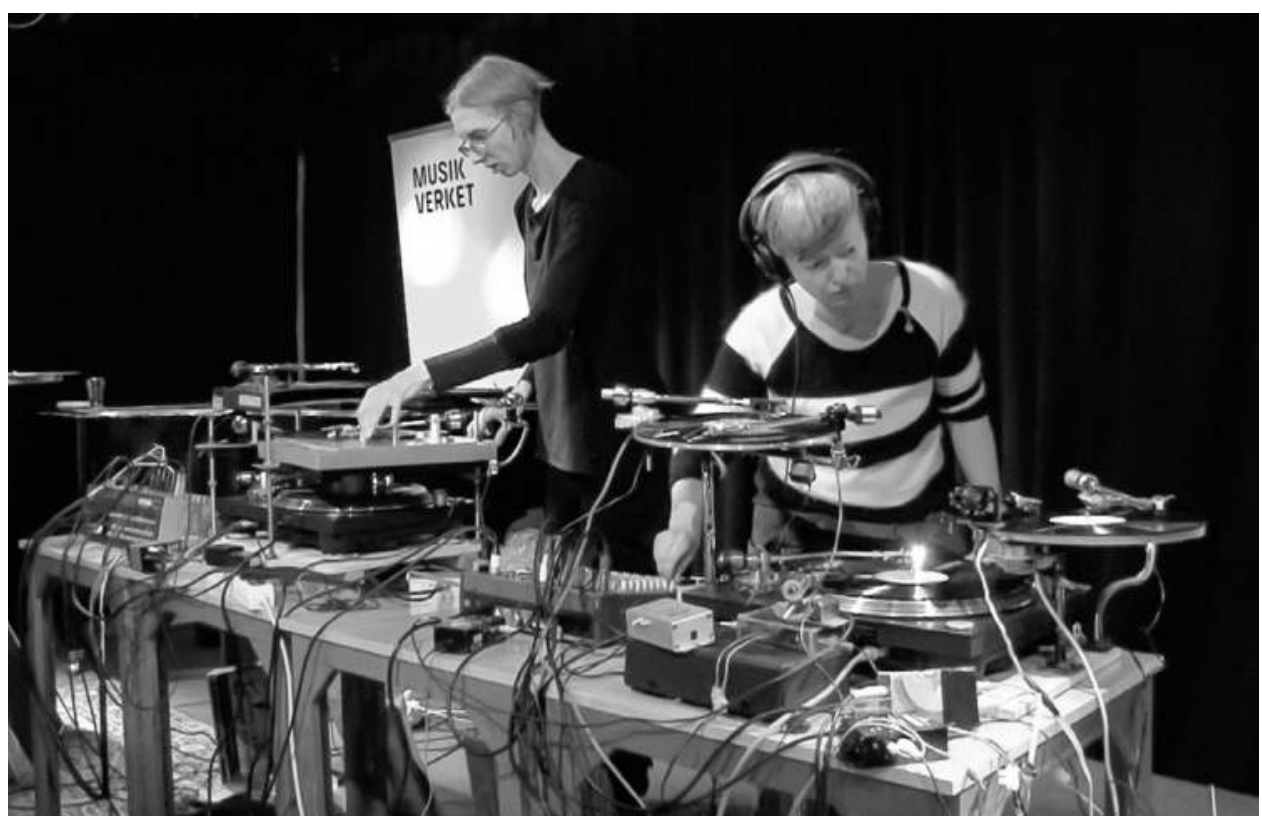

Figure 1: Vinyl Terror and Horror, Greta Christensen and Camilla Sørensen, from the concert in Stockholm 2014. Photo by Torbjön Ivarsson, Svenskt visarkiv.

ried about the reception of the work. We know that there are many who consider the preservation of traditions as the most important task of the archive and who might get upset about this use of the material. This concern was also shared by Sørensen and Christensen. They were initially reluctant to take on the task when they realized that we wanted them to cut and destroy LPs with material from the archive collections. Luckily it turned out that these concerns were exaggerated, the concert was well received and Vinyl Terror and Horror later staged the same performance at several places in Europe. But why all these worries? Archivists seem to be constantly concerned about how their materials will be used; about truthfulness to collectors, authors, informants and former archive workers. At the same time, everyone seems to agree that the overall purpose of archiving is that the collections should be available and re-used by both old and new target groups.

From an intellectual viewpoint, we understand that what is collected by museums and archives changes through the gathering process itself and, not least in its repository and through re-use. But why are we afraid that the cultural heritage will be abused?

There are several reasons for having a strict policy when it comes to sharing sensitive material. One is, of course, to follow laws and regulations, but other considera- 
tions of a more moral nature should also apply. In research ethics the "requirement to protect the individual" is a norm-individuals should be protected from undue observation of their lives, not subjected to "mental or physical harm, humiliation or affront." ${ }^{\prime \prime}$ It must be ensured that the general public is able to trust a state-owned archive in the cultural heritage field—not least because people must feel confident that material entrusted to the archive will be used in a responsible manner. But nevertheless we know that when we play music from archive transcriptions, it is never the same as that which was once recorded. New times and new contexts not only change the ways of performing music, but also the understanding of it. The ethical responsibility towards informants and others involved in the event, therefore, also has an aesthetic dimension when it concerns cultural heritage. ${ }^{4} \mathrm{We}$ have to follow the laws about economic and non-profit rights, but also to respect artistic freedom.

Representation

Archiving always involves choices when some objects or cultural expressions are chosen to represent certain traditions, cultures or nations. This is of course at the expense of other objects or expressions: those that are not collected and will therefore fall by the wayside and eventually disappear.

The collection and documentation of folk music and music-making has most often not been governed by democratic principles of everyone's equal rights, but by utopian visions of individuals and organizations, and sometimes by state and national interests and needs. ${ }^{5}$

During the past 30-40 years many national archives have tried to change their role and reevaluate their work. Changing from being tools in the creation process of na-

3 "Ethical Research Principals." The Swedish Research Council, 2002.

4 Ethical considerations concerning the field documentation of music are often complex. There are often many stakeholders involved. An obvious category is of course that of informants, i.e. those who are recorded or in some way contributed material to a collector or an archive. The informant may also be part of a cultural grouping or community that may have opinions as well as legal rights regarding the use of "their" cultural heritage. And there is also the documentalist-the collector/researcher. The collection work might have had specific purposes or research questions that any new use and dissemination of the material may have to consider.

5 But the driving force is perhaps just as often the joy of individual amateur collectors, something that is easily forgotten in the discussion. A large part of the collections in our archives have been created through private initiatives where the goal has often only been the activity of collecting itself, and the reward for the work has been the satisfaction over a complete collection of jazz records, stamps or beer labels. Such collections are often brought to the archives as donations from bequests or relatives and are an important source for archive growth today. 
tion states into functioning as democratic resources for their users-everyone's right to his or her history. Perhaps it is our understanding of what a nation state is that has changed? The old goal to present the nation as homogeneous with a unique and unified culture is not so clear any longer. But now there are indications that the pendulum is swinging back.

In a budget proposal the Swedish parliament in 2014, Sverigedemokraterna [the Sweden Democrats] - the largest right-wing nationalist party in Sweden-moved to strengthen the budget for Svenskt visarkiv [The Swedish Centre for Folk Music and Jazz Research] by SEK 6 million (about €650,000). The money was supposed to be earmarked for exclusively "Swedish" traditions. ${ }^{6}$

The management of the archive was of course somewhat challenged and confused by this sudden proposal. But not completely surprised. This political party had made other statements regarding the protection of Swedish culture in line with this proposition. But why this budget investment in a sound archive? What was it that Sverigedemokraterna wanted to achieve by investing more taxpayers' money in Svenskt visarkiv? Probably they had realized the importance of being in control of people's collective memories. Like many other nationalist political parties, the preservation of all things "Swedish" is high on their agenda. This includes, of course, control over the preservation of cultural expressions. Similar ideas have been discussed in other studies of how ideological movements have attempted to politicise and use music. The formation of Nazi Germany has been described as an "aesthetic project" (Geisler \& Andersson 2007: 11-13). The aim was to create uniformity and cultural coherenceone nation, one people, one culture. The Swedish ethnologist Alf Arvidsson observes in the discussion of what he calls "the construction of the good music" that the central position of folk music in many political movements has nothing to do with its musical characteristics but a lot to do with its origin and creation (Arvidsson 2008: 363).

The Sweden Democrats' motion was rejected by the Swedish Parliament, which was a relief for many in the archive's staff and management. But before the decision was taken, there were lively discussions about how to circumvent the intentions of the proposal.

Archives matter

The heading of the meeting celebrating the transfer of the ICTM Secretariat from Ljubljana to Vienna 2017 was "Musics matter." This article is concerned with music archives and their capacity as ideological powers in the societies where they exist. I

6 Motion till Riksdagen [Motion to the Swedish Parliament]: 2014/15: 2895 by Aron Emilsson (SD)

2 I 8 
will discuss how different times and ideologies affect the work in and with music archives and also how the meaning of collections varies over time. The article also deals with the role of music archives as active co-creators of the music cultures that they themselves document, and our responsibility as scholars and collectors to recognize and relate to this.

Here I will try to problematize the role of archives from a couple of different aspects. Archives are always linked to a context; in one way or another they have been created in order to preserve or to bring order among documents and records of different kinds. Many music archives were created on their own private initiative by individual enthusiasts who had the ambition to arrange and convey their own special interests. Others have been created on the initiative of politically founded interests to communicate a certain version of reality and history in line with their ideological positions.

We know that archives have existed for more than 4000 years. One of the most well-known historical archives is the clay tablets of the ancient city-state of Ebla, a town located in present-day Syria. Ebla had its political heyday around 2400-2250 BC. It ended when the town was conquered and destroyed by King Naram-Sin of Akkad. A second golden age occurred about 1850-1600 BC. The first music archives of greater importance in Europe were connected to the church and monasteries and later also to the musical activities at royal courts. Notation of Gregorian chant can be traced back to the eighth century. An essential development-which was of decisive importance for the development of folkloristic and later ethnomusicological archives-was the interest in folk culture that emerged in the late eighteenth century (cf. Lundberg 2015a).

The word "archive" has been used in English and many other European languages since the early $17^{\text {th }}$ century. "Archive" originates from the late Latin word archivum, which is originally derived from the Greek archeion, whose original meaning was a 'building for public authorities', 'town hall', from ả@ $\chi$ ' ( $\approx$ 'government'). It refers, therefore, to a seat of power. Its original meaning is close to words like "crest," "the first," "foremost," "topmost" (c.f. archbishop, archduke and arch enemy, but also acropolis). The Latin arx, 'castle', has the same root.

It is easy to understand that a prerequisite for states and their authorities has been the control of records and documents. For written documents and symbolically important objects there is a need for long-term authorization, references that guarantee the continuity of meaning and significance beyond the individual politician's term of office or life, and which can be referred to in times when political powers are questioned. The gathering and keeping of documents (from the Latin documentum, 'something with which you can retain knowledge' or in more prosaic modern language, simply 'learning material') is thus the exercise of power-bringing together texts and symbols in a demarcated space that can be controlled (Hammarlund 2016). 
It is commonly known that institutions such as schools, museums, archives and later national media are active agents in the forming of communities. But how do they affect the culture that they themselves are a part of? It is easy to be fooled into believing that they are merely reflections of existing cultural forms, but as a matter of fact they are also dynamic parts of the culture and should be seen as cultural expressions in themselves. The paradox of archives as a reflection of the current culture and at the same time a co-creator of the same is similar to the discussion of the concept of culture in the anthropological sense. "Culture" can be seen as the sum of the ideas, actions and thoughts in a certain a community or other type of grouping, and at the same time we know that people's ideas, actions and thoughts are shaped by the culture they live in. If this argument is used to describe the role of music archives in society, the archive becomes both what is created and what creates.

Cultural heritage institutions as all kinds of publicly available collections of cultural expressions involve some degree of the exercise of power. The overall question is, of course, which cultural expression is valuable enough to be collected in the archives, and which is not.

It should be noted, however, that there is an important difference between different kinds of music archives depending on their general orientation. Schematically, there are two main categories of music archives. The first consists of the national archives, many with roots in the nationalist movements of the $19^{\text {th }}$ century and created as part of the construction of a nation as a homogeneous and cohesive culture. The second is the type of archive that aims to present a selection of the world's cultures. There are archives with roots in comparative musicology such as the well-known Phonogram archives in Berlin and Vienna. Similar collections can be found at many universities. My discussion here is primarily concerned with the national archives of the first kind. These are archives with a more or less outspoken aim to preserve and present what was considered to be representable for the nation as an important cultural heritage.

Simply put, archives can act as political tools for:

- $\quad$ Expressing identity on a collective level for societies, communities and nations

- Demonstrating unity (or diversity)

- Presenting evidence of a common glorious past

- Serving as models that can show us or teach us what is the most valuable or "right" cultural heritage

We have now discussed some general aspects of music archives and their prerequisites and positions in a musical context and in society as a whole. We will now look at two examples of collecting works and archives. Both were developed at about the same time but created with different conditions and goals. 
In the year 1908 an appeal was published in Fataburen, the journal of the Nordic $\mathrm{Mu}$ seum in Stockholm. The appeal was signed by the Swedish prince Eugene and many other well-known persons with an interest in Swedish folk culture. The aim was to generate interest in the newly formed Swedish Folk Music Commission-a body that would promote the collection of important elements of a rapidly disappearing cultural heritage and preserve it for future generations. The Commission had been formed the previous year and in the call it was written:

It is a known fact that Swedish folk music has been undergoing decline for decades, that our genuine old songs and ballads, which are said by connoisseurs to be among the most beautiful in the world, are about to disappear, and are being supplanted by songs that lack almost all musical value. Degeneration is quick. Among the younger generations these beautiful melodies are already forgotten. Without our intervention they would now no longer be able to survive in tradition. ${ }^{7}$

It was stated by the Folk Music Commission that the most important musical heritage is "genuine old songs and ballads" and the commission also declared that there is a particular need for contributions such as "transcriptions of folk songs and old hymns, herding tunes, walking tunes, wedding songs, long dances, polskas, old waltzes etc.“ Apparently, the focus of interest was largely instrumental music. This was partly new. In the early days of the collection of folk culture, collectors were more concerned with songs and lyrics. The change of focus can be explained ideologically, but also by the simple fact that the enthusiasts as the driving force happened to have a special interest in instrumental folk music.

The Commission's work is by far the largest and most comprehensive collection project of Swedish folk music ever. The main task was to carry out a survey of Swedish folk music, region by region, which resulted in the 24 volumes of Svenska latar [Swedish Folk Tunes]. The work was led initially by Nils Andersson and taken over by Nils' companion Olof Andersson. The latter had been engaged to assist with fair copies and field transcriptions, but after Nils' death in 1921 the collecting was conducted entirely by Olof Andersson. In 1940 the last of the 24 volumes of Svenska latar was published and the Folk Music Commission's work was completed. The entire collection of the FMK, around 45000 hand-written pages with nearly 150000 folk melodies, was published on the Internet by Svenskt visarkiv [The Centre for Folk Music and Jazz Research] 2007. The Commission's work has had a huge impact on what is now

7 "Upprop" (Call). Free translation by the author. 
regarded as Swedish folk music. Svenska låtar came to function as a canon for Swedish folk musicians.

\section{Tirén's foik Collection}

In the same period, several other documentation projects were conducted in Sweden. One of the more important was led by Karl Tirén between 1909 and 1916. Tirén undertook a remarkable collecting project of Sami joik. At that time the joik tradition was almost unknown outside Sami culture, and northern Sweden was seen as a wilderness to explore and discover. Tirén's achievement matched the spirit of the time, but dealt with a previously ignored subject. Tirén collected independently, but received certain grants to cover loss of income and travel costs.

Initially he documented what he heard with pen and paper. But he was well aware of the limitations of transcribing joik on paper. In 1912 he was offered the loan of a phonograph by The Royal Academy of Science. Tirén was provided with the equipment by the director of the Natural History Museum's ethnographic department: Carl Vilhelm Hartman. Hartman understood the usefulness of the phonograph for folk music collecting, and also the value of being able to play such recordings in the museum's exhibitions.

In early 1913 Karl Tirén set out on the first collecting trip equipped with the phonograph, and a surprising number of successful recordings were made. A selection of recordings was played in May of the same year at one of the Natural History $\mathrm{Mu}-$ seum's Ethnographic Department's “Exotic Phonogram and Gramophone Concerts." Between 1913-15 Tirén recorded more than 300 cylinders. In 1915 he made his final phonographic joik journey: he was invited to his collaborator Maria Persson's wedding. She had been his foremost source of information and had guided him in the world of joik. In 1942 he published the book Die Lappische Volksmusik with transcriptions and analysis of his collected material. The book was written in German, which was the dominant academic language in Sweden at the time. Apart from organizing his collection, he continued for many years to give lectures in schools and for different cultural societies, visiting town halls and other meetings. Well-spoken and enthusiastic, he recounted the story of his journeys and his meetings with the Sami culture.

Karl Tirén was very eager to cooperate with the Folk Music Commission, and his first expeditions were actually funded by the Commission. But Nils Andersson was not interested in incorporating the joiks into the archive of the Folk Music Commission.

Why was that? One reason that is often stated is that Nils Andersson opposed the use of the phonograph (Ternhag 2000, Lundberg 2010 and Boström 2010). It may seem strange, because the phonograph was used in many parts of Europe at that time 


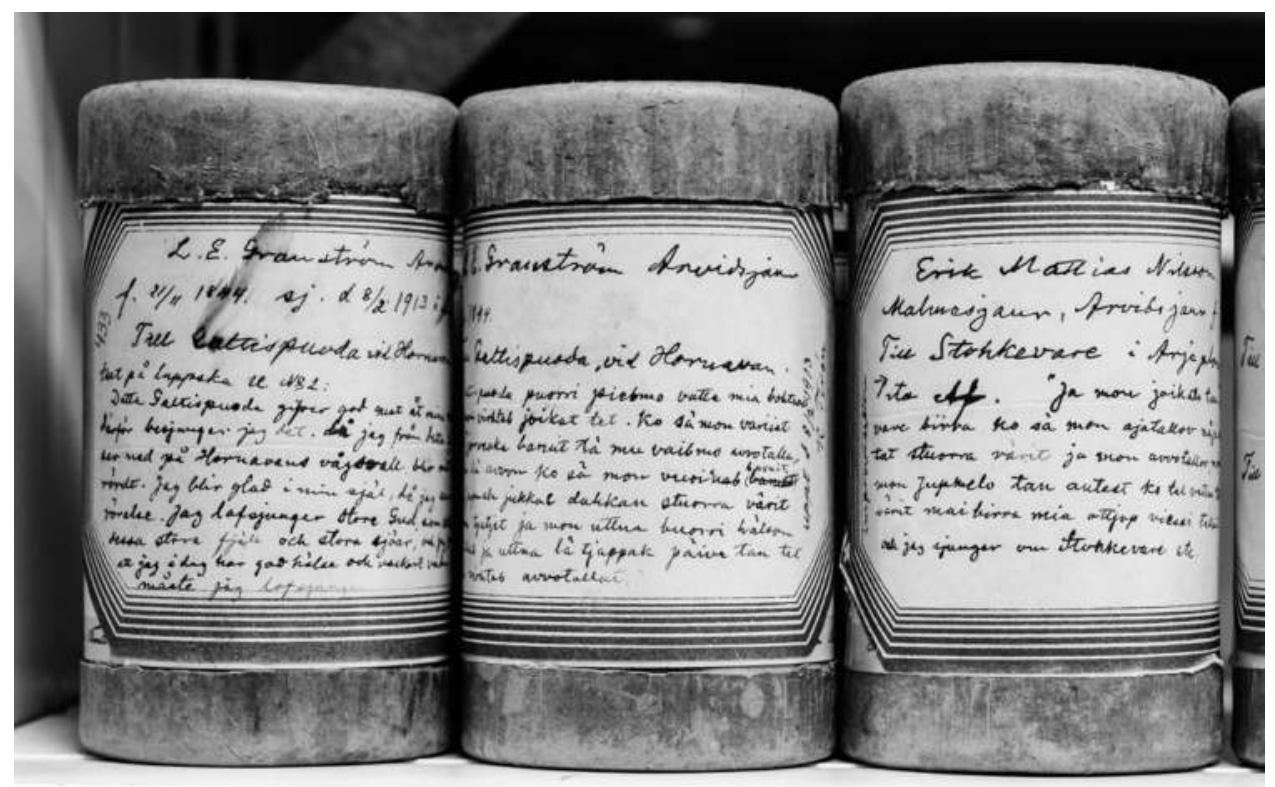

Figure 2: Wax cylinders from the Tirén collection. Photo by Eric Hammarström, Svenskt visarkiv.

and proved to be an excellent tool for collecting folk music. The reasons behind Andersson's standpoint are difficult to understand-possibly he would have liked to ensure the opportunity to "correct" errors in the performances of the music when he transcribed it. In order to avoid others interfering in the interpretation of the material, he might have thought that it was best not to have recordings as a primary source that could be discussed. But there are also other reasons why the Tirén collection was not included in the Folk Music Commission's collection. One was of course the issue of whether or not this was really "Swedish culture." At that time, the Sami were seen as an example of "the culture of others." The location of the joik recordings at the Natural History Museum's Ethnographic Department underlines this. The joiks became part of the presentation of "primitive music" from different parts of the worldmainly from Africa and Australia.

\section{The cultural heritage model}

In some recent articles, I have worked on a model trying to explain and understand the interaction of the archives with the cultures that they function within (Lundberg 2015a, 2015b and 2018). 


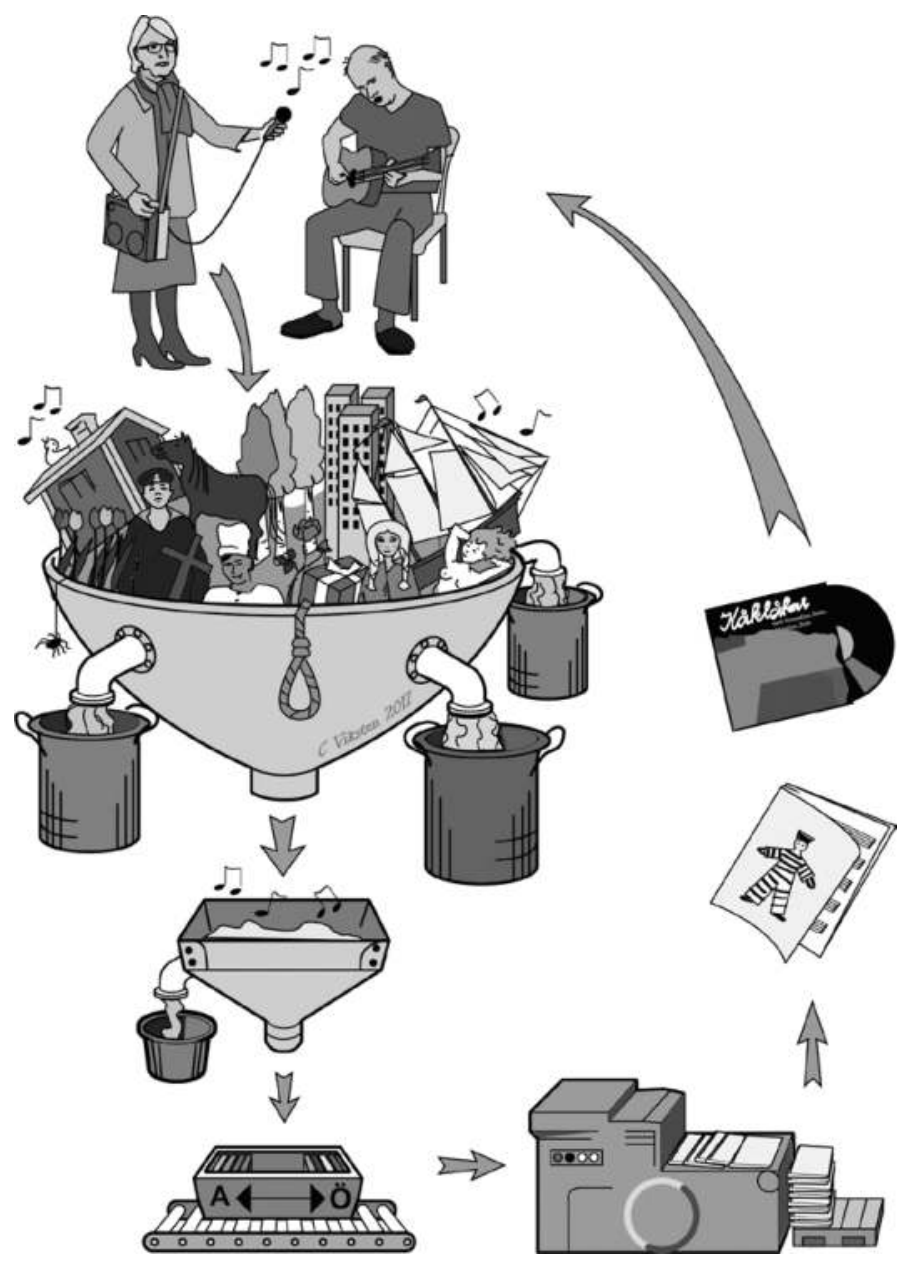

Figure 3: Cultural heritage process. Illustration by Cristina Viksten.

When music or other cultural expressions are collected by archives and museums, their function changes. Simply put, they can be said to change from being culture to becoming cultural heritage. What often happens is that the collected material is organized and published, which in turn can spread and eventually affect the living culture outside. The process where culture becomes a cultural heritage can be called "cultural heritageing." ${ }^{8}$ By introducing the concept of "cultural heritageing" instead

8 See Lundberg 2015a. The concept "kulturarvande" ["cultural heritageing"] was used by the Swedish 224 
of the more frequently used "heritagisation" and "heritisation," I want to stress that the cultural heritage process is an activity performed by someone and not an analytical observation. ${ }^{9}$ The difference between the concepts might be small but is nevertheless crucial for the understanding of the phenomenon. In my view, the idea of cultural heritageing as an active act makes it clear that the gate keepers involved-cultural politicians as well as institutions like museums and archives with their collectors and researchers-have important roles and a responsibility in this process (see figure 3).

Cultural heritageing can be described in four steps: identification-categorisation-standardisation-symbolisation.

Identification means that a selection of practitioners and/or songs is chosen as typical or representative of, for example, a music style, an area or a group of people. In this way the genre is clarified. Many of the folk musicians recorded in the Svenskt visarkiv's collection project during the 60 s and 70 s had extensive repertoires with general Swedish popular music and songs. Through the selection process of the collecting work, the part of the repertoire that was defined by the collectors as folk music became categorised and purified. Via the publication of printed music, research reports and recordings, the repertoire was standardised and a musical canon was created and spread to an interested audience and among the practitioners themselves. Some of the tunes and instruments have taken on a representative meaning as national symbols-for instance the Swedish nyckelharpa [keyed fiddle] and the polska dances.

The work of the Folk Music Commission as well as the Tirén collection are distinct examples of how cultural heritageing functions. The Commission presumed that the Swedish folk music that was considered worth preserving was older instrumental dance melodies and herding music. But the Commission also makes it clear that more modern dance music such as polkas, polkettas, mazurkas, and Viennese waltzes should not be collected, despite the fact that they were undoubtedly a large part of that era's contemporary folk culture. But an even clearer demarcation is made with regard to traditional musics within the different minority cultures that existed in Sweden. Minorities that in many cases had lived in the country for centuries, such as Jews, Roma and Finns were not included in the collecting project. Neither were the Sami, an indigenous culture that had existed in the country significantly longer than the ethnic Swedes. One effect of the work of the Folk Music Commission was a clarification of the content of the concept of "Swedish folk music" as the $18^{\text {th }}$ century rural dance music and the music belonging to the herding culture.

sociologist Qaisar Mahmood (2012) to describe the active choices that individuals and institutions make in the use of history to create values and identities.

9 The concept of heritisation has been discussed and problematised by, for instance, El Kadi \& Elkerdani (2006) and Ronström (2019). Heritagisation is discussed in Harrison 2013 and Sjöholm 2016. 
The lack of minority or immigrant cultural expressions and traditions in archives and museums is normally not the result of malice or racism-which might of course be a consequence. Instead, it is more often the effect of the museums' and archives' role in the creation of official versions of our common history, and the value placed on what is determined to be worthy of being collected and archived, and what can be discarded.

If we try to understand the work of the Folk Music Commission with the help of the "cultural heritage model," we notice that the Commission identified Swedish folk music as older forms of music and the music of the herding culture. Through categorisation and the publication of repertoire books a homogeneous standard was created - which has influenced musicianship to our day. But perhaps most important in the Commission's work is that it makes it clear that contemporary popular culture or, for that matter, the music of minorities, is not regarded as folk music, at least not Swedish folk music. Sami music has remained an interest of ethnographers and anthropologists studying the music of "others."

\section{Why do we collect music?}

It seems that human beings have a congenital need to organize. To understand the world around us we have to create order or at least an understanding of how it is structured. Given the long history of archives, we can understand that this human need is not new. However, the conditions for organizing, preserving and disseminating culture have changed drastically in our digital age. Perhaps it is against this background that we should understand the French historian Pierre Nora when he observes that our time is characterized by an obsession with archives. Increased opportunities for preserving and collecting have also led to increased specialization. In the classical period, music archives of royal families, the nobility and the church were produced. Today, materializations of the memory are democratized, decentralized and multiplied. "The indiscriminate production of archives is the acute effect of a new consciousness, the clearest expression of the terrorism of historized memory" (Nora 1989: 14). This could be understood as a duty to remember. The change from memory to history forces each social group to redefine its identity by documenting and thus writing its own history. The duty to remember makes everyone become their own historian. But must we keep everything forever? The question is really justified, not least considering that most archives are troubled by problems of limited space.

Looking back through history we can observe that the motivations and goals for archiving have varied. The work of the early collectors in the $19^{\text {th }}$ and $20^{\text {th }}$ century often had educational aims - to ensure that the public, musicians or other target groups 
used and appreciated, in the collectors' eyes, the most valuable music. During other periods, the objectives are better described as Volksbildung - to increase knowledge about history and musical traditions. In some cases, the goal was purely about cultural heritage "to preserve for future generations." We can also observe how the significance, meaning and value of collections have varied over time.

As has been pointed out earlier in this article, the mission of cultural heritage archives oscillates between two poles, which in principle are constant, but where the emphasis has varied over time. On the one hand, an archive is a place for orderly storage-where cultural heritage accorded secure preservation and is available for research and historiography. On the other hand, an archive can play an active part in cultural life as a source and inspiration for musicians. If we look at music archives through the perspective of the cultural heritage process we might also regard them from a third perspective as instruments for cultural policy—creators of cultural heritage.

The collection and archiving of music, in earlier times as well as today, has to some extent almost always been related to these poles. But the approaches have often varied depending on ideologies in society.

\section{The archive loop}

In discussions about the influence of music archives on the music culture they are documenting, the ethnologist Owe Ronström and I have used the term „archive loops.“ A fundamental premise is the view of cultural heritage archives as active parties in the traditions they are collecting. The British anthropologist Brian Durrans reasons in a similar way regarding museums: "Museums not only collect and store fragments of culture: they themselves are part of culture" (Durrans 1993: 125). Cultural heritage archives in general and music archives in particular have something of a special position in that they often have a more direct relationship to the traditions they document than, for example, museums. The view of archives as a kind of "frozen" picture of history at a certain moment in time can be contrasted with another approach where archives are seen as a part of an ongoing and living tradition. When the collections of archives are presented in publications and then re-used by new users, they are affected by the changes that result from cultural heritageing. Then new documentation can thus be made where archive influences on the material are an integral part of the tradition. The process can be described as a kind of cycle or loop which we can comprehend by viewing the archives as active parts of the tradition and not as passive documentation institutions.

The Folk Music Commission's collections are characterized by the thoughts and 
ideas of late romanticism about the preservation of cultural memories and heritage. One can see the Commission's efforts as a form of cultural policy-an elevation of special cultural forms at the expense of others. The hope of the collectors was that the music would be passed on to future generations, and that through collecting and publishing they would assure its survival. When Vinyl Terror and Horror used recordings from the same archive, this can be seen as going along with the intentions of the Commission, but also as the complete opposite, a postmodern composition idea based on fragments of a cultural heritage which, through a combination of modern digital and analogue sound carriers, becomes something completely new-an abrupt break with tradition. The question of "right and wrong" in these contexts is really a matter of perspectives. These kinds of questions force us to take a stand on what we really mean by value-adding terms such as "tradition," "heritage" and "sustainability."

The British ethnomusicologist Janet Topp Fargion argues for a broader definition of "preservation" in connection with music archives. "[W] no longer do ethnomusicology to "preserve" music, to keep it from extinction. Aware of the range of activities actually engaged in by today's ethnomusicology archives, I suggest a much broader definition of preservation, namely, to describe it as the facilitation of the continuation of tradition" (Fargion 2009: 769).

All forms of music are always both old and new. Everything depends on from what perspective it is perceived. "Traditional music" in an everyday sense often means "such music as people played back in the old days." But the concept of tradition contains a continuous development, a mixture between old and new. Music archives often find themselves at this intersection.

This view of cultural history based upon the idea that we cannot understand our own time without understanding the past is a strong argument for archives and cultural heritage institutions in general.

When Sverigedemokraterna argue that we should invest more taxpayers' money in the preservation of "Swedish culture," they depart from a view of tradition as something static. But they also assume that it is possible to distinguish and purify cultural expressions and to avoid new influences and stimuli.

\section{Rationales for archiving today}

All ideological aspirations in the field of archiving have been characterized by the insight that cultural heritage is a matter of identity. The initiators of the Folk Music Commission were worried that what they regarded as „real“ Swedish folk music would quickly degenerate or soon be forgotten. The rescue action was to quickly organize a collection project aimed at collecting and publishing and thus creating a standard- 
ised repertoire of "good music" which was not influenced by the popular styles of the new era (early 20th century). The purpose of the Sverigedemokraterna in the early $21^{\text {th }}$ century was similar when they moved into the Swedish parliament to increase the resources for collecting "Swedish culture"-the fear was once again that Swedish culture seemed to be threatened and increasingly mixed up with other cultural forms.

If we argue that access to our cultural heritage is a fundamental democratic and human right, this must of course apply to all people. This may be an insoluble problem-we cannot gather everything and preserve it forever. What we can do, however, is to consciously explain the processes that underpin the choices that have been part of the cultural heritage process.

"History is written by the victors" is an expression usually attributed to Winston Churchill. Archives are keyholes to history for users in future times and the selection made by collectors and archives is, for today's folk musicians, often the only point of access to the history that is available. We have the collections we have-for good and for bad, all characterised by their time's "victors." The collectors of the early $20^{\text {th }}$ century who worked with the Swedish Folk Music Commission did not have cultural diversity and gender issues on their agenda, and we cannot do anything about that. However, it is our task as researchers to put things in perspective and problematise the collections so that today's archive users understand the background and origin of the material. We must also be aware that our work today is characterised by our time and our values that we may not even be aware of.

Anthony Seeger has assumed that ethnomusicologists will be primarily remembered for their collections and not for their theories or methods (Seeger 1986: 267, cf Fargion 2009: 76). But possibly one can take his reasoning a step further and argue that it is primarily the collections themselves that will live on, and in most cases both the collectors and the motives for their work will be forgotten. However, from a research perspective, this is extremely important-if we do not understand how and why the collections were generated, we cannot fully interpret or comprehend them.

No one can predict the ways their collections will be used. Some will become one of the building blocks of cultural and political movements; some will bring alive the voice of a legendary ancestor for an individual; some will stimulate budding musicians, some will soothe the pain of exile, and some will be used for restudies of primary data that may revolutionize approaches to world music. (Seeger 1986: 264)

Music making is an activity that can be charged with many, and widely differing, types of messages, opinions and meanings. With music as a cultural icon, people can enhance their self-esteem, but also demonstrate to others who and what they are or what they sympathize with. A very important and difficult task and responsibility for 
ethnomusicologists and archivists is to try to ensure that the fruits of ethnomusicological work cannot be misused. In Sweden, nationalist and xenophobic forces have often used folk culture archives in recent years as arguments, as examples of the "real" Swedish culture that must be defended against other cultures that are threatening to take over. The Folk Music Commission's efforts to streamline Swedish folk culture plays into the hands of such forces, and ethnomusicologists then have a particular responsibility to explain the origin of our archives and provide a perspective on their background and role in history.

References

Andersson, Greger and Ursula Geisler. 2007. Myt och propaganda. Musiken i nazismens tjänst $i$ Sverige och Tyskland. Stockholm: Forum för levande historia.

Andersson, Nils \& Olof Andersson. Svenska låtar. published by 1921-1940.

Arvidsson, Alf. 2008. Musik och politik hör ihop. Diskussioner, ställningstaganden och musikskapande 1965-1980. Möklinta: Gidlunds förlag.

Boström, Mathias. 2010. "100 år med Folkmusikkommissionen. Översikt och vägledning." In Det stora uppdraget. Perspektiv på Folkmusikkommissionen i Sverige 1908-2008, Boström, Mathias, Dan Lundberg and Märta Ramsten, eds. Stockholm: Nordiska museets förlag, 13-38.

Durrans, Brian. 1993. "The Future of Ethnographic Exhibitions." Zeitschrift für Ethnologie, 118/ $1,125-139$.

El Kadi, Galila \& Elkerdany, Dalila. 2006. "The Process of Heritization in Egypt.” In Cairo Cosmopolitan: Politics, Culture, and Urban Space in the New Globalized Middle East, Diane Singerman, Paul Edouard Amar and Paul Amar, eds. Cairo: American University in Cairo Press, 345-371.

Emilsson, Aron m.fl. (SD). 2014. Motion till riksdagen: 2014/15:2895. https://data.riksdagen.se/ fil/12FF2812-3F70-43FC-9662-607A9ED8564B (15.05.2019).

Fargion, Janet Topp. 2009. “'For My Own Research Purposes’? Examining Ethnomusicology Field Methods for a Sustainable Music.” The World of Music 51/1, 75-93.

Hammarlund, Anders. 2015. Documentum. Ett resonemang om samlande och samlare. Stockholm: Svenskt visarkiv.

Harrison, Rodney. 2013. Heritage. Critical approaches. Milton Park, Abingdon: Routledge.

Lundberg, Dan. 2010. "Folkmusik - en definitionsfråga." In Det stora uppdraget. Perspektiv på Folkmusikkommissionen i Sverige 1908-2008, Boström, Mathias, Dan Lundberg, and Märta Ramsten, eds. Stockholm: Nordiska museets förlag, 225-238.

.2015a. "Archives as Applied Ethnomusicology." In The Oxford Handbook of Applied Eth-

nomusicology, Pettan, Svanibor and Jeff Todd Titon, eds. New York: Oxford University Press, 671-708.

230 
2015b. "När musik blir till kulturarv." In Lekstugan. Festskrift till Magnus Gustafsson, Boström, Mathias, ed. Växjö: Smålands musikarkiv.

2018. Singing Through the Bars. Prison Songs as Identity Markers and as Cultural Heritage. Stockholm: Svenskt visarkiv 44.

Mahmood, Qaisar. 2012. Alla har rätt att kulturarva. http://www.sverigesmuseer.se/stafettbloggen/2012/10/qaisar-mahmood-alla-har-rattatt-kulturarva/ (07.04.2019).

Nora, Pierre. 1989. "Between Memory and History: Les Lieux de Mémoire." Representations 26, 7-24.

Ronström, Owe. 2019. "On the meaning of practicing folk music in the 21 st century." In Puls 4. Stockholm: Svenskt visarkiv, 10-25.

Seeger, Anthony. 1986: "The Role of Sound Archives in Ethnomusicology Today." Ethnomusicology 30/2: 261-76.

Sjöholm, Jennie. 2016. "Heritagisation, Re-Heritagisation and De-Heritagisation of Built Environments. The Urban Transformation of Kiruna, Sweden.” Dissertation, Luleå: Luleå University of Technology.

Swedish Research Council. 2002. Ethical Research Principals.

Ternhag, Gunnar. 2000. Fojksamlaren karl Tirén. Umeå: DAUM.

Tirén, Karl. 1942. Die lappische Volksmusik. Aufzeichnungen von fuoikos-Melodien bei den schwedischen Lappen. Stockholm: Gerber.

"Upprop." 1908. Fataburen. Stockholm: The Nordic Museum.

Vinyl Terror and Horror web page http://www.vinylterrorandhorror.com/live.html (07.04.2019).

Abstract

Archiving always involves choices-when some objects or cultural expressions are chosen to represent certain traditions, cultures or nations. This is of course at the expense of other objects or expressions. Those that are not collected and will therefore fall by the wayside and eventually disappear.

The collection and documentation of folk music and music-making has most often not been governed by the democratic principles of everyone's equal rights, but by utopian visions of individuals and organizations, and sometimes by state and national interests and needs.

During the past 30-40 years many national archives have tried to change their role and re-evaluate their work. Changing from being tools in the creation process of nation states into functioning as democratic resources for their users-everyone's right to his or her history. But now the pendulum is swinging back.

In the latest budget proposal to the Swedish parliament the Sweden democrats- 
the right-wing nationalist party who want to close the borders and stop immigration-moved to strengthen the budget for Svenskt visarkiv (The Swedish Centre for Folk Music and Jazz Research) by SEK 6 million (about $€ 650$ 000). The money was supposed to be earmarked for exclusively "Swedish" traditions.

In this article, I discuss these oscillations in cultural policies and their effects on music archives. The article also deals with the role of the music archives as active co-creators of the music cultures that they themselves document. 


\section{On Engaging Up and Expertise in Ethnomusicology: The Example of Expert Services in the Programme for Safeguarding Intangible Cultural Heritage}

This article builds on experiences related to my involvement in the programme for safeguarding intangible cultural heritage (hereafter: ICH programme) on national and international levels, as well as on several papers that I have presented during the past few years. In one I argued that the ICH programme has demonstrated but has not yet acknowledged a great need for cultural translation, where the role of academically trained ethnographers is irreplaceable, and suggested collaborative-academic ethnomusicology as a workable solution for the discipline in the early 21 st century. In another presentation I argued that today's principal shadows in the field pertain not to the relationship of ethnomusicologists with communities they research and collaborate with, but to the involvement and roles played by ethnomusicologists in top-down decision-making processes. In yet another paper I addressed so-called administrative ethnomusicology, which has remained under-conceptualized in the literature. In the presentation from which this article emerged, the emphasis was on cultural brokerage or mediation, while here I return the focus to the fundamental question of engagement with powerful institutions such as UNESCO, and the issue of disciplinary expertise in such encounters. I examine the status of engagement in ethnomusicology versus the concept of studying up in anthropology, and provide a snapshot on the role of experts in the ICH programme. Besides involvement in the ICH programme, my rationale is informed by affiliation with post-socialist, Southeastern European ethnomusicology, notably Croatian, which incorporates a long history of engagement in public policy, the doubts emanating from such a position, as well as from war experience during the 1990s, and the predominance of ethnomusicology at home. However, these more specific elements of my professional habitus will not be addressed in this article. My narrative is here intended to be "general," behaving as if ethnomusicology is a relatively consistent discipline worldwide (although one could easily provide evidence of the opposite). That is, I refer here to a kind of ethnomusicological canon or mainstream supported by organizations such as the International Council for Traditional Music and the Society for Ethnomusicology, and to the corresponding English-language literature. 
Engaging up is, from one side, derived from Laura Nader's invitation to "study up" powerful institutions and bureaucratic organizations for "such institutions and their network systems affect our [anthropologists'] lives and also affect the lives of people that anthropologists have traditionally studied all around the world" (Nader 1972: 293). This is precisely the case with the UNESCO-led programme of ICH. This programme is a prime case of cultural policy intervention into traditional anthropological subjects-grassroots, local, indigenous groups or communities or, since more recent times, communities of practice, non-dominant groups, marginalized groups, etc. ("communities, groups and, if applicable, individuals" in ICH vocabulary). The reflexive turn in anthropology and related disciplines, including ethnomusicology, constitutes one of the programme's backbones (particularly as regards the central agency of communities concerned), and experts (coming primarily from ethnographic disciplines) are actively involved throughout.

Since Nader's seminal article, a significant anthropological literature has been produced on the workings of power. Of relevance here are in particular studies in multilateral organizations such as UNESCO (e.g. Müller 2013), development (e.g. Mosse 2011), and heritage production (e.g. Bendix et al 2012). Although some of the authors built their scholarly arguments on experiences gained through their expert services in the projects under study, these two spheres are treated as distinct. For instance, David Mosse worked for a decade as an anthropologist-consultant in a participatory development project funded by a British agency and implemented in western India. He is positive about the importance of such engagements. As he claims, "there is greater need than ever for anthropologist involvement in the complex and contradictory arenas of international aid," notably in terms of engagement "with the discourses of moral responsibility and policy vision (about what is to be done), with the strategic politics of programme action, and with critical reflection" (Mosse 2006: 941). But when it comes to ethnography about the project, he strongly argues for boundary-making between field and desk, social life and ethnographic analysis: "While fieldwork has changed beyond recognition—becoming ever more intensely social—ethnographic writing (interpreting, objectifying, and textualizing) remains a solitary process that disembeds knowing from its relationships, denying (to varying degrees) the social its claim to power, to ownership, to negotiation" (ibid.: 937). In parallel, Mosse opposes "an epistemological position that implies that the limits of what can be known, revealed, or written about are determined by social relationships," and that "'fairness' in research is a question of respect (and unfairness, disrespect) rather than verifiability" (ibid.: 944). To write ethnographies of public policy, powerful institutions and 
their authorized representations, such as Britain's Department for International Development in Mosse's case, is very different from the fieldwork and applied work that we are accustomed to. Reciprocity, responsibility, friendship, collaborative interpretation, benefits for the researched community—all these elements that Mosse subsumes under the notion of fieldwork "social relationships"-are not recommended. Instead, he argues for a re-affirmation of the Malinowskian boundary between field and desk, for a verifiable ethnographic account which "breaks fieldwork relations, cuts the network, and erects boundaries," which is therefore "necessarily anti-social" (ibid.: 935).

It can be concluded that studying up in no way implies engagement for the benefit of the "up" that is studied. Mosse's thought-provoking positions are in sharp contrast to those that prevail in ethnomusicology. Generally speaking, ethnomusicologists are very positive about the interlocking of studying and engagement, and cherish deeply collaborative and dialogical relationships with their research subjects. However, engagement in ethnomusicology relates to those who are, in Nader's vocabulary, "down" or "sideways," while those who are "up" are more or less invisible, as if they do not exist.

\section{Engagement vs. engaging up: the ethnomusicological angle}

In ethnomusicology, one can find a lot about collaborative bottom-up interventions, empowerment and advocacy of communities, but one can find hardly anything about experiences in top-down decision-making processes. For instance, in a comprehensive handbook of applied ethnomusicology (Pettan and Titon 2015), it is acknowledged in the introduction by Jeff Todd Titon that ethnomusicologists, among other roles, work "as consultants, arts administrators, [...] expert witnesses, and in various other capacities formulating and administering cultural policies" (Titon 2015: 6), but there are no subsequent studies elaborating these roles. The only exception is Clifford Murphy, who delineates his work of ethnomusicologist-as-public-folklorist in the United States, and argues that the involvement of ethnomusicologists and/or folklorists is "often critical to any hope of sensitive cultural intervention on the part of the government" (Murphy 2015: 728). Based on my involvement in the ICH programme and other cultural policy interventions, I would argue the same. Anthony Seeger is another author who represents a rare but significant exception to the prevailing position among influential scholars, as will be evident in references to his work throughout this article. $^{1}$

1 A volume edited by Max Peter Baumann (1991) represents yet other exception. In the introduction, Baumann stresses "the need for an ongoing 'dialogue across the borders' between scholars and cultural 
The lack of studies on engaging up in ethnomusicology is, if at all, taken as a consequence of the lack of time and motives on the part of such ethnomusicologists, especially if they are employed outside of academia, to reflect on their engagement in the form of scholarly articles. This indeed makes up a part of the explanation. As for myself, even though my primary position in an academic institution assumes the production of scholarly publications, I have deliberated over and over again my engagement with powerful institutions (alone and in conversations with colleagues and friends), but I have only shared some of my insights and doubts in the form of presentations at scholarly meetings (such as those mentioned above), while this article is the first case of presenting them in the form of an article published in English and thus intended for an international audience. The lack of time has indeed something to do with such a state of affairs. However, much more importantly, the engaging up is left on its own in ethnomusicology (ethnomusicological mainstream literature), without theoretical, methodological, epistemological and ethical ground to rely on. That is, more specifically, it is overloaded with factors that may be called suspect in political-ethical terms, humbleness as regards professional expertise, and a gap between disciplinary centers and peripheries. ${ }^{2}$

politicians" (1991:11), but this need is addressed in subsequent chapters in rather general terms, lacking actual case studies. Nevertheless, two points raised in the final discussion bring to mind my experience with the ICH programme-Chou Wen-Chung who pointed out that instead of trying to "'control' policy, [...] positive influence can be asserted in relatively small ways that produce far-reaching effects" (Fujie 1991: 417); and Max Peter Baumann, who warned "that ethnomusicologists should be aware of the kind of language they use when speaking with politicians, not only in terms of avoiding scholarly jargon, but also in phrasing the vocabulary in terms they [politicians] know and use themselves" (ibid.: 418). These points will be considered later in this paper.

2 Those who can read Croatian can consult my articles published in 2015 and 2017, where I more extensively discuss participatory mechanism and the role of experts in the ICH programme on national and international levels (framed within the topic of the bypaths of humanities, 2017), and epistemological issues, social engagement and market pragmatism (framed within the topic of work beyond textual representation in ethnomusicology, 2015). The above-mentioned factors additionally complicate writing for audiences beyond one's own scholarly tradition, lineages, language, history, etc., which is the main reason why up to now I have not published on this field of topics in English, but did in Croatian. Looking from the perspective of my engagement in the ICH programme on an international scale, through my representation of the ICTM, I felt I additionally had to take care that my arguments are well-justified, well-balanced and based solely on publicly available sources, which adds additional complexity when writing in my non-native language and for an international readership. Therefore, it may be appropriate to add that all interpretations presented in this article are my own and nobody else is responsible for them. 
As for the suspect, the main point is that engaging up resembles "harnessing up" ethnomusicological capacities for oppressive ends such as military purposes, colonial conquest, nationalism, social engineering in totalitarian/authoritarian regimes, along with their misuse in the marketplace. Even ethnomusicological approaches prior to the reflexive turn in the 1980s and 1990s could be added to the list of topics that (may) make today's ethnomusicologists wary of any kind of involvement (not to say collaboration) with the workings of power. As is to be expected, literature on these topics deals with others, not us or myself, and/or with the past, not the present. This is one of the reasons why I do not find it particularly helpful in elucidating the concept of engaging up. I suppose that self-reflexivity and profound contextualization are of major importance in this matter; that is, I think that the discussion is more promising if it starts from one's own challenging experience. On the other hand, more importantly, engaging up is substantially different from what I called "harnessing up" because it relies on the notion of engagement, i.e., it presupposes, as noted at the beginning of this section, collaborative bottom-up interventions, the empowerment and advocacy of communities (which is surely not the case when ethnomusicology and ethnomusicologists are harnessed up). According to Rebecca Dirksen, engagement means "a deep and sustained engagement" of ethnomusicologists with communities they study, as well as their engagement "as public intellectuals" (Dirksen 2012: [unpag.]). In addition, engaged ethnomusicology is actually one of the alternative terms for the whole field of applied ethnomusicology (ibid.). For the present article, the component of acting as a public intellectual-meaning also in the public sphere and on larger socio-political issues-is especially important. It implies engagement in arenas and on issues beyond those that are directly related to specific communities and their needs. That is, this component of engagement makes a link between engaging up and engaging with communities. In the workings of powerful institutions, communities and their agency exist, much more often than not, only as principles or ideas, not as actuality. What remains therefore, as one can guess, is to advocate community agency in general terms, yet with vigilance, because turning actualities into generalities is a multiply slippery terrain; e.g., it can easily result in the fetishization of "community," or "ethnographic veto" in the words of Berger (2014: 317), or the objectification that is discussed in numerous studies (e.g. Baron 2010). Further on, there is actually no room for advocacy - advocacy of specific aims - as decision-making processes and the role of experts in them presuppose impartiality, objectivity, expertise and separation from the field. Besides, it also goes without saying that the framework of sought-after objectivity is saturated with hierarchies. Say, for example, the decisions regarding the inscriptions on two international lists of ICH come about through the participation of three major parties: (i) the Intergovernmental Committee for the Safeguarding of the Intan- 
gible Cultural Heritage (24 States Parties to the ICH Convention, elected on the basis of equitable geographical representation and rotation every four years) which decides on the inscriptions; (ii) the Evaluation Body (six individual experts and six accredited NGOs with expertise in $\mathrm{ICH}$, composed according to the same basic principles as the Committee) which examines the nominations and provides recommendations and draft decisions to the Committee; and (iii) states parties which submit their nominations on the basis of the "widest possible participation of communities, groups and individuals concerned" in all phases of their preparation, which is also confirmed through their free, prior and informed consent to the nomination files. Not to mention hierarchies further on, at national and local levels. One of the main lessons I learnt through my service in the Evaluation Body, where I represented the International Council for Traditional Music (2013-2015), as well as through my long-lasting service in the Croatian Expert Committee for ICH (since 2002), is that the effectuation of principles around participation, communities' benefits and public good is limited by what is possible and feasible in the actual socio-political context, either out of necessity (because of the multiplicity of actors and interests in decision-making processes) or out of intention, strategically (because often an individual or collective entity can do more by not targeting too far ahead and/or needs to take care to keep her/its role viable). ${ }^{3}$ Some examples in support of this statement are given in a snapshot below.

Taking all these ingredients of engaging up as suspect, it is no surprise that it is almost not a topic at all in ethnomusicology (ethnomusicological mainstream literature). And when it does appear, it is justified primarily by existential reasons, the scarcity of employment opportunities in academia which forces ethnomusicologists to look for jobs in public agencies and the private sector. Engaging up is certainly not easy-going. It is more relaxing to work with communities, as this is ethically non-controversial, indisputable, in contrast to when one is thrown into the currents of political, economic and social hierarchies. Even in the cases when ethnomusicological work fits comfortably into governmental policy, the link is somehow not acknowledged - take for example minority studies in European ethnomusicology in relation to the general agenda of the European Union. I am not saying that ethnomusicologists are not usually some steps ahead of their respective governments in the advocacy of libertarian ideas. But I would say that this link has remained highly neglected and under-theorized, which does not benefit the discipline and the people we work with. ${ }^{4}$

3 That is, in more general terms, "[s]ubject-area specialists like ethnomusicologists can play a role in cultural policy as long as we recognize the limits of our influence and are willing to work within them" (Seeger 2006: 226).

4 The term libertarian (libertarian ideas) is used to avoid specific political positioning (which is a 
Humbleness

I would locate another set of reasons for the lack of studies on engaging up in ethnomusicology in a certain humbleness as regards expert knowledge and skills. As in the basic meaning of the term "expert," some definitions are indeed problematic for today's ethnomusicologists, such as the one from US English in the Oxford Dictionary, which defines it as "a person who has a comprehensive and authoritative knowledge of or skill in a particular area" (emphasis added; https://en.oxforddictionaries.com/definition/us/expert). Interestingly, the definition from non-specified English in the same dictionaries does not incorporate these problematic words-expert is "a person who is very knowledgeable about or skilful in a particular area" (https://en.oxforddictionaries.com/definition/expert). It is also worth mentioning that in my native language the term derived from the same origin—ekspert—is defined more specifically, as "a person who is invited to give his/her judgment [opinion] on controversial or difficult questions." ${ }^{5}$ This is just to illustrate a known fact that we think, write and act from multiply different perspectives. While my colleague from the US may refrain from engaging in matters based on the idea of "comprehensive and authoritative knowledge and skills," I may be intrigued to "accept the invitation to engage in controversial or difficult matters." Of course, one may object that these are nuances, that differences in discourses and practices of expertise cannot be explained through dictionary definitions. Indeed so. My main point regarding the issue of expertise relates to the following: an emphasis on collaborative, dialogical and horizontal knowledge production necessarily results in the denial, neglect and/or invisibility of expert knowledge and skills. A genuinely collaborative endeavor requires consistency, for one cannot emphasize the value of horizontally produced knowledge and actions and at the same time acknowledge the importance of his/her individual contribution. Take as an ex-

prerequisite—-paradoxically or not, whether we like it or not—-for experts who engage up, as indicated above). I borrowed the term from Klisala Harrison (2012), who speaks about a similar matter, yet with a somewhat different, more economic than political emphasis. Namely, she noted that "[n]othing comprehensive has been published [...] on the financial, political, and institutional influences on the currently growing interest in applied work in ethnomusicology. As research funders in contexts of government and industry in the West increasingly privilege real-life applications of knowledge that have market value, often via neoliberal political values, this informs and contributes to the privileging of knowledge that can be applied. [...] [H] ow applied ethnomusicologists negotiate the epistemic turn toward applied knowledge on the level of government and industry research support involves not only the perspectives that researchers have agency to create, but also researcher perspectives about applied knowledge that are encouraged by the funders (which may be in conflict with the former)" (Harrison 2012: 512). This brings us back to the above mentioned pragmatism of acting.

5 "vještak, stručnjak, znalac, poznavalac; osoba koja se poziva da dade svoj sud u spornim ili teškim pitanjima” (Klaić 1987: 359). 
ample Samuel Araújo. As a "participant” (not a leader) in a truly horizontal, dialogical research and social action, the most he can acknowledge is his facilitating and coordinating role, but not his professional (not to say academically gained) competences (cf. Araújo and Members of the Grupo Musicultura 2006; Araújo 2008). Yet, to my understanding, he is nevertheless the key figure-there would hardly be any dialogical research and action in Maré neighborhood without him, and he has obtained such a position not only thanks to his personality, ethics and human virtues, but also thanks to his professional, academically gained, ethnomusicological competences. This is my interpretation. As for Araújo himself, he is ethically and epistemologically consistent, meaning very humble. The whole field of applied ethnomusicology is humble when it comes to the question of professional knowledge, skills and/or expertise in the effectuation of community-based projects. At times they are mentioned (e.g., the "unique skills and resources the community lacks" in Dirksen 2012: [unpag.]), but very seldom are they further elaborated. ${ }^{6}$ The whole field is far away from any trace of Mosse's rationale about disembedding knowing from fieldwork relationships. Some suggestions on the existence, importance and facets of professional expertise in the sphere of $\mathrm{ICH}$, apart from a humanist commitment to community needs (which is amply addressed in ethnomusicological literature), are given in a snapshot below.

The third factor that has caused a lack of studies into engaging up is in the gap between disciplinary centers and peripheries. I shall comment on it only briefly because, as announced at the beginning, my narrative is intentionally general here, directed towards the ethnomusicological mainstream. The gap refers to the fact that theories and methods in ethnomusicology which resonate worldwide (say, publications that are read and referred to worldwide) have been created primarily by scholars from the West (or, perhaps it would be more appropriate to say from the Group of Seven countries), especially by the US and US-related scholars, who, however, have comparatively less experience in engaging up with highly positioned entities in the socio-political system such as national governments and ministries of culture. Thus,

6 More typically, they are contextualized negatively, as in the following example: "Seldom has partnership worked when the ethnomusicologist plays the role of expert and imposes solutions to problems perceived from a distance, or fails to understand the musical community's perspective" (Titon 2015: 7). In folklore studies, however, especially in reference to the production of the Smithsonian Folklife Festival, specific professional skills have been acknowledged to a degree (see, e.g., Baron 2010), despite the fact that partnership and an understanding of the community's perspective are unquestionable, as in the previous example. 
understandably, they cannot elaborate some kind of scholarly-based basics on the whethers and hows of engaging up. ${ }^{7}$ And conversely, ethnomusicologists and ethnomusicologies elsewhere, those with ample experience of engaging up on different matters (such as general education, festivals, exhibitions, public or state media, cultural policies at large, development programmes, etc.), lack the capacity, means and confidence in addressing the topic of engaging up, as they act and speak from scholarly peripheries. Take me as an example. I dare to argue for engaging up in ethnomusicology thanks primarily to my partaking in the scholarly mainstream, and experiences gained outside of my national context (e.g. my representation of the ICTM at UNESCO), while otherwise I would probably not expose myself to a suspicion of being harnessed up, betraying ethical norms, etc. ${ }^{8}$ At the same time, such positions give me a kind of confidence that I have something to offer (even if it is not well articulated in terms of theories and methods), as well as an idea that the ethnomusicological audience at large (including the "center") might be interested in reading this article. All in all, the moral is that a serious study into engaging up would require overcoming a boundary between the centers and peripheries of ethnomusicological thinking and acting on a worldwide scale.

Taking all these three factors-suspicion, humbleness and a gap, it is not surprising that the paper which most directly addressed and spoke in favor of engaging up in ethnomusicology was written a long time ago in an atmosphere of the wartime joining of intellectual forces, and long before ethnomusicologists became so humble. It was Charles Seeger's paper on applied musicology and government, where he imagined that applied musicology would "enter the field of contemporary music, (1) to describe this field, (2) to estimate its trends, (3) to predict the course of these trends, (4) to aid in the setting up of a critical method and value theory for musicology in general, which would be useful in both the applied and the general fields, (5) to formulate objectives for large-scale music development, both governmental and non-governmental, and (6) to check up continually on the interplay of critical and scientific methods, not only in its field but also in the relating of its field to other fields" (Seeger 1944:

7 According to Rebecca Dirksen, "Charles Hale, Anthony Seeger, and Barbara Kirshenblatt-Gimblett have each mused over the role of academics in Europe and Latin America [...] as politically engaged players expected to comment on social issues, in contrast to the comparatively 'anemic' display of civic participation by current American academics" (Dirksen 2012: [unpag.]). Anthony Seeger found it "exhilarating to be in a country [Brazil] where university professors were considered to be trustworthy experts and where the use of ideas for political ends was expected" (Seeger 2006: 226).

8 Even though, as an applied ethnomusicologist, I might/should anyhow be willing to place myself "in positions of vulnerability, discomfort and sometimes even subservience, embracing unfamiliar and sometimes counterintuitive approaches to appreciate process and outcomes" (Harrison and Pettan 2010: 7). 
19). Indicatively, seventy years later, Svanibor Pettan and Jeff Todd Titon argued that "the best outcomes occur in small-scale projects resulting from long-term partnerships and mutual goals," while "[t]op-down, bureaucratic solutions are apt to be less successful and more likely to have negative consequences" (2015: 53-54). Quite the contrary: "applied musicology" was for Charles Seeger "an indispensable aid in the planning and technical coordination of large-scale, long-term music activities" (1944: 19). There is no doubt that the world, and the place of humanities in it, has changed enormously during the last seventy years, but precisely taking into account its current dynamics, including the huge impact of the ICH programme worldwide, I have nothing else to say except to invite us to revive Seeger's suggestions.

\section{A snapshot: participation cum expertise from the Washington conference to the latest developments in the ICH programme}

The genealogy of the ICH programme can be explained as a response to three sets of questions. Two of them are well documented in the literature: the question of intellectual property rights, initiated by Bolivia in the early 1970s, and the question of processual and intangible aspects of heritage, put forward by East Asian and African countries, in particular Japan (see e.g. Hafstein 2004). Of interest here, however, is the third key question of community participation and agency versus top-down administrative and expert authority. A crucial step towards the primacy of bottom-up participatory approaches took place as an outcome of the conference co-organized by UNESCO and the Smithsonian Institution in Washington in 1999. It was dedicated to the assessment of the implementation and future prospects of the Recommendation on the Safeguarding of Traditional Culture and Folklore, adopted a decade earlier by UNESCO. The conference was the culmination of the preceding long and extensive process of discussions and their outcomes: from 103 countries that responded to a questionnaire on the Application of the Recommendation issued by UNESCO in 1994, to eight regional seminars held in the period from 1995 to 1998 with representatives from 111 countries. The conference itself included 37 invited participants, selected in line with UNESCO's principles of equitable representation of various geographical regions and types of participants (representatives of state administrations and NGOs, scholars, advocates and practitioners of traditional culture and folklore).

On the basis of a detailed reading of the publication from the conference (Seitel 2001), there is no doubt that the authority of communities (local, grassroots and indigenous communities) gained a more prominent place than one could conclude on the basis of previous seminars and fulfilled questionnaires. Obviously there were some skillful and influential advocates of community participation at the conference. Their 
presence is also perceivable in the texts that presented the outcomes of the questionnaire (Kurin 2001) and regional seminars (Seeger 2001). These texts are inclusive and consensual regarding various perspectives, and are both precise and open to various readings. They are thoughtfully written, taking into account a general trend, all agreements and disagreements, emphases in discussions, but also pushing the agenda of community agency as much as possible to not to endanger a broadly-based collaborative venture of so many participants in this long and extensive process of decision-making. That is, these texts reveal very competent culture brokers (cf. Kurin 1997). In the end, the final recommendations to state parties and UNESCO operate on the terrain of shared authority between communities and other actors of safeguarding while arguing for the inclusion of communities in various aspects of safeguarding, more actively than was the case previously under the initial 1989 Recommendation. Can one say that it was too little, not really an appreciable step forward? Quite the contrary, I would claim, especially taking into account the priority of consensual solutions, as well as the 1989 Recommendation which did not even recognize the role of communities, not to mention advocating their agency. Politics is the art of the possible. It is also the art of small steps. They are an essential part of developing ideas within the framework of international instruments such as recommendations and conventions, which are legal documents very concise, succinct in expression, in which every single word has to be justified, supported by unspoken arguments, and which at the same time has to accommodate a reasonable measure of various interpretations. Therefore, looking at one such document compared to another, one can notice just small differences in emphases which only when added together create some noticeable and then appreciable and then significant steps forward. ${ }^{9}$ As a member of the Evaluation Body of the Intergovernmental Committee for the Safeguarding of ICH and a rapporteur in two cycles, I have also found myself in the role of refining thick, concise texts, sometimes scarcely negotiated viewpoints, first in direct communication and then in written form. Sometimes, actually quite often, rather disparate viewpoints can inhabit the background, as was the case, in my impression, at the Washington conference. It is also important to notice the dynamics of individual expert contributions to collective decision-making. Without Seeger, Kurin and a number-a limited number - of other expert scholars, it would be difficult to come to quality (libertarian) solutions, in this case to the shift from the 1989 Recommendation based on

9 As noted by Anthony Seeger (yet not related specifically to the Washington conference), "[t]he more elevated the document the more important small changes can be-and the more difficult they are to make. It may well be worth a week to change a particular word or small phrase in a convention because, should the document become policy, that word could be important to artists in many countries" (2006: 226). 
authoritative expert knowledge to the 2003 Convention based on participatory knowledge production. ${ }^{10}$

Further on, the effectuation of the objectives set out in the ICH Convention likewise depends to a large degree on experts (and among them, on experts from ethnographic disciplines). They are at the forefront of those who, as far as possible, prevent various manipulations of the concept of intangible heritage for the sake of the prestige of state parties on an international level, or the nationalization of the notion of community, or economic gains separate from the interests of the communities concerned, and so on. On an international level, the deliberations on these and similar issues are to a large degree linked to the evaluations and inscriptions on the two international lists (the Representative List and the Urgent Safeguarding List), the Register of Best Safeguarding Practices (called the Register of Good Safeguarding Practices from 2017) and the programme of International Assistance. As noted above, the submissions are examined by the Evaluation Body, and then its recommendations and draft decisions are examined and decided upon by the Committee at its annual sessions. These agenda items always take up the largest part of the session. Thus, for instance, following the recommendation of the Evaluation Body, in 2015 the Intergovernmental Committee amended stipulations concerning the purpose and objectives of two international lists, the adequate description of the dynamics within communities concerned, the subject of consent demonstrating community participation, consent to a multinational nomination and the adequate involvement of all communities that share multinational elements, the translations of lyrics in elements belonging to oral traditions, the excerpts from inventories on national levels, the dynamics of cultural and human rights as regards the involvement of children, and the issue of so-called inappropriate vocabulary. ${ }^{11}$ All this may sound rather technical and dry, yet the implication is that the room for avoiding key principles and objectives of the Convention becomes additionally narrowed.

Let me to explain just one of these points, the "subject of consent demonstrating community participation." The widest possible participation of communities, groups and, where appropriate, individuals in the nomination process is one of the criteria for

10 Besides Anthony Seeger, another ethnomusicologist deeply involved in the development of the ICH programme from its early days was Wim van Zanten. In 2002, he edited a glossary of ICH terms that was supposed to be adopted as an appendix to the Convention (see van Zanten 2004), but finally it did not happen. He participated in all statutory meetings of the Convention up to 2012 as a member of Dutch delegation or as a representative of ICTM, as well as in a series of UNESCO expert meetings and meetings of the ICH Researchers Forum. The latter also resulted in publications (van Zanten 2009, 2012).

11 See Decision 10.COM 10 in "Decisions," 10th Session of the Committee, 2015, https://ich.unesco.org/ en/10com 
inscriptions. Besides a narrative description of their participation, submitting States are obliged to provide evidence of communities' free, prior and informed consent to the nomination. In preceding cycles, the Committee and the evaluation Bodies focused on the format of the consent, looking for diverse forms of evidence and personalized and individual expressions, as well as at the adequacy of community representatives or intermediaries, while less attention was paid to the question of who provided the consent, and when, where, and for what purpose. As we noted in our report, ${ }^{12}$ we often encountered difficulties in determining whether consent was given to the actual nomination or was simply expressing the writer's support for the element itself. There was often no concrete reference to the nomination process, the resultant file and/ or the role of the signatory in either the definition of the element, the identification of its viability and threats, or in the planning and implementation of the proposed safeguarding measures. Commonly, the documents referred to the merits of the element and support for its recognition by the international community, accompanied sometimes by notes referring to the identification of the signatory with the element and/or the way the signatory is involved in its enactment and safeguarding. In the case of cultural organizations, the consents commonly referred to their mission and activities related to the element. In one example, the evidence offered disclosed an understanding of the element that significantly differed and partly even contradicted the definition of the element in the file. In another such example, part of the consent documents were provided by passers-by on the street who could not have had insight into the nomination file, nor could they have participated in its elaboration. In other words, the Body was quite often faced with consent documents that failed to demonstrate that they were "informed." Thus, as we concluded, free, prior and informed consent should primarily mean consent to the nomination of the element, while the format it takes is of secondary importance (even though the Committee in the previous cycle decided that "individualized expressions of consent are preferable over form letters, petitions or uniform evidence of consent"). The proposed decision, which was subsequently endorsed by the Committee, reads as follows: the Committee "reminds States Parties that free, prior and informed consent above all means 'consent to the nomination of the element, as formulated in the file', instead of support for the element itself, its merits and/or its recognition by the international community." ${ }^{3}$ The whole procedure, although on a smaller scale, resembles the one at the Washington conference. Multiple disparities of views are directed gradually towards consensual

12 "Report of the Evaluation Body on its work in 2015," agenda item 10 at the 10th Session of the Committee, 2015, https://ich.unesco.org/en/

13 Decision 10.COM 10, para 13, in "Decisions," 10th Session of the Committee, 2015, https://ich.unesco. org/en/10com 
"technical" decisions. The work of the Body as a whole can be termed "technical" as it has to be impartial, objective and, in particular, concentrated solely on the file (text under examination) without being allowed to take into account the actual situation on the ground. A shift from political to technical has been analyzed in depth in the literature on international development (see, e.g., Mosse 2011). Indeed, experts have to endorse this basic rule of procedure, or stay out of the decision-making process. But more than that, as much as political turns into technical, the opposite also applies: technical decisions, when/if implemented, turn into political realities on the ground.

The Evaluation Body and the Committee

It makes sense to explain how the Evaluation Body, operative since 2015, came into being. The system of evaluation in the period of the Masterpieces of the Oral and Intangible Heritage of Humanity (proclaimed in 2001, 2003 and 2005) has been described by Anthony Seeger (2009). At that time, evaluators were anonymous experts commissioned by the UNESCO Secretariat, either directly or, more often, through organizations in formal consultative relationships with UNESCO such as the ICTM, while the highest decision-making authorities were an International Jury, which examined the evaluations, and the Director-General of UNESCO, who proclaimed the masterpieces. All masterpieces were transferred in 2008 to the Representative List, and since then the Committee has been the highest authority in charge of inscriptions. In the subsequent two years (2009-2010), the nominations for the Representative List were examined by the Subsidiary Body (composed of State Members, one from each of six electoral groups, usually Members that were also represented in the Committee), while non-anonymous individual experts examined the submissions for the Urgent Safeguarding List, the Register of Best Safeguarding Practices, and International Assistance. As these experts were under significant pressure when defending their recommendations to the Committee, a better solution was found in the establishment of a collective body - the Consultative Body. So from 2011 to 2014, there were two evaluation bodies - the Subsidiary Body (structured in the same way as in 2009-2010), and the Consultative Body (composed of six individual experts and six accredited NGOs, one from each electoral group), the former in charge of examining nominations for the Representative List, and the latter in charge of the three remaining mechanisms.

Since 2015, the two bodies have been replaced by a new, single Evaluation Body (composed of six individual experts from countries other than those represented in the Committee, and six accredited NGOs, one from each electoral group). The main reason for the establishment of a single body was to improve impartiality-i.e., to "ensure coherency and consistency of recommendations due to the application of the 
same standards in the evaluation," and to allow for "commonalities and specificities of the Convention's four mechanisms [...] and each of their criteria" to come "more clearly [...] to the fore," as noted in the "Report of the Evaluation Body on its work in 2015." 14 A change in the evaluation process was initially recommended by the Internal Oversight Service of UNESCO— to "suspend the Subsidiary Body, so that all nominations are evaluated by one common and independent body," informed by "the fact that the members of the Subsidiary Body are representatives of State Parties," which among "many stakeholders" raised "considerable discontent and concerns about possible conflicts of interest." This recommendation provoked a great deal of discussion at the 2013 Session of the Committee where it was presented, ${ }^{15}$ but ultimately it was endorsed, first by the Committee, and then confirmed by the General Assembly of the States Parties to the Convention. It was and is still expected that the bodies reach consensus in their assessment and recommendations. And this has indeed been achieved, with just a few exceptions out of hundreds of files processed from 2009 onwards.

Generally speaking, the dynamic at the sessions of the Committee is that the Committee endeavors to inscribe as many elements of $\mathrm{ICH}$ as possible, ${ }^{16}$ relying in that, of course, on the fulfillment of the criteria for inscription, while the Body more strictly and minutely (i.e., more "technically") relies on the assessment of information provided in the files in relation to the inscription criteria, and on that basis recommends or does not recommend inscription. ${ }^{17}$ In discussing unfavorable recommendations (otherwise, the practice is that the Committee does not discuss but simply endorses the recommendations), members of the Committee quite often recall a difference be-

14 Agenda item 10 at the 10th Session of the Committee, 2015, https://ich.unesco.org/en/10com.

15 "Report on the evaluation by the Internal Oversight Service [...]," agenda item 5.c at the $8^{\text {th }}$ Session of the Committee, 2013, https://ich.unesco.org/en/8com

16 It is very interesting that the whole process from the submission of nominations to the moment of their inscription pertains strictly to "files" (especially since only information provided in the files should be examined, and not realities on the ground), but with the act of inscribing, the "file" automatically becomes (i.e., returns to being) an "element," a living practice recognized by the mechanism of inscription. From the legal perspective, I suppose that this shift from living practice to file and back to practice may not be taken for granted. From an anthropological perspective, this is one of the major disciplinary issues-how a practice becomes a text-based (representation of) practice, and how the latter in return molds the practice.

17 The inscription criteria are defined in the Operational Directives (https://ich.unesco.org/en/directives), and explained in detail in the Aide-mémoires (https://ich.unesco.org/en/forms). Aide-mémoires incorporate jurisprudence generated over the years by the Committee and the Bodies, and serve as an aid in elaborating submissions, as well as in their evaluation. There are five criteria for the two lists (mutually different concerning the aspects of representativity versus urgency, and safeguarding measures adequate to different aims of the two lists), and all have to be met. The register and the international assistance consist of a greater number of criteria, but it is not obligatory to meet all of them. 
tween the "letter" and the "spirit" of the Convention, where the Body has a mandate to assess the files according to the letter, while Committee needs and wishes to also take into account the spirit of the Convention (particularly the spirit of international cooperation and assistance), thus inscribing elements whose files seem at first sight (if one follows only the letter) as if they do not fulfill the inscription criteria. Another comparable opposition is between "statements" and "evidences" in the files: the Body looks for evidences in a stricter way, while the Committee, to my understanding, is sometimes willing to interpret statements as evidence. ${ }^{18}$ To be a little bit less diplomatic, let me add that the Committee has inscribed a certain amount of elements unjustifiably, against the letter and/or spirit of the Convention. Therefore, in order to prevent mis-inscriptions as far as possible, the Body has to act strategically, i.e., to use Charles Seeger's words, it needs to estimate and predict the trends. As its work actually finishes a month in advance of the Committee's session (with a written report including observations and recommendations, and overall and individual draft decisions), it is important to predict in advance how the discussion at the session may evolve. ${ }^{19}$ The Body also has to make a good estimate of how far an idea can be pushed without jeopardizing its endorsement by the Committee and its subsequent implementation. For instance, it is much better to address an important issue in the overall recommendations and draft decisions than in the draft decisions on individual files, since the latter are going to be under much greater scrutiny (and willingness to change the recommendations) than the former, while at the same time the overall decisions are of much greater importance in the long-run. Also, as for the draft decisions on individual files, it is advisable that they rely explicitly, literally speaking, on already existent wording in the Convention, Operational Directives or the previous Committee's decisions (i.e., on the so-called jurisprudence of the Convention), since it is otherwise much easier for the members of the Committee to argue against the proposed decision. Likewise, it goes without saying that although the evaluation and inscription are strictly text-based, it is advisable to be at least basically informed-through literature-regarding the subject concerned because that will, of course, make you a more

18 Similarly, speaking of evaluations in the Masterpieces programme, Anthony Seeger argued that "without the evaluations provided by the NGOs [including the ICTM], the programme would have been far less meaningful and some of the action plans would certainly have been less effective" (2009: 113).

19 The chair and the rapporteur represent the Body at the session, and present its observations, recommendations and draft decisions. However, apart from that, they can speak only if directly asked by a Committee Member, and only by answering the question that is posed. This means, at that stage, that their possibility to contribute to the discussion and the resulting decision is minimal (yet still exist; the more cogent the answer the greater possibility that it will be heard). Altogether, the rules regarding who and when (in which agenda items and stages of decision-making) is allowed to speak are very strict, designed in a similar way to the whole UN system. 
competent reader of the file that you have a mandate to examine. ${ }^{20}$ In sum, serving on the Committee requires consistent strategic and diplomatic small steps, as well as professional competence; as Charles Seeger said in reference to UNESCO, "when working through government, patience, ingenuity, and watchfulness were important" (cited in Pescatello 1992: 182). Such workings of experts were significant means which to a degree "curbed" "nationalist efforts to celebrate forms of intangible heritage as if they are found exclusively within a nation's borders," which Anthony Seeger identified as one of the major issues in reference to proposals and proclamations of the previous Masterpieces programme (2009: 124).

Another level of complexity as regards the role of experts at the Committee's sessions comes with the fact that they partake not only as members of the Body (as one could presume from the description above) but also as delegates of member states of the Committee and other states parties to the Convention, either as the only delegates or, more often, as members of delegations led by persons from the political, usually diplomatic sphere. Generally speaking, it seems to be even more challenging to act as a representative of a state party, and contribute through this- the most influential channel to the deliberations and decisions of the Committee-than to serve in the Body. In this type of engagement, experts may sometimes have a hard time reconciling their professional commitments with their loyalty to possible "higher interests" of their national administrations. Yet in other cases, when they are less limited by national interests, they may be-and often are-among the main guiding forces in the effectuation of the Convention's principles and objectives (including the letter and spirit of the Convention). I cannot recall any instance when a positive development in the work of the Committee was not supported by some experts who were influential due to their position in national delegations. In other words, a substantial guiding force of ideas that managed to turn into the Committee's decisions are typically—although not exclusively—experts familiar with the challenges discerned by and after

20 This is very different from the Masterpieces phase. At that time, the evaluators were, if not specialists for the traditions under examination, they at least had a solid knowledge of them. This was one of the main criteria for their selection, but excluded in-country specialists in order to ensure impartiality (cf. Seeger 2009: 117-118). With a collective Body, however, it is neither possible for these twelve people to have some specific knowledge about the proposed elements, nor is this desirable, as all files deserve to be treated on an equal basis and, as in the Masterpieces phase, possible conflicts of interests should be avoided (say, an interest to promote a community with which a member of the Body has collaborated; for the same reason, a member is excluded from the examination of files submitted by his/her country). The competences expected from the members of the Body are defined in general terms of knowledge and experience in one or more domains of ICH. But this, on the other hand, indicates that the ICH has become (or is in the process of becoming) a specialized field on its own. The rise of university courses and programmes in ICH also testifies to the solidification of ICH studies as a separate discipline. 
the reflexive turn in ethnographic disciplines, who partake both in the Body and the Committee. Besides, the role of officials in UNESCO's Intangible Heritage Section, which at the same time functions as the Secretariat of the Convention, should also be mentioned. As they administer the development of the Convention on an international level on a daily basis, and are the most knowledgeable about all the challenges it brings, they are also instrumental in (facilitating) the course of legislation and the resulting implementation. ${ }^{21}$

On a national level: facilitation, brokerage, expertise

On a national level, experts play two main — and often mutually overlapping-roles: the role of facilitators and the role of ICH brokers. UNESCO places a lot of emphasis on so-called capacity building, with elaborated materials and guidance tools for "strengthening capacities to safeguard ICH for sustainable development," as it reads in the title of UNESCO's brochure. ${ }^{22}$ The training materials were developed by UNESCO's Intangible Heritage Section in collaboration with renowned ICH experts, and are delivered by expert facilitators through interactive workshops organized in countries and regions around the world. The workshops cover different topics (implementation on a national level, inventorying, safeguarding, sustainable development, gender, etc.), and are intended for different types of stakeholders (from culture bearers and representatives of local communities to supporting NGOs, local experts and other actors on local, national and/or regional levels). For the last couple of years, the workshops intended for the training of trainers-future facilitators-have been given new impetus, and there is a trend to deepen occasional facilitation into regular consultancy, primarily to governmental bodies in charge of ICH. As the network of workshops and facilitators grows, some desirable characteristics of facilitators have been identified. As it was summarized at one of the workshops that I attended in 2016, they are expected to be knowledgeable (on ICH and the Convention, analytical, creative, able to translate), collaborative (good active listener, good communicator, adaptive to the audience, able to create an inclusive environment, able to expand their networks, have a sense of humor), impartial (factual, non-judgmental, neutral, objective), and diplomatic (able to bring conflicting

21 It seems appropriate to recall at this point Tony Bennett's argument against the dichotomization between experts and researchers versus bureaucrats and politicians, as well as between the theoretical and the practical. According to Bennett, they all belong to the more inclusive category of intellectuals (2006). To my experience, this argument cannot be generalized; it applies well in certain situations, but not in others.

22 https://ich.unesco.org/doc/src/Global_capacity-building_programme-EN.pdf 
perspectives together while respecting all of them). These desirable characteristics resemble those of culture brokers, as they are termed in folklore studies and its applied branch of public folklore. ${ }^{23}$ Indeed, one can argue that on a national level experts work primarily as brokers who bring together two main parties involved in the safeguarding of ICH - communities and governments, along with other possible actors. For instance, as demonstrated in the survey of the International Council for Traditional Music which was conducted in 2014 in order to prepare the quadrennial report to UNESCO regarding the role of the ICTM and its members in ICH-related activities, the professional life of a number of ICTM members has shifted for some years now towards facilitation, brokerage and expertise in relation to ICH. In particular, an increasing number of ICTM members are assigned by their governments: (i) to participate in national committees for $\mathrm{ICH}$, in inventorying on a national level and the preparation of nominations for international lists; (ii) to facilitate broader access to ICH documentation (e.g., through the creation of digital repositories of sound or multimedia archives); (iii) to advance collaboration with communities and groups in developing safeguarding measures; (iv) to provide training in fieldwork, archival, and documentation methodologies; (v) to assist communities in creating an environment conducive to the transmission of knowledge to new generations; and (vi) to participate in the elaboration of mechanisms aiming to promote synergies between ICH and other cultural and development programmes. The arrival of the Convention, in addition, created room for new research and resulting studies, audio-visual publications, symposia and so on, while some ICTM members were additionally encouraged to employ distinctly collaborative ways of knowledge production and dissemination. Even in countries that did not join the Convention (such as Australia or Canada), a number of colleagues are dedicated to some types of activities related to the ICH programme, and some also endeavor to convince their governments to join the Convention. ${ }^{24}$ On the other hand, some colleagues were confused because the types of activities that they were asked about constitute their everyday work but are not framed within the ICH programme. This is understandably so because, as emphasized throughout this article, the ICH programme is no doubt the product of ethnographic disciplines, including ethnomusicology and ethnochoreology; to be more precise, it is the product of the participatory and reflexive branches of these disciplines.

23 On the application of the concept in the ICH programme see Jacobs et al. 2014.

24 The report is available at https://ich.unesco.org/en/accredited-ngos-00331. 
I am sure about the main argument of this article. Engaging up is the reality of professional lives of a significant - and judging from the spread of the ICH programme, an increasing - number of ethnomusicologists. In the same way as brokerage, it "requires balancing personal ethics and responsibilities to collaborators [communities] with the obligations and responsibilities to a current employer" (Atkinson Wells 2006: 14). Our obligations and responsibilities to current "employers" (be they UNESCO, state governments or similar entities) have remained under-conceptualized in ethnomusicology. Such entities are usually considered as a coherent establishment, an abstract power elite, the 'other', that is, almost as a rule, unfavorable if not hostile towards communities with whom we study and collaborate. This methodologically cozy position is of limited use. We could do more good by directing our research attention to detailed examination of decision-making processes and our role in them, with all their dynamics, fluidity, evolving nature, human agency and (good enough) intentions. That is, ethnomusicology needs new theoretical cum experiential perspectives on engaging up, which would be inclusive of the "rest of the world," as it has probably much more experience in engaging up than the West.

On the other hand, alas, I also have doubts. Is the kind of pragmatism suggested by this article justified, such as notions of small steps, the art of the possible, technical assistance, a limited reach and small-scale strategies? Where is the border that should not be crossed as regards "free, prior and informed" consent to consensual solutions, that is, as regards acceptance of, as it may be, otherwise unacceptable solutions due to the subordinate position of experts in relation to policy makers? Shouldn't such cases provoke open and loud opposition? Would not it be better to take David Mosse as a model, and thus break relationships established with powerful fieldwork partners, and maintain a critical stance and scholarly integrity? Or, pertinent to the ICH programme, what if community participation is, ultimately, a means of neoliberal governmentality? Who are, after all, the locals alias the communities of the programme? Is there some other framework emerging, apart from top-down and bottom-up clichés? What is the borderline between respect for different social arrangements around the world and the betrayal of libertarian ideas? And more broadly, how to navigate between the "universal" and the "specific?" What about the wrongs we commit? Even more, what about wrongs we do not even recognize? Or, looking at the most recent development in the life of the inscriptions, why engage up when the whole system of evaluation fell apart at the session in 2016 (when the Committee overturned more than $80 \%$ of unfavorable draft decisions related to individual files)? Or, conversely, was that incident actually a way of finding a new, more "consultative," "collaborative" 
or "participatory" mechanism of evaluation (as many members of the Committee argued at the session in 2017, and as was already, in a way, integrated into the Body's recommendations)? And so on and so forth. Once upon a time, the Clash were a significant catalyst in my formative years. As in the meantime I have deserted youthful rebellion, I incline towards reversing their moral: "If I stay, there will be trouble / And if I go it will be double." So we, scholars and ethnomusicologists, are better off staying.

\section{References}

Araújo, Samuel, and Members of the Grupo Musicultura. 2006. "Conflict and Violence as Theoretical Tools in Present-Day Ethnomusicology: Notes on a Dialogical Ethnography of Sound Practices in Rio de Janeiro." Ethnomusicology 50/2: 287-313. . 2008. "From Neutrality to Praxis: The Shifting Politics of Ethnomusicology in the Contemporary World." Muzikološki zbornik 44/1: 13-30.

Atkinson Wells, Patricia. 2006. "Public Folklore in the Twenty-First Century: New Challenges for the Discipline." The fournal of American Folklore 119/471: 5-18.

Baron, Robert. 2010. "Sins of Objectification? Agency, Mediation, and Community Cultural Self-Determination in Public Folklore and Cultural Tourism Programming." The fournal of American Folklore 123/487: 63-91.

Baumann, Max Peter. 1991. "Introduction: Towards New Directions in the Dialogue of Music Cultures." In Music in the Dialogue of Cultures: Traditional Music and Cultural Policy, M. P. Baumann, ed. Wilhelmshaven: Florian Noetzel Verlag, 11-14.

Bendix, Regina F., Aditya Eggert and Arnika Peselmann, eds. 2012. Heritage Regimes and the State. Göttingen: Universitätsverlag Göttingen.

Bennett, Tony. 2006. "Intellectuals, Culture, Policy: The Technical, the Practical, and the Critical.” Cultural Analysis 5: 81-106.

Berger, Harris. 2014. "Call and Response: Music, Power, and the Ethnomusicological Study of Politics and Culture: 'New Directions for Ethnomusicological Research into the Politics of Music and Culture: Issues, Projects, and Programs." Ethnomusicology 58/2: 315-320.

Ceribašić, Naila. 2015. "Povrh tekstualnog predstavljanja u etnomuzikologiji: Od epistemologije do angažmana i pragme.” Arti musices 46/2: 185-201.

. 2017. "O participacijskom mehanizmu, ulozi zajednica i stručnjaka u programu nematerijalne kulturne baštine: Prilog analizi stranputica humanistike.” In Stranputice bumanistike, P. Bagarić, O. Biti and T. Škokić, eds. Zagreb: Institut za etnologiju i folkloristiku, 153-185. Dirksen, Rebecca. 2012. "Reconsidering Theory and Practice in Ethnomusicology: Applying, Advocating, and Engaging Beyond Academia." Ethnomusicology Review 17: [unpag.].

Fujie, Linda, compiled. 1991. "Final Discussion (Summary)." In Music in the Dialogue of Cul- 
tures: Traditional Music and Cultural Policy, M. P. Baumann, ed. Wilhelmshaven: Florian Noetzel Verlag, 416-419.

Hafstein, Waldimar. 2004. "The Making of Intangible Cultural Heritage: Tradition and Authenticity, Community and Humanity." PhD dissertation, Berkeley: University of California.

Harrison, Klisala. 2012. "Epistemologies of Applied Ethnomusicology." Ethnomusicology 56/3: $505-529$.

Harrison, Klisala, and Svanibor Pettan. 2010. "Introduction." In Applied Ethnomusicology: Historical and Contemporary Approaches, K. Harrison, E. Mackinlay and S. Pettan, eds. Newcastle: Cambridge Scholars Publishing, 1-20.

Jacobs, Marc, Jorijn Neyrinck and Albert van der Zeijden, eds. 2014. "Brokers, Facilitators and Mediation: Critical Success (F)Actors for the Safeguarding of Intangible Cultural Heritage." Volkskunde 3: 249-416.

Klaić, Bratoljub. 1987. Rječnik stranih riječi. Zagreb: Nakladni zavod Matice hrvatske.

Kurin, Richard. 1997. Reflections of a Culture Broker: A View from the Smithsonian. Washington: Smithsonian Institution.

Kurin, Richard. 2001. "The UNESCO Questionnaire on the Application of the 1989 Recommendation on the Safeguarding of Traditional Culture and Folklore: Preliminary Results." In Safeguarding Traditional Cultures: A Global Assessment, P. Seitel, ed. Washington: Center for Folklife and Cultural Heritage, Smithsonian Institution, 20-35.

Mosse, David. 2006. "Anti-Social Anthropology? Objectivity, Objection, and the Ethnography of Public Policy and Professional Communities." The Fournal of the Royal Anthropological Institute 12/4: 935-956.

. ed. 2011. Adventures in Aidland: The Anthropology of Professionals in International Development. New York and Oxford: Berghahn Books.

Murphy, Clifford R. 2015. "The Applied Ethnomusicologist as Public Folklorist: Ethnomusicological Practice in the Context of a Government Agency in the United States." In The Oxford Handbook of Applied Ethnomusicology, S. Pettan and J. T. Titon, eds. Oxford and New York: Oxford University Press, 709-734.

Müller, Birgit, ed. 2013. The Gloss of Harmony: The Politics of Policy Making in Multilateral Organizations. London: Pluto Press.

Nader, Laura. 1972. "Up the Anthropologist: Perspectives Gained from Studying Up." In Reinventing Anthropology, D. Hymes, ed. New York: Pantheon Books, 284-311.

Pescatello, Ann M. 1992. Charles Seeger: A Life in American Music. Pittsburgh and London: University of Pittsburgh Press.

Pettan, Svanibor, and Jeff Todd Titon, eds. 2015. The Oxford Handbook of Applied Ethnomusicology. Oxford and New York: Oxford University Press.

Seeger, Anthony. 2001. "Summary Report on the Regional Seminars." In Safeguarding Traditional Cultures: A Global Assessment, P. Seitel, ed. Washington: Center for Folklife and Cultural Heritage, Smithsonian Institution, 36-41. 
. 2006. "Lost Lineages and Neglected Peers: Ethnomusicologists outside Academia." Ethnomusicology 50/2: 214-235.

. 2009. "Lessons Learned from the ICTM (NGO) Evaluation of Nominations for the UNESCO Masterpieces of the Oral and Intangible Heritage of Humanity 2001-5." In Intangible Heritage, L. Smith and N. Akagawa, eds. London and New York: Routledge, 112-128.

Seeger, Charles. 1944. "Music and Government: Field for an Applied Musicology." In Papers Read at the International Congress of Musicology Held at New York, September $11^{\text {th }}$ to $16^{\text {th }}, 1939$, A. Mendel, G. Reese and G. Chase, eds. New York: Music Educators' National Conference for the American Musicological Society, 11-20.

Seitel, Peter, ed. 2001. Safeguarding Traditional Cultures: A Global Assessment. Washington: Center for Folklife and Cultural Heritage, Smithsonian Institution.

Titon, Jeff Todd. 2015. “Applied Ethnomusicology: A Descriptive and Historical Account.” In

The Oxford Handbook of Applied Ethnomusicology, S. Pettan and J. T. Titon, eds. Oxford and New York: Oxford University Press, 4-29.

van Zanten, Wim. 2004. "Constructing New Terminology for Intangible Cultural Heritage." Museum International 221-222 (56/1-2): 36-43.

. 2009. "Prior Informed Consent: Experiences with Ethnomusicology Recordings." In

Intangible Cultural Heritage and Intellectual Property: Communities, Cultural Diversity and Sustainable Development, T. Kono, ed. Antwerp, Oxford, and Portland: Intersentia, 283-308. . 2012. "The Relation Between Communities and Their Living Culture as Represented by Audiovisual Files." In The First ICH-Researchers Forum: The Implementation of UNESCO's 2003 Convention: Final Report. Osaka: International Research Centre for Intangible Cultural Heritage in the Asia-Pacific Region (IRCI), 87-92.

Internet Sources

https://en.oxforddictionaries.com/definition/us/expert (07.04.2019).

https://en.oxforddictionaries.com/definition/expert (07.04.2019).

https://ich.unesco.org/en/10com (07.04.2019).

https://ich.unesco.org/en/ (07.04.2019).

https://ich.unesco.org/en/8com (07.04.2019).

https://ich.unesco.org/en/directives (07.04.2019).

https://ich.unesco.org/en/forms (07.04.2019).

https://ich.unesco.org/doc/src/Global_capacity-building_programme-EN.pdf (07.04.2019).

https://ich.unesco.org/en/accredited-ngos-00331 (07.04.2019). 
Partnership with communities studied, and engagement for their benefit are firmly established in ethnomusicology. Conversely, engagement with powerful entities such as national governments and UN agencies is terra incognita in ethnomusicology. This paper revisits the concepts of studying up vs. engaging up in cultural anthropology, followed by discussion on the causes for the lack of related studies in the ethnomusicological mainstream literature-suspect in political-ethical terms, humbleness as regards professional expertise, and gap between disciplinary centers and peripheries. The challenge of engaging up is exemplified by the author's experience related to her expert services in the programme of intangible cultural heritage. It is argued that engaging up and expertise represent main shadows in the field of today's ethnomusicology, applied ethnomusicology in particular, which urge for thorough reflection. 


\title{
"And from the Ruins of Time They Blossom":
}

\author{
On the Moral Imperative in Ethnomusicology
}

In springtime of the year that followed, it arrived sad and cold, A courier from the Baron of Pirovano rode slowly into Langenau. There, he saw an old woman, weeping.

Viktor Ullmann/Rainer Maria Rilke, Die Weise von Liebe und Tod des Cornets Christoph Rilke, Finale (1944; Ullmann 1993: 49-50) ${ }^{1}$

Avant propos: On the Moral Imperative to Perform

How is it even possible to perform the music of the Holocaust? What are the ethical responsibilities that the performer faces, sounding the voices of those silenced in the past? How do we understand performance of a work such as Viktor Ullmann's Die Weise von Liebe und Tod des Cornets Christoph Rilke (The Chronicle of Love and Death of the Flag-Bearer, Christoph Rilke), whose closing scene serves as the epigraph to this essay (Ullmann 1993)? Does it commemorate those who perished together with its composer in the concentration camps, where the melodrama for dramatic speaker and piano was created, but never performed? Is its chronicle of love and death in the violence of war merely a work of great beauty, or are we-am I, as the performer of Ullmann's Weise, as well as the Artistic Director of the New Budapest Orpheum Society, which will record the melodrama-obliged to transform allegory into agency, affording performance moral imperative?

These are the questions that have motivated me as an ethnomusicologist and performer for much of my career, and that provide a series of issues critical for ethnomusicological thought, past, present, and future. Such issues ask us to bear witness to and act upon the moral imperative we have as ethnomusicologists. Among such issues in the pages that follow are those to which my own work as an ethnomusicologist/ performer has been witness, the lessons I learned over many years, also engaging with

1 All translations in this essay are those of the author. 
Vienna, its rich tradition of ethnomusicology, and its remarkable history of Jewish music. Underlying such issues, moreover, are the very themes of the present volume, which not only accompany the move of the ICTM Secretariat to Vienna, but have also provided a leitmotif for the intellectual history of ethnomusicology. Performance has played a crucial role in the practices that make musics matter. It may well be, indeed, that it is through performance that musics come to matter in some of the most critical ways for the field of ethnomusicology.

Performance creates the possibility that the gap, or aporia, between self and other might be narrowed, in some instances, even closed (see Bohlman 2012). Performance provides a means of activist pedagogy, in which the distinctions between student and teacher, performer and audience, are turned on their heads, creating what I call the cabaretesque in this essay. The matter of music also becomes the materiality of music through acts of performance. Above all, the musical matter sounded through ethnomusicological performance bears witness to the acts and activism encompassed by the ethical pair, responsibility and response. When we perform as ethnomusicologists, we make music matter, and we do so by embracing the moral imperative that is inseparable from our field.

The moral imperative of ethnomusicology takes many forms, and it arises from many different types of performance. The ethical questions that challenge the field, moreover, stretch across the history of ideas with which ethnomusicology is associated, and for that reason, too, I examine the emergence of ethnomusicology's moral imperative as a condition of intellectual history. In the pages that follow I reflect for the most part on my own activities as an ethnomusicologist/performer, the projects and performances I have undertaken since 1998 as the Artistic Director of the Jewish cabaret ensemble, the New Budapest Orpheum Society (NBOS). We draw our repertory primarily from moments of prejudice and pogrom in modern history, especially that of Central and Eastern Europe from the late nineteenth century to the present. The confluence of past and present - the return of anti-Semitism to Europe during the twenty-first century is the clearest example of the latter-is critical for the ways in which history and ethnography together provide the musics that make our performances matter. As an ensemble - the NBOS contains eight musicians, vocalists and instrumentalists-we mobilize performance and take it to the many stages that afford it ethical and political meaning, from local synagogues in Chicago to cultural institutions and clubs worldwide-and even to the Universität für Musik und darstellende Kunst in Vienna, the new home of the ICTM Secretariat. It is that insistent coupling of mobility and materiality that is especially critical to making music matter for the NBOS and the ICTM, and to which I now turn. 


\section{On Ethnomusicology and Moral Imperative}

Throughout its history, ethnomusicology has been a field deeply concerned with its identity and theoretical practices, especially the ways in which these shape the ways scholars and musicians interact with the lived-in societies they study and musically represent. The persistent practices of self-reflection-and self-criticism, too-provide an important opportunity to think about ethnomusicology's moral imperative and the models we use to represent our field. As ethnomusicologists bear witness to the imperatives of ethics and moral philosophy, it is important to recognize that they do so not only on the global plane of political crisis and the large-scale issues of racism, decoloniality, and genocide, but also in the local, often everyday interactions that are critical to the ways ethnomusicologists listen to the voices of others to understand human society.

The moral imperative I address here is not an isolated concept, but one that connects ethnomusicology historically to ethical and moral action as philosophical action and practice. As we seek ways to embrace a moral imperative for ethnomusicology, it is critical, therefore, to consider what ethics and moral philosophy are, as well as what they are not. Ethics is not religion. Ethics is also not ideology. The moral imperative of moral philosophy does not result from the decisions of those wielding the instruments of power, for example, a political élite or a priesthood. Ethics, when we integrate it into ethnomusicological theory and practice, does not ask us to privilege one set of beliefs or social actions over another, rather it seeks ways of identifying musical practices shared by as many as possible, at once the whole of a given society and all human beings.

The foundational issue for the moral imperative of ethnomusicology, nonetheless, is anything but easy and straightforward, for it proceeds only upon respect for the diverse forms of citizenship in every society. For Aristotle, whose philosophy is steeped in ethics, particularly the Nicomachean Ethics (Aristotle 1925), citizenship begins with a set of prospects for being good so that all who are citizens can live well. Immanuel Kant approached the issue of citizenship more aggressively, not to mention more expansively than Aristotle, introducing duty (the concept of "deontology" in moral philosophy) as a condition for living in an ethical society (Kant 1964). More recently and particularly influential in shaping modern ethnomusicological thought, moral philosophers have reframed the universalist claims for duty by developing concepts of social contract, which draw human rights into a sphere of fairness that through action generates justice (see especially, Rawls 1971, and cf. Williams 1985). It is the implementation of such forms of action that ethnomusicology's moral imperative asks of us (see also Bohlman 2007). 
As I turn more directly to ethnomusicology, I do so with obeisance to the modern field's early indebtedness to Vienna. Historically, Vienna was one of the first sites for such representational models, notably Guido Adler's 1885 essay on the "Scope, Methods, and Goal of Musicology" (Adler 1885). The model I sketch here may be more limited in scope than all fields of music scholarship, but I mean to be no less emphatic in suggesting that the ethnomusicological practices I represent are critical for our field, which is to say, not a subject to compromise. The model itself takes the form of a moral compass, with four directional coordinates, intended metaphorically to locate the field in the lived-in worlds in which musics matter for the field (see figure 1).

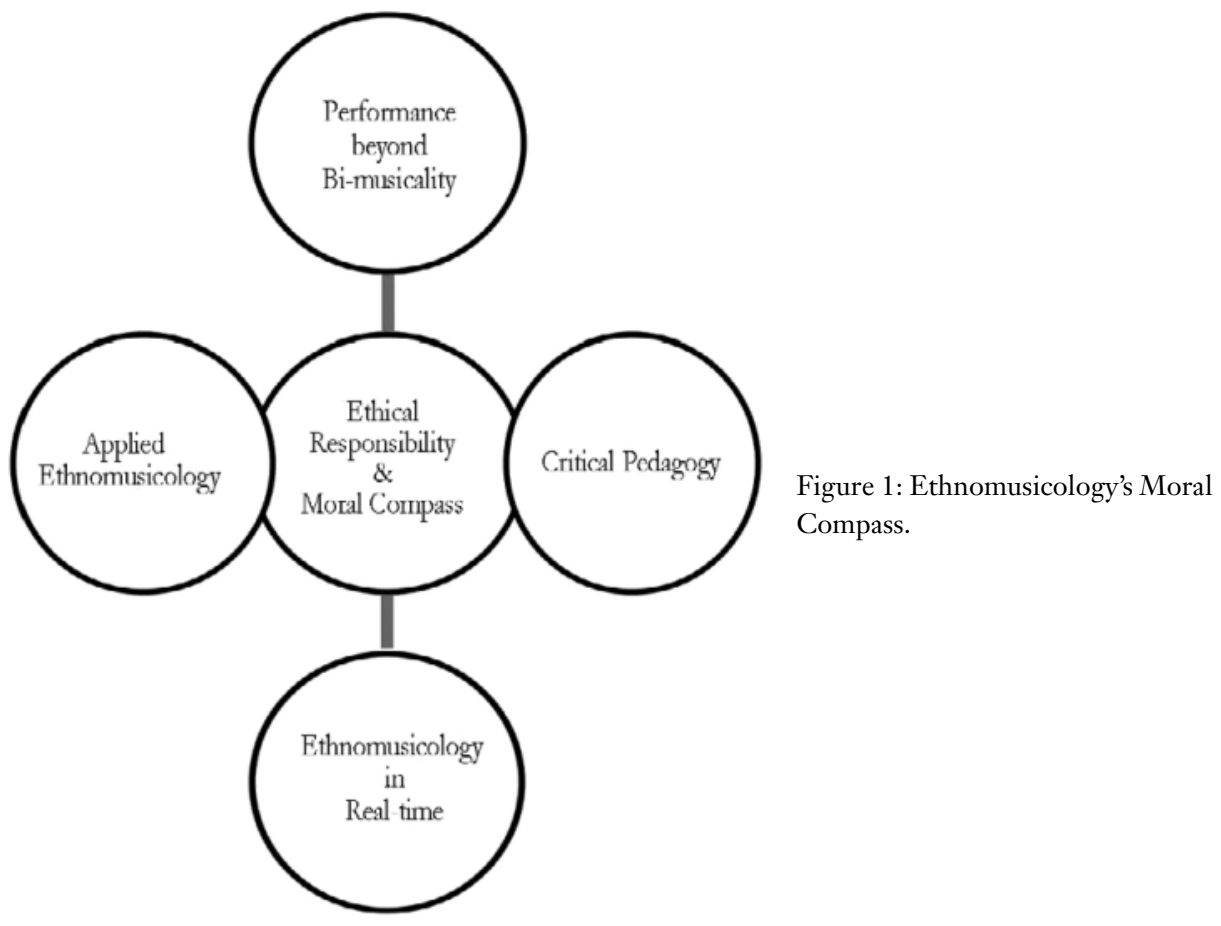

I make no claims here that this model is new, but rather I believe that it forms a core in the historical longue durée of our field. As ethnomusicology coalesced around a collective of common practices in the course of the nineteenth century, the themes of response and responsibility emerged ever more critically: colonialism and racializa- 
tion; the destruction of traditional cultures and genocide; the preservation of endangered heritages. Ethnomusicologists did not always act ethically and morally in the fullest sense of their responsibility and response. That's not my point. Still, ethnomusicologists confronted these critical issues and sought a variety of solutions. They could not and did not distance themselves from the ethical and moral issues of their day. And we cannot do so either.

\section{Beyond Foundational Mytbs: Ethics and Ethnomusicology's Beginnings}

The beginnings of ethnomusicology's histories are captured by many different foundational myths. Many of these surround individual biographies-Alexander Ellis and his contribution to the physical measurement of musical pitch in the nineteenth century (Ellis 1885), the "Berlin School" between the world wars of the twentieth century, or the four "Founding Fathers" of the Society for Ethnomusicology in the 1950s (see Nettl 2010). The growth of recording collections-the phonogram archives of Vienna and Berlin in fin-de-siècle Europe, archives of traditional music, both local and national, in the mid-twentieth-century USA. The formation of national narratives of folk music and scientific advances in the preservation and measurement of music converge to transform foundational myths to the modern history of global encounter from which ethnomusicology cannot be separated. Critical to the inseparability of encounter from the histories of sound that emerge from it have been the ethical questions that it raises, that is, the questions of ownership, appropriation, colonialism, and frequent violence that themselves are inseparable from the field's myths and histories (for a collection of essays examining many of the field's histories, see Bohlman 2013).

Of the many moments of beginning that have consistently shaped the early and modern histories whose confluence led to the formation of the ICTM, especially in its earlier stages as the International Folk Music Council (IFMC), the global history of folk song and folk music that emerged from the seminal publications on folk songs by Johann Gottfried Herder (1744-1803), especially the two-volume, six-folio Volkslieder (Folk Songs), has played a crucial role in transforming myth to history (see Herder 1778/79; Herder 1807; for a partial translation, see Herder and Bohlman 2017: 44104). Though myths about Herder's collections abound-claims they were volumes of German folk songs, or the products of a scholar with no concern for ethnographic context - they largely miss the more complex and lasting history of Herder's foundational moment for the field of ethnomusicology. Critical for that moment was, in fact, its engagement with the growing ethical uncertainty that grew from the global encounter on which it depended. I turn briefly to the ways in which the earliest concepts of world music reacted to that ethical uncertainty. 
Throughout Herder's publications of and on folk song, music enters history from myth as silence, not infrequently as a record of loss and death. In his volumes of folk song, history accrues at an accelerating pace from the earliest sections to the final sections, which appeared posthumously in print four years after Herder's death in 1803 (see Herder 1807). The teleology of Herder's representation of encounter is powerfully eschatological, by no means surprising, for, as a Lutheran pastor Herder was acutely aware of the need for ethical underpinnings in his thought and in the philosophy of his day. Folk songs- the music of the many parts of the world to which he turned for his examples-were imbued with history. And with ethical meaning that reflects moral practice.

Increasingly, as we move through Herder's volumes of world music, the Volkslieder (1778/79) and its second, posthumous edition, Stimmen der Völker in Liedern (1807) with its songs previously gathered at colonial encounter, the number of laments and songs of death proliferate. The laments record sadness and terror, the loss that occurs at moments of encounter. In the posthumously published appendix, the violence of colonial encounter overwhelms Herder's folk songs, particularly in the concluding folio of songs from and about the colonization of Madagascar, eleven songs that Herder translated from the colonial accounts of the French Count Évariste de Forges de Parny. The terror in colonial Madagascar, in the heart of darkness, is that of encounter with the armies and the missionaries of the Europeans, the racialized "whites" whose presence is vilified in the songs. We hear this terror, for example, in the lamentHerder designates it a Totenklage — for the fallen son of the King of Madagascar, sung by King Ampanani himself, and in call-and-response with the people of Madagascar:

Ampanani: $\quad$ My son has fallen in battle! Oh, my friends, weep over the son of your leader. Take his body to the place in which the dead live. A high wall will protect him, for there will be the heads of bulls on that wall, which will be armed with threatening horns.

Respect the place in which the dead live. Their sadness is terrible, and their revenge is gruesome. Weep over my son.

The Men: $\quad$ Never again will the blood of the enemies turn his arm red.

The Women: Never again will his lips kiss those of another.

The Men: $\quad$ Never again will fruit ripen for him.

The Women: Never again will his head rest on a tender bosom.

The Men: $\quad$ Never again will he sing, resting under a tree thick with leaves.

The Women: Never again will he whisper new enticements to his beloved.

Ampanani: Cease, now, with your weeping over my son! Happiness should follow the mourning! Tomorrow, perhaps, we too will follow to the place he has gone.

(German in Herder 1975: 540-41; translation from Herder and Bohlman 2017: 101) 
For Herder, calling song into being, hence giving it ontological meaning, was an act of moral imperative. In aesthetic terms, the ethical potential of song grows from its transformation from object to subject, which itself is a crucial ontological move throughout the history of ethnomusicology, but with particular narrative potential if myth was to give way to history. We witness ethical motivation for this ontological moment in the history of ethnomusicology in the final passage in Herder's last major essay on music, the chapter called simply "Von Musik" (On Music) in his collection of aesthetic writings, Kalligone, of 1800.

If one gathers, without any prejudice, the affects that melodies and songs invest in human feeling and afford to all collectivities of human society, from the family to the nation, music would rise as a narrative of miraculous tales from the lowest rung to which it has been assigned to realize its relation to the culture of bumanity. "The concepts of music come from transitory impressions; either they disappear entirely, or if they are deliberately repeated from the strength of imagination, they are more burdensome than unpleasant" [from Herder, Über die menschliche Unsterblichkeit]. [...] As we know so very well, it is music that we experience within ourselves that lifts us up from the earth at the very moment of death. (Herder, "Von Musik," in Kalligone, trans. in Herder and Bohlman 2017: 259)

Johann Gottfried Herder's final recognition of the ethical dimensions of music is remarkable as a summation of his understanding of a much larger epistemology of music and the human, in which folk music, art music, and all forms of world music are not fundamentally separable. Again, it is inseparability that draws attention to the moral imperative. Herder consciously takes up his earlier work on folk song again from a quarter-century earlier, realizing a process of return that is crucial to the ways myth becomes history. Looking across the aesthetic domain that forms from a lifework dedicated to song, we recognize a unity that connects the culturally-specific folk songs in the anthologies of 1774 and 1778/79 through the theological writings of his middle years to the ethically-grounded aesthetics of his late writings.

By investing the ontology of music with the ethical, Herder envisions a collectivity-of choral singing and communal dance - that expands considerably upon earlier European aesthetics of what music was and could be, above all as an extension of speech. "We cannot listen often enough to the intimate passages that move us. How they echo, and we wish for their return without satisfaction, until we (so we imagine) absorb these passages and they become part of our soul" (Herder, "Von Musik," Kalligone; trans. in Herder and Bohlman 2017: 258). Herder's move from myth to history through song becomes more focused and more human, while at the same time the range of music's metaphysics becomes more expansive and more universal.

Because of this moral imperative in singing as human experience there is much that 
is at stake in Herder's late reflections on the moment of folk song as he approaches the final stage of his life. He hesitates not to call that moment also a moment of death. It contains humanity and the universe, life and death. Folk song and history, which live through their return, however transitory it may be, are endowed with remarkable force, the very power to realize life itself, and to do so in the moment in which song asks those who experience it to seize its moral imperative.

\section{Beyond Bi-musicality: Ethnomusicology, Performance, and the Cabaretesque}

From Herder's foundational moment in the history of ethnomusicology I return to the present and the moments of performance that constitute the ways in which ethnomusicologists retrieve the sound past in search of its ethical meaning for our engagement with others. We refer to these practices of performance in various ways-participant-observation and bi-musicality are among the most common-but I concern myself here with the ways in which performance employs commemoration. To do so, I turn again to the ways in which my own work as a performer of Jewish music, especially that lost to the trauma and destruction of twentieth-century history, has developed into a form of commemoration beyond bi-musicality, to which I give the name "cabaretesque."

Trauma, we so often believe, strips human experience of agency, in the Jewish Holocaust, the Shoah, but also in other instances of genocide and the victims of racism, past and present, as the refugee crises-Syrians, Somalis, Rohingya, Mexicans, to name some of the most obvious-of our own day, that is, the ethnographic present for the present volume, bear witness. Those afflicted by trauma are victims of actions beyond their control. Their response is one of silence, the inability to cross the threshold of adequate expression. All that must be expressed remains inexpressible, trapped and immutable in the fear that further trauma is possible, if not immanent (Bohlman 2012).

Performance and commemoration, when combined, are meant to restore some measure of the agency lost to trauma. The music of commemoration, such as that we gather for performances of music from the Shoah, fills the void opened by trauma. Music resists trauma by insisting that silenced voices might be heard again, might be allowed to speak again, if not for themselves, then through performance and performers. The performer seeks to recover what has been lost to trauma, suturing the sonic shards of lives that are themselves irrecoverably lost.

The restoration of agency through performance lies at the heart of the commemorative work of my colleagues and me in the New Budapest Orpheum Society. Through performance and recording we retrieve Jewish voices lost to violence 
throughout the longue durée of the Jewish diaspora, but especially to the Shoah in the twentieth century. The task of affording agency does not diminish in the twenty-first century, especially with the rise of anti-Semitism within European populist movements (see Bunzl 2007). The research and performance that the New Budapest Orpheum Society undertakes-we take our name from the original Budapester Orpheumgesellschaft, which thrived in Vienna from ca. 1888 to 1918-enters a space ripped open by trauma and constituted of musical works created in the twentieth century, overwhelmingly misplaced, neglected, or lost because of the Shoah (Bohlman 2012).

The enormity of the archive of trauma with which we work is scarcely fathomable. Real libraries and archives are opened, searched again and again for the fragments that might have slipped into an unrecognized crevice. Collections in far-flung and unexpected places were examined, revealing treasures great and small. This is what we could contribute from a tradition of ethnomusicological practice we have forged as response and responsibility over the two decades we performed together (listen, for examples, to the CDs, New Budapest Orpheum Society 2002, 2009, and 2014). Whenever possible, we collaborate with other performers and scholars, always with the goal of using music to enhance the memorywork necessary to confront trauma (the poster in figure 2, for example, describes the music we brought to the stage to complement a stage work by the Viennese performance artist, Eduard Freudmann, on April 22, 2018).

The larger theoretical and methodological framework in which the NBOS works is the performative process I call the cabaretesque, which may begin with ethnomusicological bi-musicality, but moves beyond because of the need to confront the moral imperative in the musical materials with which we work. It is our task to make the sketches, fragments, and testimonies from the survivors of trauma performable. There is no aspect of the materials we research that does not require transformation so that they might enter the archive of Jewish memory. Incomplete lyrics and melodies from oral tradition have to be reconstructed through comparison. Harmonies are fitted to melodies, and then transformed to arrangements that we, as an eight-member ensemble, could perform. We translate lyrics in various directions-especially to the languages in which we regularly perform, Czech, English, French, German, Hebrew, Russian, and Yiddish - at each stage making the performances our own, but doing so to restore the agency necessary for the moral imperative we seek to realize through performance.

The ensemble members expand the goal of memorywork also by seeking to locate performance in the ethnomusicological framework to which we give the name, cabaretesque, a theoretical concept formed at the confluence of the performative and the ethical. To understand better the ethnomusicological implications of this confluence I 


\section{New Budapest Orpheum Society}

Making Sacred All the Whispers of the World The Memorywork of Jewish Cabaret

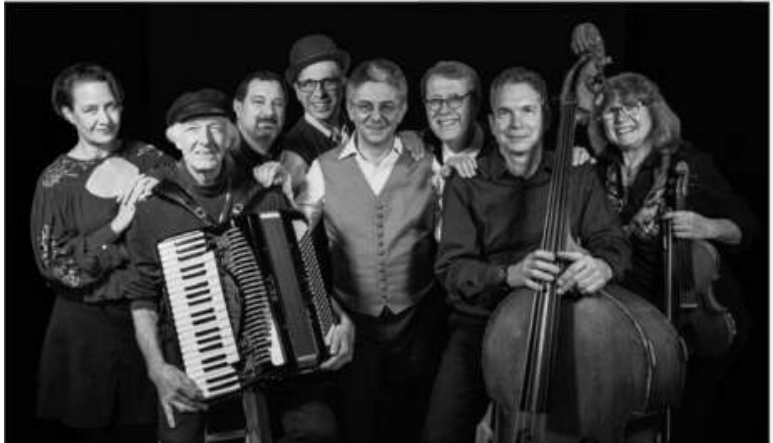

In this performance complementing Eduard

Freudmann's April 23nd performance of "The White Elephant Archive, Setring No. 37 (Bond Chapel, 7:30 pm), the New Budapest Orpheum Sociery (Humunitic Division, ensemble-in-residence) resounds the songs of struggele, sarvival, and acrifice frotn the tragic history of twentiech-century Jewish modernity.

During the course of the evening the audience will fourney through the Yiddish songr ceated by Mondectuie Getirtig for the Cracow Ghetro and bear witness to the mesuge of songs from the Golden Age of Yiddish film. Milestones of metaphor and allogory give meaning to a historical path that pase through cities as diuparate as East European sbtetls and the cosmopolitan cities of The Duchess of Chinere. Repertories gathered through the research of the ensemble - works by Vikeor Ullmann and Leo Straus from the concentration camp at Theresienutadt/Tenexin, Hebrew songs circulating on postcands between Berlin and Jerusalem and componers such as Secphan Wolpe and Kurr Weill, newly-componed Rusian songs by tly Levinson - will be experienced in all thair stapgering besury. The New Budapest Orpheum Society puys homage to the past, present, and future, seeking the acred withis the whimpes aill andible for as in the rwenty-fint century when we lisen.

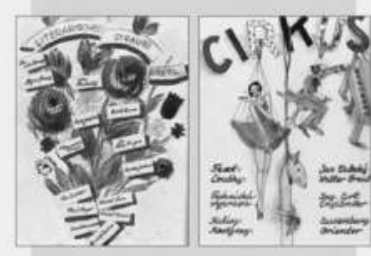

Sunday, April 22

8 pm | Fulton Recital Hall 1010 E. 59 $59^{\circ}$ Street, Goodspoed Hall, $4^{\text {th }}$ Floor

Free Admission

music.uchicapa edu

event hotline: 773.702 .8069

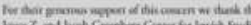

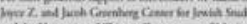

Figure 2: The New Budapest Orpheum Society in performance, April 22, 2018. The images on the posters are from performances in the concentration camp at Terezín/ Theresienstadt.

now turn to a closer examination of the performance theory itself. My first goal in this essay is definitional, in other words, establishing the cabaretesque as an ethnomusicological concept that allows us to understand what it is that distinguishes cabaret as a genre of music for the stage. My second immediate goal is ontological, aesthetic, and political, seeking to understand the cabaretesque for the ways it allows us to perceive cabaret in forms and genres of expressive performance that are not specifically cabaret, and to develop the potential for moral imperative through new modes of performance.

In order to theorize the cabaretesque, I draw upon Mikhail Bakhtin's well-known concept of the carnavalesque. The cabaretesque relates to and distinguishes itself from the carnavalesque in general and specific ways. I seek to relate the two concepts in 
textual, contextual, and historical ways. Bakhtin develops the concept of the carnavalesque by turning his concept of "heteroglossia" toward Carnaval, in other words, the social realm created during Christian pre-Lenten festivities. The concept emerges most notably in Bakhtin's book, Rabelais and Folk Culture of the Middle Ages and Renaissance, known usually as Rabelais and His World (Bakhtin 1984).

As a set of performance practices for ethnomusicology, the cabaretesque recognizes a different set of complex ethical questions that may well be absent from bi-musicality or participant-observation. We might think of the functions of the cabaret song for a moment, which possesses the repeatability of fixity in heteroglossia, the principle of intertextual and multiple linguistic meanings that Bakhtin locates in the carnavalesque, for example, the traditional associations with contrafacts and cover versions of songs. Contrafacts and covers, however, must also be malleable, because fundamentally they are fitted to new texts that are able to distort meanings because of the recognition of an original melody. The audience has ownership of a stock of repeatable speech acts, for example, its distinctive dialect or accent. The actors-performers on the stage-ethnomusicologists in performance, for example-possess the skill to transform them through constantly shifting contexts.

There are historical implications in the ways and moments in which the cabaretesque emerges from the carnavalesque and thus productively extends to ethnomusicology, making music matter in new ways. The cabaretesque is already emerging in medieval mystery plays from the Bakhtinian world of Rabelais, not least in the ways in which acting troupes move the stage from place to place. More specifically in Jewish tradition, it is the cabaretesque that transforms the medieval Purimspiel (musical play from the biblical book of "Esther," for the holiday of Purim) into a means of transforming tradition in early modern Europe. The same could be said of Italian commedia dell'arte in later centuries, which also relies on the mobility of the acting and singing troupes, with their heterogloss mixture of fixed and malleable characters. Yiddish theater, which itself borders on cabaret and influences modern operetta and musical theater, relies on the mobility of theatrical and musical troupes during the renaissance of Yiddish literature and the golden age of Yiddish and Jewish film music. In South Asia the cabaretesque in the ways Baul singers from West Bengal and Bangladesh turn pilgrimage songs and bhajans on their heads, undoing the religious tensions between Hindus and Muslims (see Kibreah 2016). In similar ways, it was the Bene Yisrael, that Jewish community of some two millennia in western India, that reimagined the Hindu kirtan as Jewish in the late nineteenth century, just as the Bene Yisrael were performing at increasingly intense levels as theater musicians on the Marathi-language stages of the Maharashtra region of India (see Schultz forthcoming).

The cabaretesque locates music in time and place, in the worlds, both real and imaginary, that are inhabited by human beings and communities. The singer and lis- 
tener perform their sense of arrival, and they musically join others in the ontological moment of copresence with others (see Gumbrecht 2004). In its ontological specificity, the cabaretesque borrows much from ritual, but it also dislodges music from ritual, especially through the transformation from oral tradition to written tradition. The cabaretesque makes performers and audiences sense the time and space of music appear as real, which is to say, it makes them matter because of their ethical proximity to us.

\section{Beyond the Stage of History: Musical Film Matters}

Just as I journey to the Bakhtinian Middle Ages in search of ethnomusicological avatars for the cabaretesque, so too do I discover a modern dramatis personae for cabaret by focusing queer theory on cabaret in the twentieth and twenty-first centuries. Once again, I draw upon the possibilities that ethnomusicology offers to retrieve musics lost to the trauma of history to commemorate the Jewish experience of the twentieth century. From the cabaret stage I move to the stage of an age of Jewish film music, which flourished from the mid-1920s to the Shoah, resuming retrospectively and commemoratively thereafter until the mid-1950s. As a testimony to the very emergence of sound in cinema, Jewish film music mattered a great deal, owing its efflorescence in many ways to the cabaretesque. It was this age of Jewish film music that the New Budapest Orpheum Society sought to realize through commemoration and performance (see figure 3 for the ensemble's double-CD compilation of Jewish film music; New Budapest Orpheum Society 2014).

The transformation from music for the cabaret stage to Jewish film occurred seamlessly during the 1920s and 1930s, but did so through ways in which we would understand the cabaretesque to stage acts of queering. The heteroglossia of its skits turns the staged worlds of cabaret inside-out in order to become disruptive and to dismantle norms of a society too comfortable with the exercise of power. In the Central European cabaret with which the New Budapest Orpheum Society works, for example, cross-dressing and drag performance are so extensive as to dismantle the very notion of the norm — and of what might be assumed to be norms (see, e.g., Tucholsky 2016).

Therein lay the ethical work of the cabaretesque, as the worlds it represented on stage and in film were turned inside-out. Self became other, other became self. The world on the stage or in a film was made to appear as if it were everyday, albeit with reflections and shadows that change the ways it was perceived. Musicians performed diegetically in films such as The Fazz Singer (1927) - Al Jolson and Yosele Rosenblatt-and Der blaue Engel (1930) - Marlene Dietrich and Friedrich Holländer, with his band, Weintraub's Syncopators - as in an intimate space where the self and other 


\section{As Dreams Fall Apart The Golden Age of Jewish Stage and Film Music 1925-1955}

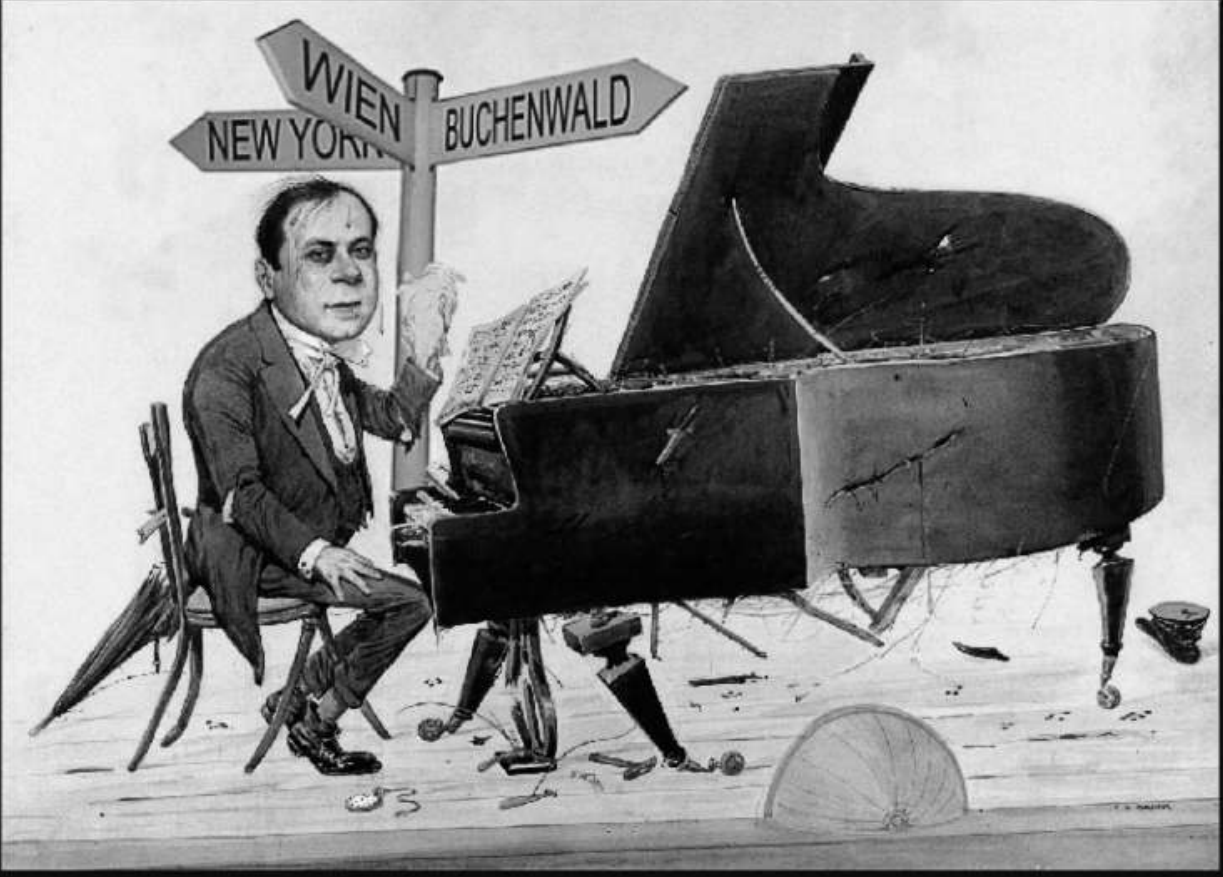

\section{New Budapest Orpheum SOCIety}

Figure 3: As Dreams Fall Apart (cover), with Hermann Leopoldi at the Piano. New Budapest Orpheum Society 2014.

explore their intimacy through the interplay of darkness and light. Revelation and reflection become one, as the cabaretesque becomes the mirror through which spectator and listener enter the moment in which we see ourselves as others (cf. The fazz Singer 1927 and Der blaue Engel 1930).

Historically, the cabaretesque emerged at a moment when cultural theory and the techniques of cultural production explored the transformation of meaning through reflections from mirrors. The mirror was important for the psychoanalytic theories of Sigmund Freud and Jacques Lacan. Mirrors project the gaze of cubist and surrealist 
painters, and of impressionist and twelve-tone composers. And mirrors become the lens of the alter-ego in the films that captured cabaret and embedded it in Jewish film history. The mirror in film noir becomes the oracle for the film song of the great cabaret composers, Hanns Eisler and Friedrich Holländer, whose songs provided a sound history for Jewish film music.

The metaphorical mirror in the cabaretesque also shapes the ways in which nothing is really as it seems. The cabaretesque engenders dreams, and it creates the illusions that allow the viewer/listener to believe it is possible to enter alternative worlds. Is Jakie Rabinowitz/Jack Robin, the Al Jolson title role in The Fazz Singer, white or black, Jew or non-Jew, star of the New York stage or son of the immigrant cantor? He is, of course, all of these because, in cabaretesque style, he performs all these roles (see Rogin 1996). What would cabaret be if it did not possess the power to distort, distract, and divert our gaze from the harsh realities of the world beyond the footlights and outside the frame of the film?

Sound entered film at one of the most auspicious and spectacular moments in the history of Yiddish theater. From its earliest years in the nineteenth century, Yiddish theater troupes had been mobile and cosmopolitan, moving from across the shtetl culture of Yiddish-speaking Eastern Europe to the metropoles of Central Europe, Vienna not least among them, as they absorbed growing numbers of Jewish immigrants entering the public sphere of the nineteenth century. In Vienna, Berlin, Budapest, and other cities with growing Jewish populations, Yiddish theater provided a musical and narrative mirror for new forms of Jewish stage music. Jews arriving from the shtetl shed the traditional cloaks of tradition and engaged-sometimes haplessly, often successfully-with the challenges of modernity. Both allegory from the biblical past and alienation from present modernity heightened the fragility of the characters on the Yiddish stage. The cabaretesque in Yiddish musicals restaged that fragility, rerouting immigration to exile, from the familiarity of the past to exile into the future (see Bohlman 2002).

The future for Yiddish theater and the Yiddish musical was the New World, especially the great metropoles of the United States and Argentina. Already by the beginning of the twentieth century, Yiddish stage music was attracting audiences in New York City and Chicago. By the 1920s, an active Yiddish theater scene had established roots and spread into most areas of American popular music, from vaudeville to jazz to cinema. And it was Yiddish theater that provided a critical component of the template-together with operetta and blackface minstrelsy-for the emergence of the musical and its mirrored companion, the film musical (Rogin 1996).

It was this theater scene that The Fazz Singer captured in 1927, weaving together the larger themes of allegory, alienation, and exile from the many streams of American popular music. Yiddish theater paved the way for new film composers and stars, such 
as Boris Thomashefsky (1890-1957), Abraham Ellstein (1907-1963), and Molly Picon (1898-1992). Because these themes from American Jewish music continued to reflect the traditions of Yiddish stage music, it is hardly surprising that they could quickly be transformed by Yiddish cinema and its golden era of the 1930s, which would prove to be perhaps the most spectacular—and short-lived—of all traditions of Jewish film music.

The synchronization of sound with film transformed music and the ways it entered time and narrated history. The impact on Jewish music for the stage was profound, intensifying the moment of modernity that made Jewish music a global phenomenon. As Jewish stage music was recast as film music, it acquired a new sound. The intimacy of the salon and the pathos of Jewish art song absorbed the cosmopolitan styles of a new generation. Folk song became popular song; local repertories entered the urban scene as jazz and popular dance. Classical forms unfolded into new modes of experimental improvisation. Instruments multiplied in number and ensemble structure, making jazz even more global than it had been in the aftermath of World War I. The sacred was secularized, and the secular was sacralized. On the screen, Jewish music found a new place in history; as the soundtrack of the modern film, Jewish music truly mattered. It seemed, indeed, that Jewish film music could sound an alternative space for history itself, and critically, it would sound the ethical dimensions of that space, before it was destroyed during the Shoah.

Jewish music found its way from stage to film in many different ways, some direct, others circuitous. Early film musicals often kept the stage clearly in view of the camera, giving the viewing public the sense that they were witnessing a live musical performance, not merely its representation in a cinema. Musical films often took musical performance on the stage as their subject matter, becoming musicals about musicals, connecting stage to film through the cabaretesque in music. The materiality of Jewish film music only multiplied the ways it came to matter on the eve of global moral collapse.

The musical journey between stage and film also unfolded as detours through the rise of fascism, World War II, and the Shoah, resulting in both the survival and revival of Jewish music thereafter. In the course of the Shoah, Jewish operetta and film composers suffered quite different fates, often tragic. Many were composers who employed cabaretesque techniques directly to engage with difference and diversity, including queerness, such as Emmerich Kálmán (1882-1953), whose 1928 Die Herzogin von Chicago (The Duchess of Chicago, see Kálmán 1928), with its representation of ethnic and racial difference on the stage, was banned and led to Kálmán's exile and demise (see figure 4). Kálmán fled Austria already before the Anschluss and attempted to re-establish—or refashion—his stage career in the United States. With the type of inversion that is central to the cabaretesque, he shifted his compositional vocabulary 


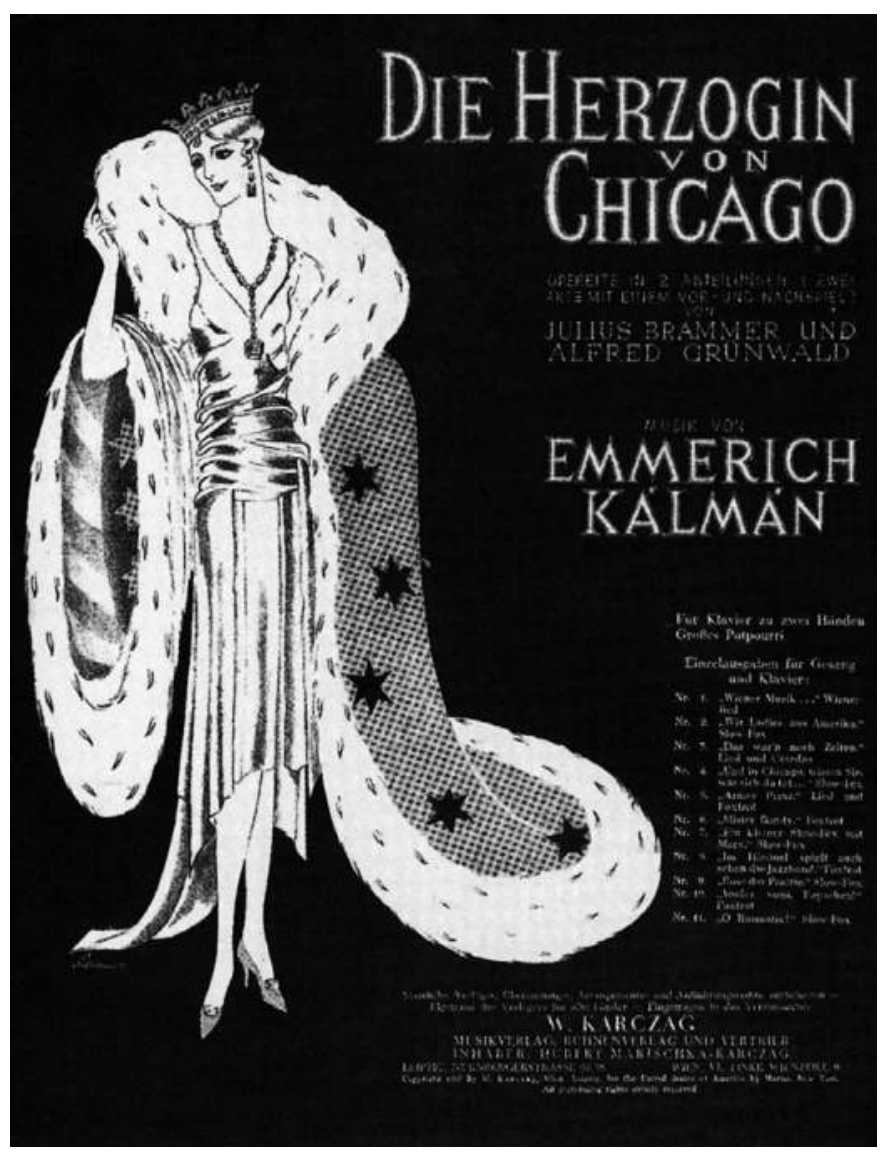

Figure 4: Cover of the piano-vocal score for Kálmán, Source: Kálmán 1928.

from operetta to the Broadway stage, doing so, however, by transforming traditional Viennese operetta themes to jazz. Kálmán's search to find an American jazz-inflected voice for the musical stage brought only limited success. When he composed his final work for the United States, Arizona Lady, in 1953, the last year of his life, it was a German radio performance that brought the unfinished score briefly to life in 1954. With a libretto about contested border-crossing between Mexico and the United States, $\mathrm{Ar}$ izona Lady had its premiere and revival almost sixty years later, first in Chicago (2010) and then in Berlin (2014-2015 season). The New Budapest Orpheum Society, too, has sought to find the jazz-inflected voice of an exiled Jewish composer, affording it new possibilities through the moral imperative of commemorative performance (see e.g., Julia Bentley's recording of "Wir Ladies aus Amerika" on New Budapest Orpheum Society 2014, track 4).

After the Holocaust, film and film music increasingly became the scripts for the 


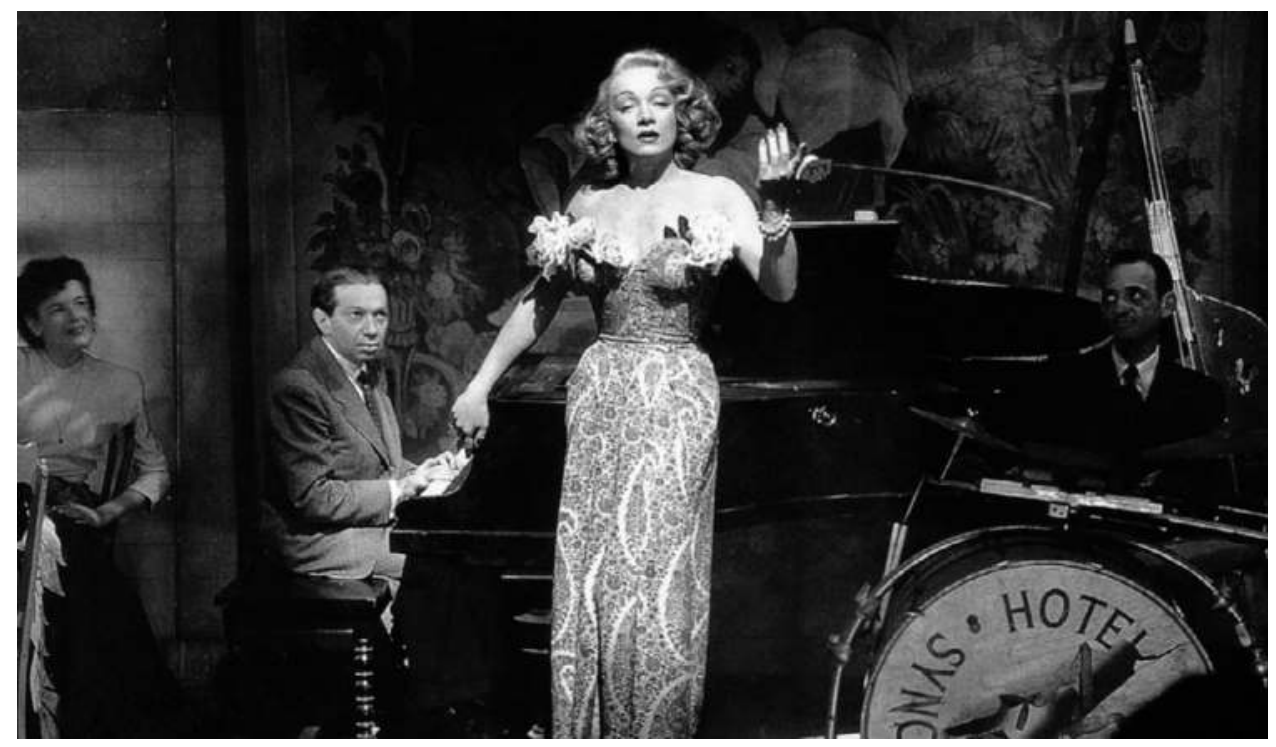

Figure 5: Marlene Dietrich and Friedrich Holländer at the Hotel Eden, A Foreign Affair, film directed by Billy Wilder. Still photo from: A Foreign Affair 1948.

counterpoint between utopia and dystopia, conditions both juxtaposed and inverted by the cabaretesque. It is this counterpoint that stages the mise en scène for Friedrich Holländer and Billy Wilder (1906-2002) in their 1948 film, A Foreign Affair, which provided the basis for another recording project of the New Budapest Orpheum Society. Filmed in part in the rubble of post-World War II Berlin, A Foreign Affair blurs the cinematic boundaries between documentary film and feature-length film. The cruel realities of war and destruction lie in "the ruins of Berlin," but the film itself weaves comedy and film noir together. Billy Wilder and Friedrich Holländer returned to Berlin from American exile once again to play their pre-war roles as film director and cabaretiste. The music mixes the diegetic and the non-diegetic in complex ways. Holländer is playing, but so are Marlene Dietrich and Holländer's fellow musicians in the Hotel Eden Syncopators on the cabaret stage, mirroring the house band in Der blaue Engel eighteen years before, on the eve of the Shoah (figure 5).

Throughout the film, mirrors are used to project images of the real and reflectedruins and illusions - a standard technique of film noir and the cabaretesque. Upon completing A Foreign Affair, Holländer and Wilder were to pursue their careers in cabaret and film in quite different ways. Holländer rediscovered his métier by bringing jazz from the United States back to the German cabaret stage, spending the remainder of his life performing in German clubs. Wilder, who had returned to Berlin in part to search for remaining traces of family members-among them his mother, 
who had disappeared in the Shoah-returned to Hollywood, where he would be a critical player in subsequent eras of American cinema. The ethical counterpoint formed by the utopia and dystopia of the Shoah rarely yielded to the resolution of return. If indeed jazz marked the point of arrival for postwar Jewish film, where witness to history was sounded through the cabaretesque and the moral imperative it enacted at the end of the Shoah.

\section{"And from the Ruins of Time They Blossom:" Black Lives Matter and the Racialized Body in Performance}

I reach my conclusion in this exploration of why musics matter in my work as an ethnomusicologist/performer by way of reflecting on moral imperative as a means of acting on the confluence of past and present in real-time, which I believe ethnomusicology is critically well suited to achieve. In my own research over what have become many decades I have been researching the historical longue durée in which the racialized body is represented through religious texts in a number of different religions, especially in the transformation of biblical texts over time (see, e.g., Bohlman 2019). Particularly striking are the ways in which race and violence converge, doing so, however, at moments when sacred text gives way to song. Music, in fact, marks these moments of violence to the racialized body with remarkable frequency. I follow the transformation of these texts-translation and exegesis in the broadest sense-at the moments in which music arrests the listener's attention through response to moral imperative.

Such moments collapse time, making music matter, when the ordinary becomes the extraordinary. The racialized body in these texts, moreover, is also the woman's body, a sexualized body, also bringing us themes of gender studies and music critical to the history of the Institut für Volksmusikforschung und Ethnomusikologie (Haid and Hemetek 2005). As I draw this essay to its close, moreover, I remind the reader that it was a woman, in the epigraph, whose voice, or lack thereof, called attention to the love-death of the final work for the musical stage from the Shoah. And it is with the racialized body of women, a theme in the longue durée of biblical texts, that I conclude, reflecting one of my most recent projects, a sustained study of the Song of Songs (Hebrew: Shir ha-shirim) in the intellectual history of ethnomusicological translation.

Historians of religion frequently observe that the Shir ha-shirim, was not only the most beloved book of the Hebrew Bible and the most common subject for sermons during the Middle Ages, but that it was the most frequently translated in early modern theological writings. From the Renaissance to the present, the Song of Songs served as the basis for musical settings more frequently than any other book of the Bible. 
In conclusion, I'd like to reflect, if still tentatively, on the reasons that it continues to draw our attention, in modern contexts and modernist texts, to moments of moral responsibility.

To do so I turn to two examples, which allow me to return to the "daughters of Jerusalem," whose presence in the Shir ha-shirim signifies the racialized body. It is these daughters of Jerusalem, coming from elsewhere-they are foreigners, migrants, racialized others-who are notable because they are black, their difference realized as beauty. It is at the moment of realizing difference, moreover, that voice acquires new meaning. Here is Johann Gottfried Herder acknowledging that moment, at the foundational moment of modern ethnomusicology, which he did in chorus with Johann von Goethe and Moses Mendelssohn, among others:

Her voice falls silent; Thus it is heard in an entirely different way:

I am black and yet so gentle,

You daughters of Jerusalem!

Just as the tents of cedar

Provide shelter for Solomon.

Johann Gottfried Herder, Lieder der Liebe (1778; trans. Herderand Bohlman 2017: 112)

The black bodies of the daughters of Jerusalem signified difference for Toni Morrison in a different way for her allegorical realization in the 1977 novel, Song of Solomon (Morrison 1977). In the novel, too, her characters often break into music-African American song-when difference and distance are negotiated. Black lives matter in counterpoint with musics that matter.

O Solomon don't leave me here here

Cotton balls to choke me

O Solomon don't leave me here

Buckra's arms to yoke me

Solomon done fly, Solomon done gone

Solomon cut across the sky, Solomon gone home.

Toni Morrison, Song of Solomon (1977)

I reach the end of this essay by returning to the tradition of performing Jewish music with which I began, approaching the music of the Shoah as a moral imperative. I return to the spaces that Viktor Ullmann might have realized on the stage of the concentration camp at Terezín/Theresienstadt, had he survived the camps. Instead, he finished the sketches-the fragments filled with unfilled space—about ten days before he was deported to Auschwitz, where he was murdered at the moment of his arrival 
in October 1944. The spaces left empty of bodies, allegorical and real, in Die Weise von Liebe und Tod des Cornets Christoph Rilke, cannot be filled through the performance of cabaret or cabaretesque, but their ethical dimensions become material, and therefore they matter very much indeed. Just as music called these ethical dimensions into being, they signaled the possibility of reconciliation. It is such reconciliation, finally, that has followed me through this essay on performance in ethnomusicology, growing from the racialized bodies at the moment of moral responsibility. Through Viktor Ullmann's musical transformation of allegorical text in the depths of the Shoah, it was possible to acknowledge the tragedy of such moments and the moral imperative for ethnomusicology to respond to them through acts of performance that prevent them from falling silent.

They draw close to each other.

And their fear disappears.

There's nothing to stop them:

No yesterday, no tomorrow:

For time has come to an end.

And from the ruins of time, they blossom.

Die Weise von Liebe und Tod des Cornets Christoph Rilke, Act II, Scene 4 (Ullmann 1993: 39-40)

References

Adler, Guido. 1885. "Umfang, Methode und Ziel der Musikwissenschaft." Vierteljabresschrift für Musikwissenschaft 1/1: 5-20.

Aristotle. 1925. Nicomachean Ethics 9: The Works of Aristotle Translated into English. Translation by William D. Ross. Oxford: Oxford University Press.

Bakhtin, Mikhail. 1984. Rabelais and His World. Trans. by Hélène Iswolsky. Bloomington: Indiana University Press.

Bohlman, Philip V. 2002. "Jüdische Lebenswelten zwischen Utopie und Heterotopie, jüdische Musik zwischen Schtetl und Ghetto." Lied und populäre Kultur / Song and Popular Culture: Fabrbuch des Deutschen Volksliedarchivs 47: 25-54. .2007. "On the Ethical Dimensions of Music." SEM Newsletter 41/3: 4-5. 2012. "Analysing Aporia." Twentieth-century music 8/2: 1-19. . 2019. Wie sängen wir Seinen Gesang auf dem Boden der Fremde! Jüdische Musik des Aschkenas zwischen Tradition und Moderne. Berlin, Münster, Wien, and Zürich: Lit Verlag. . ed. 2013. The Cambridge History of World Music. Cambridge: Cambridge University Press. 276 
"And from the Ruins of Time They Blossom":

Bunzl, Matti. 2007. Anti-Semitism and Islamophobia: Hatreds Old and New in Europe. Chicago, IL: Prickly Paradigm Press.

Ellis, Alexander J. 1885. "On the Musical Scales of Various Nations." Fournal of the Society of Arts 33: 485-527.

Gumbrecht, Hans Ulrich. 2004. The Production of Presence. Stanford, CA: Stanford University Press.

Haid, Gerlinde, and Ursula Hemetek, eds. 2005. Die Frau als Mitte in traditionellen Kulturen: Beiträge zu Musik und Gender. Vienna: klanglese 3, Institut für Volksmusikforschung und Ethnomusikologie.

Herder, Johann Gottfried. 1778. Lieder der Liebe: Die ältesten und schönsten aus Morgenlande, nebst vier und vierzig alten Minneliedern. Leipzig: Weygandsche Buchhandlung.

.1778/79. Volkslieder. Leipzig: Weygandsche Buchhandlung.

. 1807. Stimmen der Völker in Liedern, Johann von Müller, ed. 2nd ed. of Volkslieder (1778/79). Tübingen: J. G. Cotta.

. 1955. Kalligone, Heinz Begenau, ed. Weimar/Vienna/Cologne: Hermann Böhlaus Nachfolger.

1975. Stimmen der Völker in Liedern and Volkslieder, Heinz Rölleke, ed. Stuttgart: Reclam.

Herder, Johann Gottfried, and Philip V. Bohlman. 2017. Song Loves the Masses: Herder on Music and Nationalism. Berkeley: University of California Press.

Kálmán, Emmerich. 1928. Die Herzogin von Chicago. Libretto by Julius Brammer and Alfred Grünwald. Vienna: W. Karczag.

n.d. Arizona Lady. Libretto by Gustav Beer and Alfred Grünwald. Unfinished manuscript posthumously performed in 1954.

Kant, Immanuel. 1964. Groundwork of the Metaphysics of Morals. Translation by Herbert James Paton. New York: Harper \& Row.

Kibreah, Bertie. 2016. "Ensnare the Thief in the House of Wind: Negotiating Musical Routes of Bāul-ness in Bangladesh.” In Resounding Transcendence: Transitions in Music, Religion, and Ritual, J. Engelhardt and P. V. Bohlman, eds. New York, Oxford: Oxford University Press, 29-42.

Morrison, Toni. 1977. Song of Solomon. New York: Alfred A. Knopf.

Nettl, Bruno. 2010. Nettl's Elephant: On the History of Ethnomusicology. Urbana: University of Illinois Press.

New Budapest Orpheum Society. 2002. Dancing on the Edge of a Volcano: Fewish Cabaret, Popular, and Political Songs 1900-1945. Audio CD. Chicago: Cedille Records. CDR 90000065. . 2009. Fewish Cabaret in Exile. Audio CD. Chicago: Cedille Records. CDR 90000110. .2014. As Dreams Fall Apart: Stage and Film Music in the Golden Age of Jewish Stage and Film Music 1925-1955. Audio CD. Chicago: Cedille Records. CDR 90000151.

Rawls, John. 1971. A Theory of Fustice. Cambridge, MA: Harvard University Press. 
Rogin, Michal Paul. 1996. Blackface, White Noise: Jewish Musicians in the Hollywood Melting Pot. Berkeley: University of California Press.

Schultz, Anna. Forthcoming. Songs of Translation: Bene Israel Migration, Gender, and Textual Orality. New York, Oxford: Oxford University Press.

Tucholsky, Kurt. 2016 [1931]. Seifenblasen: Eine Geschichte, die ein Film werden sollte. Berlin: Rowohlt.

Ullmann, Viktor. 1993. Die Weise von Liebe und Tod des Cornets Christoph Rilke. Mainz: Schott.

Williams, Bernard. 1985. Ethics and the Limits of Philosophy. London: Fontana.

Filmography

Der blaue Engel. 1930. Der blaue Engel. Directed by Josef von Sternberg. Music by Friedrich Holländer and Robert Liebmann. Produced by Erich Pommer. UFA.

A Foreign Affair. 1948. A Foreign Affair. Directed by Billy Wilder. Music by Friedrich Holländer. Produced by Charles Brackett. Paramount.

The Fazz Singer. 1927. The Fazz Singer. Directed by Alan Crosland. Music by Louis Silvers. Produced by Jack L. Warner and Darryl F. Zanuck. Warner Bross Pictures. The Vitaphone Company.

Abstract

Performance in many forms has been central to the ways ethnomusicologists have collected, studied, and taught the musics of other cultures. To various degrees it has been important to demonstrate competence through performing other musics to understand them and to participate in music making to gain the perspectives of scientific observation. As ethnomusicology increasingly acquires socio-political relevance today, however, performance in the field has moved far beyond the assurances of bi-musicality and participant-observation. Performance today empowers ethnomusicologists to engage directly with ethical and political issues, and transform them, through performance, to express the moral imperative that is critical to what ethnomusicologists do as twenty-first-century scholars, teachers, and activists.

Taking the performance activities of the University of Chicago-based cabaret, the New Budapest Orpheum Society, for which I serve as the Artistic Director, as a point of departure, I begin by developing performance and ethnomusicology's moral imperative historically, locating it already in the foundations of the field. The article moves toward the field's recent history by developing a model for what I call here "ethnomusicology's moral compass." The model draws together different disciplinary practices 
to argue for the ways they become dynamic through their shared commitment to ethical response and responsibility. Two reflexive case studies of the performance activities of the New Budapest Orpheum Society and its engagement with the music of the Shoah close the article, lending it further methodological application by connecting the theory of the cabaretesque to ethnomusicology's moral imperative. 


\section{Notes on Contributors}

Rasika Ajotikar successfully defended her PhD from the School of African and Oriental Studies (SOAS) at the University of London. She is currently a research assistant in the Musicology department at Georg August University Göttingen, Germany. Since 2017 she has been working on the Felix van Lamsweerde archive of Indian music through engagement with critical archival theories and studies on caste, gender, sexuality and postcolonial theories. Her doctoral research in the music department at SOAS focused on an anti-caste cultural movement in contemporary western India while broadly examining the history of musicianship through the lens of caste, gender and sexuality. Her ethnographic work has involved working and collaborating extensively with activists and musicians from this anti-caste movement in the western Indian state of Maharashtra, which has led to a number of translation and performance projects.

Samuel Araujo is Professor of Ethnomusicology at the Federal University of Rio de Janeiro and has taught at other institutions in Brazil and abroad such as the University of Chicago (Tinker Visiting Professor) in 2014, the University of Puerto Rico and the Universidad Nacional Autonoma de Mexico, both in 2016. His research on the political and aesthetical dimensions of music and sound praxis has emphasized the role of academic research in the public sphere, and has been published in a number of periodicals and books released in Brazil and abroad. He has developed participatory research initiatives integrating academic and non-academic collaborators and involving activist groups as well as non-governmental and governmental institutions in Brazil, Portugal and Colombia.

Philip V. Bohlman is Ludwig Rosenberger Distinguished Service Professor in Jewish History in the Department of Music at the University of Chicago, where he is also artistic director of the cabaret ensemble New Budapest Orpheum Society. His research ranges widely across Europe, North America, the Middle East, and South Asia, and focuses especially on religious, racial, and cultural encounter and conflict. He is Honorarprofessor at the Hochschule für Musik, Theater und Medien Hannover. Among his recent books are Hanns Eisler - In der Musik ist es anders (with Andrea F. Bohlman; Hentrich \& Hentrich, 2012), Song Loves the Masses (with Johann Gottfried Herder; California, 2017), and Wie sängen wir Seinen Gesang auf dem Boden der Fremde (LIT Verlag, forthcoming), and with the New Budapest Orpheum Society the Grammy Award-nominated CD, As Dreams Fall Apart: The Golden Age of Jewish Stage and Film Music, 1925-1955 (Cedille, 2014). 
Naila Ceribašić is an ethnomusicologist, a scholarly advisor at the Institute of Ethnology and Folklore Research in Zagreb, and professor of ethnomusicology at the University of Zagreb. Her research interests and publications include traditional music in Croatia and South-Eastern Europe, the history and ethnography of the public practice of traditional music, festivalization and heritage production, cultural politics, war and post-war social developments, gender aspects of music-making, musical expressions of minority communities, ethnomusicological theories and methods, and applied ethnomusicology. For the last fifteen years she has been involved in various ways in the Intangible Cultural Heritage Programme, first on a national, and then on an international scale. Since 2012 she has represented the ICTM at UNESCO, and in that capacity has served in the body that examines submissions for the international lists, the register of good safeguarding practices and international assistance (2013-2015). This was followed by her facilitation of capacity-building workshops and participation in several expert meetings organized by the Secretariat of the Convention.

Beverley Diamond is Professor Emerita at Memorial University of Newfoundland, where she served as Canada Research Chair in Ethnomusicology and also founded and directed the Research Centre for the Study of Music, Media, and Place (MMaP) from 2003-15. She previously taught at Queen's University and York University. She has contributed to Canadian cultural historiography, feminist music research, and Indigenous studies. Her research has explored social constructs of technological mediation, Indigenous theory as it relates to sound worlds, and, most recently, concepts of reconciliation and healing. Publications include Native American Music in Eastern North America (OUP, 2008) and co-edited anthologies: Aboriginal Music in Contemporary Canada. Echoes and Exchanges (McGill-Queen's UP, 2012), and Music and Gender (U Illinois P, 2000), among many others. Diamond has been recognized with a Trudeau Fellowship (2009-12), fellowship in the Royal Society of Canada (2008), the Order of Canada (2013), the Social Sciences and Humanities Research Council of Canada's Gold Medal (2014) and an Honorary Doctorate from McGill University. She is a Past-President of the Society for Ethnomusicology.

Cornelia Gruber is an assistant researcher in ethnomusicology at the Hanover University of Music, Drama and Media (HMTMH). Her ethnomusicological research and teaching center on gender and queer studies, and dance anthropology, with a focus on decolonizing and feminist perspectives. In 2018 she earned her $\mathrm{PhD}$ at the University of Vienna. Her doctoral thesis, "Gendered Dance Spaces. An Intersectional Approach to Dancing in Southwest Madagascar" deals with issues of gender interdependency, embodiment of relational positionalities and performativity through the act of dancing. 
Ursula Hemetex is the director of the Department of Folk Music Research and Ethnomusicology at the University of Music and Performing Arts Vienna. In 1987 she earned her PhD in Musicology, followed in 2001 by her habilitation in Ethnomusicology, both at Vienna University. She is professor of ethnomusicology and teaches mainly at the University of Music and Performing Arts Vienna. Her main focus of research is Music and Minorities in Austria. She has published widely in the field of ethnomusicology and Music and Minorities (with a focus on Roma, Burgenland Croats and recent immigrant groups, as well as refugees). She was the chairperson of the ICTM Study Group on Music and Minorities since its establishment in 1999 till 2017 and was appointed General Secretary of the ICTM in 2017. She received the Wittgenstein Award for her research on Music and Minorities in 2018.

Marкo Kölbl holds a PhD in Ethnomusicology and works as a research and teaching fellow at the University of Music and Performing Arts Vienna. He is specialized in music and dance of minorities and migrant communities with an interest in intersectional, queer-feminist and postcolonial perspectives. Areas of research are death and mourning, voice, dance; ongoing field research with the Croatian minority in Burgenland, migrant communities in Vienna, specifically Afghan refugees, as well as Croatia, Herzegovina and Iran. His teaching covers both theoretical approaches and musical practice, vice chair of the ICTM Study Group on Music, Gender and Sexuality (2015-2019).

Dan Lundberg is Chief Librarian/Head Archivist and Associate Professor in musicology at Stockholm University (Sweden) and Åbo Akademi University (Finland). Lundberg's main areas of research involve questions about music and identity, as well as Swedish and European folk music from an ethnomusicological perspective.

Dan Lundberg is the director of the Archive and Library Department at Statens musikverk, (the Swedish Performing Arts Agency). The department includes three institutions: the Music and Theatre Library, Svenskt visarkiv - the Centre for Swedish Folk Music and Jazz Research, and Caprice Records.

From 2004-2007 Lundberg was an adjunct professor in Music and Cultural Diversity at the University of Gävle. He is active within the international ethnomusicological research community and, among other positions, was President of the ESEM (European Seminar in Ethnomusicology) for the period 2008-2014.

Selena Rakočević is associate professor at the Department of Ethnomusicology, Faculty of Music, University of the Arts, Belgrade and at the Academy of Arts, Novi Sad. Ethnochoreologist and ethnomusicologist, author of the books Interwaving dance structures (2011), Traditional dances of the Banat Serbs (2012) and Vocal tradition 
of the Serbs from Lower Banat (2002), and co-editor (together with Liz Mellish) of the book Dance, field research and intercultural perspectives. The Easter customs in the village of Svinița (2015). Her research focuses on musical and dance traditions in the multiethnic context of Banat, music/dance relationships and the history of ethnochoreology and ethnomusicology in South-Eastern Europe. Selena has been a board member of the ICTM Study Group on Music and Dance in South-Eastern Europe since 2008.

Adelaida Reyes is Professor Emerita at New Jersey City University, with a PhD in Ethnomusicology awarded by Columbia University. She has taught at Columbia University - New York University, the Humanities Faculty at Charles University in Prague - Czech Republic, and the Juilliard School of Music. She is a recipient of a Lifetime Achievement Award from the Society of Ethnomusicology, mid-Atlantic Chapter, and has been awarded Lifetime Membership by the European Society for Ethnomusicology. She is the author of Songs of the Caged, Songs of the Free (Temple University Press) which won the Book of the Year award for 2000 from the International Association for Studies of Popular Music (IASPM) - USA, and of Music in America (Oxford University Press), and has written numerous articles. She is currently serving as vice-chairperson of the ICTM Study Group Music and Minorities.

Hande SaĞlam is the head of the archive and the deputy director of the Department of Folk Music Research and Ethnomusicology at the University of Music and Performing Arts Vienna. She studied composition at Bilkent University/Ankara, obtained her Master's degree in music theory from the University of Music and Performing Arts Vienna, and received her doctoral degree in ethnomusicology at the same university. Hande Sağlam serves as secretary of the ICTM Study Group on Music and Minorities and chair of ICTM National Committee of Austria.

Her research areas are music and minorities, music in the diaspora, music from Turkey, the Anatolian âşı tradition, transmission of traditional musics, archiving, and methodologies of fieldwork.

Anthony Seeger is an anthropologist, ethnomusicologist, audiovisual archivist, and musician. He has taught at the National Museum in Rio de Janeiro (1975-1982), the Brazilian Conservatory of Music (1980-1982), Indiana University (1982-1988), and UCLA (2000-2013). He was the founding director/curator of Smithsonian Folkways Recordings at the Smithsonian Institution in Washington DC (1988-2000). He served as director of the Indiana University Archives of Traditional Music, curator of the Folkways Collection, and faculty director of the UCLA Ethnomusicology Archive. His three books, three edited volumes, and over 100 articles focus on the music of Indigenous peoples of Lowland South America, audiovisual archiving, music ownership, 
and other topics. He is a past president and Secretary General of the ICTM, a past president of the Society for Ethnomusicology, and Fellow of the American Academy of Arts and Sciences.

Britta Sweers is Professor of Cultural Anthropology of Music at the Institute of Musicology (since 2009) and Director of the Center for Global Studies (since 2015) at the University of Bern (Switzerland). Since 2015 she has also been President of the European Seminar in Ethnomusicology (ESEM). Having studied at Hamburg University (Ph.D. 1999) and Indiana University (Bloomington; 1992/93), she was Assistant (2001-2003) and Junior Professor for Systematic Musicology and Ethnomusicology at the Hochschule für Musik und Theater Rostock (Germany) from 2003 to 2009. Her research addresses the transformation of traditional musics (particularly in the British Isles, the Baltic countries, and Scandinavia) in global contexts, music and nationalism, gender, applied ethnomusicology, and soundscape. Some major publications include Electric Folk: The Changing Face of English Traditional Music (2005), Polyphonie der Kulturen ([“The Polyphony of Cultures"] CD/CD-ROM 2006/8), Grenzgänge - Gender, Ethnizität und Klasse als Wissenskategorien in der Musikwissenschaft (["Crossing Borders - Gender, Race and Class as Categories of Knowledge in Musicology"] ed.; w. Cornelia Bartsch, 2016). She is co-editor of the European Fournal of Musicology and of the Equinox book series Transcultural Music Studies.

Tan Soor Beng is Professor of Ethnomusicology at the School of the Arts, Universiti Sains Malaysia, Penang. She is the author of Bangsawan: A Social and Stylistic History of Popular Malay Opera (Oxford University Press, 1993), and co-author of Music of Malaysia: Classical, Folk and Syncretic Traditions (Routledge, 2017) and Longing for the Past, the 78 RPM Era in Southeast Asia (Dust-to-Digital 2013), which won the joint SEM Bruno Nettl Prize, 2014. Tan is the Editor-in-Chief of Wacana Seni, Fournal of Arts Discourse, serves on the Advisory Editorial Boards of Asian Music (USA) and Ethnomusicology Forum (UK), and is an elected board member of the ICTM. She is actively engaged in the practice of community theatre for young people in Penang. 